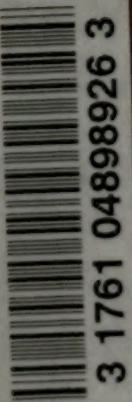



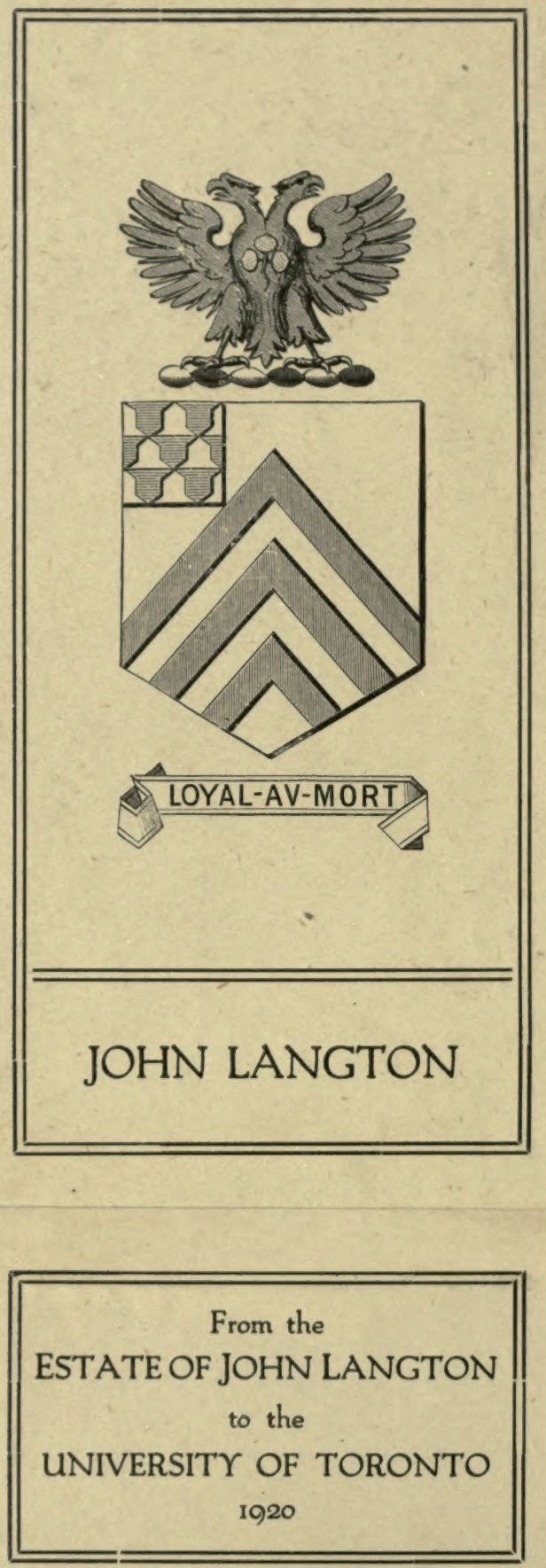



\section{THE DESIGN OF STATIC TRANSFORMERS}


Digitized by the Internet Archive in 2007 with funding from Microsoft Corporation 


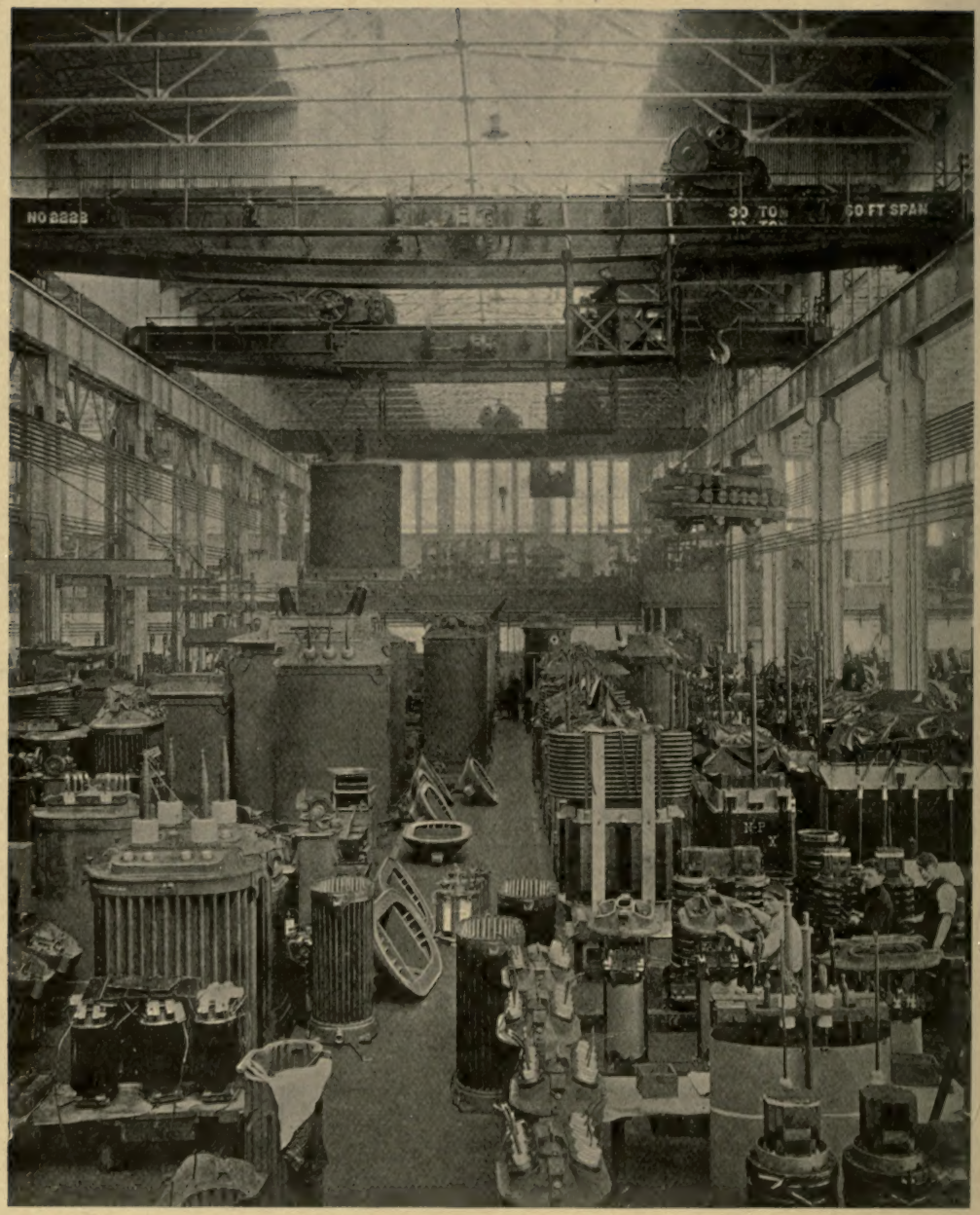

[Frontispiece.

View of assembling department in a transformer manufacturing works. 


\section{THE}

\section{DESIGN OF STATIC \\ T R A N S F O R MER S}

BY

\section{H. M. HOBART, M. Inst. C.E.}

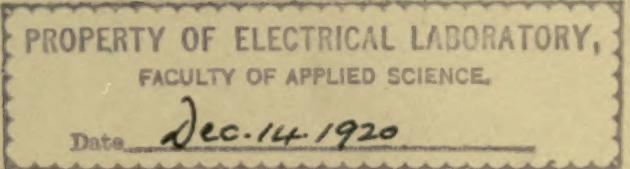

LONDON

CONSTABLE \& COMPANY LTD

1911

D. VAN NOSTRAND COMPANY 
IIBRAR

NOV 11967

\section{ERSITY OF TORONIO}




\section{P R E F A C E}

Tur present treatise is exclusively of a practical nature. It constitutes, however, merely a brief introduction to the practical aspects of transformer design and construction. If the reader has not already acquired a knowledge of the theory underlying the subject, he could not do better than to study either Prof. Gisbert Kapp's "Transformers," or Prof. J. A. Fleming's "The Alternate-current Transformer." In spite of the ten years which have intervened since the publication of the last edition of the latter work, it still remains, in my opinion, one of the very clearest expositions of the theory of the transformer. My own work in this field, so far as it is set forth in the present volume, simply deals with the application to practice of the theory so admirably set forth by Profs. Pleming and Kapp in the excellent treatises to which I have referred. Although remarkably few books have been written on transformers, nevertheless there exists a fairly extensive liturature on the subject, but it is in the form of articles and papers. Amongst the most noteworthy recent contributions may be mentioned the paper by Messrs. A. P. M. Fleming and K. M. Faje-Hansen, which was read in November, 1908, at the Institution of Electrical Engineers, and the paper read in June, 1909, by Mr. E. G. Reed, at the Thirty-second Annual Convention of the National Electric Light Association.

A perusal of my treatise entitled "Electricity" (Constable if Co., Tondon, 1910), will assist to an understanding of the terms "power factor." "inductance," "reactunce" and "impedance," if the reader is not already clear as to the meaning of these terms. 
It has been deemed desirable that the present work should deal with the fundamental principles of practical designing, but so soon as these principles have been assimilated, the reader should proceed to study carefully the many essential constructional details. A Bibliography of a considerable number of papers relating to static transformers is given at the end of Chapter I. In conclusion, I wish to acknowledge the work of my former assistant, Mr. Evelyn Cood, who carried through many of the calculations, under my direction, and prepared a good many of the curves and diagrams. My assistant, Mr. C. Martin, compiled from my data certain portions of Chapters VIII. and IX. My thanks are due to the several manufacturing companies whose designs are described for their courtesy in providing me with the necessary information and for photographs and drawings.

H. M. HOBART, M. Ins'r. C.E.

LoNDoN,

December, 1910. 


\section{'TABLE OF CONTENTS}

ins:

FIRTISITECE

PACIE:

PREFACE . . . . . . . . . . vii

LIST OF ILLESTR.ITIONS + . . . . . . . xi

I. IXTRODUCTORY . . . . . . . . 1

11. THE LEADING DIMEXSIONS OF A TRAXSFORMER OF A GIVEX RATING + . . . . . . . 16

III. TIIE (ORE LOSS ANI THE "ANXIAI, EFFICIEN(Y" . . 5!

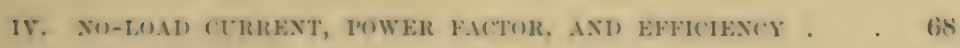

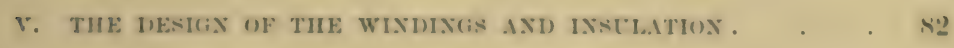

v1. THE INFLCENCE OF FREQTEXCY . . . . . . Si

VII. TUE REGLLATIOS OF TRANBFORMERS . . . . . 9:3

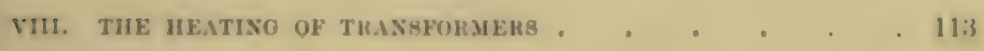

IX. TRLXSTORME CASES AND TAXKS . . . . . . 145

x. FOHCRD-COOLED TRAXSFOLAERs . . . . . 155 



\section{LIST OF ILLUSTRATIONS}

ท16.

TITLE.

PAGR

1. Outline *ketch of a Representative Design of a Core-typo Single-phase Transformer . . . . . . .

2. Outline sketch of a Representative Design of a Shell-type Single-phase Transformer . . . . . .

3. Outline Sketch of a Type of Transformer adapted from Dr. Kittler's "Iandbuch der Elektrotechnik," 1892 . . 19

4. I)iagrammatic sketch of "Berry "Transformer . . . 21

j. 1700-kva 25-cycle Core-type Three-phase Westinghouse Transformer

6. 100-kva Single-phase 100000 -volt Shell-type Transformer, built by the Westinghouse $\mathrm{Co}$. for the Southern Power Co.

7. Curves showing Full-load Efficiency of Single-phase Transformers for lifferent Rated Outputs, Frequencies and Primary Voltages

8. Curves showing "Volts per Turn" for Single-phase Transformers for Different Rated Outputs, Frequencies and Primary Voltages

9. Curves showing "Volts per Turn" of Single-phase Transformers of Different Rated Outputs and Periodicities. Curve A-50 Cycles; Curve B-25 C5cles .

11. Siaturation Curve of Representatire Sheet Steel . . . 34

11. IIysteresis Loss ('urvos for Various Periodicities for Old High Ioss Sheet Iron.

12. Hystroreis Ioss Curves for Various Periodicities for Law Lans Alloy Steel .

13. Filly ('urrent Loss ('urves for Various Periodicities for (H)l Low Resistance Sheet Iron

11. Eldy Current Loss Curves for Various Perivicities for Modern High Reeistance Alloy Steel . . . . .

15. Total Ioss Curves for Various l'oriodicites for (Old High lass Sheet Iron .

16. Total Loss Curves for Various L'eriodicities for Low Loss Alloy Steol

17, 18. Curves showing the Relative IIysteresis and Blyly Current Luss as a Porcentage of the Totul Juss for High and Law Inses Stred

19. C'urves showing the liffect of Various Kinds of Core Insulation on the Nett Fffective Iron in Transformer Cores for Various Thicknerees of Stampingw 
vic.

TITLE,

20, 21. Types of Sections of Transformer Cores

PABE

45

2.2-25. 'Types of Sections of Transformer ('ores . . . . 46

26. Core Section for Elliptical-shaped Coil . . . . . 46

27. Curves showing the Relation between the Output and the Width of Winding Space

2S. Section of 20 -kw $5000 / 200$-volt Transformer Core (I)imensions in Centimeters).

29. Section of Winding and Core of $20-\mathrm{kw} 5000 / 200-$ volt Transformer (I)imensions in Centimeters) . . . . . 49

30. Simple Concentric Winding . . . . . . . jl

31. Triple Concentric Winding . . . . . . . 51

32. Sandwich Winding . $. \quad . \quad . \quad . \quad 52$

33. Simple Concentric Winding with Subdivided Primary . . 52

34, 35. Curves showing Relation between space Factor of Winding Window and Rated Output for Various Primary Voltages (Fig. 34, Kectangular Core Section; Fig. 35, Crucifurm Core Section)

36. Sketch of Core for 20 -kw $5000 / 200$-volt 50-cycle Transformer .

37. Annual Efficiencies of $20-\mathrm{kw}$ Transformers at Various I Load Factors

38. Profit to Electricity Supply Company in per cent. of Cost of Power supplied to $20 . \mathrm{kw}$ Transformers at Various Load Factors

39. No-Load Current Diagram

4). Curve showing Variation of Power Factor with the I soad for a 20-kw Transformer.

41, 42. Characteristic Curves of 20 - $\mathrm{kw}$ Transformer (Fig. 41, Core Loss $=190$ watts ; ('opper I Loss $=360$ watts. Fig. 42, Core Loss $=360$ watts ; Copper Loss $=190$ watts) . . . .

43. Curves showing the Relation between the No-Load Current and the Rated Output for Transformers having (a) High Grade and (b) Ordinary Grade Laminations

44. Curves showing the Relation between the Iron Loss and the Rated Output for several Lines of Designs for different Periodicities by Various Firms A, B, C, D and E

45, 46. Curves showing the Influence of Varying the Periodicity and Primary Pressure upon the Core Loss and No-Load Current of a $20-\mathrm{kw}$ Transformer

47. Curves showing the Relation between the Regulation and the Rated Output for several Iines of Designs for Different Periodieities by Firms A, B, C and D .

48. ('urves showing ratio of Tabour Cost to C'ost of Active Material for Natural Air-cooled and Oil-cooled Transformers

49. Outline J)rawing showing the Arrangement of the Windings: of the $20-\mathrm{kw} 5000 / 200$-volt Transformer 
rin.

TITLE,

PME:

50. Sectional Drawing showing Details of Primary and Secondary Windings for a 20-kw 5000 200-volt single-phase Trunsformer.

31. I)rawing showing l)etails of Primary and Secondary Windings for a 20 -kw 5000200 -volt Single-phase Transformer.

52. Curve showing Thickness of Insulation between l'rimary and Secondary Windings of Transformers

5:3--5ว. Outline Irawings of Transformers for $20 . \mathrm{kw} 5000,200$ Vults : (a) 15 Cycles, (b) 25 Cycles, (c) ju) Cycles

56. Diagram showing Magnetic Leakage in Core-type Transformer

57. I)iagram showing Magnetic I Leakage in Core-type Transformer

59. Curve of Values for $f$ in Formula " P'ercentage Reactance I)rop $=f_{l i c}: "$

59. Transformer Iliagram with no Reactance, but with an $I R$ Drop of 15 per cent. . . . .

60. Transformer liagram with 30 per cent. Reactunce Drop and 15 per cent. IR Drop. Power Factor =Unity . .

61. Transformer Diagram with 30 per cent. Reactance Drop and 15 per cent. I li l)rop. Angle of Lag $\phi=30^{\circ}$. Cos $\phi=0,8 \$ 6$

62. Transformer I)iagram with 30 per cent. Reactance Irop and 15 per cent. I Ii Drop. Angle of I agg $\phi=6 i 3^{2}$. ( os $\left.\phi=1\right), 440$

63. Transformer Diagram with 50 per cent. Reactance Irop and 15 per cent, I Il I rop. Angle of Iag $\phi=75^{5}$. Cos $\phi=0,21$.

64. Transformer Iliagram with 30 per cent. Reactance Hrop and 15 per cent. I li Irop. Angle of Iag $\phi=90$. ('os $\phi=0$ ) .

6i. Variation of Irop with I'ower Factor and Angle of Lag .

66. Regulation I)iagram of :(0-kva 5000$): 200$-volt 50)-eycle single. phase Transformer . . . . . . .

67. Modified Regulation Diagram of 20 -kva phase Transformer

68. Regulation Curves of 20 -ksa 5000 2(k)-volt single-phase Transformer .

69. Arrangement of Coils in Core-type Transformer for Three-wire Secondary .

i). Arrugement of Coils in Core-type Trunsformer for Three-wire Secondary .

71. Arrangenent of Coils in Core-type Transformer for Three-wire Secondary .

72. Air-cooled Transformer. Ciurve showing the Time tukn fur Trunsformers of Viarious Custputs to reach Final Temperature at Full Toal . . 116

i4. Heating Curves of 7, j. kw Transformer . . . 117

75. 40000 -volt Oil-immersed Transformer . . . . . IIs 
vice

TITLE.

PAC:E

76. Heating Curves of Oil Transformer. (See Fig. 7 for Key to l'ositions of Thermometers for Curves $A, B,(U$ and I))

77. Diagram showing Pusitions of Thermumeters for the Heating Curves shown in Fig. 76

78. Heating ('urves for 5-kva Transformer in Air and Oil. C'urve A in Case without Oil. Curve B in Case with Oil . . 121

79. Heating Curve for 50-kva Transformer in Air and in Oil . 121

80. Curves showing Temperature Rise of 'Transformers in Air and in Oil .

81. Curve showing Time for $\dot{0}^{\circ}$-kva Transformer to reach $40^{\circ} \mathrm{C}$. at Various Loads

82. Curves showing Quantity of Oil used for Single-phase Transformers

83. Temperature Curves for 10-kva Single-phase Oil-cooled Transformer in Small and Large Cases

84. Cases for 10.kva Transformer Temperature Test, showing Various Positions of Thermometers . . . . .

85. Temperature Test on a 10-kva Single-phase Translormer, with a Load of $8 \mathrm{kw}$ (for Positions of Thermomoters T1, T2, T3, see Fig. 84) .

85.A. Elevation of Ribbed Cast-iron Case

85B. Plan of Ribbed Cast-iron Case .

86. Method of Jointing the Sides and Bottom of a Transformer Case

87. Westinghouse 1000-kva 100000 -volt 60 -cjcle Oil-immersed Self-cooled Transformer

88. Johnson and Phillips' 600-kva 'Transformer for Oil Immersion

89. Diagram showing Construction of an Air-blast 'Transformer

90. Coils of a Shell-type Air-blast Transformer after Completion of Impregnating Process . . . . . . .

91. Diagrammatic Sketch of American General Electric Co.'s Air-blast Transformers

92. 5j0-kva 50-cycle Air-blast Transformer by the Westinghouse Co.

93. Diagram showing Arrangement of 'Transformers and Blowers .

94. Bank of Air-blast Transformers

95. 10000-kva Oil-insulated Water-cooled Westinghouse Transformers

96. View of the Interior of the American General Electric Co.'s 10000 -kva 100000 -volt 60-cycle Design for a Watercooled Oil immersed Transformer before the Cooling Coils have been Mounted

97. American General Electric Co.'s 10000 -kva 100000 -volt Design with the Cooling Coils in Place 
94. Westinghouse Oil-insulated Water-cooled Transformer for

High Pressure and Small Current

49. Westinghouse Oil-insulated Water-cooled Transformer for

Iow Pressure and Large Current

99. 1500-kva Water-cooled Oil-immersed Transformer, built by the American General Electric Co.

100. ()il-immersed Transformer provided with Cylindrical Barrier to promote Circulation . . . . . . 172

101. Forced Oil-cooled Transformer and Accessory Plant . . 173 



\section{THE DESIGN OF STATIC TRANSFORMERS}

\section{CHAPTER I}

\section{INTRODUCTORY}

A PAPER by Mr. George Westinghouse, entitled "The Electrification of Railways," was read at a recent ${ }^{1}$ meeting of the Institution of Mechanical Engineers. The paper was prefaced by the following paragraph:-

"As an illustration of the wonders of the laws of nature, few inventions or discoveries with which we are familiar can excel the static transformation of the electrical energy of alternating currents of high pressure into their equivalent energy at a lower pressure. To have discovered how to make an inert mass of metal capable of transforming alternating currents of 100000 volts into currents of any required lower pressure with a loss of only a trifle of the energy so transformed, would have been to achieve enduring fune. The facts divile this honour among a few, the beneficiaries will be tens of millions."

At a later point in his paper, Mr. Westinghouse writes as follows :-

"I was led in 1885, to interest myself in the American patents of Gaulard and Gibbs (a Frenchman and an Englishman), covering a system of electrical distribution by meus of

8.T. 
alternating currents, with static transformers to reduce these currents from the high pressure necessary for the economical transmission of electrical energy to the lower pressures required for the operation of incandescent lamps and for other purposes. No inventions ever met with greater opposition in their commercial development than those relating to the generation, distribution and utilisation of alternating currents."

The zeal displayed twenty-five years ago by Mr. Westinghouse in the matter of the introduction and the extension of systems employing alternating electricity has continued down to the present day, and while, in my opinion, one result has been to employ alternating electricity in a good many instances where continuous electricity would have afforded the more economic solution, nevertheless the engineering profession is in no small measure in Mr. Westinghouse's debt for the immense progress made in the last twenty-five years in the use of alternating electricity and in the development of the static transformer.

It must not be concluded that America was the principal scene of the early development of the static transformer. On the contrary, in Dr. J. A. Fleming's "Alternate Current Transformer," the first edition of which was published in 1889, will be found a record of work done in England on a larger scale than had at that time been approached in America. The volumes of the Journal of the Institution of Electrical Engineers, for the years from 1888 to 1892 (Vols. XVII. to XXI.), contain a number of papers which are of very great interest as bearing upon developments during the period when alternating electricity was first being introduced on a large commercial scale. Amongst these papers may be mentioned: " Alternate-current Transformers," by Kapp ; "Central Station Lighting : Transformers $v$. Accumulators," by Crompton; "Alternate-current Working," by Mordey; "Transformer Distribution," by James Swinburne; "On some Effects of Alternating-current Flow in Circuits having 
Capacity and Self-induction," by J. A. Fleming; "Some Experimental Investigations of Alternating Currents," by Alexander Siemens; "Experimental Researches on Alternatecurrent Transformers," by J. A. Fleming.

There could be no better introduction to the subject than that afforded by a careful study of these seven papers and more especially of the discussions to which they gave rise. Some twenty years have since elapsed, and the present trentise is largely based on the work of those who, profiting by the pioneer investigations of Crompton, Ferranti, Fleming, Forbes, Kapp, Mordey, Siemens, Swinburne, Silvanus 'Thompson and Elihu Thomson, have carried on the more prosaic task of developing the commercial transformer of the present day.

My first intimate acyuaintance with the static transformer was formed in 1889 when, under the torrid blaze of a bank of incandescent lamps which constituted the "load," I spent a month or so at the daily task of pulling little truck-loads of transformers into place against the wall of the testing room, measuring their "cold" resistance, connecting up their primaries, "flushing" their secondaries for polarity-ousting from the sacred premises those found in various respects unsound, and subjecting the survivors to a "load" test for some specified number of hours. This process was followed by a measurement of the "hot " resistance and by the registering of ench transformer's number and test results in a record book. The largest of these transformers was only some 7 or $8 \mathrm{kw}$, and the most usual sizes were those of but a couple of kilowatts rated capacity. They were nearly all for a periodicity of 125 cyeles per second, and the primaries were usmally womd so that they could be connected either for 1000 or 2000 volts, the secondaries usually being connected to give either 52 or 104 volts on no loarl. The measuring of the core loss was uo part of my task ; indeed I strongly suspect that but litte attention was then given to any such obscure detail. A gest or so later found me renewing my acquaintance with static trunsformers. This time the 
scene was an instrument calibrating and experimental department. Our duties, so far as related to transformers, comprised testing the insulation resistances between primaries and secondaries and "to frame," of transformers of various sizes and types. We duly reported on the insulation resistance, which, in those early days, was often so low as to be well within the range of a very unsensitive testing set. On transfurmers of other than our own firm's manufacture we made core-loss measurements, estimated the weights of copper and iron and sometimes ascertained the numbers of turns and other particulars of the windings.

- The subject of core loss gradually came prominently to the front and for a long time we werefully occupied in studying the methods and results set down in Ewing's " Magnetic Induction in Iron and Other Metals," and in ourselves making ballistic tests of sheet iron and steel. The facilities of our department were placed at the disposal of the company's purchasing agent, who was scouring the world's markets for suitable sheet iron. I well remembered that it was not long before we ascertained that the cheapest grades of material often had (if annealed from a suitably high temperature) the lowest core loss and that plates rolled from Swedish soft charcoal-iron, while they cost much more, were no better as regards core loss than were the cheap grades of sheet steel used for various non-electrical commercial purposes, such, if I remember rightly, as shipper's labels. The chief difficulty consisted in obtaining in great quantity material of the good quality of the occasional sample. But even our best results of that time (1890 and 1891) related to materials which were far inferior, as regards core loss, to the low-loss alloys at present (1910) employed, and were also much more prone to "ageing." Contemporaneously with the testing of magnetic materials, we were required to make tests of the core losses of completed transformers, for by this time (1891) our company's designers were becoming keenly alive to the importance of keeping down the core losses and were engaged 
in modifying their designs as regards the proportions of the magnetic and copper circuits. At that time we measured these core losses by dynamometer-wattmeters of the Siemens pattern. Inconsistencies in the measurements compelled us to turn our attention to the study of errors in wattmeters, and we were led to realise the importance of "swamping" the inductance of the pressure coil by the use of very high resistances, wound non-inductively, in series with the pressure coil. This, of course, involved weaker forces and the use of weaker torsion springs. The friction of the contacts dipping in the mercury cups constituted an annoying source of error. We were guided through these difficulties to no inconsiderable extent by the inspiring co-operation of Mr. Ernst Danielson, who had then (1891 and 1892) joined the company by whom I was employed. Danielson encouraged me to study Dr. Fleming's "Alteruate-current Transformer" and to draw vector diagrans, in the way explained by Fleming, for the actual cases of certain of our firm's transformers.

Among varions interesting transformers of other firms which came through our hands, I well remember a Swinburne hedgehog transformer. A certain transformer from another firm, interested me deeply at the time. This transformer had fully twice as much iron and twice as much copper as the more usual desigus, and although the material of the core was of excellent magnetic quality, this lavish expenditure for active material had been so ill-utilised that both the core loss and the regulation of this transformer were much worse than for a transformer of the more usual proportions. Such instances contain very important lessons for engineers.

The next "discovery" which then impressed me, and still impresses me, as being of especially striking importance was brought about as follows: It had then come to be the custom for the transformer-designing department to make its own core-loss tests, merely bringing the dynamometers to the instrument room in order that we should calibrute them at 
intervals and record their "constants." One day we were accused of having given out the constant of one of these wattmeters as 10 per cent. too low; for a certain standard transformer, which was kept permanently in the testing room, was remeasured, and the readings indicated a core loss some 10 per cent. less than its known value as determined by many previous measurements. We investigated the instrument carefully, but could only confirm our original calibration. During two or three days we did little else than overhaul standards and check instruments against one another. Then it was definitely found that the same wattmeter at certain times indicated the core loss of a given transformer to be 10 per cent. greater than at other times. Further investigations disclosed the fact that the low readings were obtained when the circuits were supplied from an alternator with its armature windings embedded in slots, while the high readings were obtained when an alternator was used whose armature windings consisted of flat coils resembling "pancakes" and bound down on the surface of the armature. Thus the wattmeter was vindicated, and we were impressed with the practical significans:e of the shape of emf wave supplied by an alternator. 'I'he slotted alternator was one of the earliest which our firm had built. It was, of course, a single-phase machine, and it had only one slot per pole. This gave it a very "peaked" wave. We confirmed this by determining by the Joubert contact method (using our Thomson quadrant electrometer) the wave shapes of both machines not only on no load, but also on full load. The old "pancake" or "smooth-core" type had practically a sine wave both at no load and at full load, while the wave of the iron-clad alternator was very peaked under both conditions, and (for a given terminal pressure) had a crest pressure some 10 per cent. higher than the crest pressure of the "smooth-core" alternator. In other words, the form factor (defined by Fleming on p, 583 of Vol, I. of the 2nd edition of his " Alternate-current 
Transformer" as the ratio of the root-mean-square, or virtual value, to the true mean or average value) was 10 per cent. higher for the iron-clad machine than for the smooth-core machine. Some firms at that time took adrantage of the lower core loss obtained on such uni-slot machines. The core losses which they quoted for their transformers were such as would be obtained when the "form factor" was at least 10 per cent. higher than that of a sine-wave alternator. The furm factor of a sine wave is 1,11, and the form factors of these uni-slot single-phase alternators were usually at least $(1,10 \times 1,11=) 1,22$. It is highly important that the presentday student should have these points well in mind, since they are apt to be less appreciated when read from books than when, as in our case, they were obtained at first hand by experiences which at the time were actually distressing. While the modern alternator is usually required to supply a sine wave of pressure, nevertheless various conditions temporarily occurring in electrical networks often occasion a very considerable distortion of the wave form. It is certainly decidedly important to specify that core losses shall be measured from a circuit supplying a sine wave of pressure. The unrarelling of this 10 per cent. discrepancy in the way in which it was encountered at our works was largely due to Danielson's insight.

Cp to this time (1892) our transformers had almost all been designed for 125 cycles and for a lighting load, i.e., for supplying incandescent lamps. Owing to the non-indnctive character of this load, there had been no occasion to devote any special attention to decreasing the inductance of the windings. The problem of transformer design had related chiefly to combining a minimum mean length of magnetic circuit with a minimum mean length of turn of the winding. In the commercial development of the polyphase induction motor, which became an important matter in 1892 and 1893, it was soon found quite impossible to employ these lighting 
transformers with good effect. It was not at first clearly appreciated that the non-intermixing of the primary and secondary coils was so especially a fault; on the contrary, it was considered that the difficulties were due to the increased saturation of the core accompanying the use of these 125 -cycle transformers on the 60-cycle circuits, which were at first usually employed for power purposes. For the same terminal pressure halving the periodicity doubled the flux required in the magnetic circuit. This did not so greatly increase the core loss, since the doubled density was partly offset by the halved periodicity; in fact, the core loss was only increased by some 35 per cent. by employing the same transformer at the same pressure, but on a circuit of half the periodicity. But these transformers had not been sufficiently liberally designed to permit of this 35 per cent. increase in the core loss, and there was also in some cases the further trouble of greatly increased magnetising current due to the greater saturation. The enunciation at about this time of the oneand-sixth-tenths power law of hysteresis by Dr. C. P. Steinmetz was very opportune, and was of great assistance in transformer design. In placing on the market transformers of lower periodicity for power work, in order to avoid the necessity for new parts throughout, the same general type (the shell type) was retained and the same general proportions of the winling space, but occasion was taken to intermix to a moderate extent the primary and secondary coils, so as to decrease the inductive drop, i.e., so as to obtain closer pressure regulation with inductive loads.

The incursion into the power field rapidly led to requiring transformers of larger size and introduced great difficulties in the matter of so designing the transformers that they should not overheat. 'The years 1893 and 1894 saw the extensive commercial introduction of the principle of immersing the transformer in oil. No inconsiderable difficulties were experienced in obtaining a suitable oil, and a great deal of 
experimenting was done before a commercial stage was reached. The matter was chiefly worked out by Mr. W. S. Moody, to whom (and also to Prof. Elihu Thomson) the development of not only the oil transformer, but also the air-blast transformer (which was developed simultaneously) was in great measure due. At this time (1893 to 1895$)$ there was a rapid increase in the pressures employed in transformers. Up to 1892 pressures of 2000 to 3000 volts had only been exceeded in special cases, but during the immediately following years, pressures of 10000 and even 20000 volts were fairly frequently employed, and the general experience then was that these pressures could be best handled with the air-blast type of design. As the reader knows, transmission plants are now (1910) in operation where the transformers are wound for pressures of 80000 and even 100000 volts, but in 1894 a pressure of 20000 volts was considered distinctly high. In America the manufacturers did not then build three-phase transformers, but employed groups of three single-phase transformers.

Another variant introduced by this time (1894 to 1895 ) was the increasing use of the low periodicity of 25 eycles per second. This was chiefly brought about by the bad experiences obtained with 50-cycle and 60-cycle rotary converters. For installations where rotary converters were likely to be required it became usual to employ 25 cycles per second, and this periodicity has ultimately found very considerable favour, as it permits of advantages in transmission-line design und also in other directions, especially as regurds the constants of the designs of generators and motors.

It was not until 1895 that I was first given a really considerable amount of responsible transformer designing. But these earlier episodes had afforded a good preliminary training, and I took on the task with much interest. But it is only when one comes right down to doing the actual task that one is capable of fully appreciating the magnitude of it, 
and although I have designed large numbers of transformers during the last fifteen years, nevertheless the prospect as regards as-yet-unworked possibilities broadens with each successive year, and I am each year more certain that the subject of transformer design cannot be covered by the enunciation of rules, formulæ and constants, but that the designing of a transformer or of a line of transformers for any particular rating or ratings still affords, and will for many years continue to afford, ample scope for careful thought and work. It is not in contradiction to this view that I put forward in the course of this treatise various rules and tables, but rather that they may be employed as rough starting points, and in the full realisation that it is often not only expedient, but in the interests of obtaining the best results that wide departures from these preliminary indications should be made as the design proceeds.

I should like to direct special attention to the almost predominating importance in transformer design and construction of the selection and testing of materials. We have to consider not only that the materials shall be initially of the correct quality, but that they shall not "age." It was Mr. G. W. Partridge who, some twenty years ago, first directed attention to the "ageing of transformers." No less important is the question of deterioration of the insulating materials, and of the cooling oil in which the transformer is immersed. There are also exceedingly difficult questions of the effects of the oil on the insulating materials, and these effects render certain otherwise-excellent insulating materials quite unsuitable for oil transformers.

The Epstein method of testing iron has been adopted in Germany and constitutes the basis for contracts for the supply of core plates. In this country contracts are much less definite on this point, and it would be of great advantage to adopt the Epstein method.

The present treatise should be regarded as merely an intro- 
duction to the practical designing of transformers, and the reader should realise that there are many matters of great importance which have not been included. The briefest description of these numerous very important suljects, such as the mechanical stresses in the windings, the insulation of extra-high-pressure transformers, the design of terminals and bushings, corona phenomena, the testing of sheet steel for transformer cores, the testing of transformer oil, the extra insulation of the end turns (which are subjected to excess pressures at the instant of switching in), ground shields and other protective devices, the question of employing three single-phase or one three-phase trunsformer, the use of the "delta" or "Y"-connection of three-phase transformers, and the subject of single-coil transformers (sometimes known as compensators or auto-transformers), as distinguished from transformers with distinct primary and secondary windings, would have necessitated a treatise far larger and more expensive than this little introductory volume. I have confined my discussion of the subject to those points regarding which a reasonable approach to definite designing methods is practicable, and I believe that I have supplied a link which has not existed, at any rate in a form which has met the needs of students, who, although they understand the underlying theory, are at a loss how to proceed when called upon to work out an actual design. With a view to facilitating the further study of the static transformer, I am concluding this introductory chapter with a brief biblingraphy of some useful papers on the sulject, and I am of opinion that after completing his stuly of the present treatise, the realer will be in a position to consult with adrantage the pupers therein mentioned.

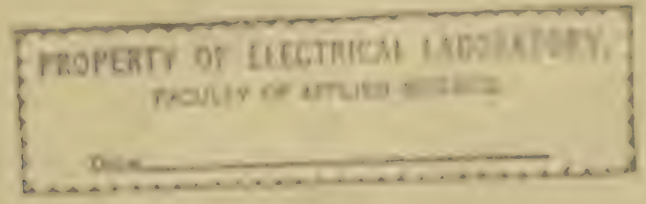


A BIBLIOGRAPHY OF A NUMBER OF IMPORTANT PAPERS WHICH HAVE BEEN PUBLISHED DURING THE IAST TWENTY-THREE YEARS ON THE SUBJECT OF THE STATIC TRANSFORMER.

1888.

Gisnent Kapr.-On Alternate-current Transformers. (Journ. Inst. Elec. Engrs., Vol. 17, p. 96.)

R. E. B. Crompton.-Central Station Lighting; Transformers $v$. Accumulators. (Journ. Inst. Elec. Engrs., Vol. 17, p. 349).

1889 .

W. M. Mordey.-Alternate-current Working. (Journ. Inst. Elec. Engr8., Vol. 18, p. 583.)

H. J. RYan.-Transformer Curves. (Trans. Am. Inst. Elee. Engrs., Vol. 6.)

\section{1.}

James Swrmbure.-Transformer Distribution. (Journ. Inst. Elec. Engrs., Vol. 20, p. 163.)

Dr. J. A. Fleming.-On Some Effects of Alternating-current Flow in Circuits having Capacity and Self-induction. (Journ. Inst. Elec. Engrs., Vol. 20, p. 362.)

Nikola TesLa.-Experiments with Alternate Currents of Very High Frequency. (Trans. Am. Inst. Elec. Engrs., Vol. 8, p. 26\%.)

1892.

Alexander Siemens.-Some Experimental Investigations of Alternate Currents. (Journ. Inst. Elec. Engrs., Vol. 21, p. 164.)

Dr. J. A. Fleming.-Experimental Researches on Alternate-current Transformers. (Journ. Inst. Elec. Engrs., Vol. 21, p. 594.)

C. P. Steinietz.-On the Law of Hysteresis. (Trans. Am. Inst. Elec. Engrs., Vol. 9, pp. 3 and 621.)

1893.

C. P. Steinmetz.-Note on the Disruptive Strength of Dielectrics. (Trans. Am. Inst. Elec. Engrs., Vol. 10, p.64.)

Fliederick BEDELL.-Hedgehog Transformer and Condensers. (Trans. Am. Inst. Elec. Engrs., Vol. 10, p. 513.)

1895 .

C. P. Steinmetz.--Theory of the General Alternating Transformer. (Trans. Am. Inst. Elec. Engrs., Vol. 12, p. 245.)

1896.

BeEton, Taylor AND BARR.-Experimental Tests on the Influence of the Shape of the Applied Potential Iifference Wave on the Iron Losses of Transformers. (Journ. Inst. Elec. Engrs., Vol. 25, p. 474.) 
C. K. Hrgert.-An Analysis of Transfurmer Curves. (Traus. Am. Inst. Elec. Fngrs., Vol. 13, p. 207.)

1898.

W. F. Wuite.-Alternating-current Transformers from the Station Manager's View-point. (Trans. Am. Inst. Eleec. Engrs., Vol. 15, p. 50.5.)

F. W. CirTER. -The Design of Transformers. (Trans. Am. Inst. Elee: Fngrs., Vol. 15, p. 639.)

1899.

W. I. Rовв.-Series Are Lighting from Constant-current Trans. formers. (Trans. Am. Inst. Elec. Engrs., Vul. 16, p. 533.)

1903.

F. O. BL.ICKWELL. $-\mathrm{Y}$ or $\triangle$ Connection of Transformers (Trans. Am. Inst. Eilec. Engrs., Vol. 22, p. 385.)

1904.

E. W. RICE, JR.-The Relative Fire-risk of Oil Transformers and AirBlast Transformers. (Trans, An. Inst. Vlec. Engrs., Vol. 23, p. 171.)

W. S. Moomy.-Terminals and Bushings for High-pressure Transformers. (Trans. Am. Inst. Elec. Engrs., Vol. 23, p. 225.)

J. S. P'rck.- The Use of Ground Shields in Trunsformers. (Traus. Am. Inst. Elec. Engrs., Vol. 23, p. 533.)

1906.

D). D. K. Morits Axn G. A. Iister. - The Testing of Transformers and Transformor Iron. (Journ. Inst. Elee. Eingrs, Vol. 37, p. 264.)

K. I. Cints. -The ('urrent Trausformer. (Trans. Am. Inst. Eilec. Engrs., Vol. 25, p. 715.)

\section{7.}

J. Eirsters. - Teating of Elentric Machinery and of Materials fur lis Construction. (Journ. Inst. Flee. lingrs., Vol. 38. p. 28.)

II. Bont.v. - Modern Transfurmer Thenign. (Journ. Inst. Klec. Lingrs., Vol. 38, p. 390.)

II. W. Tomer. - Relative Merits of Three-Thase and One- Thase Transformers. (Trans. Am. Inwt. KHev. Fingra, Vol. 26, Fart 1, p, s13.)

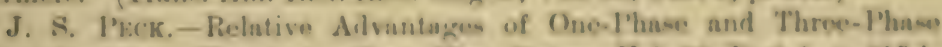
Transfurmers. ('Trans. Am. Inat. E.7ec. Engrs., Vol. g6, l'urt 1, p. s15.)

C. C. Cirgseres. - Furcend Oil and Firrod Water Cirrulatiun fur Cualing Oil-insulated Transformers. ('Trans. Aus. Inst. Elene. Fingrs., Vol. 26. Part 1, p. 835.) 


\section{THE DESIGN OF STATIC TRANSFORMERS}

S. M. Kixtner.-Choke-Coils versus Extra Insulation on the Endwindings of Transformers. (Trans. Am. Inst. Elec. Engrs, Vol. 26, Part 2, p. 1169.)

W. S. Moovy.-Protection of the Internal Insulation of a Static - Transformer against High-frequency Strains. (Trans. An. Inst. Eilec. Engrs., Vol. 26, Part 2, p. 1169.)

II. W. Toвey.-Notes on Transformer Testing. (Trans. Am. Inst. Elec. Engrs., Vol. 26, Part 2, p. 1169.)

1908.

Dr. R. Goldschmidt.-Standard Performances of Electrical Machinery. (Journ. Inst. Elec. Engrs., Vol. 40, p. 45̃.̌.)

Dr. H. BoHLE.- " Magnetic Reluctance of Air Joints in Transformer Iron. (Journ. Inst. Elec. Engrs., Vol. 41, p. 527.)

A. P. M. Fleming axd K. M. Faye-Hansen.-Transformers : Some Theoretical and Practical Considerations. (Journ. Inst. Elec. Engrs., Vol. 42, p. 373.)

1909 .

E. G. KeED.-Transformers. (Report of 32nd Annual Convention of the National Electric Light Association, held at Atlantic City in June, 1909, Vol. 1, p. 581.)

A. B. Reynders.-Condenser Type of Insulation for High-tension terminals. (Trans. Am. Inst. Elec. Engrs., Vol. 28, Part 1, p. 209.)

K. C. RANDALL. - High-voltage Transformers and I'rotective and Conrolling Apparatus for Outdoor Installations. (Trans. Am. Inst. Elec. Engrs., Vol. 28, Part 1, p. 189.)

- L. W. CrubB.-Method of Treating Transformer Core Losses giving Sine-wave Results on Commercial Circuits. (Trans. Am. Inst. Elec. Engrs., Vol. 28, Part 1, p. 432.)

Lloyd And Fisher.-The Testing of Transformer Steel. (Trans. Am. Inst. Elec. Engrs., Vol. 28, Part 1, p. 439.)

Moody AND FAccioli.-Corona Phenomena in Air and Oil and Their Relation to Transformer Design. (Trans. Am. Inst. Elec. Engrs., Vol. 28, Part 2., p. 769.)

L. T. Robinson.-Electrical Measurements on Circuits Requiring Current and Potential Transformers. (Trans. Am. Inst. Elec. Engrs., Vol. 28, Hart 2, p. 1005.)

Hilleiband and Cinarters. - Some Phases of Transformer Regulation. (Trans. Am. Inst. Elec. Engrs., Vol. 28, Part 2, p. 1253.)

1910.

Marchant and Watson.-High-tension Transmission on Overhead Lines. (Journ. Inst. Elec. Engrs., Vol. 44, p. 423.)

R. D. Gifford. - The Influence of the Cooling Media upon the Rise in Temperature of Soft Iron Stampings. (Jouru. Inst. Elec. Engrs., Vol. 44, p. 753.) 
Digiry ANi Mrut.1s.- Physical Properties of Switch and Transformer Oils. (Journ. Inst. Elec. Engrs, Vol. 45, p. 16.5.)

A. P. Youxg.-Current Transforners, (Juurn. Inst. Elec. Kingrs, Vol. 45, p. 670.)

J. J. Frask.-Observation of Harmonics in Current and in Voltage Wave Shapes of Transformers. (Proc. Am. Inst. Elec. Engrs., Vol. 29. Number 5, p. 665.)

Ayolif Siraxe.-Determination of Transformer Regulation under Inal and Some Resulting Investigations. (Proc. Am. Inst. Elec. Eingrs., Vol. 29, Number 7, p. 1089.)

II. W. ToBeY.-Dielectric Strength of Oil. (I'roc. Am. Inst. Elee. Engrs., Vol. 29, Number 7, p. 1171.)

F. C. GreEx.-Problems in the Operation of Transformens. (I'roc. Am. Inst. Elec. Engrs., Vol. 29, Number 12, p. 1919.)

\section{1.}

Harris J. Rrax.-Open Atmosphere and Dry Transformer Oil as Iligh-voltage Insulators. (Proc. Am. Inst. Elec. Eingrs., Vol. 30. Number 1, p. 1.)

J. M. Wers.-Temperature Gradient in Oil-immeneal Transformers. (Proc, Am. Inst. Elec. Engrs., Vol. 30, Number 1, p. 119.)

W. J. Woolininge.-Hysteresis and Eddy Current Exponents for Silieon Steel. (Proe. Am. Inst. Elec. Engrs., Vol, 30, Number 1, p. 139.) H. R. Wirsox.-Commercial Problems of Transfurmer Tesign. (Proc. Am. Inst. Elec. Eingrs., Vol. 30, Number 1, p. 143.) 


\section{CHAPTER II}

THE LEADING DIMENSIONS OF A TRANSFORMER OF A GIVEN RATING

A NUMBer of papers have been contributed to the proceedings of scientific societies and to technical periodicals, dealing with methods of determining upon the leading dimensions when embarking upon a transformer design. Most of these papers, however, are overweighted with complex formulæ and are useless to the practical designer. In the majority of technical colleges the students investigate many interesting phenomena concerning the transformer, but it is rare to find a graduate who has the remotest idea of how to proceed in designing a commercial transformer. This, of course, cannot be due to any real difficulties associated with transformer designing; nothing is more simple and straightforward so far as relates to the underlying principles. Nevertheless, like all designing problems, there are very many practical points based on long experience to which careful consideration must be given. It is particularly true of transformer designing that past experience goes a long way in aiding the engineer in the case of any particular new design which he undertakes. It is the object of the present chapter to set forth correct (though simple) preliminary methods for guidance in the commercial designing of transformers which are required to conform to stipulated conditions. Various data, curves and rules will be introduced from time to time to aid in carrying on the design at those points where it is necessary to make assumptions. The data thus introduced are based on my experience as applied to a large number of designs of various ratings. So far 
as it has been practicable to reduce this data to rules, this has been done.

One cannot but feel that the study of transformer design has been considerably neglected in favour of the study of the design of other kinds of electrical machinery. 'This is to be regretted, since transformers constitute by no means a minor detail in electrical engineering work, and it is important that they should be well designed and well built. The number of transformers in use is increasing at an enormous rate. The most unique characteristic of electricity as distinguished from other forms of energy is the high efficiency with which transformations may be effected. Since in all but the smallest sizes of static transformers efficiencies in

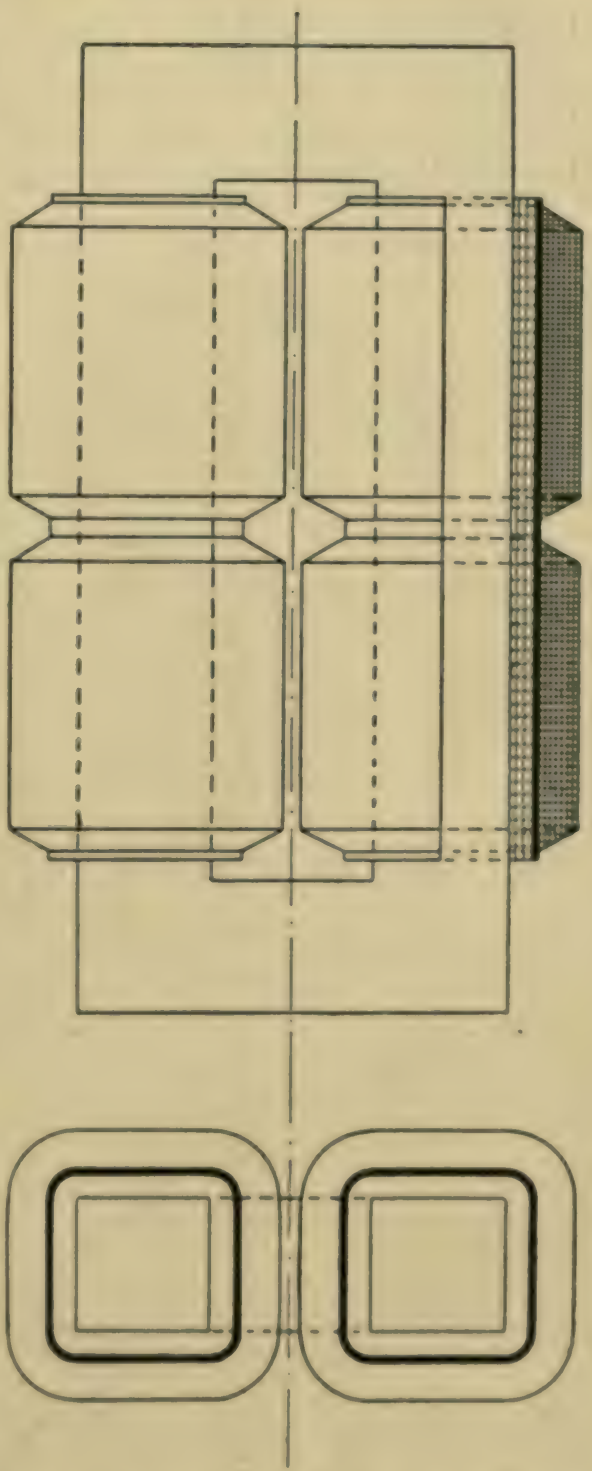

F10. 1-Outline sketch of a representative design of a care-type sungle-phase tran-former.

excess of 90 per cent. are customary, and since in some of the S.T. 


\section{THE DESIGN OF STATIC TRANSFORMERS}

large transformers which are now coming into use, efficiencies of from 98 to 99 per cent. are obtained, there is but little incentive, except as regards capital cost, for refraining from interpolating transformers at convenient points in the system.



FIG. 2.-Outline sketch of a representative design of a shell-type singlephase transformer.

Were engineers to fully recognise this point they would not be so much concerned with the relative advantages and disadvantages of different forms of electricity, since any particular kind of electricity may be transformed into any other kind and at very high efficiency. Even when recourse to motor-generators must 
be made, the loss in transformation is very low indeed, and with the extension of the term "transformer" to comprise "motorgenerator," there is no reason why efforts to standardise periodicity, pressure or number of phases should be pushed very far. It is usually a much better plan to employ in each particular case the number of phases, the periodicity and the

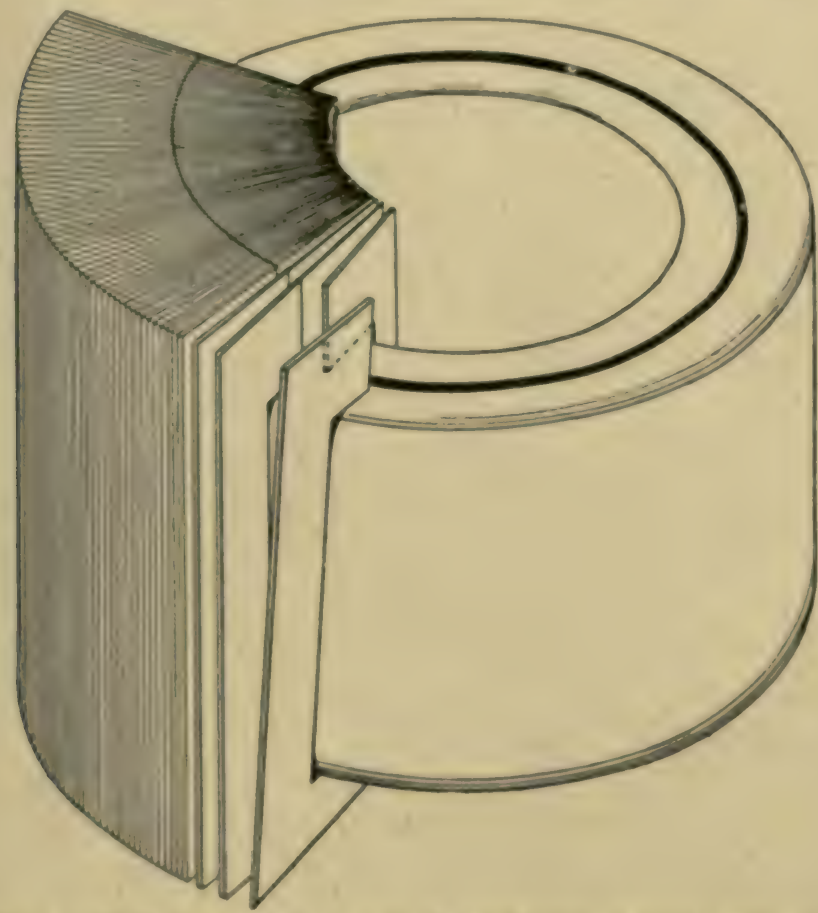

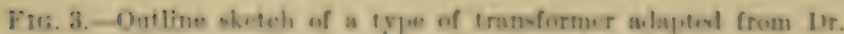
Kitcler's "IIandbuch" der Blektrotuchnik," 1892.

pressure lest adapted to the work to be performed, and to uhtain electricity of the preferred kind by the interposition of suifable transformers. I am certain that this policy will be fur more generally followed in the course of a very few years, and that the aggregate capacity of the transformers and motor generators absorbed anmually in engineering undertakings will be many times greater even than at present. This absolnte 
increase will not be simply in proportion to the increased annual turnover of electrical machinery, but will constitute a much larger percentage of the total annual turnover than is now the case. Hence manufacturers who refrain from taking up the building of transformer's are, in my opinion, ill-advised, since they will not be so well prepared to participate in the increasing turnover in electrical machinery.

\section{The Relative Merits of Various Types of Transformers.}

The two main types of transformers are the core type and the shell type. The iron circuit of the former is composed of a rectangular frame, upon the vertical legs of which the primary and secondary windings are placed. In the shell type of transformer the windings interchange places with the iron magnetic circuit of the core type, and the magnetic circuit is built around the two vertical sides of the more or less rectangular-shaped windings. It will thus be seen that, as regards mechanical construction, the characteristics of the two types are precisely reversed. In the core type the copper windings envelope a considerable portion of the magnetic circuit, while in the shell type the magnetic circuit envelopes a considerable portion of the copper windings. Practically the entire surface of the windings of the core type are exposed to the surrounding medium (either air or oil), while in the shell type a very large portion of the surface of the core is thus exposed.

In Fig. 1 is shown an outline sketch of a representative design for a core-type transformer. In this type it will be seen that the two long parallel legs of the rectangular magnetic circuit carry the primary and secondary windings, the latter generally being next the core. A representative design for a shell-type transformer is shown diagrammatically in Fig. 2. Another type, illustrated in Fig. 3 and adapted from an illustration in Kittler's "Handbuch der Electrotechnik" (1892), may be designated the "circular-shell type." The arrange- 
ment indicated in Fig. 3 is the predecessor of a type which has been put forward on various occasions, and, like most types, has its characteristic advantages and disadvantages. A modern development of the "circular-shell" type is known as the "Berry" transformer, and is shown diagrammatically in Fig. 4. The "Berry" type is quite similar to Fig. 3 as regards the disposition of the magnetic circuit and of the primary and secondary windings; but the construction of the iron portion is different, in that it is made up of a number of distinct groups of core plates. The "Berry" type is thoroughly discussed by Mr. A. F. Berry in Vol. II. of "Modern Electric Practice."

Much of a controversial nature has been written regarding the relative merits of the two main types of transformers, namely, the core type and the shell type, and the now-generally-accepted conclusion is, that, so fur as electrical design is concerned, there is very little to choose between the two types. It is,

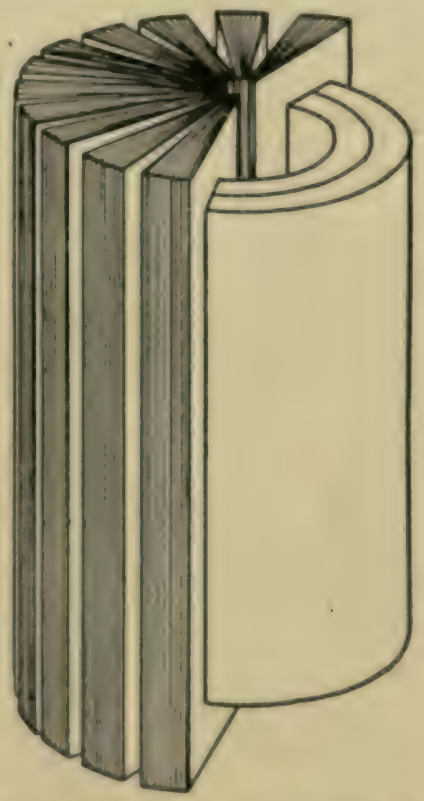
however, interesting to note Fus. 4.-Diagrammatie shetch of that the shell type is rarely - Berty tran-former.

manufactured except by the firms who took it up many years ago, and who have been making it ever since, and that those manufucturers who have only recently emburked upon transformer-building have, in nearly every instance, decided in fuvour of the core type. Even those manufucturers who adopt the shell type for single-phase transformers nevertheless build their three-phase transformers of the core type. In fact, the core type is pre-eminently more suitable for three-plase 


\section{THE DESIGN OF STATIC TRANSFORMERS}

transformers. In Fig. 5 is shown a core-type three-phase transformer, and in Fig. 6 a shell-type single-phase trans-

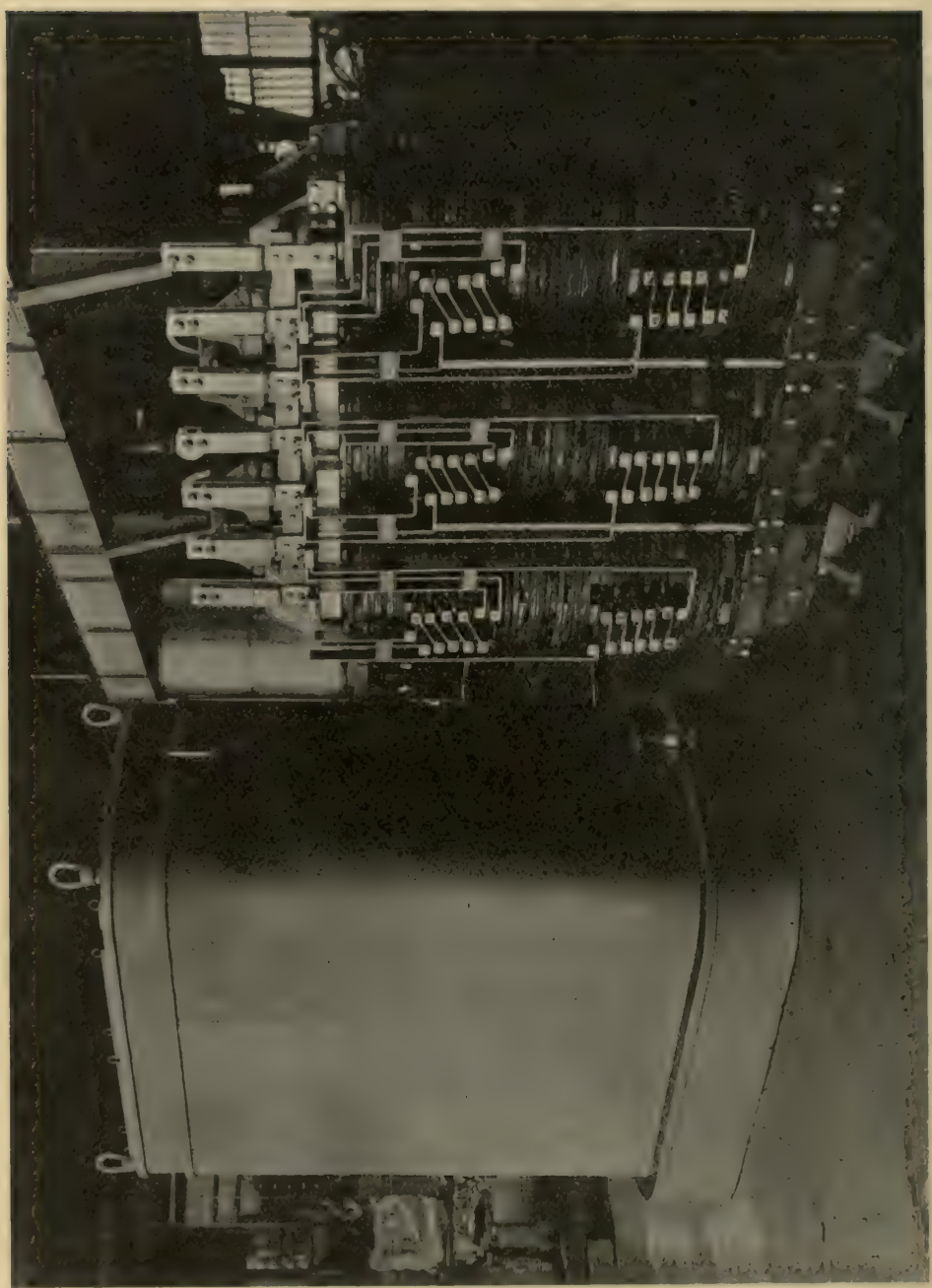

है

former. These transformers were both built by the Westinghouse Company.

The absence of radical advantage in any one type as regards 


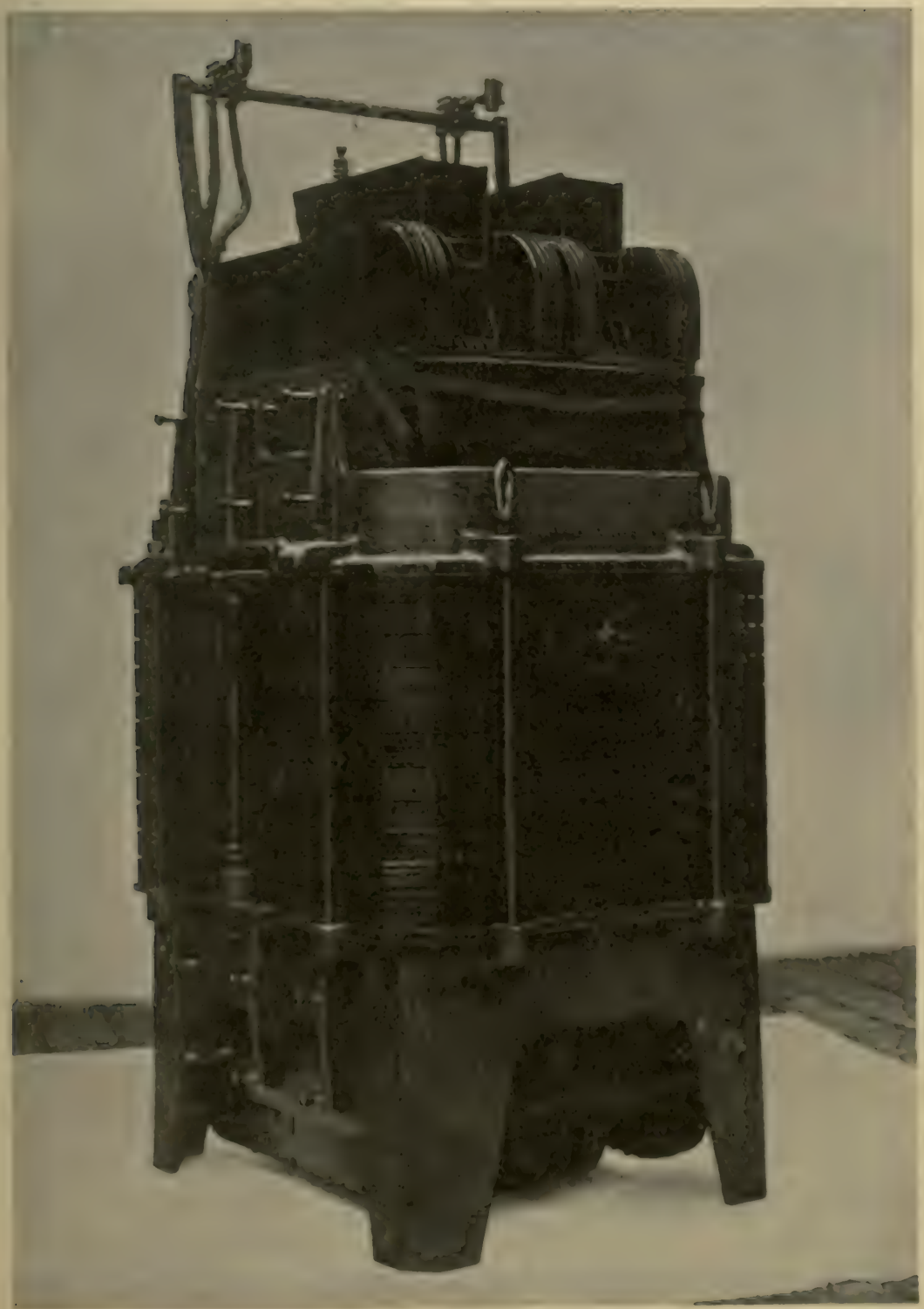

Fir. 6. - 100-kwa single-phase low ono-volt shell-eyge transfurmer built by the Westinghoume Co. for the Southern l'ower Cis. 
electrical design has been shown by A. P. M. Fleming and Faye-Hansen ${ }^{1}$ in a paper recently read before the Institution of Electrical Engineers.

\section{Illustrative Example in 'I'rangformer Design.}

For the purpose of explaining designing principles I propose to make calculations for a single-phase 50-cycle transformer of the rectangular-core type for a rated output of 20 kilovoltamperes. I shall work out the design for a primary pressure of 5000 volts and for a secondary pressure of 200 volts. Let it be required that the regulation at full load shall be within 2,0 per cent. The transformer is to be designed for use on circuits having a periodicity of 50 cycles per second, and supplies a load consisting exclusively of incandescent lamps. Consequently the power factor of the load is 1,00 , and the output of the transformer is in this instance not only 20 kilovoltamperes, but also $20 \mathrm{kw}$. Let us denote the power factor by $G$. Thus we have $G=1,00$. When the nature of the load to be put on the transformer is not stated or known, it is safer, in order to prevent misunderstanding between the customer and the manufacturer, to rate the transformer in kilovoltamperes. If, however, it were known that the power factor would be, say, 0,80 and the output $20 \mathrm{kw}$., then the transformer must be designed for a current corresponding to an output of $\left(\frac{20}{0,80}=\right) 25$ kilovoltamperes.

From the curves in Fig. 7 a rough preliminary estimate of the full-load efficiency for the transformer to be calculated, may be obtained. These curves may in a general way be taken as representative for all types of single-phase oil-cooled transformers up to the outputs shown, whether of the shell type or of the core type, and, in fact, no error of consequence will be

1 "Transformers :- Some Theoretical and Practical Considerations," A. P. M. Fleming and K. M. Faye-Hansen, Jour.I.E.E., Vol. XLII., p. 373. 

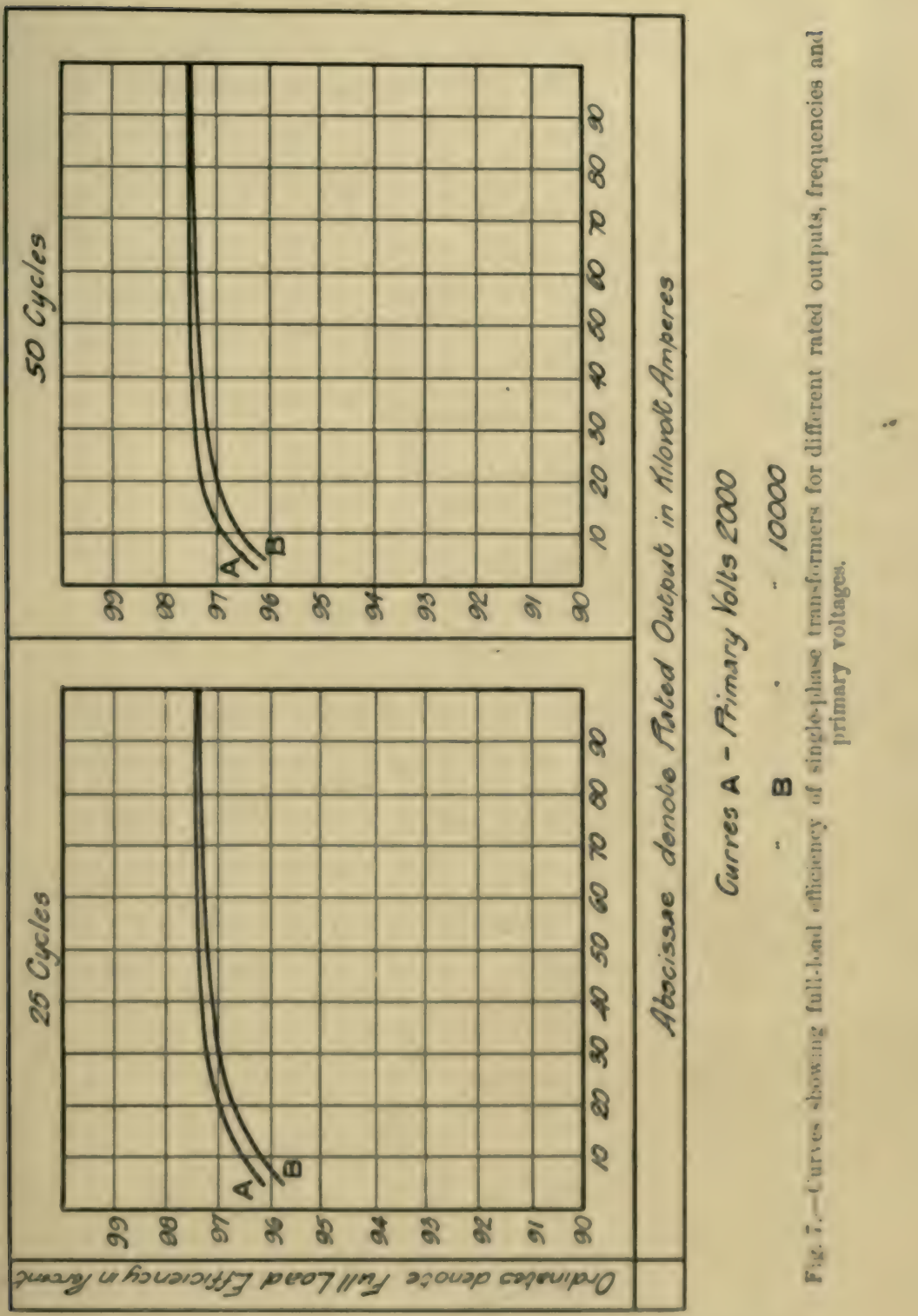

introluced by embarking upon the caleulation of natural aircooled transformers on the basis of these preliminary efficiencies. 
Few transformers of the natural air-cooled type are, however, built nowadays for so large an output as that in question, namely, 20 kva. From Fig. 7 we find that the full-load efficiency will be of the order of 97,1 per cent. In the final design it may be found that the calculated efficiency does not agree absolutely with that assumed from Fig. 7 . No radical change will have to be introduced in the calculations on this account. It will only be necessary to make a slight alteration in the current so that it shall correspond with the true efficiency and also to alter the factors dependent upon the current.

The primary current at rated load is

$$
\frac{20000}{5000 \times 0,971}=4,12 \text { amperes, }
$$

and the corresponding secondary current is

$$
\frac{20000}{200}=100 \text { amperes. }^{1}
$$

At the next step a factor is introduced and considered wherein large differences may exist, even in equally good designs. This factor is the "volts per turn." In general, the pressure between each turn of the winding may be varied over a very wide range, depending partly upon the object which the designer has in view, but more especially upon the instinct, preferences and experience of the individual designer. In designs for fairly large outputs, say, up to 300 or $400 \mathrm{kva}$, and for ligh pressures, the determining factor for this quantity (the "volts per turn") is the permissible pressure, in volts, which can, with a sufficiently large factor of safety, and with due regard to economy in the space factor, be allowed between each turn of the windings. This, of course, applies to both primary and secondary windings, since the pressure per turn

1 Strictly speaking, the secondary current at rated load would be 100 amperes only if the transformer were wound to give a terminal pressure of 200 volts at its ruted load. Usually, the secondary pressure ascribed to a transformer is that at no load. 

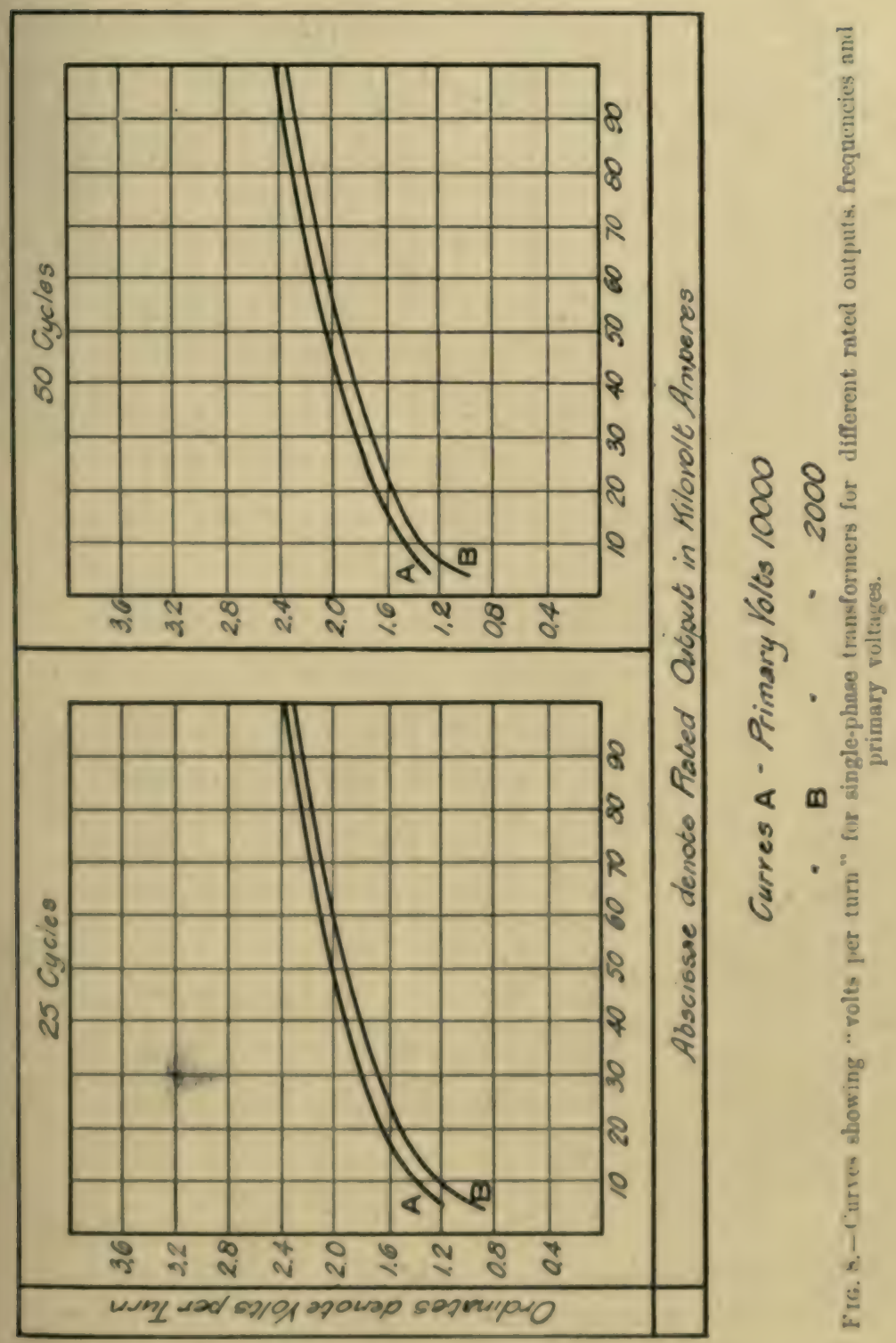

is the same in either. Inother quantity, the "rolts per layer," although not directly influencing the number of turns selected, 
does, to a very considerable extent, limit the choice of dimensions and arrangement of the primary coils. In general, the value of the "volts per layer" does not affect the dimensions and arrangements of the secondary conductors, especially

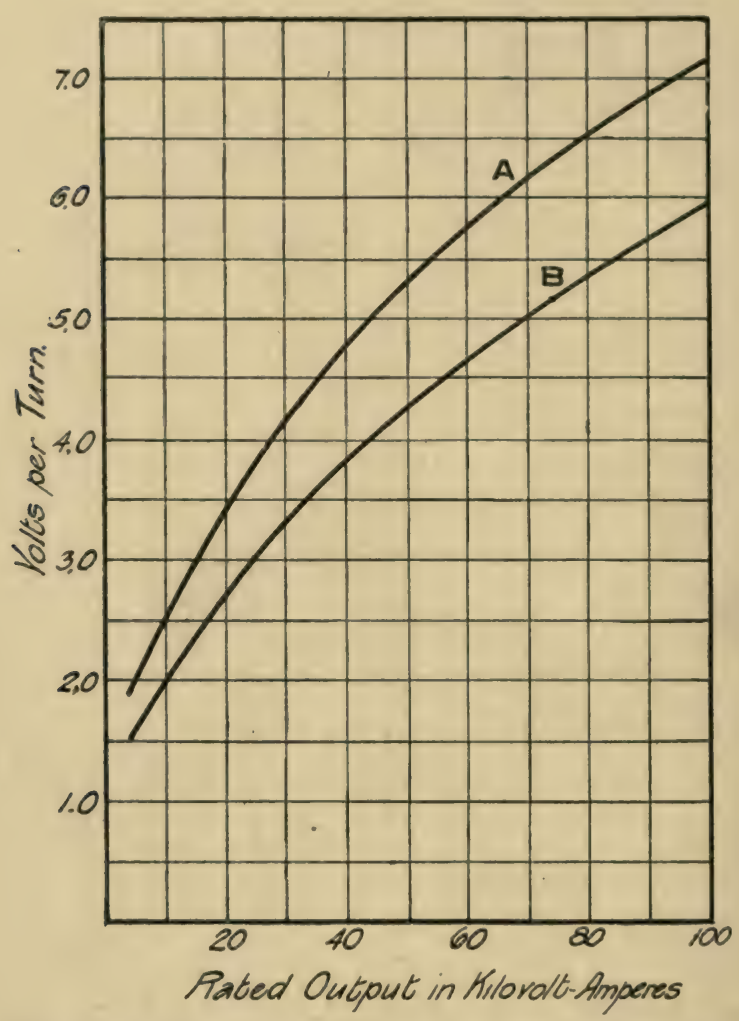

FiG. 9.-Carves showing "volts per turn" of single-phase transformers of different rated outputs and periodicities. Curve A, 50 cycles ; curve $\mathbf{B}, 25$ cycles.

where the secondary pressure is low. This is for reasons which will be more apparent at a later stage in the workingout of the design. In transformers of low and of moderate capacity, the range of suitable values for the "volts per turn" is limited by other reasons, the chief of which is the necessity 
for a large number of turns in order to obtain sufficiently small weights of steel and sufficiently low core losses. Thus the values are lower than would be the case were insulation safety factors the only consideration, and this accounts for the steepness at the start of the curves in Fig. 8, which show graphically the relation between the rating, pressure, periodicity and "rolts per turn "obtained by an analysis of a large number of successful modern designs of the core type. For shell-type trunsformers the values shown may be increased by some 10 to 20 per cent. It should be mentioned that these curves are plotted from designs proportioned in accordance with my own practice. A good many other designers prefer to employ a less number of tums and consequently higher values than those given in Fig. 8 for the "volts per turn," and although there are certain adrantages attending such proportions, yet it may occur that other (very often essential) qualities are sacrificed by their employment. Fach designer will, as he gains in experience, readily decide for himself in each case which of these two tendencies he considers it best to follow; but the reader may prefer, until he has obtained his own experience, to employ the curves of Fig. 9, which, while lying much higher than my usual values, are also much below values often employed by some designers. It may be remarked that for very large transformers of several thousands of kilowatts capacity, the "volts per turn" assume much larger values than any of those indicated in the curves. In these very large transformers the conductors are composed of strips. A circular conductor, to give so large a section, would lead to a prohibitive amount of lost space in winding the coils. These strips are usmally insulated by hand simultaneously with the process of winding the coils. It is thus possible to insulate the conductor to any degree required to ensure an ample margin of safety with the higher values of the "volts per turn." Some appropriate values for the "volts per turn" for these larye transformers may be taken from Table 1 . 
Table 1.-Valees for "Volts per Turn" in Transformers of LARge OUtputs.

\begin{tabular}{c|c}
\hline Rated output in kva. & Volts per turn. \\
\cline { 2 - 2 } 500 & 13 \\
1000 & 18 \\
1500 & 24 \\
2000 & 30 \\
2500 & 35 \\
3000 & 40 \\
4000 & 52 \\
5000 & 65 \\
\hline
\end{tabular}

For our present purpose, let us take for the "volts per turn" of the 20-kw transformer the value read from the curves in Fig. 8, namely, 1,6 volts. There will thus be required (roughly) some $\left(\frac{200}{1,6}=\right) 125$ secondary turns, and 3125 primary turns, the ratio of transformation being 25 . It is generally convenient, in the first place, to adjust the number of secondary turns to a figure which is some multiple of four or else a multiple of some even number greater than four. Consequently we shall take 124 secondary turns and $(25 \times 124=) 3100$ primary turns.

Let us now turn our attention to the consideration of the fundamental orthodox formula connecting the pressure with the number of turns, the periodicity and the total flux in the core. I consider that the most useful way of expressing this formula when used for transformer design is

$$
V=0,0444 T \sim M
$$

where $V$ represents the pressure in volts, $T$ the total number of turns in series between the terminals which have a pressure of $V$ volts between them, $M$ the total flux in megalines and $\sim$ the periodicity of reversal of the pressure, in cycles per second. This formula, however, is only correct for a transformer operated from a circuit in which the pressure wave is a sine curve, and although, in many cases, it is justifiable to make 
the sinusoidal assumption for approximate calculations, there is, in practice, often need for greater accuracy. The sine-wave assumption may in many instances involve an error of 10 per cent. or more, in calculations relating to alternating electricity apparatus. In the case of transformers, the relation between the pressure and the flux is dependent upon the wave form of the pressure, and determinations of these quantities involve the use of the "form factor" 1 of the curve. The "form factor" of a curve may be defined as the ratio of the square root of the mean of the squares ( $r m s$ ) of the ordinates of the curve, to the mean value of the ordinates. Thus, if we denote the form factor by $f$, we have

$$
f=\frac{r m s \text { value of ordinates }}{\text { mean value of ordinates }}
$$

For the case of a rectangular wave, as obtained approximately in the winding of the armature of any ordinary generator of continuous electricity, the rms value and the mean value are equal to one another, each being equal to the crest value of the curve. The form factor thus becomes equal to unity, and this is the minimum possible value which it can have. In an ordinary continuous-electricity machine, however, the equation connecting pressure and flux is

$$
V=0,040 T \sim M
$$

and thus the equivalent equation for any other form of curve having a form factor " $f$ " may be written

$$
V=0,040 f T \sim M .
$$

It will be seen that "peaked" curves have high "form factors" and "flat" curres have low "form factors" when the terms "peaked" and "flat" are taken to represent the relative forms of the pressure curves, when taken in conjunction with

I This turm was propused by l'rot. Fleming (eee "Alternating-eurrent Transformers," Vul. I., 2nil eil.. 1. is3.). 


\section{THE DESIGN OF STATIC TRANSFORMERS}

a sine wave (which has a form factor of 1,11 ). 'The effect of assuming a sine-wave curve when the curve will actually be peaked will usually not be detrimental in any respect as regards the performance of the transformer. In fact, it can easily be seen from the precise formula given above, i.e., that involving the use of the form factor, that the flux will be decreased in proportion to the "peakedness" of the pressure curve and consequently the core loss will also be decreased. If the transformer is designed for a high saturation of the core whilst assuming a sine-wave function, then this decrease in the core loss may be quite considerable if the transformer is operated on a peaked pressure-curve.

The introduction of the form factor in the flux formula, however, is very necessary when the pressure curve is flat, in order that misunderstandings shall not arise between the buyer and the manufacturer should the core loss not correspond with the specification. In any case, it would be wise to make more conservative calculations for circuits supplying flat curves than for circuits supplying peaked curves. It may be said, however, that there are few instances in modern generating plants where flat wave forms for the pressure curves are obtained from an alternator, the wave (in cases where there is any departure from the sine form) usually being more or less peaked. The modern tendency is strongly in the direction of specifying that generators shall provide a sine-wave curve of pressure at all loads. The extent of the dependence of the form factor upon the proportions and winding of an alternator is fully discussed at p. 92 of Parshall and Hobart's " Electric Machine Design" ("Engineering," London).

There can be no object gained by taking the form factor into account in a design such as that with which we are at present dealing, since the application of the form factor to the calculations is of the simplest nature, and, therefore, having no particular supply circuit in mind, we have no reason for assuming other than a sinusoidal pressure. Applying those 
particulars of the design at which we have alrealy arrived, to the formula

we have:

$$
V=0,0444 T \leftrightarrow M
$$

$$
5000=0,0444 \times 3100 \times 50 \times . M .
$$

Silving for $M$, we find that the total flux required is equal to 0,73 megaline. In selecting the value of the density at which to run the core, one must be guided to a large extent by the permeability, and by the loss per unit of weight corresponding क the grade of laninations which will be employed in constructing the core.

During the last few years, there have been placed on the market by varieus manufacturers, brands of material for trans. former cores which are greatly superior to the brands formerly employed. It is true that the price of this material, which may be termed "alloyed steel," is relatively high, being at present some $\& 30$ per ton as against some 213 per ton for the less. suitable material formerly employed. The supreme importance, however, of obtaining a minimum core loss, renders the use of the more costly material absolutely imperative, and this is now conceded by must manufacturers of transformers. As regards permeabilify, the material is, on the whole, usually inferior to the oliler rarieties of trunsformer plates, but the difference in this respeet is not very pronounced. The saturation curse in Fig. 10 is haseal on sufficiently conserva. live permeability values to allow for reasonable deviations frim normal gowal quality. It is ly ne means exceptiomal to othain material, nut only in samples lut in bulk, which shows distinetly higher permeatility than is indicuted by the standurd eurve in Fig. 10. but it is unwise to lanse desigus on the better valuns obtainable, unless the material is thoroughly tested before acceptance. Very slight varia. bions in the composition of the material are npt to be acommpantel by dispropontionate variatins in the perme. ahility. Th the transformer mannfacturer, howerer, tests with ieapect to permentility are of less importance than is the case S.T. 


\section{THE DESIGN OF STATIC TRANSFORMERS}

with manufacturers of dynamos and motors, since high permeability is of much less importance in the case of transformers owing to the relatively low densities at which the cores are usually worked. 'Transformers for use on circuits of very low

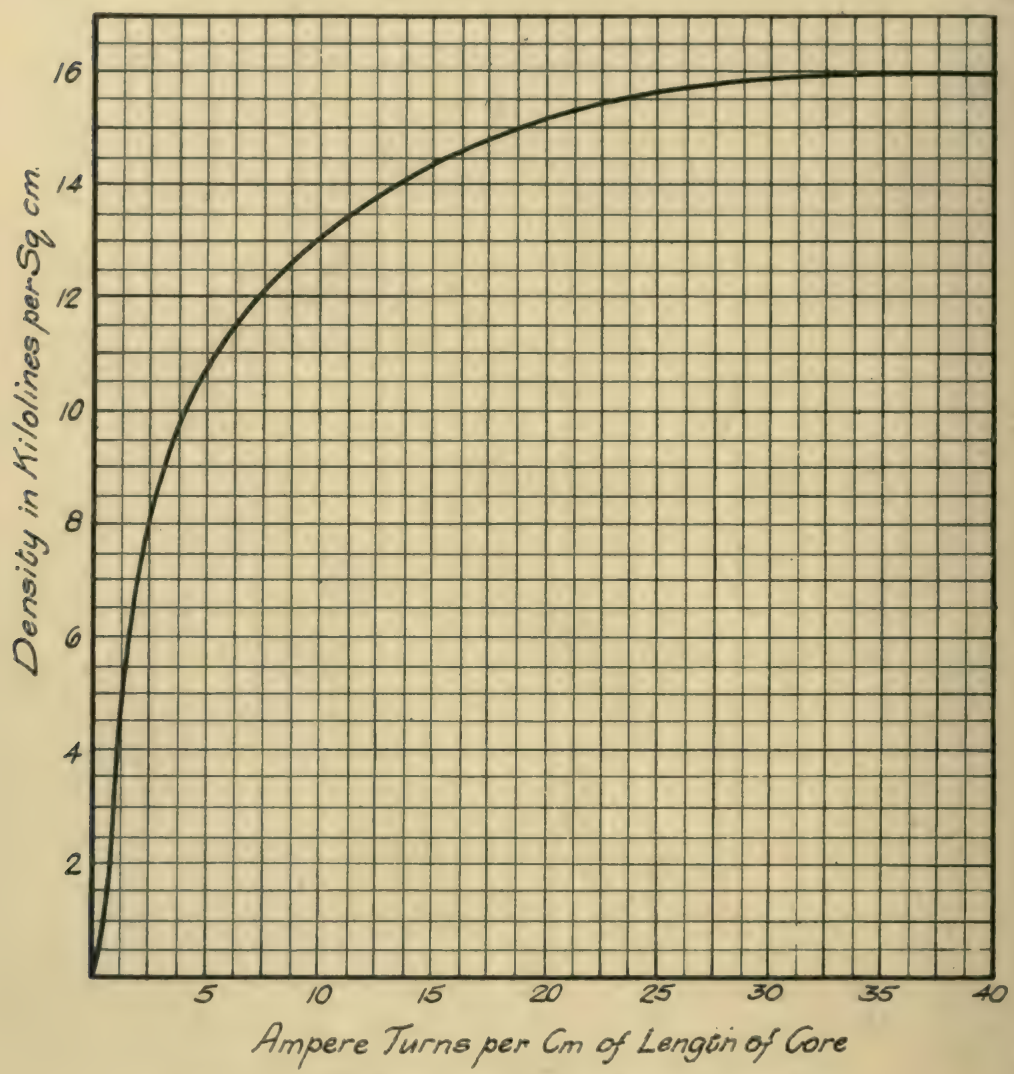

FIG. 10.- Saturation curve of representative sheet steel.

periodicity constitute an important exception to this generalisation, and the material for such transformers should be carefully specified and tested with respect to its permeability. ${ }^{1}$

1 Methods of testing sheet iron and shect steel are treated at considerable length in Chapter 1I. of Hobart and Ellis "Armature Construction" (Whittaker \& Co., London). These methods are as applicable to material for transformers as to armature laminations. 
It is in the matter of the loss accompanying reversals of maguetisation that great care must be exercised in the

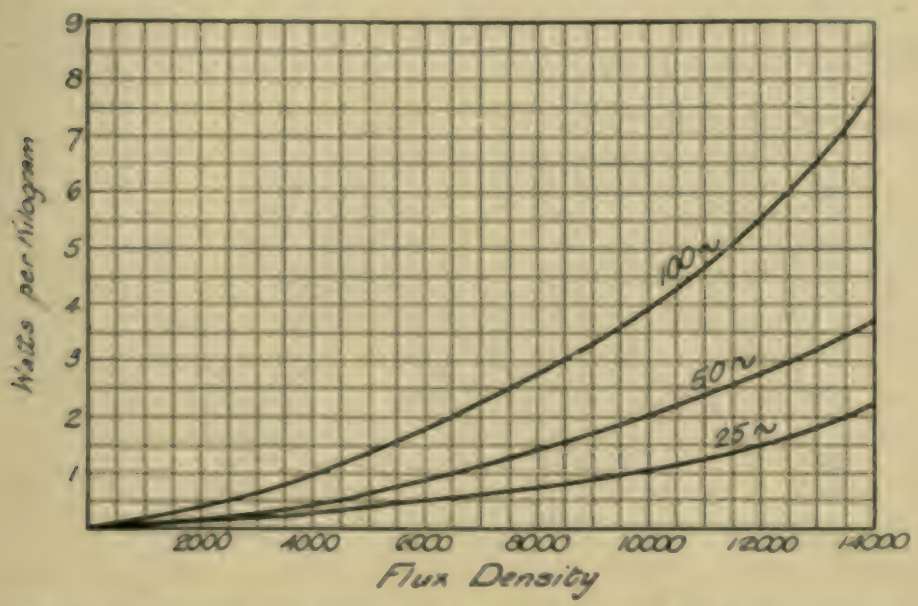

F16. 11,-IIysteresis loss curres for various periodicities for wh high low sheet iron.

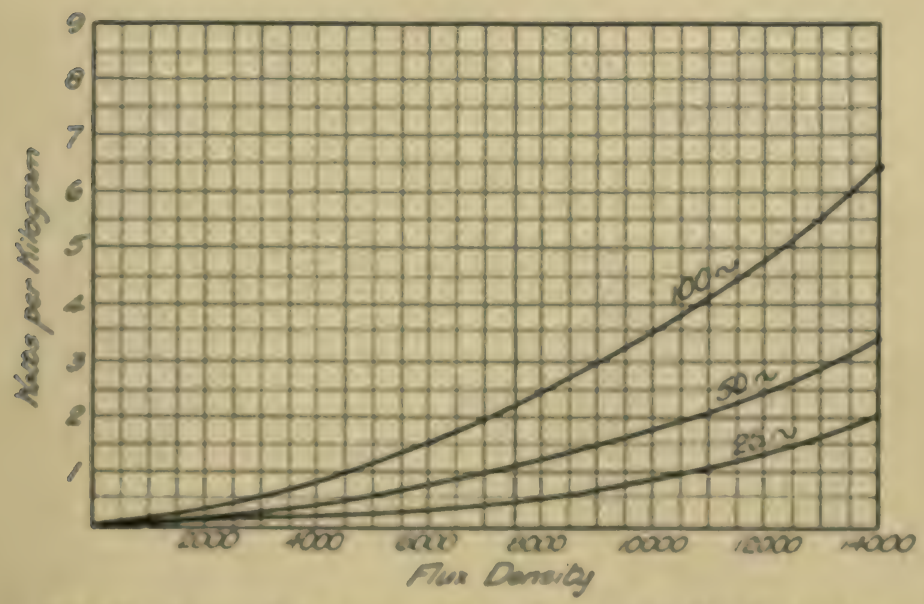

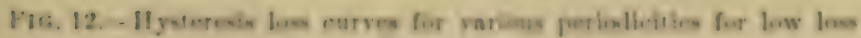
alloy atecl.

sprecifying and selection of the material for transformer cores. This lins is termed the core lins and it has two components. the hysteresis luss and the eddy loss. In the newer material 


\section{THE DESIGN OF STATIC TRANSFORMERS}

(i.e., the "alloyed steel ") the eddy loss is very nearly absent; whereas in the formerly-employed material, the eddy loss constituted a decidedly substantial component of the total core loss. In fact, it is principally in virtue of the very considerable

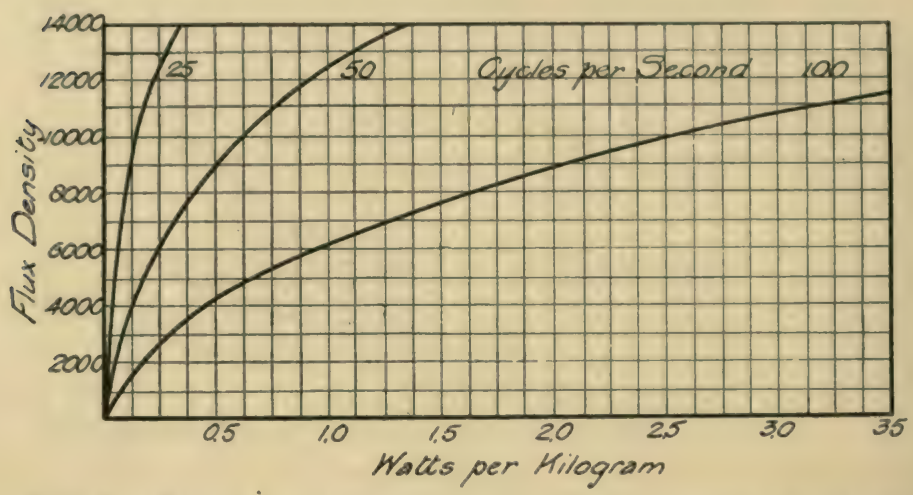

Fig. 13.--Edrly!current loss curves for various periodicities for old low resistance sheet iron.

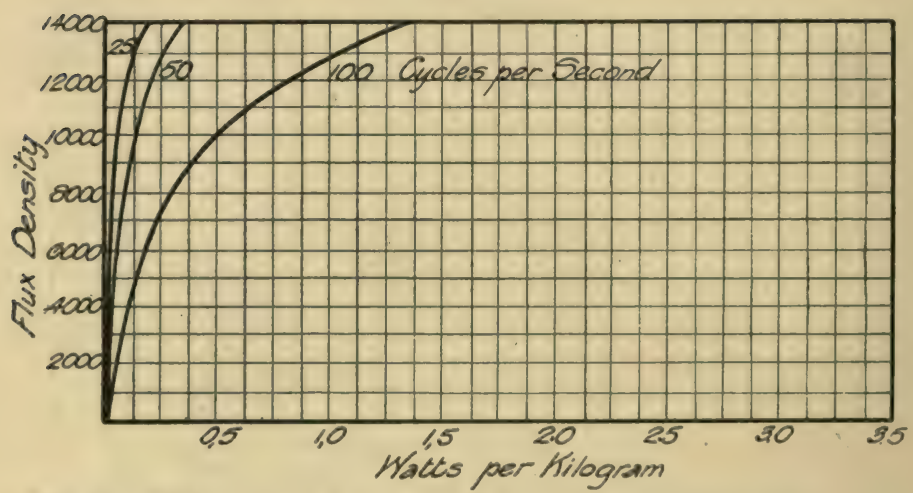

FIG. 14.-Eddy current loss curves for various periodicities for modern high resistance alloy steel.

increase in the specific resistance of the material and of the consequent great reduction in the eddy loss that the marked decrease in the total core loss has been brought about. 'The older material sometimes had a specific resistance as low as 10 microhms per centimeter cube, whereas in the new 
alloyed steel this is usually increased to 45 microhms per centimeter cube, and, in some instances, to even higher

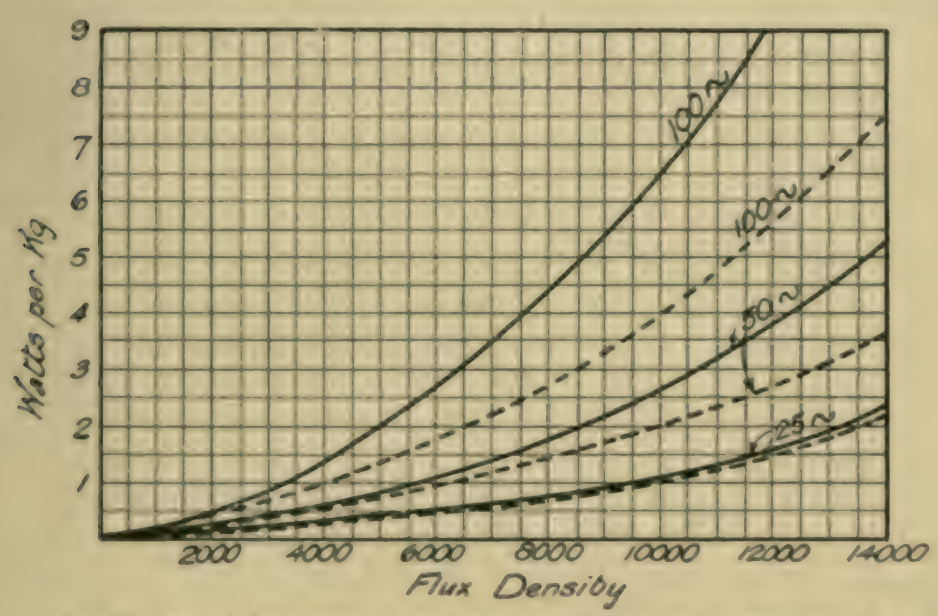

Ftc. 15.-Total luss curves for various periolicities for oht high lose sheet iron.

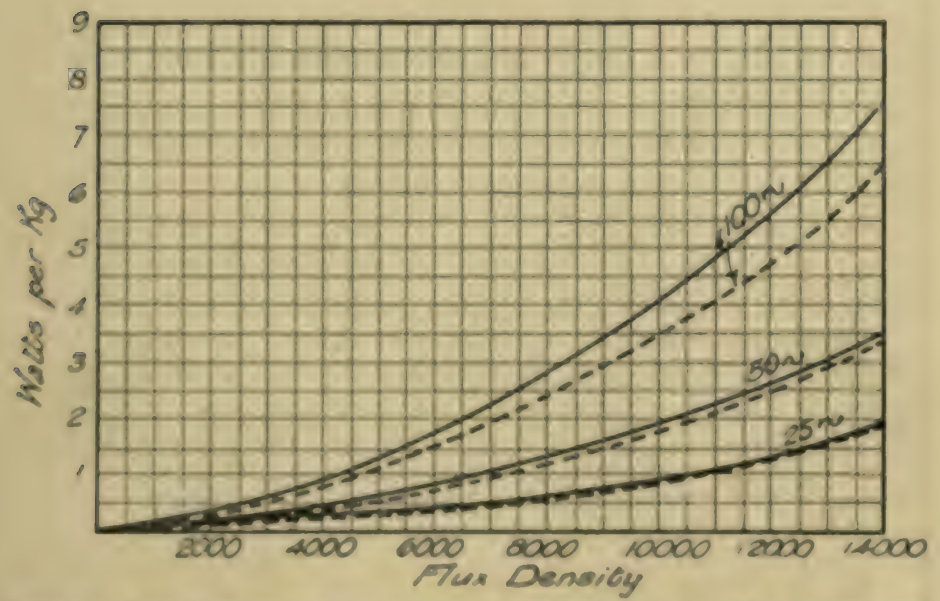

Fic. 16.-Total lone curves for sarious perionlicities for low bos alloy steel.

values. A slight decrease has, it is true, also been effected in the hysteresis component of the total core loss, as may be seen by eompring the curves in Figs. 11 and 12, but 


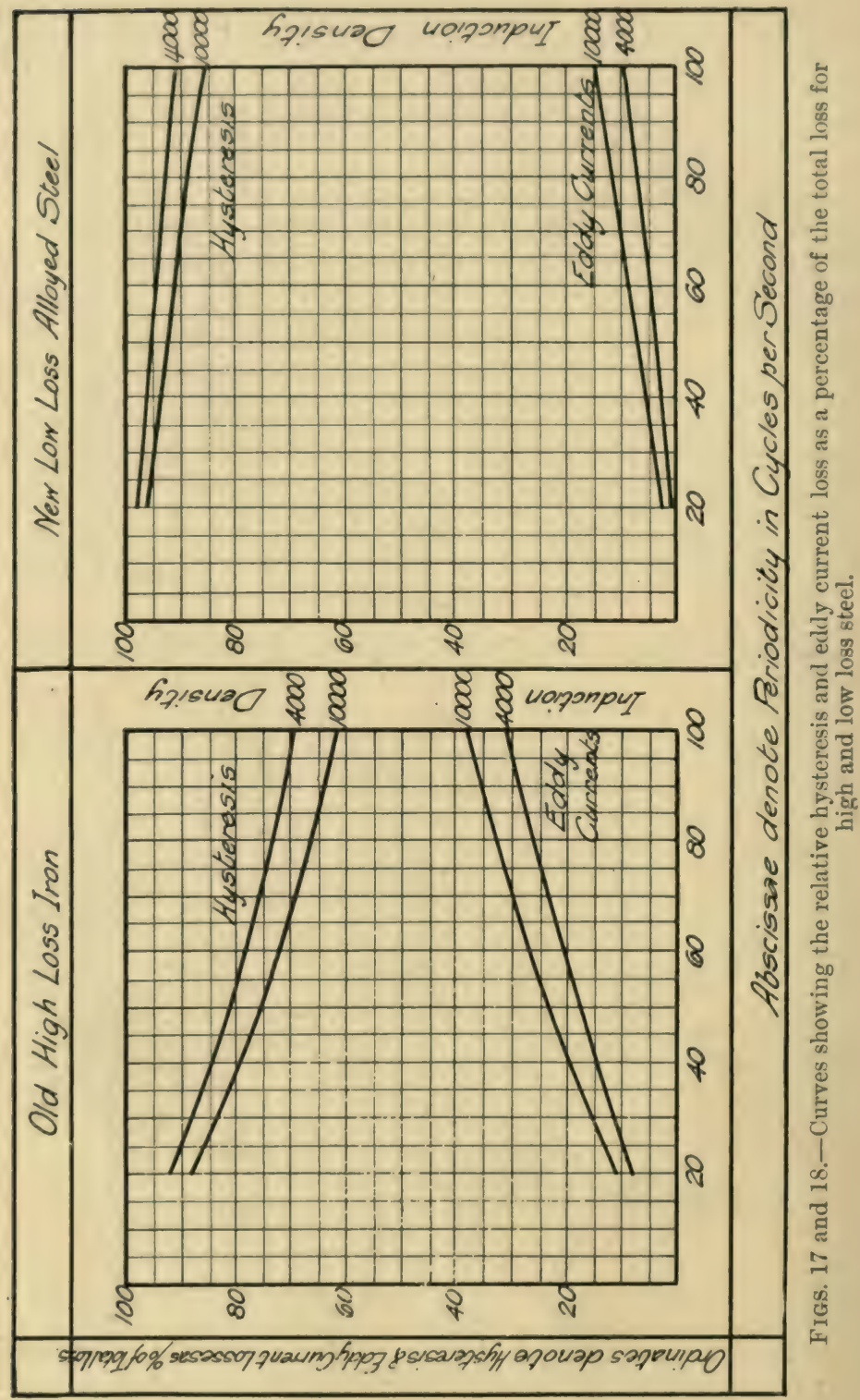


this decrease is small when compared with the decrease in the edly loss revealed by contrasting the curves of Fig. 11 with those of Fig. 13. The resultant improvement which has been effected may be seen by comparing the total core loss in the new material, as indicated by the full lines in Fig. 16, with the total core loss in the older variety as inlieated by the full lines in Fig. 15. The dotted lines in Figs. 15 and 16 represent the hysteresis component reproduced from Figs. 13 and 14, and it is interesting to note that the hysteresis component in the case of the new material, is, at low periodicities, scarcely distinguished from the total core loss. This is brought out still more strikingly by the curves in Figs. 17 and 18, where the liysteresis and eddy losses are, both for the old and for the new material, plotted as percentages of the total core loss.

The magnetic densities which may usually be employed in oil-cooled transformers consistently with obtaining results conforming with present-day standards are set forth in Table 2.

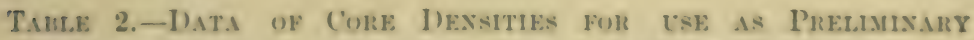

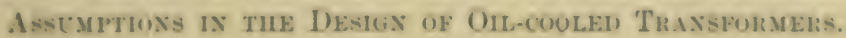

\begin{tabular}{|c|c|c|c|c|c|c|c|c|}
\hline \multirow{4}{*}{$\begin{array}{l}\text { Ilatovi } \\
\text { ontipat in } \\
\text { luva. }\end{array}$} & \multicolumn{4}{|c|}{25 cycles. } & \multicolumn{4}{|c|}{80 cycles. } \\
\hline & \multicolumn{2}{|c|}{ Single.plinse. } & \multicolumn{2}{|c|}{ Theres plinse. } & \multicolumn{2}{|c|}{ Single-jluases. } & \multicolumn{2}{|c|}{ Three-plianes. } \\
\hline & \multicolumn{2}{|c|}{ Primary pressure. } & \multicolumn{2}{|c|}{ Primary pressure. } & \multicolumn{2}{|c|}{ Prumary preseuts. } & \multicolumn{2}{|c|}{ Putmary pressure. } \\
\hline & 2000 & 10000 & 2000 & 10000 & 2000 & 10000 & 2000 & 10000 \\
\hline is & 120000 & 12000 & 11300 & 11500 & 11000 & 10 & $10 \operatorname{sen}$ & 101800 \\
\hline 10 & 13000 & $12(x) 0$ & 121000 & $12(\mathrm{MN})$ & $112(x)$ & 11000 & $11(x)$ & 10800 \\
\hline 20 & 13500 & 13600 & 12500 & $1: \delta(x)$ & 11 istou & $11(0)$ & $11(6)$ & 10500 \\
\hline 50 & 11000 & 13200 & $1: 3300$ & $13(x)$ & $113(x)$ & 11200 & $115(x)$ & 11 (x) \\
\hline$f(x)$ & $11(1)$ & 13.8180 & $14(\mathrm{x})$ & $1: 3$ ilM) & 11 sik & $11 ;(x)$ & 11500 & 11000 \\
\hline
\end{tabular}




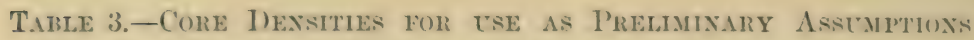

in the Desicis of Nateral ali-cooled axd of Air-Bhast Transformers.

\begin{tabular}{r|c|c}
\hline Rated output in kra. & $\begin{array}{c}\text { 50-cycle natural air-cooleud } \\
\text { transformers. }\end{array}$ & $\begin{array}{c}\text { 50-eycle air-blast } \\
\text { transformers. }\end{array}$ \\
\cline { 2 - 3 } 5 & 9000 & - \\
10 & 8500 & - \\
20 & 8000 & - \\
25 & 8000 & 12500 \\
50 & 8000 & 12200 \\
100 & 7500 \\
200 & 7000 & 12000 \\
300 & - & 11500 \\
500 & - & 11500 \\
\hline
\end{tabular}

For air-blast transformers or transformers of large capacities, the values set forth in Table 3 , will be found more appropriate. These densities may be departed from to a considerable extent without necessarily sacrificing the quality of the designs; and this matter of the selection of densities affords another instance where individual discretion must be applied. Some designers have adopted the practice, when calculating a line of standard transformers, of arranging that the density for a given periodicity shall be the same for a large range of capacities; but such a procedure either entails high no-load currents in the small sizes or uneconomical use of the steel in the larger sizes. It is for this reason that the values of the core density given in Table 2 have been adjusted to increase with increased output. The lower values are necessary with transformers of small sizes in order to obtain suitably-low values for the noload current, while in large transformers the no-load current will not exceed permissible values even when somewhat higher magnetic densities are employed. 'These higher values necessarily involve more iron loss per unit of weight, but the increased losses may be taken care of by the cooling medium,

1 These densities ean only be used where ample ventilating ducts are employed in the core. 
which, in the design we are considering, is oil. With natural air-cooled transformers the magnetic density must, however, decrease with increase of output, as shown in Table 3, and this for the reason that the output, and therefore (roughly) the aggregate loss, raries as the cube of the linear dimensions, whereas the cooling surface only raries as the square of the linear dimensions. If, therefore, the same density were used for all sizes, the heating would either be excessive with the large outputs, or needlessly low with the small outputs. 'This does not apply (or at any rate, not to so great an extent) to oil-cooled transformers, since the heating is then no longer exclusively a function of the cooling surface of the transformer itself, lut also of the surface of the containing case, and of the quantity of oil per kilowatt of total loss. The core density in air-blast transformers must also decrease with increase of output, although not to so large an extent as with natural nircooled transformers. The reason of this will be apparent from the nature of the air-blast cooling problem as discussed in Clispter X.

From Table 2, we find that for our 20-kw transformer we should employ a core density of 11,5 kilolines per sq cm. We have alrealy found that by substitution in the formula $Y=0,0414 T \sim M, 5000=0,0144 \times 3100 \times 50 \times M$, the flux works ont at $M=0,730$ megnline. Consequently the net cross-section of iren required in the magnetic circuit is

$$
\frac{730000}{11500}=68,6 \mathrm{sq} \mathrm{cm} .
$$

The core is built up of sheets haring a thickness of $0,5 \mathrm{~mm}$. These sheets are japanned on one side so that each shall be insulated from its neighbour, thus decrensing the edily loss in the core. It is, of course, essential to provide some insulation between the core plates, but there are differences of opinion as t. the preferable constitution of this insulation. Paper, vanish, and a filu of oxide crused ly amenling are alternatives 
employed by different manufacturers. While the film-of-oxide method leads to a higher iron factor, i.e., while the loss of space due to insulation is less than in either of the other two methods, it is none too reliable. Papering the plates on one side has been asserted to be the most reliable method, but it entails considerable expense whether carried out by machinery or by hand. Paper insulation also takes up somewhat more space than does a film of oxide or of varnish, and is not likely to be as permanent an insulation as that provided by a suitable varnish. The paper will ultimately be reduced to powder under the influence of the alternate heating and cooling of the core. In some cases of paper-insulated cores which were taken apart after a few year's of service, the paper was found to be in an advanced stage of disintegration, and the laminations had become oxidised under the influence of exposure to certain constituents of the paste with which the paper had been applied. The danger of disintegration is, however, lessened in oil-cooled transformers as the oil tends to preserve the paper. The thickriess of the core plate is determined upon from a study of the component losses. It is evident from consideration of the results embodied in the curves of Figs. 17 and 18 (on p. 38), that with the modern alloyed iron, the eddy loss is so exceedingly low that far less advantage is obtained by employing thin sheets than was the case with the formerly-used quality which, as has been pointed out, had very low specific resistance. Whereas with the former material it was important, in high-periodicity transformers, to employ sheets of as low a thickness as $0,35 \mathrm{~mm}$, it is my opinion that with the newer material, whose specific resistance is three times as great, there is insufficient object in employing a less thickness than $0,50 \mathrm{~mm}$; in fact, I should be inclined to adopt this or even a greater thickness, as a convenient standard for transformer cores. It must be remembered that the thicker the transformer plate, the less is the percentage of space occupied by the insulating varnish on the plate. 'Taking $0,025 \mathrm{~mm}$ as a representative thickness of core-plate varnish, 
the deductions which must be maile on account of the space occupied by insulation when plates of different thickness are employed are as set forth in Table 4.

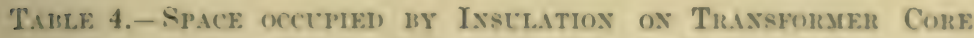
l'lates fur Variol's tulckesses of Cone Plates. (Dimksioxs זs M.s.)

\begin{tabular}{|c|c|c|c|c|c|}
\hline Thichnems of bare lamination. & 0,20 & 0,80 & 0,40 & 0,50 & 0,00 \\
\hline $\begin{array}{l}\text { Arerage thickness of insulation } \\
\text { prer core plate } \\
\text { Thickness of residual lost space } \\
\text { per cure plate. } \\
\text { Total thickness per core plate } \\
\text { (insulated and compressed) } \\
\text { Percentage which the iron cross } \\
\text { Bection constitutes of the gross } \\
\text { (cruss section of the eore. }\end{array}$ & $\begin{array}{l}0,0225 \\
0,015 \\
0,24\end{array}$ & $\begin{array}{l}0,(1235 \\
0,015 \\
0,34 \\
88,3\end{array}$ & $\begin{array}{l}0,025 \\
0,015 \\
0,44 \\
91,0\end{array}$ & $\begin{array}{l}0,025 \\
0,0 ; 5 \\
0,54\end{array}$ & $\begin{array}{c}0,025 \\
0,015 \\
0,64\end{array}$ \\
\hline
\end{tabular}

The values for core plates as given in Table 4, as also representative values when oxide insulation and paper insulation are employed, are plotted in the three curves of Fig. 19. When the core plates have a thickness of $0,50 \mathrm{~mm}$, the japan varnish will, according to the curve in Fig. 19, only occupy 7 per cent. of the gross core length. Consequently we shall be well on the safe side in allowing 10 per cent. The net core length $(\lambda n)$ should thus be taken as 0,90 of the gross core length $(\lambda g)$. Another consideration is that the thimmer the core plate, the greater will be the percentage which the skin of inferior magnetic quality bears to the total thickness of the lanination, for it is well-known that the permenbility is usually lower the less the thickness of the core plate, for any given grade of materiai. Furthernore the costs of the laminations themselves, and the outlay for the labour attending their assembly, incrense with decreasing thickness. The most usual thicknesses of laminations used in transformer manufacture vary between $0,35 \mathrm{~mm}$ and $0,50 \mathrm{~mm}$, the latter or 
even a still greater thickness being quite appropriate with modern alloyed steel.

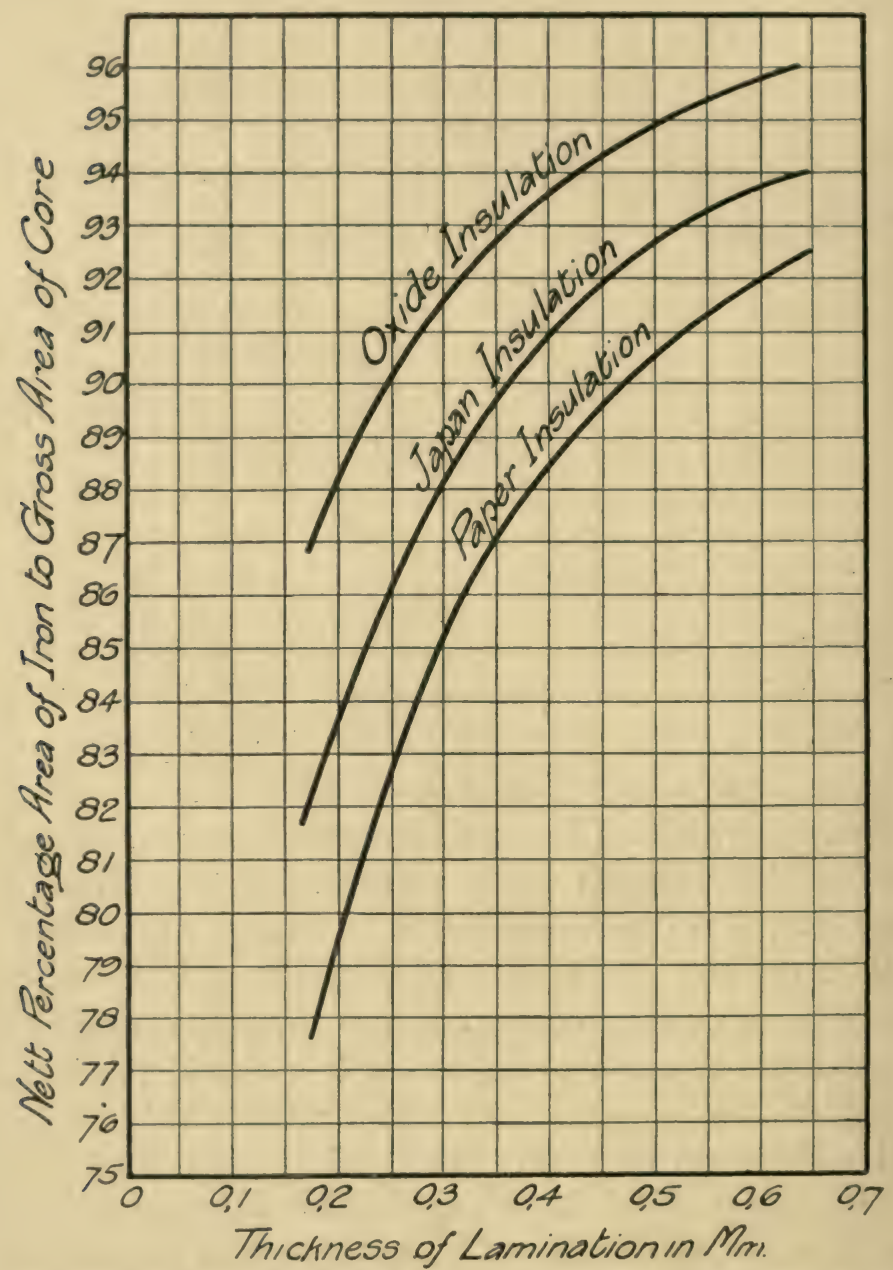

Fig. 19.-Curves showing the effect of various kinds of core insulation on the nett effective iron in transformer cores for various thicknesses of stampings.

Dipping tanks and drying ovens are essential adjuncts to the manufacture of transformers, and my opinion is that when all these facts are considered, it is best practice to insulate the 
laminations by varnishing them, either all of them on one side, or half of them on both sides (the remaining half being left bare). The object can best be accomplished by passing the plates through a pair of varnishing rollers or by dipping the plates in varnish and then drying them by passing them over
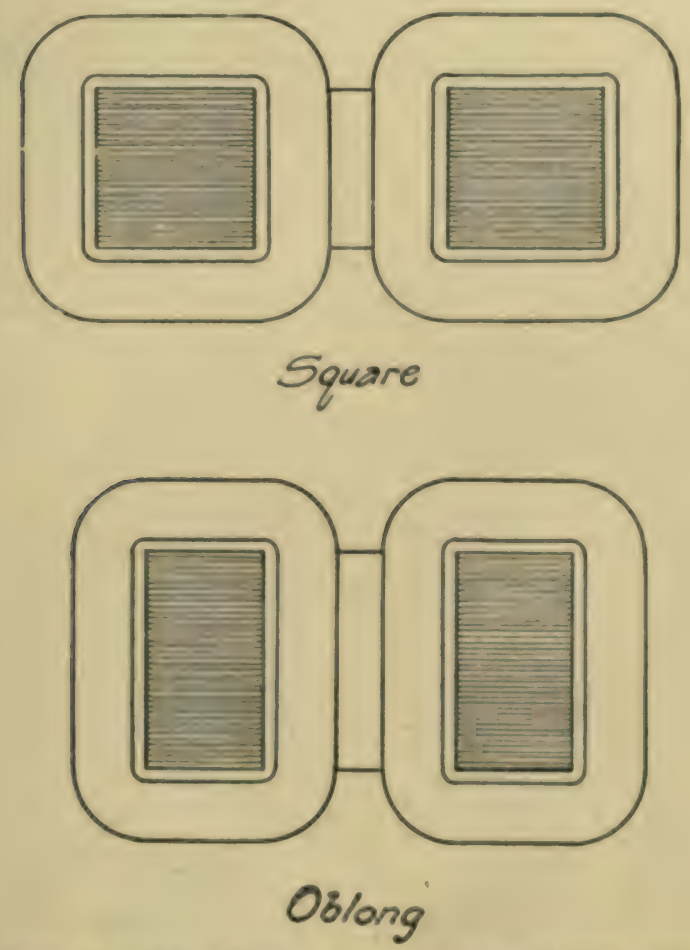

Fuss. 21 and 21. - Types of sections of tronsformer cors.

gas jets or by other henting arrangements. Should such henting not be convenient or possible, the rarnish should preferably be of a variety which is capable of drying in the open air within ten or fifteen minutes.

For our design we shall employ varnished laminations of $0,50 \mathrm{~mm}$ thickness, and thus the space tuken up by the rarnish will amount to about 10 per cent. of the gross cross-section of 


\section{THE DESIGN OF STATIC TRANSFORMLRS}

the core. In order, therefore, to obtain the required section of iron, the gross cross-section of the core must be

$$
\frac{63,6}{0,90}=70,0 \mathrm{sq} \mathrm{cm} .
$$

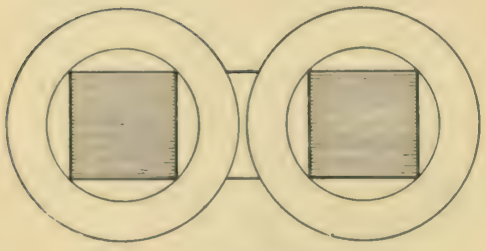

Square

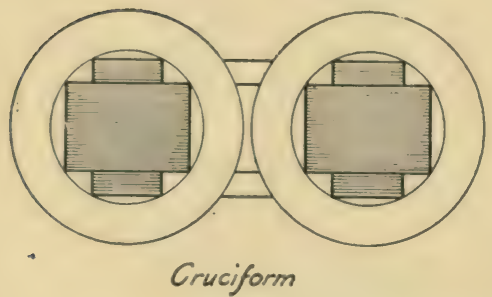

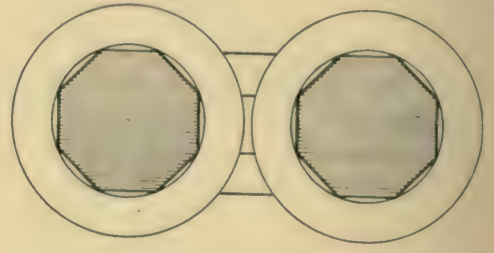

Polygonal

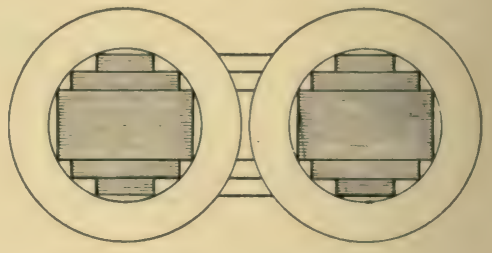

Stepped Cruciform

FIGs. 22 to 25.-Types of sections of transformer cores.

The preferable shape of the cross-section is in itself a question requiring careful study. Some of the various types which

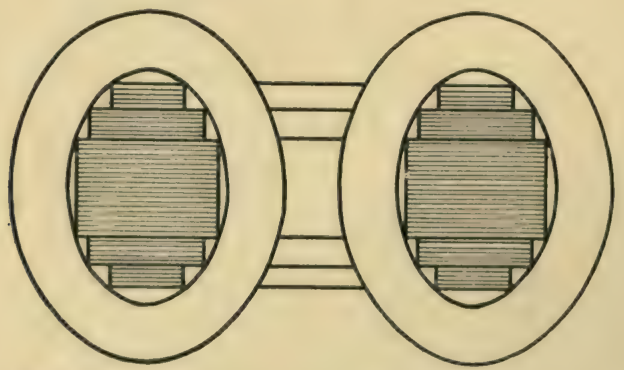

FIG. 26.-Core section for elliptical-shaped coil.

have been used, and some of which are still in common use, are indicated in Figs. 20 to 26. Figs. 20 and 21 show the square- and oblong-sectioned cores with similarly-shaped coils 
surrounding them ; Figss. 22 to 25 show circular coils surrounding variously-shaped cores, and Fig. 26 shows an elliptical coil enclosing a stepped-cruciform core. The rectangular (or square)

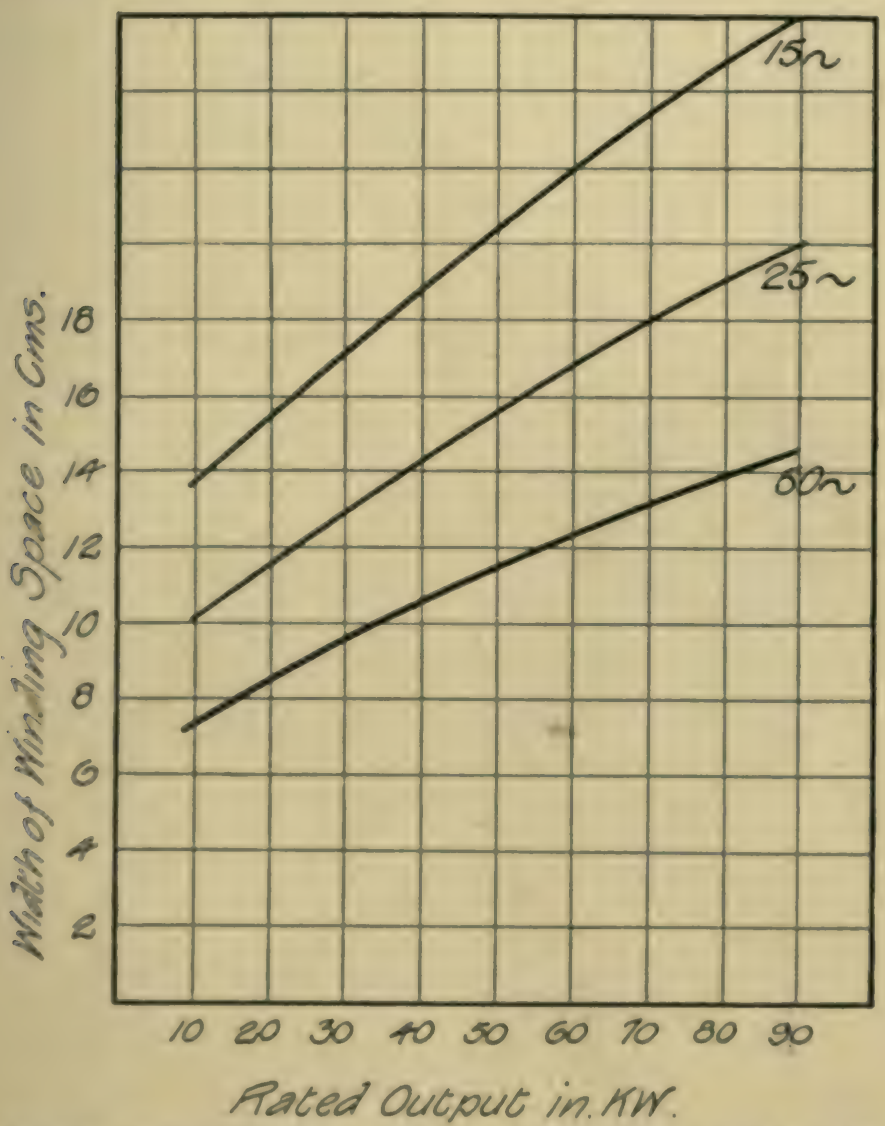

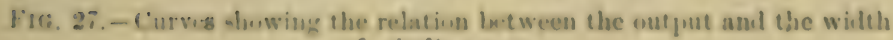
of winding rpace.

type is the simplest to build up, and is the most extensively used, wherens the polygonal (Fig. 23), cruciform (Fig. 24) and an extension of the cruciform which may be termed the "stepped" cruciform type (Fig. 25) are preferred by some lesigners. It is seen from ligs, 22 to 25 that for circular coils it is desirable 
to adopt the cruciform or stepped cruciform core, in order to secure maximum cross-section of iron with good provision for cooling and with short length of mean turn. The polygonal core (Fig. 23) is undesirable on account of the many different widths of the stampings required and of the consequently increased cost attending cutting and assembling.

For our present design, let us adopt the oblong shape (Fig. 21), and without entering upon a consideration of the most economical dimensions of the rectangle (as this is purely a matter of experience and judgment), let us employ cores measuring $7,0 \mathrm{~cm}$ wide by $10,0 \mathrm{~cm}$ deep.

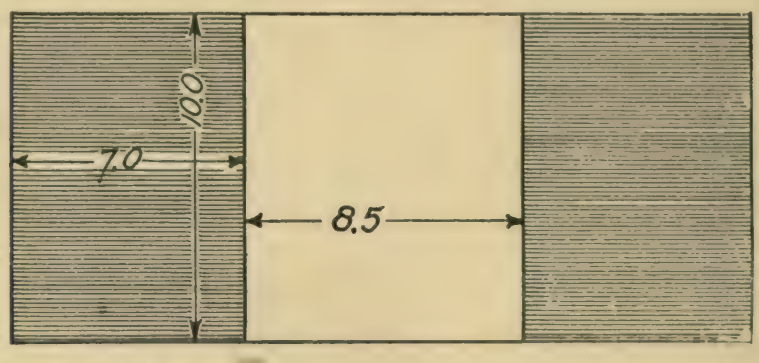

FIG. 28.- Section of 20-kw 5000/200-volt transformer core (dimensions in centimeters).

In transformers of this type, it is generally undesirable to employ great depths of winding, and, bearing this consideration in mind, there have been plotted in the curves in Fig. 27 values for the gross width of the winding space, i.e., the width of the window, for various outputs and periodicities. These curves may be used for preliminary trial designs. It is by no means intended that these values should be strictly adhered to in the final design. On the contrary, it is often necessary to appreciably alter the width of the winding window when we reach the point of laying out the shapes of the coils themselves. From Fig. 27 we find that some $8,5 \mathrm{~cm}$ constitutes a reasonable trial value for the width of the winding window of our 20-kw transformer. 
We now have all the material for sketching out a rough plan of the magnetic eircuit. The section is shown in Fig. 28. In Fig. 29 are indicated in plan the outlines of the secondary and primary windings, from which the mean lengths of the secondary and primary turns may be scaled off. These mean lengths of turn are found to be $40 \mathrm{~cm}$ and $53 \mathrm{~cm}$ respectively.

The reader will note that the depth of the secondary winding has in Fig. 29 been taken at $9 \mathrm{~mm}$, while a depth of $29 \mathrm{~mm}$ has been assigned to the primary winding. It is impracticable

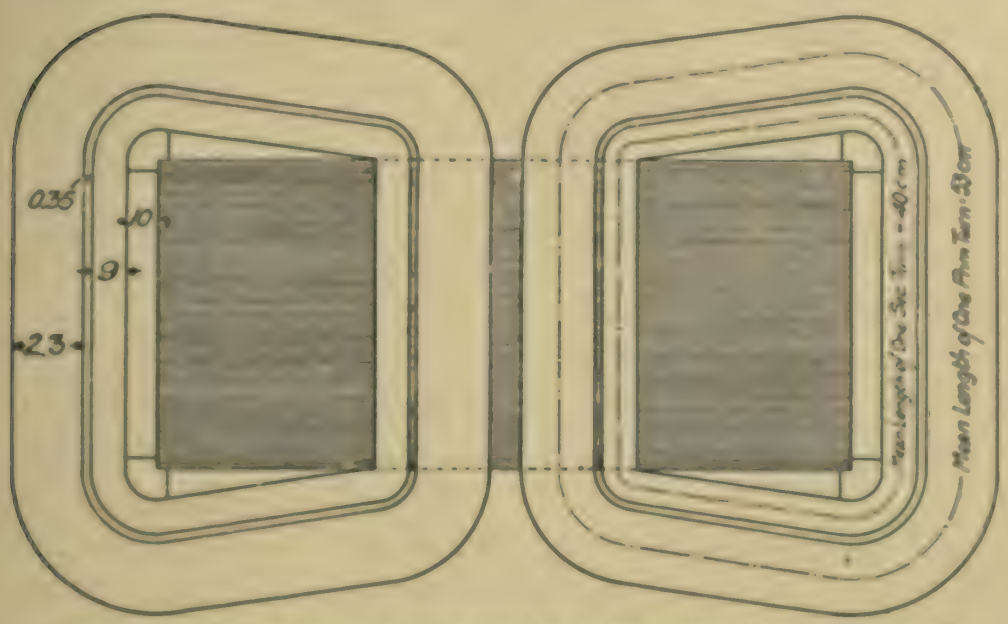

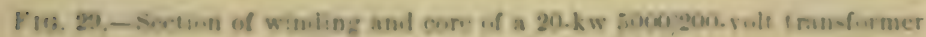
(alimensions in contimeters).

to hy down rules to cover this point, but in gemeral, the primary winding will occupy a much greater depth than the secomdary winding, although for trunsformers with so moderate a primary pressure as that of the present design the disparity will not usually be so great. The reason it is so great in this instance is that, as will be seen a few pages later, the transformer is proportioneal for the same $I^{*} U$ loss (at full load) in the primary as in the secondary, and since the primary is outside and has, conserquently, a greater length of mean turn, it is necessary t. operate it at a lewer eurrent density (in wiler

s.T. 
to bring about this equality in the losses) than is employed in the secondary. Of course, even for the same current density, the section of the primary coil will be the greater because of the greater amount of space devoted to insulation between the many turns and many layers. In other words, the crosssection through the primary coil is, for two reasons, much greater than that through the secondary coil. The first reason is that in this particular example the plan has been followed of having the full-load loss in the primary coil equal to the fullload loss in the secondary coil. The second reason relates to the inherently and necessarily lower utilisation of the space in the primary coil as compared with the utilisation of the space in the secondary coil. The second reason is fundamental, but as to the first reason, the transformer might equally well have been proportioned for a greater loss in the primary coil at full load than in the secondary coil. Had this latter plan been followed, the depth of the secondary winding would have more nearly approached the depth of the primary winding.

The winding used (see Fig. 29) is that known as the simple concentric type, which is the commonest form for this type of transformer. As applied to a core-type transformer, it is shown in plan and elevation in Fig. 30. Its advantages are that it gives a high space factor, and at the same time presents a large cooling surface to the action of the cooling medium, thus enabling the copper to be worked at comparatively high densities. To secure close regulation on inductive load, it is sometimes necessary to adopt the triple concentric winding which reduces the leakage of lines to well down toward half the value obtained with the simple concentric type. ${ }^{1}$ A triple concentric winding is shown diagrammatically in Fig. 31.

An arrangement is shown in Fig. 32 which may be termed a sandwich winding, and it might at first sight be supposed that it would lead to obtaining still better regulation. This will be

1 For a further discussion of this subject of magnetic leakage the reader should consult ('hapter VII. on the regulation of transformers. 
the case if the intermixing is carried far enough, but in Chapter VII., dealing with the regulation of transformers, it
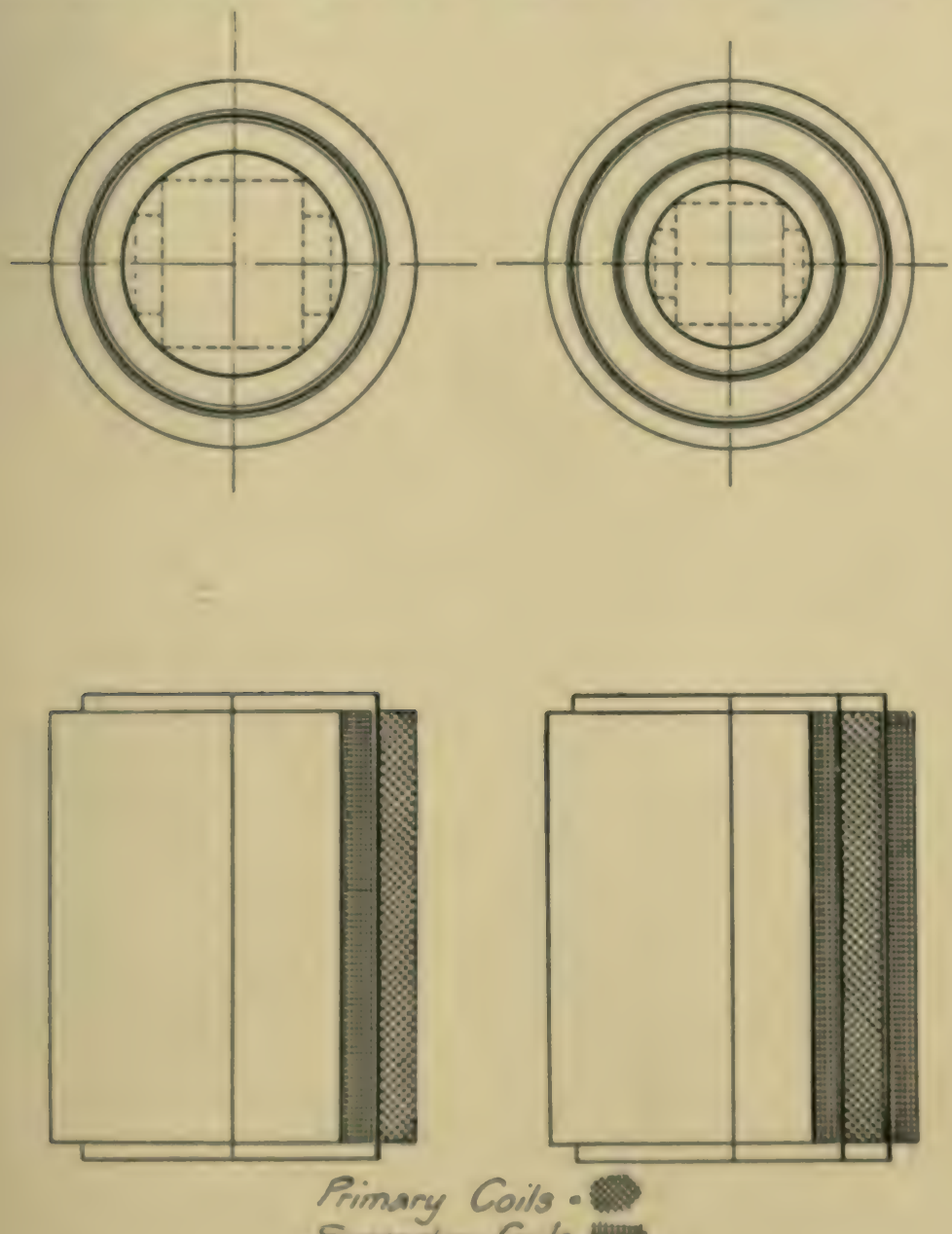

Secondary Corls

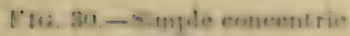
winding. Fles, 31.-Triple conenut riv
wialing.

will be made plain that there is another consideration than that of mere intermixing, namely. the reluctance of the leakage path between the primary and secondary coils. The sandwich 


\section{THE DESIGN OF STATIC TRANSFORMERS}

winding as illustrated in Fig. 32 can be excellently arranged as regards insulation, and lends itself well to the use of formwound coils. It also affords maximum facility for the replace-
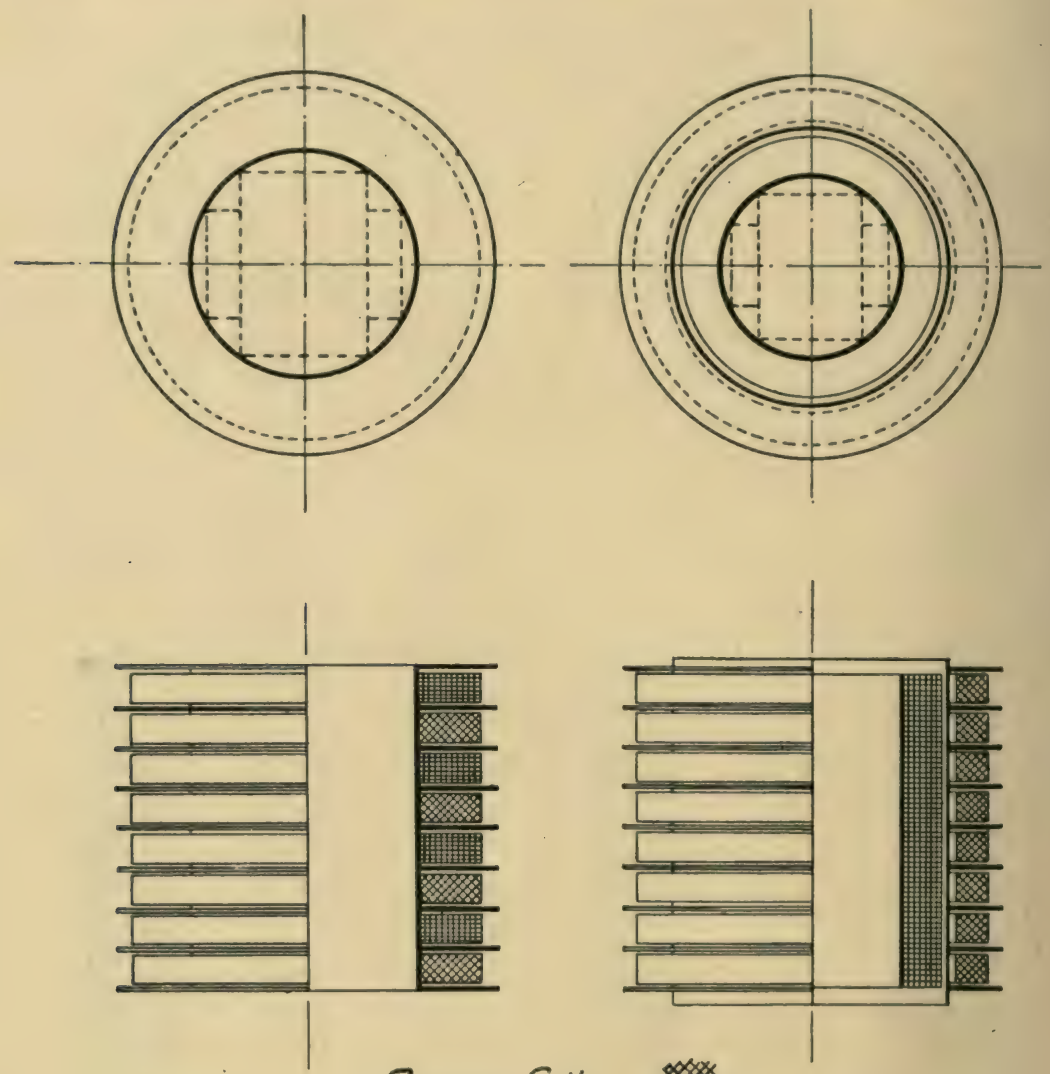

\section{Primary Coils - Secondary Goils = \#}

FIG. 32,--Sandwich winding.

FIG. 33.--Simple concentric winding with subdivided primary.

ment of damaged coils. On the other hand, unless carefully studied out, it will have a low "space factor."

In Fig. 33 is shown a simple concentric winding with subdivided primary. The arrangements shown in Figs. 32 and 33 
both liave an adrantage in the reduced pressure per layer. 'Thus if, in Fig. 33, the primary winding had consisted of a coil rumning the full length of the core, instead of being divided up into eight component coils, the pressure between the end turns of aljacent layers would have been eight times as great, and consequently more insulation between layers would have been required.

Our 20-kva transformer is to be proportioned for a total drop of 2,0 per cent. at full load of unity power factor. If of this amount we arrange that some 1,8 per cent. shall constitute the $I R$ drop at rated loai, then the coils can be so designed that the inductive drop will, for a load of unity power factor, not increase the total drop at rated load to over the stipulated 2,0 per cent. The calculation of the inductire component of the total drop is considered in Chapter VII. It is often desirable to adhere to a certain value of the regulation in standard transformers, as it is customary to operate considerable numbers of them in parallel on the same secondary circuit, and unless the regulation at rated load is the same in all of them, they will not share the load in proportion to their rated capacities. Iet us divide the 1,8 per cent. $I R$ drop equally between the primary and secondary windings, though this will not necrsarily lead to the best design in all cases. Then the pressure drop in the primary winding will amount to $(0,009 \times$ $5000=) 45,0$ volts, and that in the secondary winding to $(0,009 \times 200=) 1,80$ volts. The primary and secondary currents at full-lond are respectively 4,12 and 100 amperes. The resistance of the primary must therefore be equal to

$$
\frac{45,0}{4,12}=10,9 \text { ohms, }
$$

and that of the secondary to

$$
\frac{1,80}{100}=0,018 \text { olım. }
$$

The total length of the primary winding is $(3100 \times 533=)$ 
$164000 \mathrm{~cm}$. The section of the primary winding to give the above resistance at $60^{\circ} \mathrm{C}$. must therefore equal

$$
\frac{164000 \times 0,0000020}{10,9}=0,030 \mathrm{sq} \mathrm{cm}
$$

and since the total length of the secondary conductor is $(124 \times 40=) 4960 \mathrm{~cm}$, the section of the secondary conductor must equal

$$
\frac{4960 \times 0,0000020}{0,018}=0,545 \mathrm{sq} \mathrm{cm} .
$$

The current density at rated load equals

$$
\frac{4,12}{0,030}=137 \text { amperes per sq } \mathrm{cm}
$$

in the primary copper, and

$$
\frac{100}{0,545}=184 \text { amperes per sq } \mathrm{cm}
$$

in the secondary copper. The difference in these two densities is due to the plan adopted in this design, namely, that the percentage pressure drop shall be the same in the primary and secondary windings.

It will be observed that in our example we have adopted a method by which the current density has been deduced. There are innumerable alternative methods of carrying out a set of designing calculations, and, as a matter of fact, the experienced designer employs sometimes one and sometimes another, according to the way in which each case as it arises appeals to him, or according to his mood. 'Thus it is useful to have at hand rough representative values of current densities which, in this type of design, are found by experience to lead to good results.

As a matter of fact, however, widely different current densities may be employed in equally good designs, since, as we shall see later, the heating of an oil transformer is mainly a 
question of the loss per square decimeter of external radiating surface of the case, and is only in a lesser degree dependent upon the actual distribution of these losses in the copper ani in the iron, or upon their intensity at various parts. But for the purpose of preliminary assumptions there are brought together in Table 5 some average data based on the current densities which have been employed in a large number of instances taken from good practice.

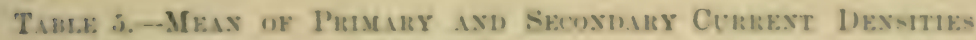

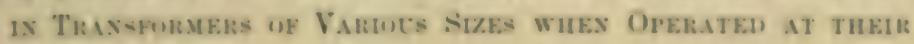
R.ITED LOADs.

\begin{tabular}{|c|c|c|c|c|}
\hline \multirow{2}{*}{$\begin{array}{c}\text { Retew ostyat } \\
\text { is knt. }\end{array}$} & \multicolumn{2}{|c|}{ as eycle. } & \multicolumn{2}{|c|}{50 erele. } \\
\hline & suble phase. & Three plasse. & Single phaner. & There plusere \\
\hline 5 & 100 & 90 & 130 & 120 \\
\hline 10 & 113 & 105 & 143 & 130 \\
\hline 20 & 130 & 125 & 160 & 150 \\
\hline s0 & 1.10 & 130 & 165 & $13 i$ \\
\hline 100 & 180 & 140 & $1 \% 0$ & 160 \\
\hline
\end{tabular}

We have alrealy found that the primary conluctor must lave a cross-section of $3,0 \mathrm{sic}$ min. Consequently for the primary wimling we shall employ a simgle-cotton-covered wire with a bare diameter of

$$
\sqrt{\frac{4 \times 8,0}{3,14}}=1,96 \mathrm{~mm}
$$

Since we have desigued our winlings to have a normal pressure of only 1,6 rolts hetween each turn, sufficient insulation is afturded by a single-cotton covering on the wire. For designs laving over 4 polts per turn, it is usually advisable to employ 
56 THE DESIGN OF STATIC TRANSFORMERS

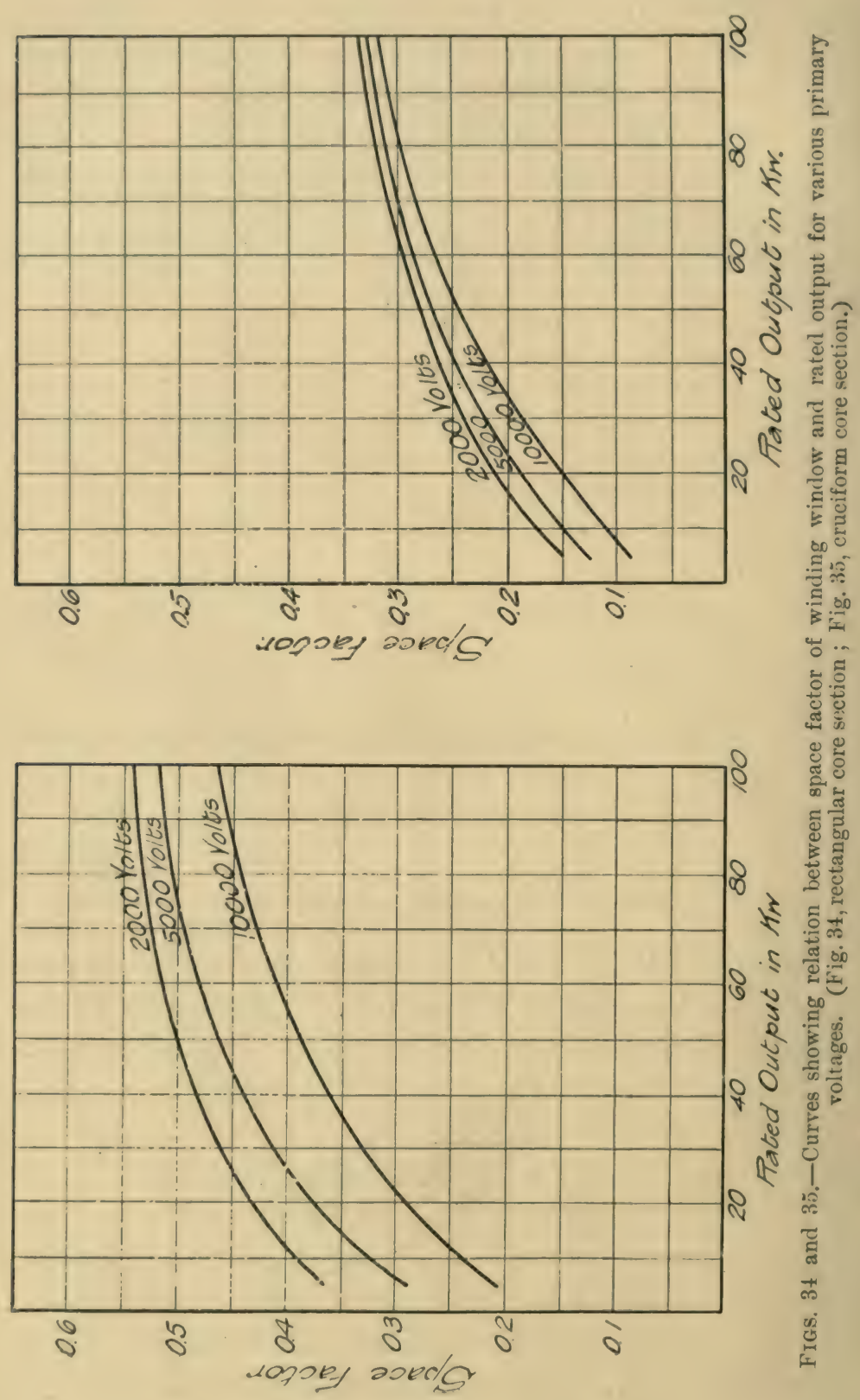


double-cotton coverings. When impregnated with suitable varnishes, double-cotton coverings will be quite reliable up to some 15 volts or more per turn. The external diameter of a single-cotton-covered wire, whose bare diameter is $1,96 \mathrm{~mm}$, will be $2,11 \mathrm{~mm}$. The secondary conductors will be made up of flat strips of a suitable section, the precise dimensions of which, however, can only be definitely and conveniently determined at a later stage of the calculations.

The total cross-section of the copper in the winding space is made up as follows :-

Primary copper $\quad \ldots \quad \ldots \quad 3100 \times 0,030=93,0 \mathrm{sq} \mathrm{cm}$.

Secondary copper $\quad \ldots \quad$.. $124 \times 0,545=67,5 \mathrm{sq} \mathrm{cm}$.

Total section of primary and secondary copper $\quad \ldots \quad 93+67,5=160,5 \mathrm{sq} \mathrm{cm}$.

This total section of copper has to be contained in the wimling space or "window," but this does not constitute the tutal section of the window since it is desirable to employ air spaces between the windings and the core. The proportion which the copper section bears to the window section is known as the "space factor," and this varies both with the tgpe of core, the type of winding, and with the pressure for which the coils are wound. Suitable values of the space factor may be obtained from the curves in Fig. 34, which apply to the rectangular core type. For the cruciform or stepped core type values corresponding to the curves in Fig. 3.5 may be taken for preliminary assumptions. It will be observed that the latter type, i.e., the cruciform core type, possesses a considerably smaller spuce factor for a given ontput, and the reason for this hecomes evilent when the winding arrangement indiented in ligs. 21 and 25 , on p. 46, are studieal. While the inside coil of the rectangular type is wound close up nguinst the core, inside the winlow, as sluwn in Fig. 29, on p. 49, the crucifiurm core, in 


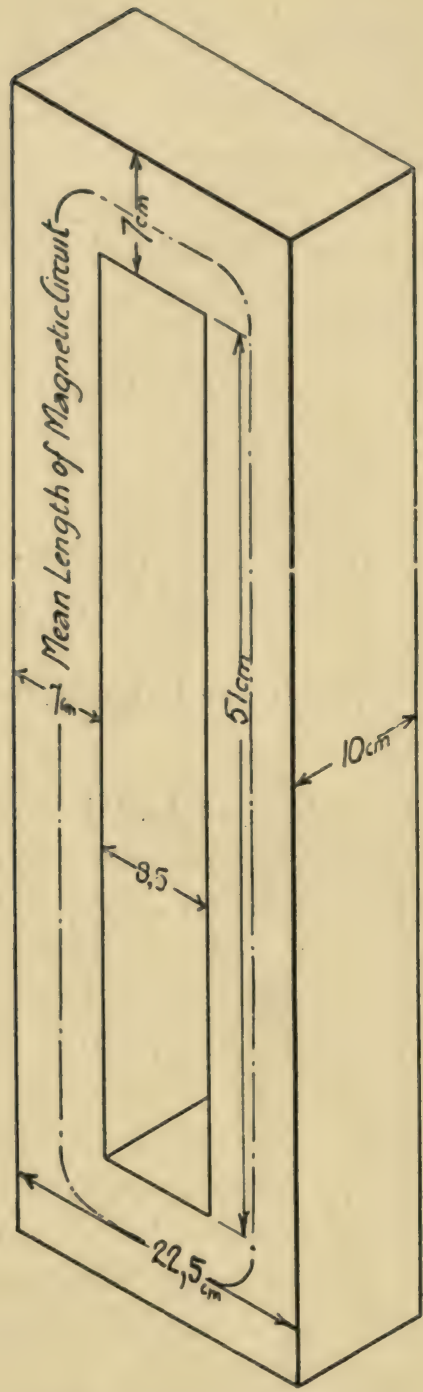

Fig. 36.-Sketch of core for a 20 -kw $5000 / 200$-volt 50-cycle transformer. virtue of its symmetrical nature, provides an air duct between the core and the inside of the coil. This duct is included in the window section, and leads to the low space factors indicated in Fig. 35.

From Fig. 34 we find that a space factor of about 0,37 may be obtained in a design such as that with which we are dealing. This value will afford a sufficient guide to obtaining the total crosssection of the winding window. Thus the total required area will be some

$$
\frac{161}{0,37}=435 \mathrm{sq} \mathrm{cm} .
$$

We have already determined the width of the winding space to be about $8,5 \mathrm{~cm}$, and therefore the length of the winding space may be estimated at

$$
\frac{435}{8,5}=51 \mathrm{~cm}
$$

The core as thus determined upon is drawn in Fig. 36. 


\section{CHAPTER III}

THE CORE LOSS AND THE ANNUAL EFFICIENCY.

WE may now proceed with the estimation of the core loss of the 20-kw transformer which we are designing. The amount of the core loss is an all-important feature of the design of a transformer, and it is often necessary to repeatedly alter the design until a satisfactory result is reached as regards this feature.

The mean length of the magnetic path may be readily calculated or scaled off from a drawing such as that in Fig. 36 (p. 58), showing the dimensions of the core. In our example the mean length amounts to

$$
2 \times(51+8,5)+4 \times 7=147.1
$$

The core has a section of $63,6 \mathrm{sq} \mathrm{cm}$, and consequently the volume of the steel is

$$
63,6 \times 147=9350 \mathrm{cu} \mathrm{cm} .
$$

One eu cm of steel weighs approximately 7,8 grams, and thus the total weight of the core amounts to

$$
0,0078 \times 9350=78,0 \mathrm{~kg} \text {. }
$$

We are now in a position to estimate the probable loss in the cure of our transfurmer due to hysteresis and eddy losses, and for this purpose we shall employ the curves in Fig. 16 (j. 37),

I In this estumate, no allowanos to male for the chortening of the magnetic fath by the eurrat on of the lines at the corners. Thus a small factor of safity

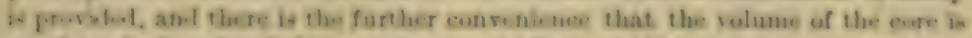

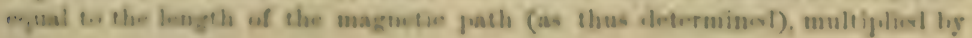
the net cromsoctinn. 
which, as already explained, represent the total specific core loss values for various densities and periodicities.

In our transformer, the periodicity is 50 cycles per second and the density is 11,5 kilolines per sq $\mathrm{cm}$. Consequently the specific core loss will be 2,6 watts per kilogram. 'The total core loss will thus be

$$
2,6 \times 73,0=190 \text { watts, }
$$

or 0,95 of 1 per cent. of the rated output.

Before we can judge intelligently whether this is a satisfactory value for the core loss, we must discuss a quantity to which the term " annual" (or " energy ") efficiency may be applied. If, as will usually be the case for small transformers supplying lighting loads, the transformer is always in circuit, i.e., 24 hours per day, or 8750 hours per year, the core loss will amount to

$$
\frac{8750 \times 190}{1000}=1660 \mathrm{kw} \mathrm{hr} \text { per annum. }
$$

The average lighting transformer is only loaded for a very small percentage of the whole year, the precise percentage depending upon the load factor. Let us assume that the transformer will be unloaded for 80 per cent. of the whole year, and that it will operate at its rated load for the remaining 20 per cent. of that time. In other words, let us assume the load factor to be 20 per cent. Of course in reality these periods of load and noload are the two extreme conditions, and the transformer will, as the hours go by, carry loads of widely varying amounts; but it simplifies the calculation and introduces no unreasonable inaccuracy to carry out our estimates on the basis of these two definite loads, no load and full load, for these two definite percentages of the entire time. At rated load we have, in addition to the core loss, an $I^{2} R$ loss of $(0,018 \times 20000=) 360$ watts in the transformer windings. Thus the $I^{2} R$ loss amounts to

$$
\frac{8750 \times 0,20}{1000} \times 360=630 \mathrm{kw} \mathrm{hr} \text { per annum. }
$$


'The output from the transformer per annum amounts to

$$
\frac{8750 \times 0,20}{1000} \times 20000=35000 \mathrm{kw} \mathrm{h} \text {. }
$$

and the input amounts to the sum of the output, the core loss and the $I^{2} R$ losses per annum. 'Thus the input per annum is made up of

Core loss $\quad \ldots \quad \ldots \quad \ldots \quad \ldots \quad 1660 \mathrm{kw} . \mathrm{hr}$.

Copper loss . . $\quad \ldots \quad \ldots 6 \quad \ldots \quad 630 \quad$,

Output... ... ... ... .. $35000 \quad$,

T'otal input... ... ... $87290 \quad$,

The "annual" efficiency (or, preferably, the "energy" efliciency) is consequently equal to

$$
\frac{35000 \times 100}{37290}=93,9 \text { per cent. }
$$

Now althongh, as already stated on p. 53, in practice certain advantages usually accrue from designing standaril transformers for the same regulation, and consequently with approximately the same eopper loss, let us, nevertheless, consider, in comparison with the transformer we have just designed and which we may designate as Transformer $A$, an alternative which we shall designate as Transformer B. Whereas in Transformer A the copper loss at rated load amounts to 1.8 per cent. of the rated ontput (i.e., to 360 watts) and the core loss to 0.95 per cent. of the rated output (i.e., to 190 watts), let us in Transformer $\mathrm{B}$ precisely reverse these values and proportion it for a copper loss at rated load of only 190 watts and for a core loss of 360 watts. While this leals to a cheaper design as regards the aggregate cost for copper and iron, it must be provided with just as large a case as the former design, since the total interunl losses at rated load are the same, and it will consequently be necessary to provide the same external radiating surface in orider to have the same temperature rise when operating at rated load. 


\section{THE DESIGN OF STATIC TRANSFORMERS}

Let us now study the "annual" efficiency of 'T'ransformer B. The $I^{2} R$ loss per annum is equal to $\frac{190 \times 8750 \times 0,2}{1000}=$ $320 \mathrm{kw} \mathrm{hr}$.

The core loss per annum is equal to $\left(\frac{360 \times 8750}{1000}=\right) 3150$ kw hr.

The output per annum is equal to $\left(\frac{8750 \times 0,20 \times 20000}{1000}=\right)$ $35000 \mathrm{kw} \mathrm{hr}$.

Thus the input to the transformer per annum is made up of :-

\begin{tabular}{|c|c|c|c|}
\hline Core loss & - & . & . 3150 \\
\hline Copper loss & - & * & 380 \\
\hline Output . & • & $\cdot$ & .35000 \\
\hline & Tots & & .3848 \\
\hline
\end{tabular}

"Annual" (or "energy") efficiency . 91 per cent.

We have assumed, however, that the load factor on the transformer is 20 per cent. If similar calculations are made for different load factors for each of these two transformers we obtain the results set forth in Table 6 :-

\section{Table 6.- "Annual" (oR "Energy") Efficiency of 20-KW}

TRANSFORMER FOR VARIOUS LOAD FACTORS.

\begin{tabular}{r|c|c}
\hline & \multicolumn{2}{|c}{ "Annual efficiency" in per cent. } \\
\cline { 2 - 3 } $\begin{array}{c}\text { Load factor } \\
\text { (per cent.). }\end{array}$ & $\begin{array}{c}\text { Transformer A. (Copper } \\
\text { loss } 360 \text { watts, Core } \\
\text { loss 190 watts.) }\end{array}$ & $\begin{array}{c}\text { Transformer B. (Copper } \\
\text { loss 190 watts, Core } \\
\text { loss } 360 \text { watts.) }\end{array}$ \\
\cline { 2 - 3 } & & \\
\cline { 2 - 3 } 5 & 83,0 & 73,2 \\
10 & 90,0 & 84,0 \\
15 & 92,7 & 88,4 \\
20 & 93,9 & 91,0 \\
30 & 95,5 & 93,6 \\
40 & 96,0 & 95,0 \\
50 & 96,5 & 95,8 \\
80 & 97,2 & 96,5 \\
100 & 97,3 & 97,3 \\
& & \\
\hline
\end{tabular}


The results obtained in 'Table 6 are plotted in Fig. 37, and it will be seen that for a load factor of 20 per cent. the difference in annual efficiency of Transformers $A$ and $B$ is some 3 per cent., whereas when the load factor is increased to 40 per cent. the difference is only some 1 per cent. It is

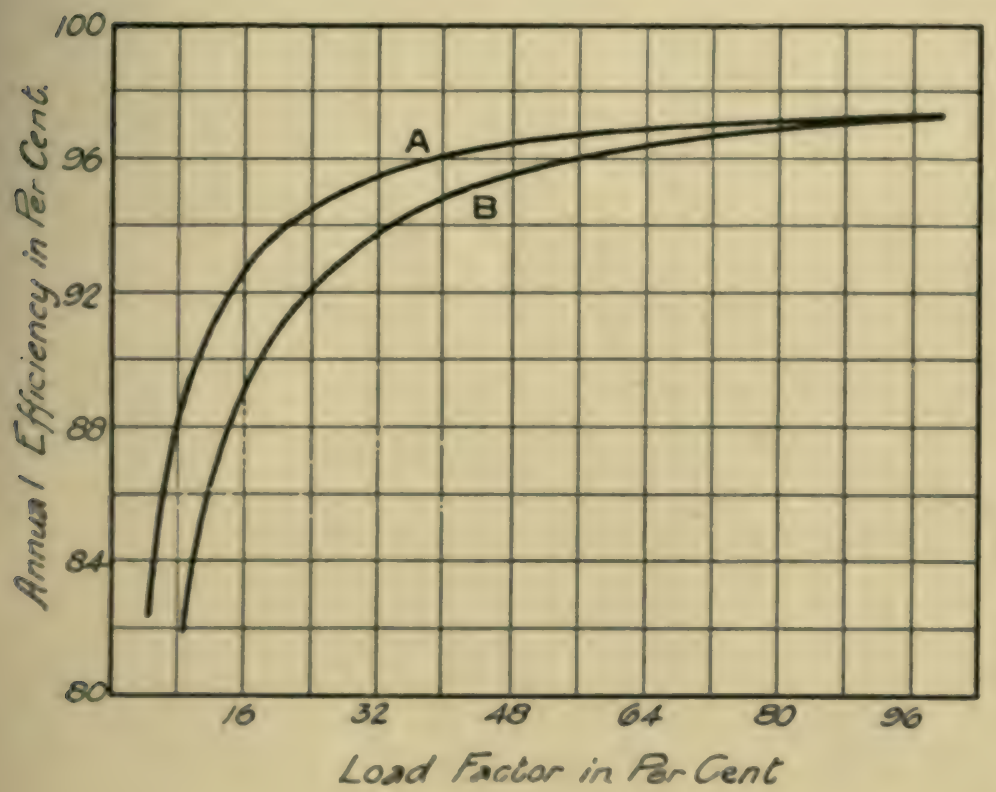

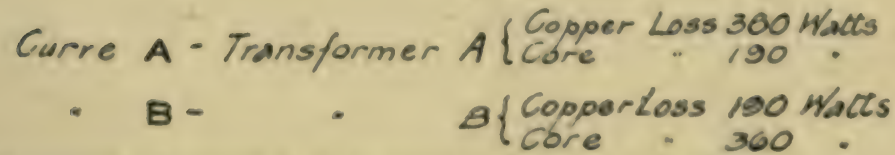

F16, 37. Annual efleciencies of 20-kw transformers at various load facturs.

very rare, however, that a lighting load factor as high as 40 per cent. or even 30 per cent. is attained in practice.

Let us continue the comparison between the two transformers from a basis of the cost of these different losses. On the assumption that the electricity supply company's total cost amounts to 21 . per $\mathrm{kw}$ hr delivered to the primary of the 


\section{THE DESIGN OF STATIC TRANSFORMERS}

transformers, and that the load factor on the transformer is 20 per cent., the cost per annum with 'Transformer A amounts to only $\$ 311$, as against $\$ 321$ for Transformer $B$. This assumption for the cost per $\mathrm{kw}$ hr is not quite correct, because the copper loss will necessarily correspond to a greater outlay per $\mathrm{kw}$ hr than the core loss, the latter being equivalent to a load of 100 per cent. load factor and the former being equivalent to a variable load, and therefore, as such, the cost per kw hr will also be variable. For a load factor of 20 per cent. the cost per kw hr of copper loss will amount to some 1,5 to 2 times the cost per $\mathrm{kw}$ hr of core loss. For our present purpose, however, let us assume the same price per $\mathrm{kw} \mathrm{hr}$ for both the copper and the core losses. In fact, the circumstance that the core loss at no load is associated with a very low power factor, may largely or fully offset the advantage that it represents a load of 100 per cent. load factor. Suppose that with both transformers the customer pays $3 d$. per $\mathrm{kw}$ hr delivered from the secondary; then in both cases he pays

$$
\frac{35000 \times 3}{240}=£ 437 .
$$

If Transformer A is employed, the electricity supply company's annual gross profit is $£ 126$, as against only $£ 116$ when Transformer B is used. The "annual" efficiency may, as already stated, appropriately be termed the "energy" efficiency, as it is the ratio of the energy output to the energy input. 'This distinguishes it from the conception to which the term efficiency is usually applied. This usual conception may appropriately be termed the "power" efficiency.

Let us at this point bring together, as in Table 7 , the data of losses and efficiency of these two designs, which we have designated $\mathrm{A}$ and $\mathrm{B}$. 
TABLE 7.-Dita of Iosses axD EFFICIENCIES of Two 20-KYA Trasaformers.

\begin{tabular}{|c|c|c|}
\hline Deslgnation. & A. & B. \\
\hline 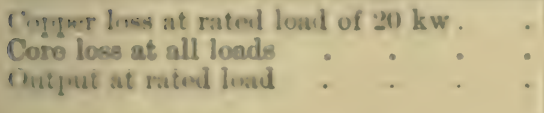 & $\begin{array}{l}3(50) \text { watts } \\
190 \quad ", \\
20000 \quad \text {,. }\end{array}$ & $\begin{array}{r}190 \text { watts } \\
360 \quad " \\
20000 \quad \% \\
\end{array}$ \\
\hline 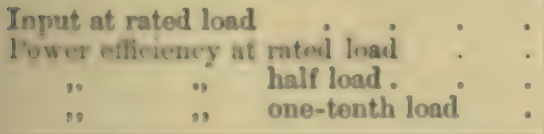 & $\begin{array}{l}20330 \\
97,5 \%, \\
97,5 \% \\
83,6 \%\end{array}$ & $\begin{array}{c}20330 \\
97,5 \% \\
93,5 \% \\
73,5 \%\end{array}$ \\
\hline 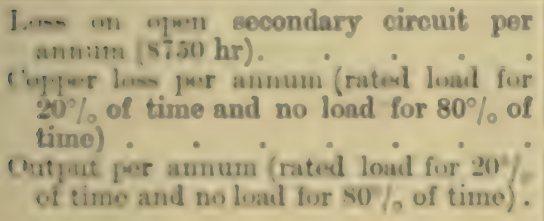 & $\begin{array}{r}630 \quad \text { ". } \\
35000 \quad \text {.. }\end{array}$ & $\begin{array}{r}330 \quad \text { " } \\
3500 \mathrm{n} \quad \text {. }\end{array}$ \\
\hline 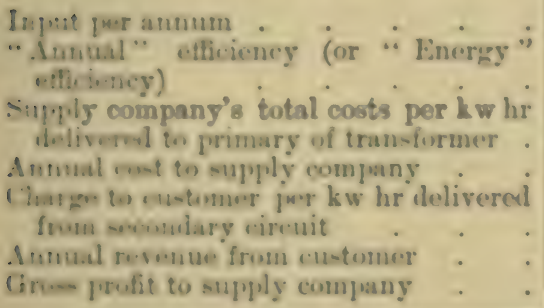 & 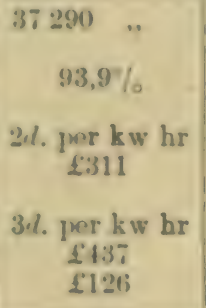 & 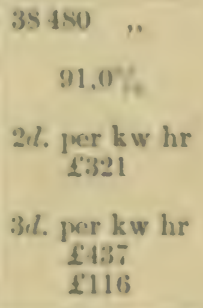 \\
\hline
\end{tabular}

In a similar manner we may calculate the profits accruing to the supply company at other load factors as set forth in Table 8.

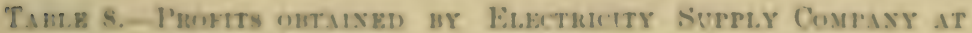

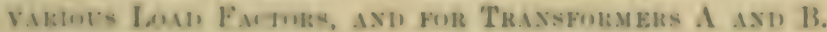

\begin{tabular}{|c|c|c|c|c|}
\hline \multirow{2}{*}{ 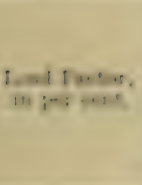 } & \multicolumn{2}{|c|}{ 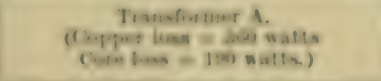 } & \multicolumn{2}{|c|}{ 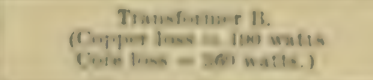 } \\
\hline & 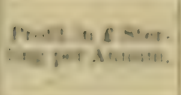 & 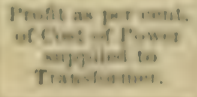 & $\begin{array}{l}\text { Probt in e Ster. } \\
\text { ling jor Amomm. }\end{array}$ & 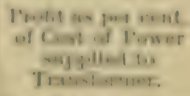 \\
\hline$\therefore$ & $\because 1$ & 22,8 & 9 & 9.0 \\
\hline 111 & $\therefore i$ & 35.2 & 35 & 20.1 \\
\hline 211 & $1 \geq 1$ & (1), 8 & 116 & 236,1 \\
\hline 801 & $\because 6$ & 41,1 & 260 & 42,3 \\
\hline inl & $\therefore .5$ & 41.4 & 326 & 42,3 \\
\hline a(1) & 5,11 & 45.8 & 840 & 14.7 \\
\hline$I(x)$ & $6,911)$ & 46,0 & 690 & 46,0 \\
\hline
\end{tabular}

4.T. 
The results in Table 8 are plotterl in Fig. 38, in which it will be seen that while 'Transformer A has a decided commercial advantage over Transformer B at low load factors, this advantage decreases with higher load factors.

In view of the considerable saving thus effected, the reader

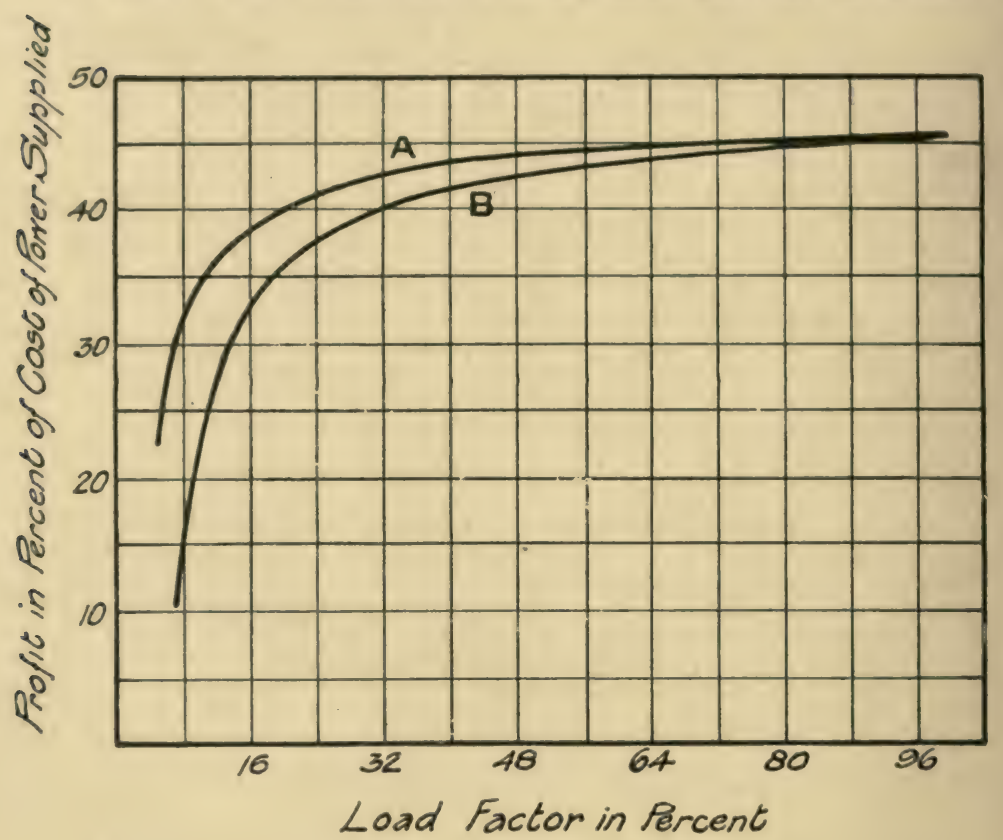

Curve $A=$ Transformer $A$ \{ Copper Loss 360 Matts

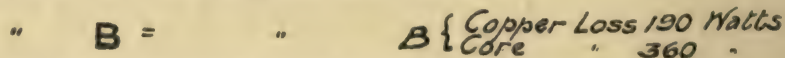

FIG. 38. - Profit to electricity supply company in per cent. of cost of power supplied to 20 -kw transformers at various load fact ors.

will be inclined to inquire whether the $20-\mathrm{kw}$ transformer should not be designed for a still lower core loss than 190 watts. Any considerable reduction in the core loss below the value of 190 watts already obtained in Transformer A would only be obtained by a design with a regulation distinctly worse than 2 per cent. This is not desiruble. The reader may be 
interested to try, with the limitation of 2 per cent. regulation ( 1,8 per cent. I IR drop), to work out a design with a lower core loss. It may be said, however, that (even with no limitation as remards outlay for material) no very radical improvement can be obtained with the grales of material at present available.

In a general way the reasons for this may be made clear. The current at no load, a further discussion of which will be griven later, will be greater than is desirable if we push the saturation up much beyond 11,5 kilolines. Hence the quantity of iron caunot be decreased by employing higher saturation. With the same magnetic eireuit, but with lower saturation, the watts per kilogram decrease, but as the total magnetic flux is decreased the turns must be proportionately increased, and in orier that the $I R$ drop shall not be decreased a larger section of conductor is necessary. The original winding space (or "winlow") thus becomes altogether inalequate, and by the time it is increased to sufficient size to contain the windings, the mean length of the magnetic circuit will have become so increased as to increase the weight of iron to nearly or quite as great an extent as the watts per kilogram in the iron have lieen decreased by lowering the saturation. Thus no considerable decrease in the core loss can be effected. Slight modifiention may, it is true, be effected by a wider and shorter winding space, as also by alterution in the cross-section of the magnetic circuit, aul it is in obtaining the most suitalue proportions in these various respects that the designer's skill may be displayed. It requires, however, not so much skill, as patient perseverance and trained instinct. It is a very tedious process th work ont the large number of alternative designs required tis ensure obtaining the best results, and it las been largely the temptation to aroid this tedious work which has led to the concorting of formula derised with the purpose of arriving at the truly economical design ly simple sulstitution. The assumptions entering into these formula, however, reniler them of litule or the use to the practical desigmer. 


\section{CHAP'TER IV}

NO-LOAD CURRENT, POWER FACTOR ANI EFFICIENCY

When the secondary circuit of a transformer is open (i.e., when the transformer is unloaded) there is a certain current flowing through the primary circuit from the source of supply, and this is commonly termed the "no-load" current. The " no-load" current is the resultant of two components, namely, the current necessary to magnetise the core to the required density and the core loss current. The calculation of the magnetising current will he taken up first. In the case of the $20-\mathrm{kw}$ transformer the procedure is as follows :-

Magnetic density in core $=11,5$ kilolines per $\mathrm{sq} \mathrm{cm}$.

Corresponding specific magnetomotive force in ampere turns per centimeter of length of magnetic circuit (from Fig. 10, on p. 34) $=6,0$ ampere turns per cm.

Mean length of magnetic circuit (from Fig. 36, on p. 58) = $147 \mathrm{~cm}$.

Total magnetomotive force required to send the flux round the magnetic circuit $=(6,0 \times 147=) 890 \mathrm{ats}$.

The primary winding comprises 3100 turns. Consequently, in order to provide the required magnetomotive force of 890 ats, the crest value of the magnetising component of the no-load current must be equal to

$$
\frac{890}{3100}=0,286 \text { ampere. }
$$

The virtual value of the magnetising component works out at

$$
\frac{0,286}{\sqrt{2}}=0,202 \text { ampere. }
$$

Obviously the above result involves the assumption that the magnetising component is sinusoidal in form. 
I.et us now consider the other component of the no-load current, namely, the core-loss component. This is oltained by diviling the core loss, in watts, by the primary pressure. Thus the core-loss component in our 20-kw design is found to be

$$
\frac{190}{5000}=0,038 \text { ampere. }
$$

These two components, the magnetising component and the core-loss component, are in qundrature with one another and may be represented sa shown in Fig. 39, in which $O A$ is the magnetising component $(0,203$ ampere), $O B$ the coreloss component $(0,038$ ampere), and $O C$ is the resultant of these two components, and is termed

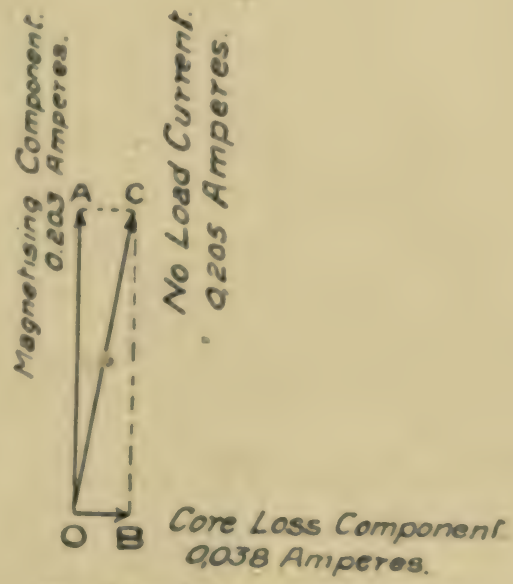

Fic. 39.-No. Inal eurrent diagram. the "no-load" current. In this case it amounts to

$$
\sqrt{0,20: 3^{2} \times 0,038^{2}}=0,205 \text { ampere. }
$$

The power factor, $G$, is obviously the ratio of the core-loss componeat to the resultant or " no-load" current, and is, at no load, equal to

$$
\frac{0.038}{0,205}=0,185
$$

It may be of interest to estimate the inductance' of the j vimary winding when there is no loal on the secondary, i.e., when the primary winding is carrying $0,20.5$ ampere. The

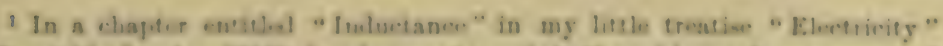

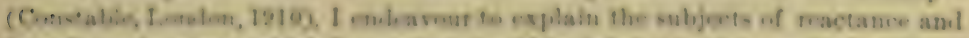

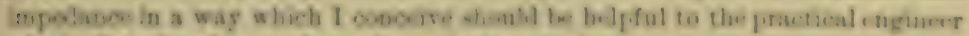

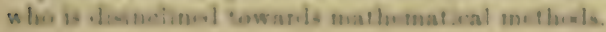




\section{THE DESIGN OF STATIC TRANSFORMERS}

reactance $S$ in ohms is the quotient of the terminal pressure and the magnetising component, and hence is equal to

$$
\frac{5000}{0,203}=24,700 \text { ohms. }
$$

The reactance $S$ is, however, also equal to $2 \pi \sim l$, where $l$ is the inductance in henrys. Therefore

$$
l=\frac{24700}{2 \times \pi \times 50}=79 \text { henrys. }
$$

The inductance might also have been estimated in the following manner. Since the total flux passing through the iron core is equal to 0,73 megalines, and since the magnetising component of the no-load current is equal to 0,203 amp (or $0,203 \times \sqrt{2}=0,286$ crest ampere), the flux per ampere becomes equal to

$$
\frac{0,73}{0,286}=2,55 \text { megalines. }
$$

'There are 3100 primary turns, and therefore the inductance may be found as follows :-

$$
l=\frac{3100 \times 2550000}{10^{8}}=79 \text { henrys. }
$$

We have seen on the previous page that for the power factor, $G$, of our $20-\mathrm{kw}$ transformer, we have, at no load, the value

$$
G=0,185 \text {. }
$$

The power factor increases rapidly as the load on the transformer increases. We have seen that at no load the wattless component of the current flowing into the transformer (i.e., the magnetising component) is 0,203 ampere, and that the energy component (i.e., the core-loss component) is 0,038 ampere. 'The full load secondary current is 100 amperes. When the secondary current is 10 amperes there must be an equivalent energy component flowing into the primary windings to provide it. Since the ratio of transformation is $(5000: 200=) 25: 1$, this energy component flowing into the primary will be 
$\left(\frac{10}{25}=\right) 0,40$ ampere. This is in addition to the corc-loss component of 0,038 ampere. Consequently, when the secondary load is $\mathbf{1 0}$ amperes at unity power factor, the primary current is made up of two components, the magnetising component of 0,203 amp. and an energy component of $(0,40+0,038=)$ 0,438 ampere. The resultant current flowing into the primary is equal to

$$
\sqrt{0,203^{2}+0,438^{2}}=0,484 \text { ampere. }
$$

Consequently, for the power factor at one-tenth load we have

$$
G=\frac{0,438}{0,484}=0,905 .
$$

Similarly, when the energy component of the primary current has increased to 1,00 ampere, the resultant current is equal to

$$
\sqrt{0,203^{2}+1,00^{2}}=1,02 \text { ampere }
$$

and the power factor becomes

$$
G=\frac{1,00}{1,02}=0,98 .
$$

The results of these few examples show clearly that the power factor at first increases very rapilly for a small increase in the energy component, and that at comparatively small loals the power factor usually renches a high ralue. 13y similur calculations, power factors for other values of the energy component may be obtained, and from them the power factor curve of Fig. 40 may be plotted. When the secondary load, instead of being non-inductive, has a power fuctor of less than unity, the primary power factor will, for all usual designs, be substantially the same at any load as the seconlary power factor.

The efliciency at various loads may be obtained as shown in Table 9. In the first two columns the load on the transformer is given. The third column contains the core loss, 


\section{THE DESIGN OF STATIC TRANSFORMERS}

which, of course, is substantially independent of the load. The third column contains the copper loss, the fourth the total input to the transformer, this being equal to the sum of the

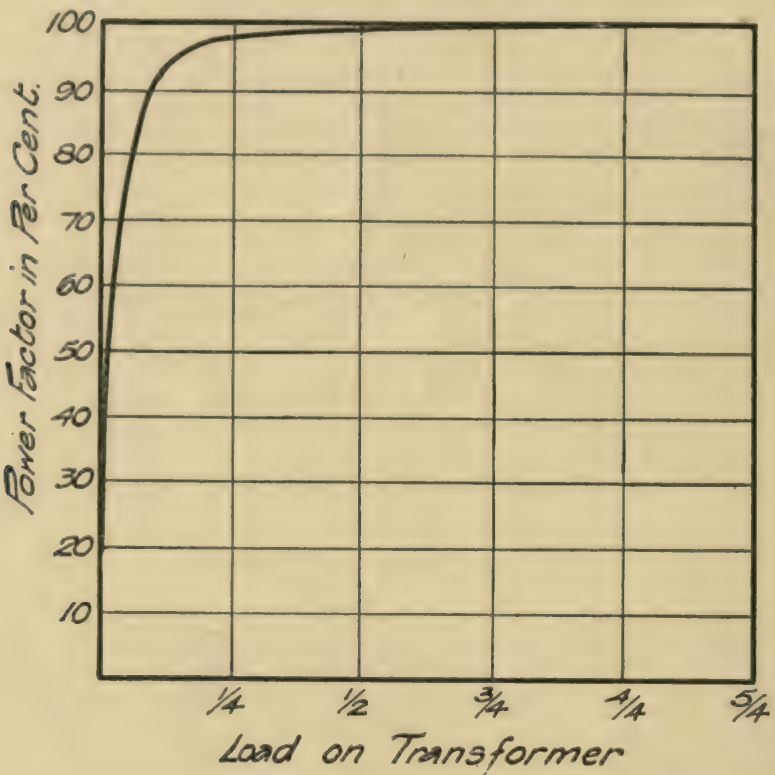

FIG. 40.-Curve showing variation of power factor with the load for a $20-\mathrm{kw}$ transformer.

three previous columns. The "power" efficiency, i.e., the ratio of column 2 to column 5 is given in column 6 .

Table 9.-Efficiency Data of 20-KW Transformer.

\begin{tabular}{c|c|c|c|c|c}
\hline \multicolumn{2}{c|}{ Load on Transformer. } & Core loss & $\begin{array}{c}\text { Copper loss } \\
\text { in kw. }\end{array}$ & $\begin{array}{c}\text { Input to } \\
\text { Transformer } \\
\text { in kw. }\end{array}$ & $\begin{array}{c}\text { Power } \\
\text { efficiency } \\
\text { in per cent. }\end{array}$ \\
\cline { 1 - 2 } \begin{tabular}{c|c|c|c|c} 
Per cent. \\
Full load.
\end{tabular} & Kw. & & 0,0036 & 2,194 & 91,20 \\
\cline { 1 - 2 } 10 & 2 & 0,19 & 0,0225 & 5,213 & 95,95 \\
25 & 5 & 0,19 & 0,090 & 10,28 & 97,35 \\
50 & 10 & 0,19 & 0,202 & 15,39 & 97,50 \\
75 & 15 & 0,19 & 0,360 & 20,55 & 97,35 \\
100 & 20 & 0,19 & 0,563 & 25,76 & 97,10 \\
125 & 25 & 0,19 & & \\
\hline
\end{tabular}

These values of the efficiency are plotted in Fig. 41, where 
NO-LOAD CURRENT, POWER FACTOR, Etc.

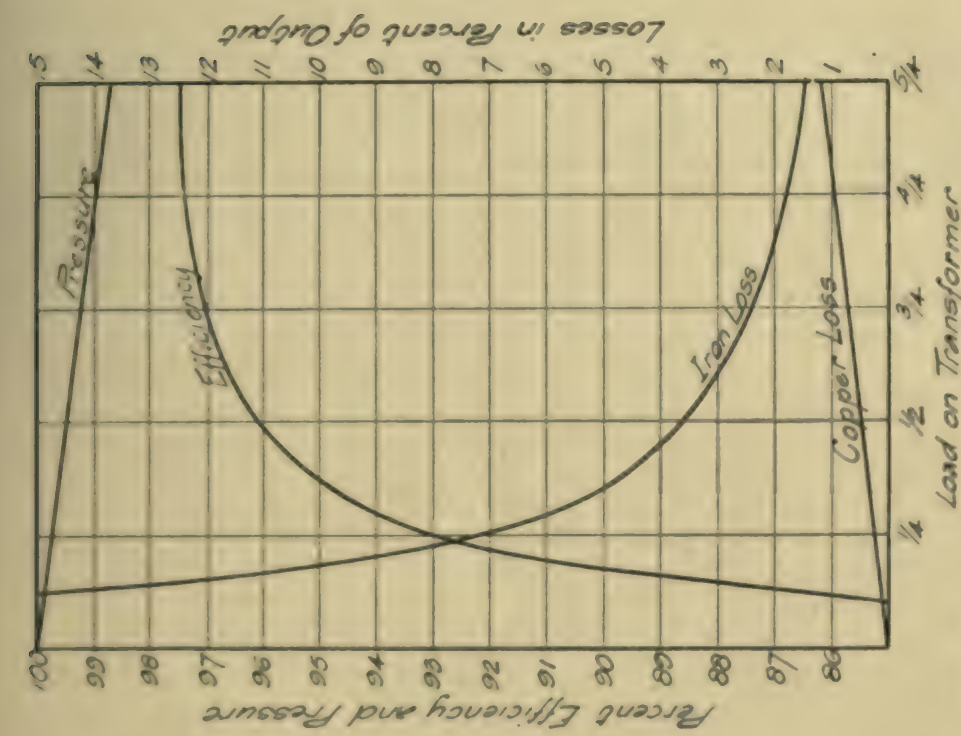

है

$\underline{\underline{E}}$

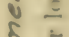

\&.

के है

is $\dddot{3}$

s

8

II

$\underline{\Xi}$

in

$=8$

$\div \frac{0}{8}$

…

है

pinchno fo puazy us sosso7

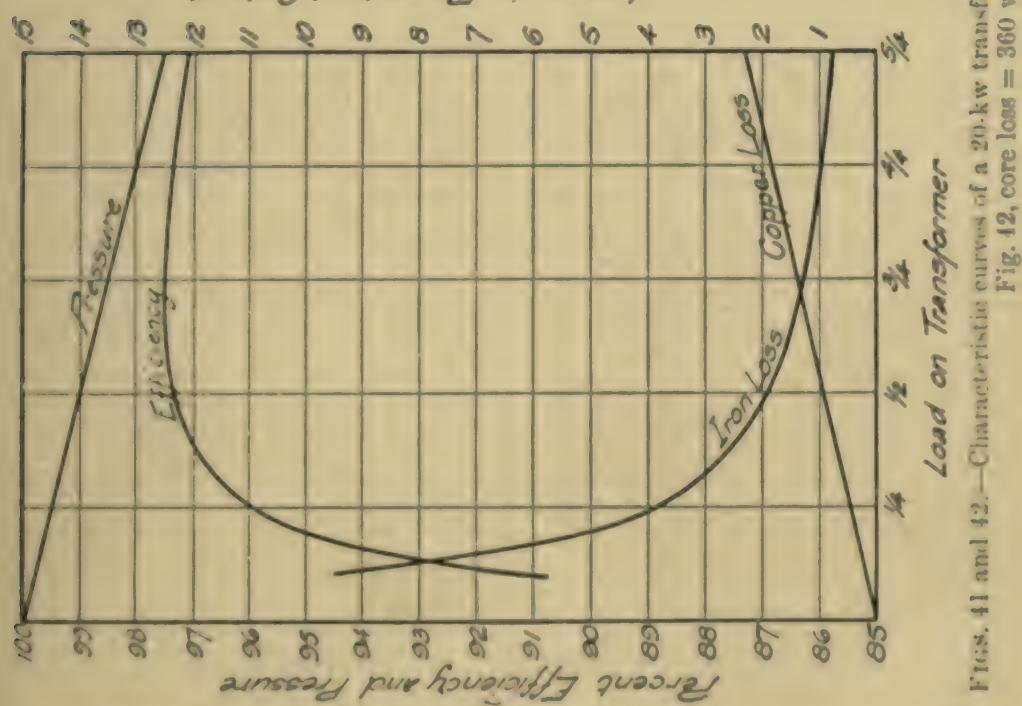

are also giren the losses as a percentage of the lond, and the rerulation for rarious non-inductire loads. 


\section{THE DESIGN OF STATIC TRANSFORMERS}

In contrast to the above transformer there are given in 'Table 10 the efficiencies of a 20 -kw transformer having a core loss of 360 watts and a copper loss at rated load of 190 watts. The values in Trable 10 are plotted in Fig. 42.

\section{Table 10.-Efficiency Data of 20-Kw Transformer.}

\begin{tabular}{|c|c|c|c|c|c|}
\hline \multicolumn{2}{|c|}{ Load on Transformer. } & \multirow{2}{*}{$\begin{array}{l}\text { Core loss } \\
\text { in } \mathbf{k w} .\end{array}$} & \multirow{2}{*}{$\begin{array}{c}\text { Copper loss } \\
\text { in kw. }\end{array}$} & \multirow{2}{*}{$\begin{array}{l}\text { Input to } \\
\text { Transformer } \\
\text { in kiv. }\end{array}$} & \multirow{2}{*}{$\begin{array}{l}\text { "Power" } \\
\text { efficiency } \\
\text { in per cent. }\end{array}$} \\
\hline $\begin{array}{l}\text { Per cent. } \\
\text { Full load. }\end{array}$ & kw. & & & & \\
\hline 10 & 2 & 0,36 & 0,002 & 2,36 & 84,68 \\
\hline 25 & 5 & 0,36 & 0,012 & 5,37 & 93,12 \\
\hline 50 & 10 & 0,36 & 0,048 & 10,41 & 96,10 \\
\hline 75 & 15 & 0,36 & 0,107 & 15,47 & 97,00 \\
\hline 100 & 20 & 0,36 & 0,190 & 20,55 & 97,40 \\
\hline 125 & 25 & 0,36 & 0,297 & 25,66 & 97,46 \\
\hline
\end{tabular}

With the employment of modern high-grade transformer laminations the core can be worked at much higher flux densities for the same core loss per kilogram than with the best grades available three or four years ago. But when the core is worked at high densities, the ro-load current is considerably increased. This is illustrated in Fig. 43, in which the upper curve represents the percentage no-load current for a line of transformers in which modern high-grade laminations worked at high densities are employed, and the lower curve represents this factor for a line of transformers built some few years ago and employing the best material then available. The core loss per kilogram is about the same in both cases for designs for a given rated output, and the greater percentage no-load current is due chiefly to the higher densities employed in the modern designs. In fact, the densities employed run up considerably higher than is desirable in the case of the smaller rated outputs for the modern designs, since the low power factors at light loads would constitute a distinctly undesirable feature from the supply company's standpoint. 
In Fig. 44 have been plotted values of the core loss as a function of the rated output for several lines of designs. These values have been taken from the published data of several large manufacturing firms, and they are for transformers of the various periodicities indicated in the figure. Most of the lesigns now (1910) on the market are proportioned for still lower core losses, since alloyed steel is now almost unirersally employed. It will be observed that for the same manufacturing

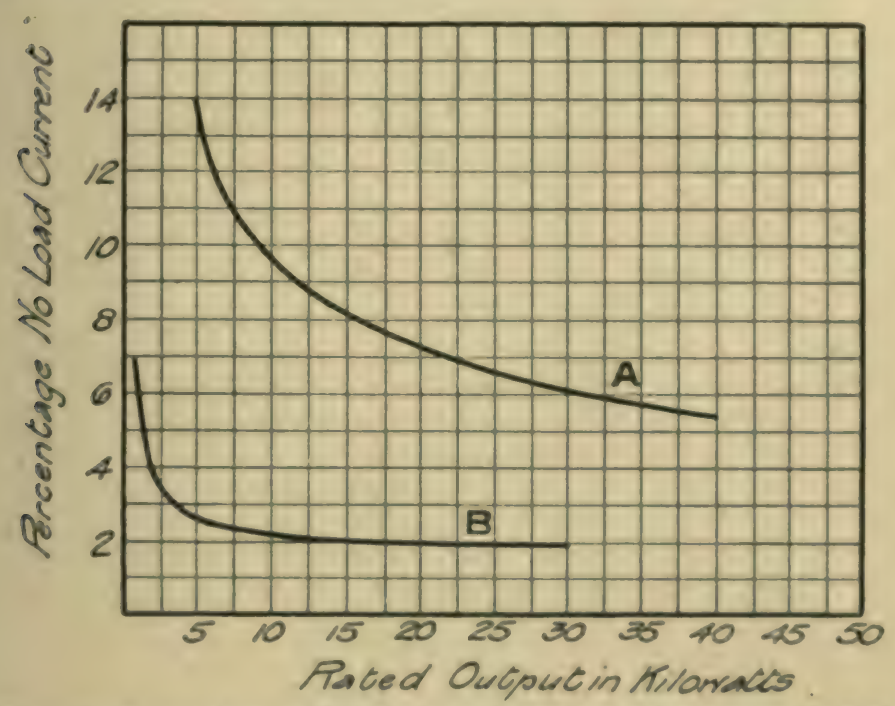

Fis: 13. Conves shewing the relation Inetwent the no-load current and the

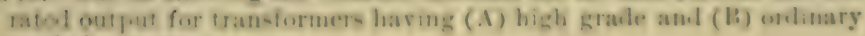
graule lamainations.

firm the higher the periodicity the lower is the core loss. This is becuuse a standard transformer designed for a periodicity of, say, 50 cycles per secomi is often also supplied for use on cirenits of preriodicities from 50 eyeles upwards. If the 50. cyele standari transformer is placed on a 100 ). geve circuit, the flux density is halved. Since the hysteresis loss constitutes a larger percentage of the total core loss than does the edily curvent lins, a considerable realuetion in the core loss results. As a rule, however, a 2s-cycle circuit rejuires a new 
76 THE DESIGN OF STATIC TRANSFORMERS

design, for if the standard 50-cycle transformer is used for this periodicity, the flux density becomes doubled, and if the

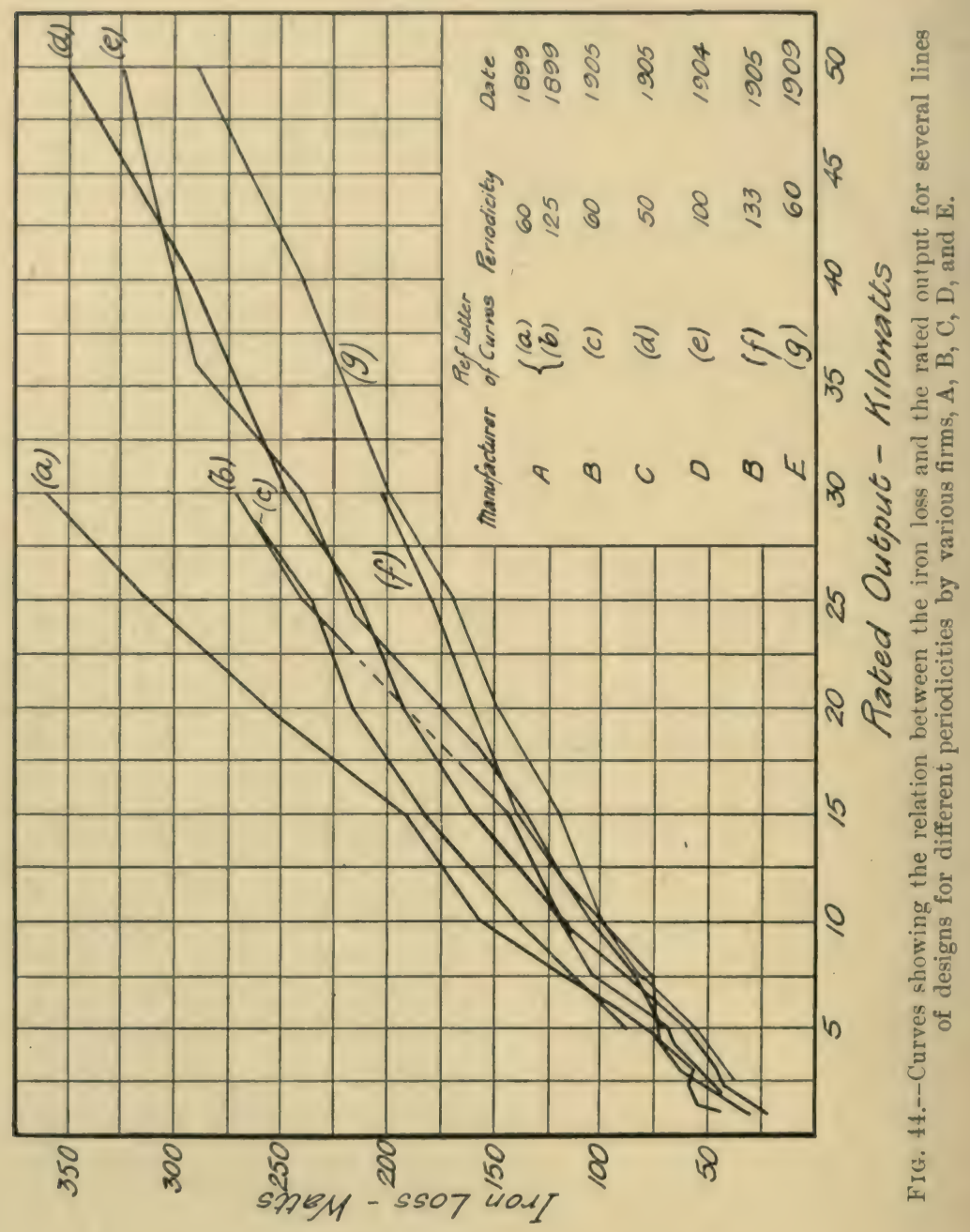

density is already high when operating from a 50-cycle circuit, the core would, at 25-cycles, then become too highly saturated, hence a large magnetising current would be required, 
NO-LOAD CURRENT, POWER FACTOR, Erc.
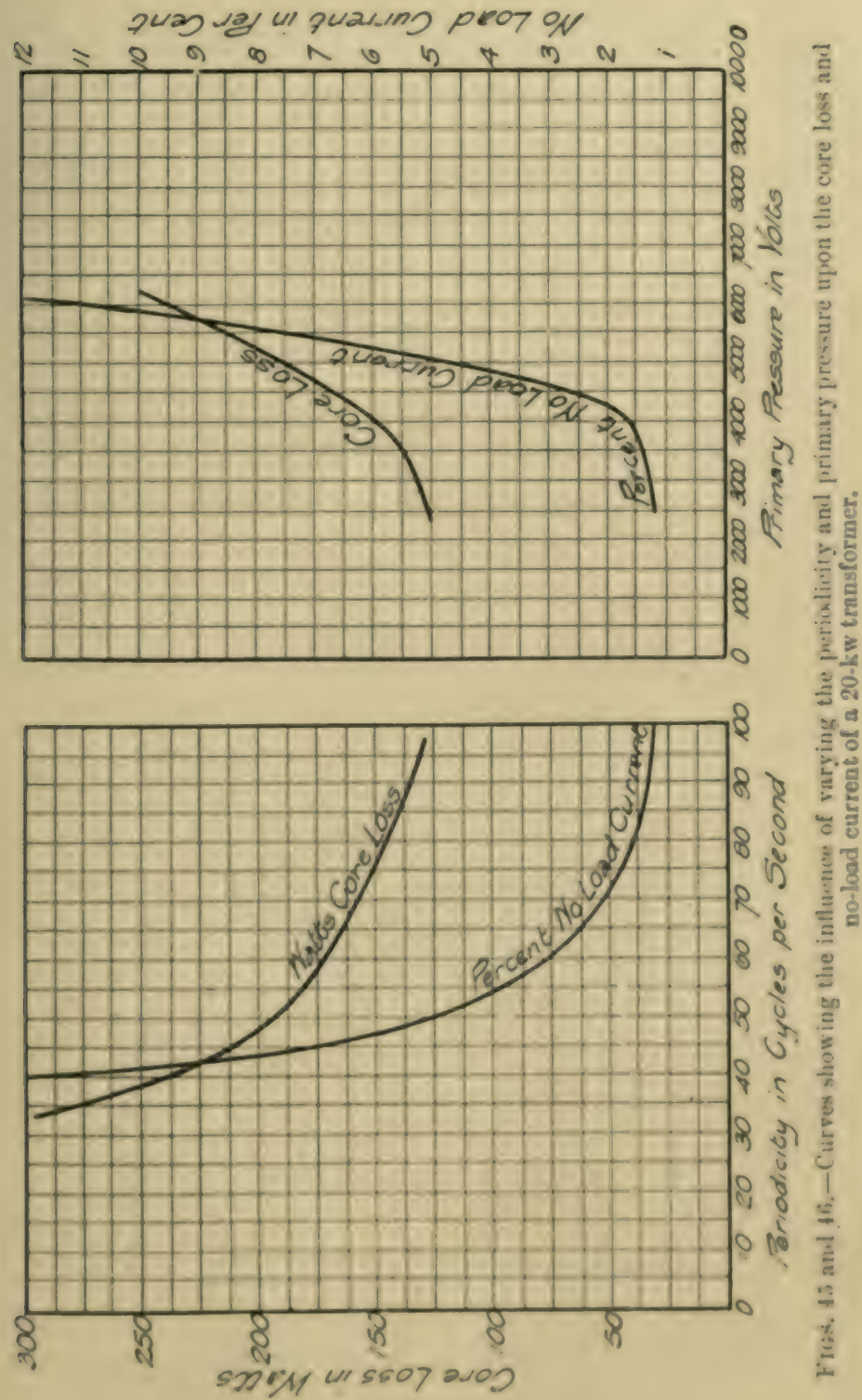

which would result in a low power factor. If, on the other hand, the density when working on a 50-cycle circuit is 


\section{8

exceptionally low, then it might be admissible to use the same design on a 25-cycle circuit. These proportions are not, however, such as yield the best results at 50-cycles.

The influence of the periodicity upon the core loss and upon the no-load current of our 20 -kw transformer is shown in Fig. 45. By increasing the periodicity from 50 cycles to 100 eycles the core loss has been decreased from 190 watts to 125 watts, but, by decreasing the periodicity to 40 cycles the core loss has been increased to 240 watts. 'The variations in the no-load current, due to various periodicities, is still more striking. Fig. 46 shows the influence of supplying different pressures to the primary terminals, upon the core loss and the no-load current.

In Fig. 47 are given curves showing the relation between the regulation and the output, corresponding to some of the curves shown in Fig. 44. From these curves it is seen that in three cases the regulation is closer the greater the rated output, and in another case it is the same for all rated outputs. Close regulation may be obtained either by working the copper at a low current density in which case a fairly large number of turns may be employed and a small flux, or it may be obtained by employing a considerably higher current density, a small number of turns. and a large flux. The latter plan generally results in a greater core loss than the former plan.

Comparing our 20-kw design, as regards core loss and regulation, with the data just given for various lines of transformers, we find that the design is fairly in accord with good practice as relates to these quantities. Of course, the designer's object is to obtain a good result at a minimum total works cost, and designs should also be compared from this point of view. Broadly, however, it may be said that what might appear an extravagant outlay when the cost of the copper and core is alone considered, often constitutes but a very inappreciable increase in the cost by the time the cost of the oil, the insulation materials, the case, the bushings and the 
NO-LOAD CURRENT, POWER FACTOR, Etc. 79

leads, as also of the labour and of the establishment charges, are all taken into account. In large concerns it is a very common occurrence (attributable to poor administration) that

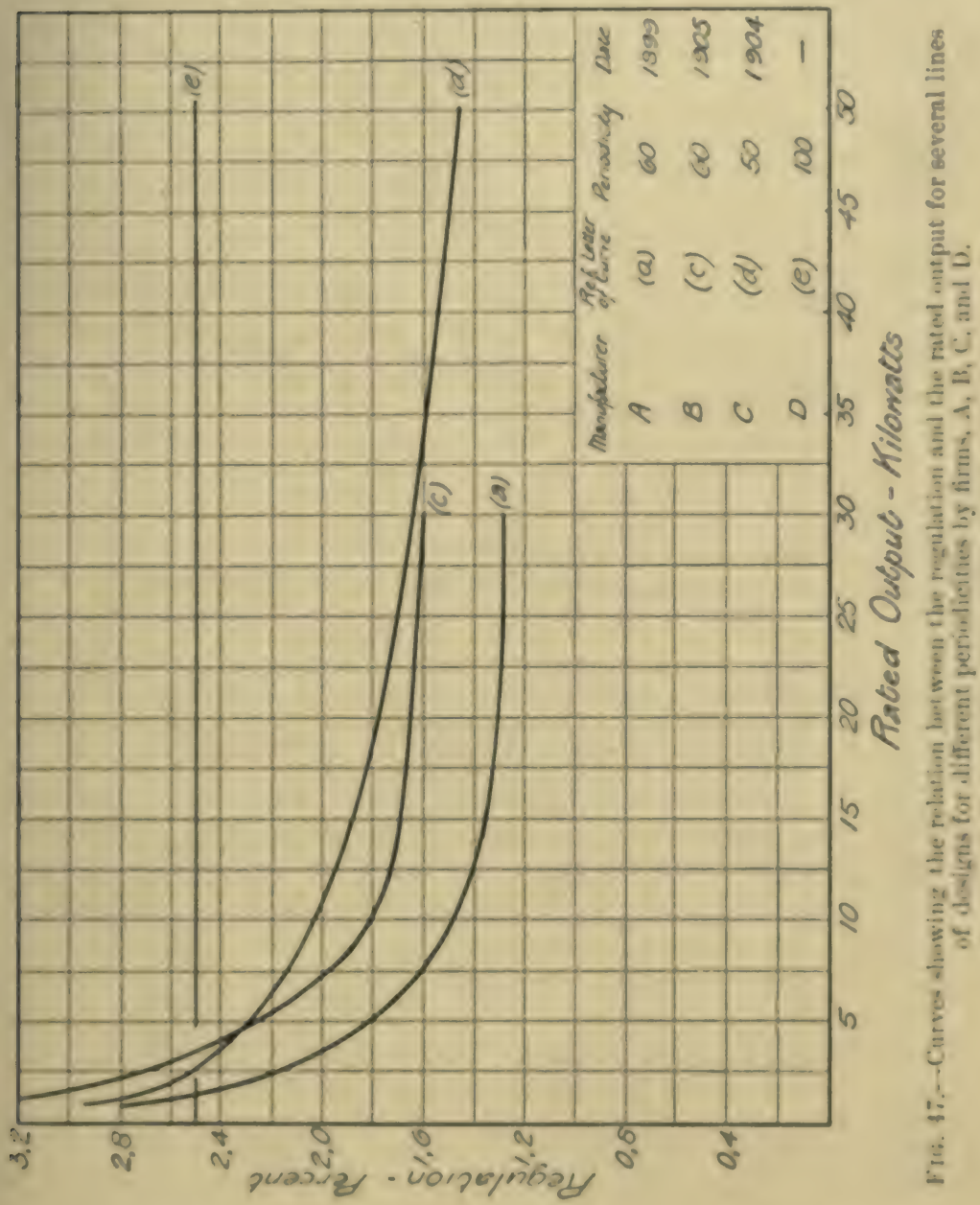

the establishment charges mount up to a very formilable percentage of the total works cost, whereas in a very small concern these charges are often kept down to a small percentage by the exereise of stremuous oversight. While it might at first glanee 
appear that a consequence of this state of affairs would be that the smaller concern could meet the price even with a more liberal outlay for material, further reflection will show that on account of the smaller percentage of the total cost represented by establishment charges, a given percentage saving

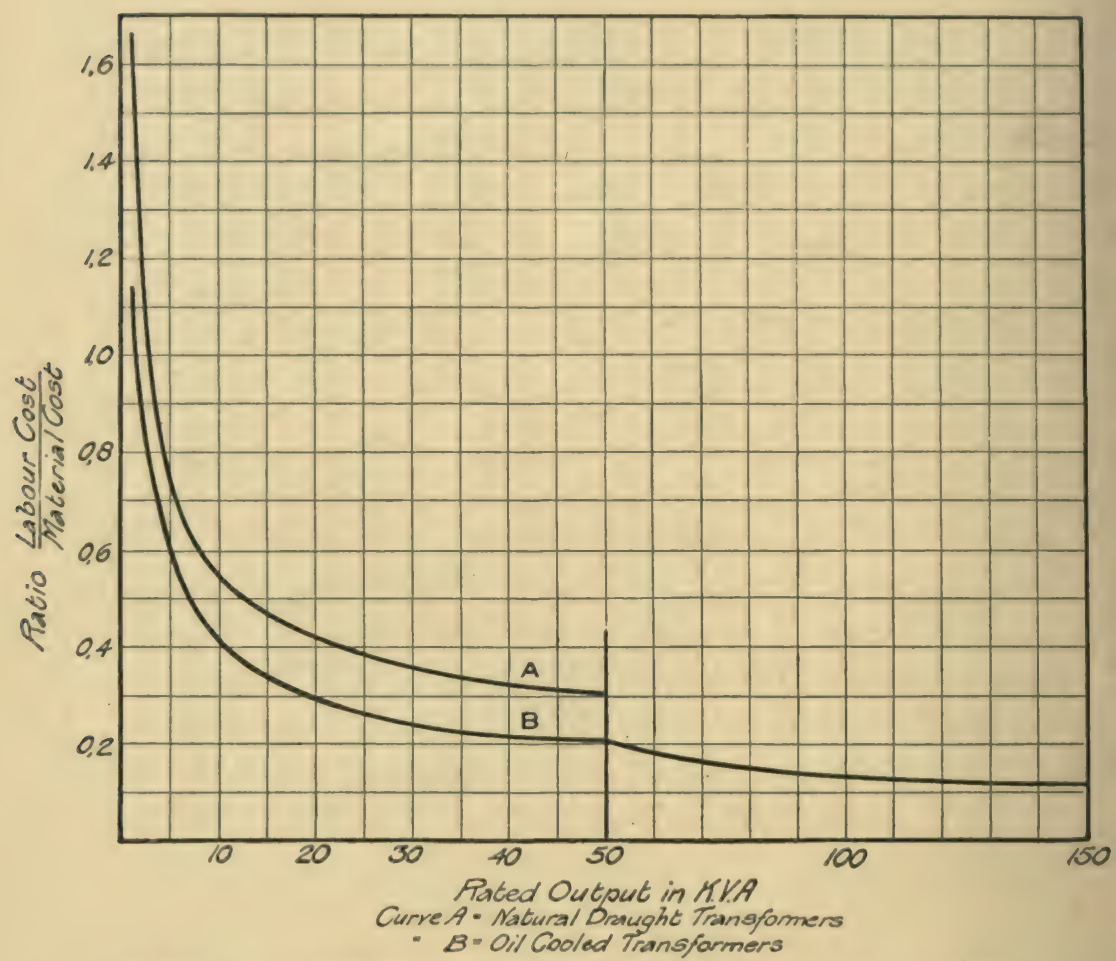

FIG. 48.-C'urves showing ratio of labour cost to cost of active material for natural air-cooled and oil-cooled transformers.

effected in the outlay for materials makes a greater percentage reduction in the total works cost than a corresponding percentage saving in materials in the case of a large firm with abnormal establishment charges.

In view of this latter consideration and of various disadvantages under which the smaller firm conducts its business, it 
will appenr fairly conclusire that the large firm can go further in the direction of a liberal outlay for material, so long as a reasonable improvement in quality is thereby attainable, than can a small firm. Of course, in many individual cases these general charncteristics of small and large firms are completely reversed, and in such cases the reverse conclusions would hold. Some curves showing the approximate ratio of labour cost to actire material cust, i.e., copper and iron (and oil for oil-cooled trausformers), are shown in Fig. 48 for both natural air-cooled and oil-cooled transformers of various capacities. The cost of the insulating materials is not included in the results from which these curves are plotted. But it is important to consiler the cost of the material in a transformer as made up of:-

I. Core.

II. Copper.

III. Insulating materials.

IV. Oil.

V. Case.

VI. Accessories (such as bushings, etc.). 


\section{CHAPTER V}

\section{THE DESIGN OF THE WINDINGS AND INSULATION}

LET us now proceed to design the windings and insulation more in detail. An outline drawing showing the location of the windings for this design is given in Fig. 49. The secondary

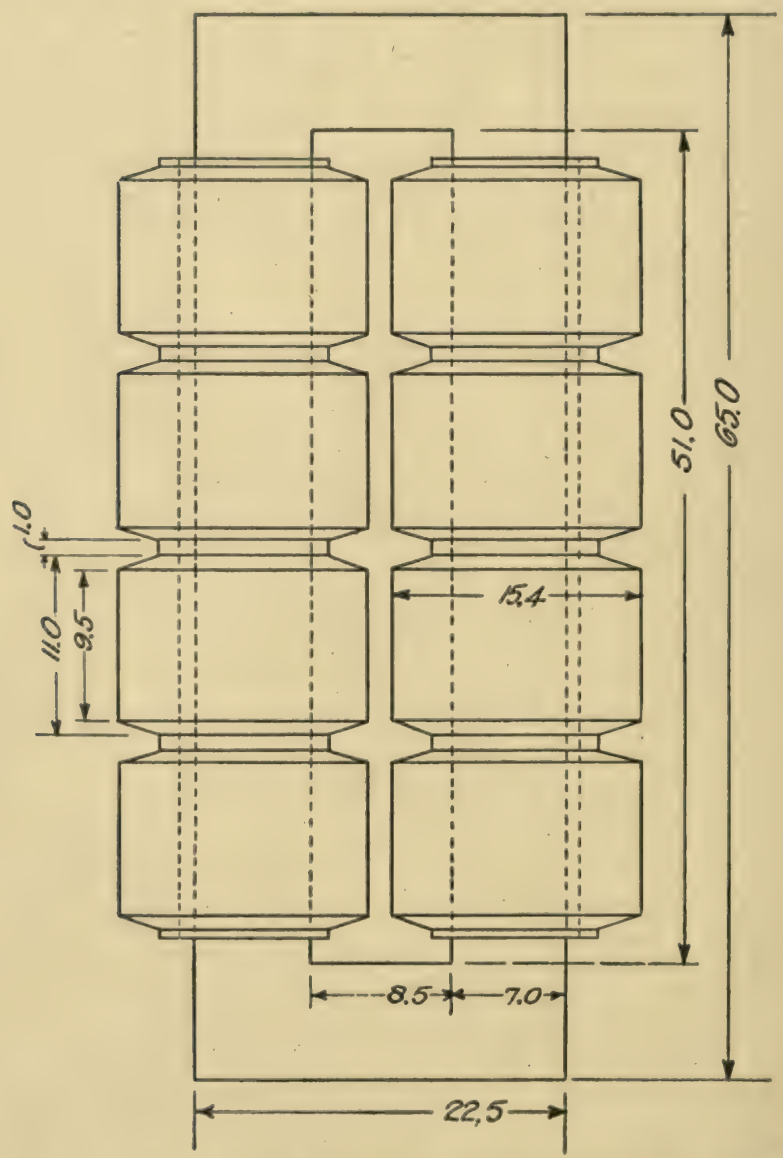

FIG. 49.-Outline drawing showing the arrangement of the windings of the 20 -kw $5000 / 200$-volt transformer. 
coils are wound the full length of each of the long vertieal cores. We have already ascertained that we shall require 124 secondary turns and 3100 primary turns. Thus each secondary coil unst contain 62 turns. - The secondary conductor is com-

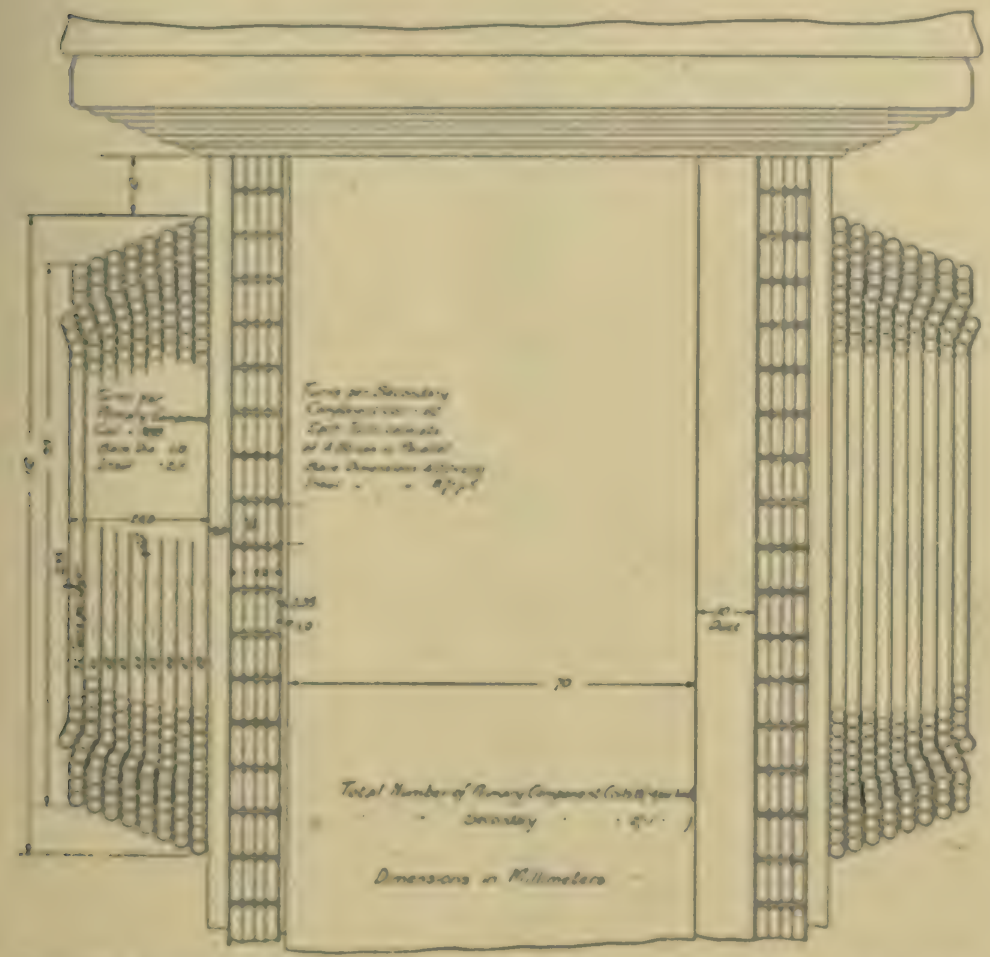

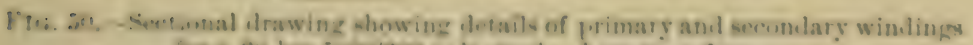

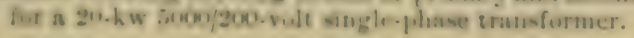

pused of four that strips, each, when bare, measuring $2,0 \mathrm{~mm}$ $\times 6,8 \mathrm{~mm}$.

The total section of the secundary conductor thus amounts to

$$
4 \times 2,0 \times 6,8=54,5 \mathrm{sq} \mathrm{mm},
$$

which is the value already estimated (on $\mathrm{p} .54$ ) to be required. These four component strips are laid one above the other, as indicated again to a large seale in Figs. 50 and 51 , and are

$$
\text { o } 2
$$




\section{THE DESIGN OF STATIC TRANSFORMERS}

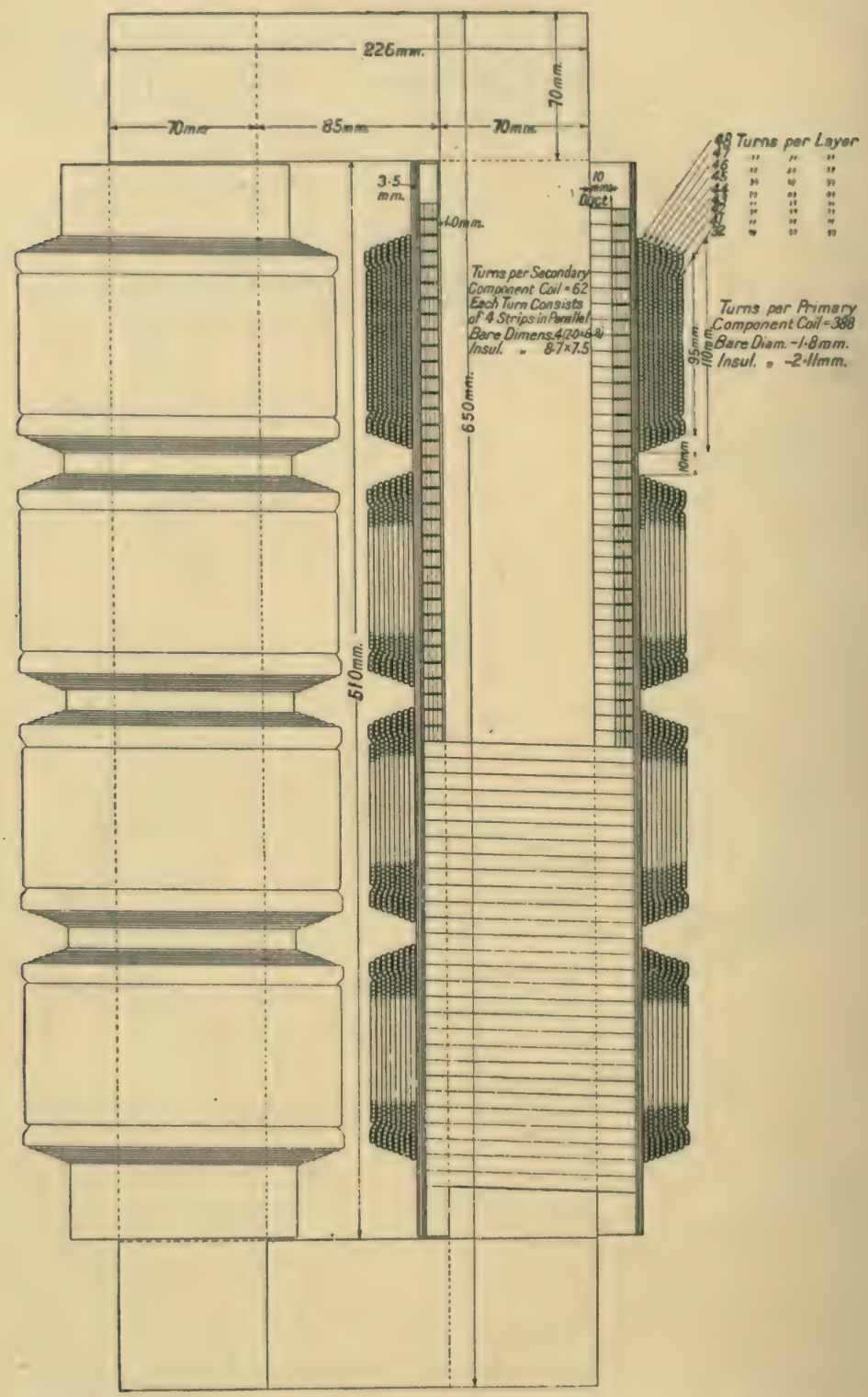

FIG. 51.-Drawing showing details of primary and secondary windings for a 20-kw 5000/200-volt single-phase transformer. 
taped together to constitute a single conductor, measuring orer the insulation $8,7 \times 7,5 \mathrm{~mm}$. The 62 turns are wound in a single layer oceupying $(62 \times 0,75=) 46,5 \mathrm{~cm}$ of the $51 \mathrm{~cm}$ total length of winding space.

The secondary eoils are in the present ease designed to be wound directly upon the cores, strips of sufficient thickness of snitable insulating material being interposed between the laminated cores and the secondary coils. While ventilating spaces for wil circulation are in themselves adrantageous, the intronal winding space (i.e., the space represented by the wimling "winilow") must often be regariled as too valuable to be slevoted to this purpose, since the values of the core loss and of the regulation are very dependent upon the eflicient utilisation of the winding window.

Diut on the onter sides, ventilating spaces are much more justifiable, and in the present design a clear space of $10 \mathrm{~mm}$ depth is provided, as indicated in Figs. 50 and 51. The secomlary eoils are held at this distance from the eore by wooden comer strips, and the laminations are left hare with a view to more efficient heat emission to the circulating oil. The coils may, as an alternative, be form-wound, slipped over the cores and wedged in place. The general plan has already been illnstrated in Fig. 29 (p. 49). It is an instance of an arrangement which I have widely used. Various detail features of the arrangenent of cores and windings are described in my British Putent No. 26112 of 1897. The insulation between the secondary und primary coils is in this instunce of a thickness of $3.5 \mathrm{~mm}$. Any of several excellent insulating materials, when suitably built up to this thickness, will aftord a barrier capable of readily withstanding the application of a test at 15000 virtual volis for five minntes. A curre to which I usually work in the propurtioning of the main imsulations of oil-immersed transformers is given in Fig. 52. This curve may be safely used when suitable insulations are intelligently emploged. With relatively expeusive materials, lesser thichnesses suffice under 
certain circumstances. On the whole, the progress at present being made in the development of improved insulating materials and methods is making it practicable to work with

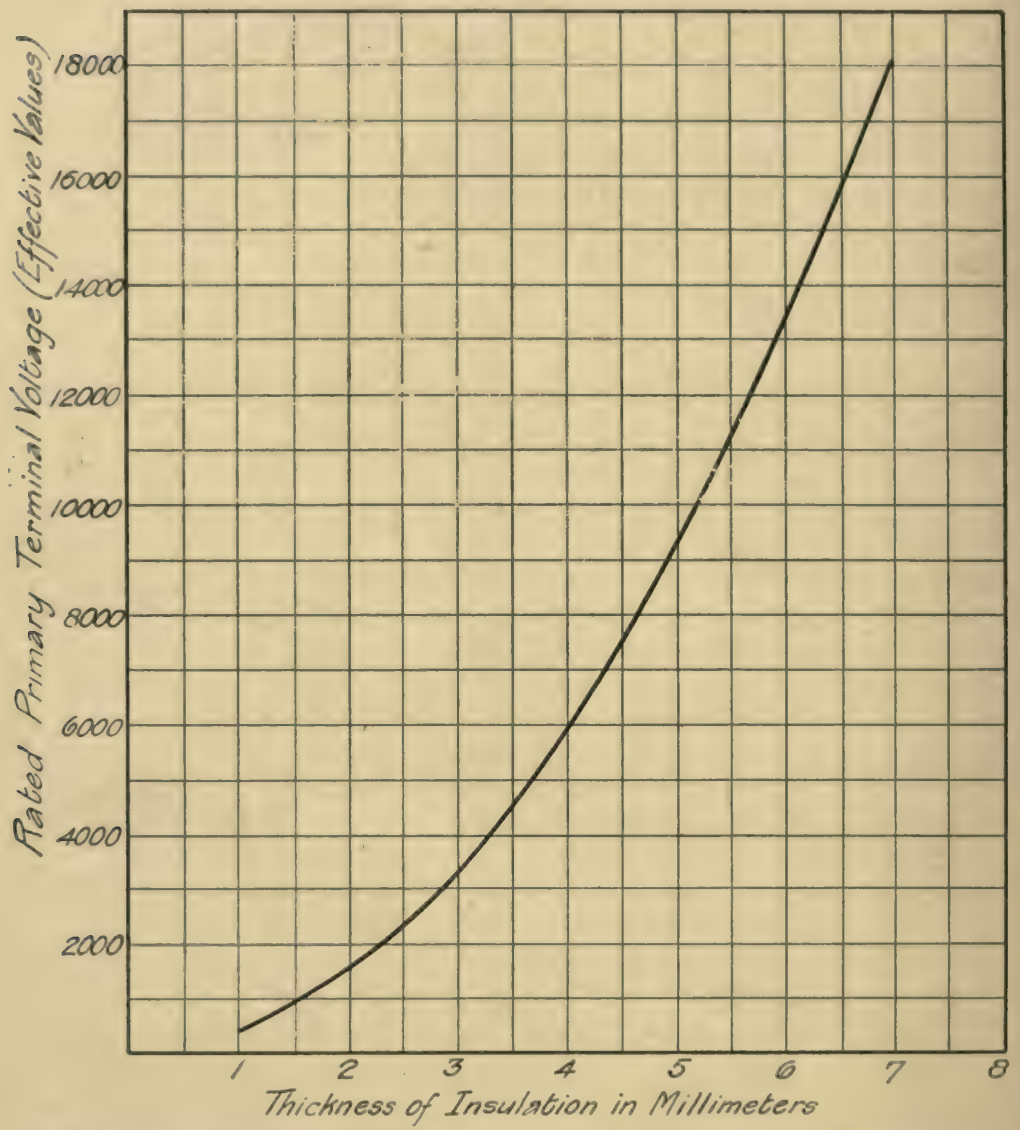

FIG. 52.-Curve showing thickness of insulation between primary and secondary windings of transformers.

less thicknesses than the values corresponding to the curve in Fig. 52.

The primary winding is divided up into eight coils, four on each leg, as seen in Figs. 49 and 51. Each coil is wound in 
nine layers with the numbers of turns per layer set forth in Figs. 50 and 51 . Fig. 50 shows in considerable detail the general arrangement of one primary coil. The 5000 primary volts are thus divided up into

$$
\frac{5000}{8}=625 \text { volts per coil. }
$$

This 62.5 volts is again divided into $\left(\frac{625}{9}=\right) 70$ rolts per layer (as an average).

Between the extreme turns of two aljacent lagers there is thus on the average a pressure of 140 volts. Had a smaller number of primary eoils been employed, the pressure per layer would lave been greater, and an uneconomically large amount of space would have had to be deroted to insulation between the layers. 


\section{CHAP'TER VI}

THE INFLUENCE OF THE FREQUENCY

IT has already been stated on p. 78 that transformers designed for a given periodicity may be and are often used on circuits having periodicities above that for which they have been designed. For circuits having periodicities below the designed figure, the large no-load current consequent upon the very high densities in the core, stands in the way of their successful use, the power factor of the circuit being seriously lowered. Moreover, the core loss at the lower periodicity is higher. The lower periodicity in itself would occasion a decrease in the core loss, but the higher flux density produces an increase in the core loss which more than suffices to offset the decrease, and the result is a considerably increased core loss. It is, therefore, often necessary and usually preferable to prepare separate designs for circuits of lower periodicities. If calculations according to the method given in the previous chapters are carried through for two other 20-kva oil-cooled single-phase transformers, differing as regards rating from the one we have considered, only in respect to their periodicities, which are respectively 15 cycles per second and 25 cycles per second, then the specifications given in columns $\mathrm{A}$ and $\mathrm{B}$ of 'Table 11 will be obtained. Column $\mathrm{C}$ of the same table contains the data of the 50-cycle transformer which we have been designing. It will be seen that with the lower periodicities the core loss has increased considerably above that of the design for 50 cycles per second, notwithstanding the much greater amount of material employed. 
TABLE 11.-SPECIFICATION FOR 15-, 25-AND 50-CYCIE, 5000 : 200-YOLT, 20-KVA SiNGLE-PIIASE Traxsformers.

\begin{tabular}{|c|c|c|c|}
\hline & A. & B. & c. \\
\hline Perindicity (in eycles per sec) & 15 & 25 & 50 \\
\hline liated output (in kilovolt atnperes) & 20 & 20 & 20 \\
\hline l'rimary pressure (in volts) & $\sin (1)$ & $50(x)$ & 5000 \\
\hline secomlary pressure (in volts) & 200 & 200 & $201)$ \\
\hline Periulicity (in cycles per sec). & 10 & 25 & 50 \\
\hline $\begin{array}{l}\text { Prelininary assumed efficiency from } \\
\text { Fig. } 7.25 \text { (in per cont) }\end{array}$ & 96,8 & 96,9 & 97,1 \\
\hline calculations (in per cent.) & 97.1 & 97,2 & 97,3 \\
\hline Promary eurrent (in amp). & 4,13 & 4.13 & 4,13 \\
\hline Seroulary eurrent (in ainp) & 100 & 100 & 160 \\
\hline "Vults per turn" (from Fig. \&, p. 27) & 1,30 & 1.35 & $1,(60)$ \\
\hline Numbler of primary turns. & 3300 & $3: 00$ & 3100 \\
\hline Flux (in megalines) [M] . & 2.25 & 1,41 & 0,73 \\
\hline Flux den-ity (in kilolines per sq $\mathrm{cm}$ ). & 14.0 & 13,5 & 11,0 \\
\hline Diet eruss-section of core (s] cm) & 1633 & 104 & 66 \\
\hline Broes & 172 & 110 & 70 \\
\hline Thimensions of core $(\mathrm{cm})$ & $12,0 \times 14,8$ & $9 \times 12$ & $7 \times 10$ \\
\hline Wiulth of wimling wimlow $(\mathrm{cm})$. & 15,5 & 11,8 & 8,5 \\
\hline Total $I R$ drop (per cent.) . & 1,8 & 1,8 & 1,8 \\
\hline Prumary / Ri drop (per cent.) & 0,9 & 0,9 & 0,9 \\
\hline Nesomulary I R drop (per eent.). & 0.9 & 0,9 & 0,9 \\
\hline Primary remi-tance (ohuss). & 10.5 & 10,8 & 10.8 \\
\hline Sinondary re-istance (ohms) & $0,01 \mathrm{~s}$ & $0,01 \mathrm{~s}$ & 0,018 \\
\hline Moun length of primary turn (cm) & 81 & 66 & 53 \\
\hline Number of secomlary turns & 132 & 125 & 124 \\
\hline Mean length of semoindary furn $(\mathrm{cm})$. & 63 & 63 & 40 \\
\hline Cruss-section of primary copper (sq $\mathrm{cm}$ ) & $0.0,32$ & $0,0: 39$ & 0.1130 \\
\hline Aggregate "cross-section of " primary & 0,92 & 0,75 & $0,5 t$ \\
\hline Gurns (sy cui) . & 172 & 125 & 93 \\
\hline $\begin{array}{l}\text { Agrregate cross-section of secomlary } \\
\text { turns (s/ cm). } \\
\text { Acorrante cross-section of primary }\end{array}$ & 121 & 96 & 97 \\
\hline $\begin{array}{l}\text { A garcante cross-section of primary } \\
\text { and secondary copler (s] cmi). }\end{array}$ & 293 & $2 \cdot 21$ & 160 \\
\hline "Space factor " of winding window. & 0,37 & 0.37 & 0.37 \\
\hline limises aren of winding window (sy cm) & 790 & 600 & 433 \\
\hline I. angth of winding window (cm) & 81 & 51 & 51 \\
\hline 'Tutal weight of sheet steel $(\mathrm{kg})$ '. & $2: 311$ & 131 & 76 \\
\hline Flux ilen-ity (kilulines jeev sy cm) & 11.0 & 13,5 & 11,0 \\
\hline Core lom per kig (from fig. 16, p. 3i). & 1.11 & 1.6 & 2.5 \\
\hline Totial core loses (watts) . . . & 2311 & 214 & 1100 \\
\hline Calctiatios of No-Lon] CURrest. & & & \\
\hline Mean length of magnet ie circuit ( $\mathrm{cm}$ ) & 182 & 166 & 147 \\
\hline Aup turns per cm (from Fig. II. p. 34) & 12 & 10 & 5.3 \\
\hline Total amp furns reppuiresl . . & $22(x)$ & 16fin & 780 \\
\hline I'rimary turns 。 . 。 & 3300 & 3200 & 3100 \\
\hline
\end{tabular}


TABLE 11-continued.

\section{Calculation of No-toad Current} -continued.

Crest value of the magnetising com. ponent of the no-load current (amp) Virtual value of the magnetising component of the no-load (eurrent (amp)

Core loss (watts)

Core loss component of the no-load current

No-load current (amp)

Power factor at no load. .

No-load current in per cent. of current at full load

\section{Windings-Primary.}

Number of primary component coils .

Number of turns "per primary component coil

Bare diameter of primary wire $(\mathrm{mm})$.

Insulated diameter of primary wire (mm)

Number of turns per innermost layer

Number of layers of turns .

Dimensions of primary component coil $(\mathrm{mm})$, . . . .

\section{Secondary.}

Number of secondary component coils

Number of turns per secondary component coil

Number of strips in parallel, constituting one turn

Dimensions of each component strip

Insulated dimensions of complete turn (min)

Number of layers

Number of turns per layer.

Dimensions of secondary component coil (cm)

\section{WEIGHTS.}

Weight of primary copper $(\mathrm{kg})$.

Weight of secondary copler (kg)

Total weight of copper ( $\mathrm{kg}$ )

Total weight of core $(\mathrm{kg})$.

Total net weight of active material (kg)

\begin{tabular}{|c|c|c|}
\hline $\mathrm{A}$ & B. & c. \\
\hline 0,67 & 0,52 & 0,25 \\
\hline 0,47 & 0,37 & 0,178 \\
\hline 230 & 214 & 190 \\
\hline 0,046 & $0,0+3$ & 0,038 \\
\hline 0,472 & 0,373 & 0,182 \\
\hline 0,098 & 0,115 & 0,22 \\
\hline 12 & 9 & 4,4 \\
\hline 8 & 8 & 8 \\
\hline 4 & 4 & 4 \\
\hline 413 & 400 & 388 \\
\hline 2,57 & 2,24 & 1,96 \\
\hline 2,75 & 2,40 & 2,11 \\
\hline 38 & 42 & 48 \\
\hline 14 & 12 & 9 \\
\hline $11 \times 4,5$ & $11 \times 3,4$ & $11 \times 2,4$ \\
\hline 2 & 2 & 2 \\
\hline 1 & 1 & 1 \\
\hline 66 & 64 & 62 \\
\hline 5 & 4 & 4 \\
\hline $6,6 \times 2,8$ & $6,6 \times 2,8$ & $6,8 \times 2,0$ \\
\hline $\begin{array}{c}7,3 \times 14,7 \\
1 \\
66\end{array}$ & $\begin{array}{c}7,3 \times 11,9 \\
1 \\
64\end{array}$ & $\begin{array}{c}7,5 \times 8,7 \\
1 \\
62\end{array}$ \\
\hline $49 \times 1,5$ & $49 \times 1,2$ & $49 \times 10,9$ \\
\hline 128 & 73 & 44 \\
\hline 68 & 45 & 24 \\
\hline 196 & 118 & 68 \\
\hline 230 & 134 & 76 \\
\hline 426 & 252 & 144 \\
\hline
\end{tabular}


TABLE 11 -continued.

\begin{tabular}{|c|c|c|c|}
\hline & $\Lambda$ & B. & c. \\
\hline 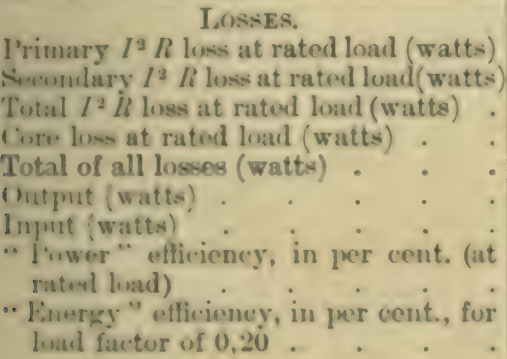 & $\begin{array}{c}185 \\
180 \\
365 \\
230 \\
595 \\
20000 \\
20590 \\
97,1 \\
93,1\end{array}$ & $\begin{array}{l}185 \\
150 \\
3655 \\
214 \\
570 \\
20000 \\
20570 \\
97,2 \\
93,2\end{array}$ & $\begin{array}{c}18.5 \\
180 \\
365 \\
190 \\
550 \\
20000 \\
20550 \\
97,3 \\
93,9\end{array}$ \\
\hline
\end{tabular}

Some of the important differences in the designs, of which the leading data are given in Table 11, are brought together in Table 12. The most striking difference is in the weights. The general outline drawings of the three designs are shown in Figs. 53, 54 and 55. These figures show very clearly the influence of the periodicity upon the relative proportions of the transformer.

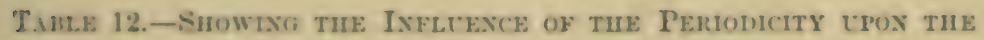
Con: Iass, Wernats, Err., of 20-Kva Traxsfonmers.

\begin{tabular}{|c|c|c|c|c|c|}
\hline 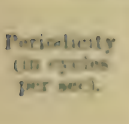 & $\begin{array}{l}\text { Cors losw } \\
\text { (in wat (ts). }\end{array}$ & $\begin{array}{l}\text { Weizlist of } \\
\text { active nuaterial } \\
\text { jer kin } \\
\text { (in kg). }\end{array}$ & $\begin{array}{l}\text { "Power" } \\
\text { efficlency ut } \\
\text { finl lisai (in } \\
\text { por cent.). }\end{array}$ & $\begin{array}{l}\text { No-lonal } \\
\text { current (in } \\
\text { per cent. of } \\
\text { full loed } \\
\text { eurrent). }\end{array}$ & $\begin{array}{c}\text { Solwad } \\
\text { power factor. }\end{array}$ \\
\hline 15 & 230 & 21,3 & 97,15 & 12,0 & 0,098 \\
\hline 28 & 214 & 12,6 & 97,23 & 9,0 & 0,113 \\
\hline 30 & 190 & 7,2 & 97,34 & 4,4 & 0,22 \\
\hline
\end{tabular}

These three desigus have been prepared on the basis of the same $I^{2} I R$ loss for all periodicities. So wide is the range of cheice of assumptions on which comparisons of this sort may be based, that the results obtained must always be considered with an open mind and with a clear recognition of the impussibility of establishing any alsolutely general comparison. 
92 THE DESIGN OF STATIC TRANSFORNERS
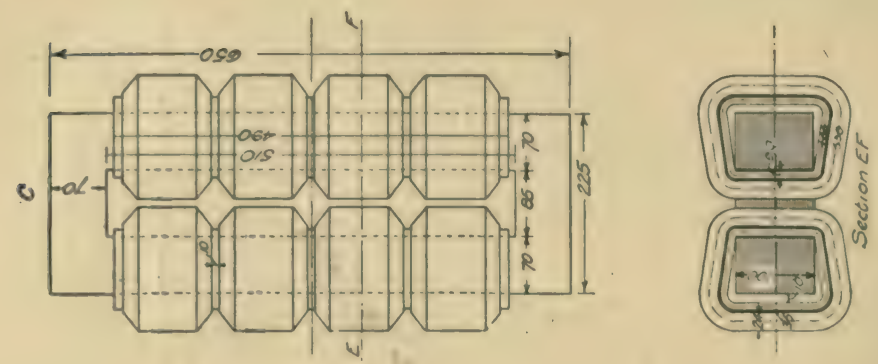

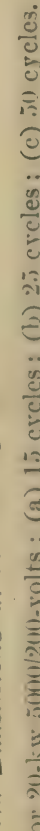
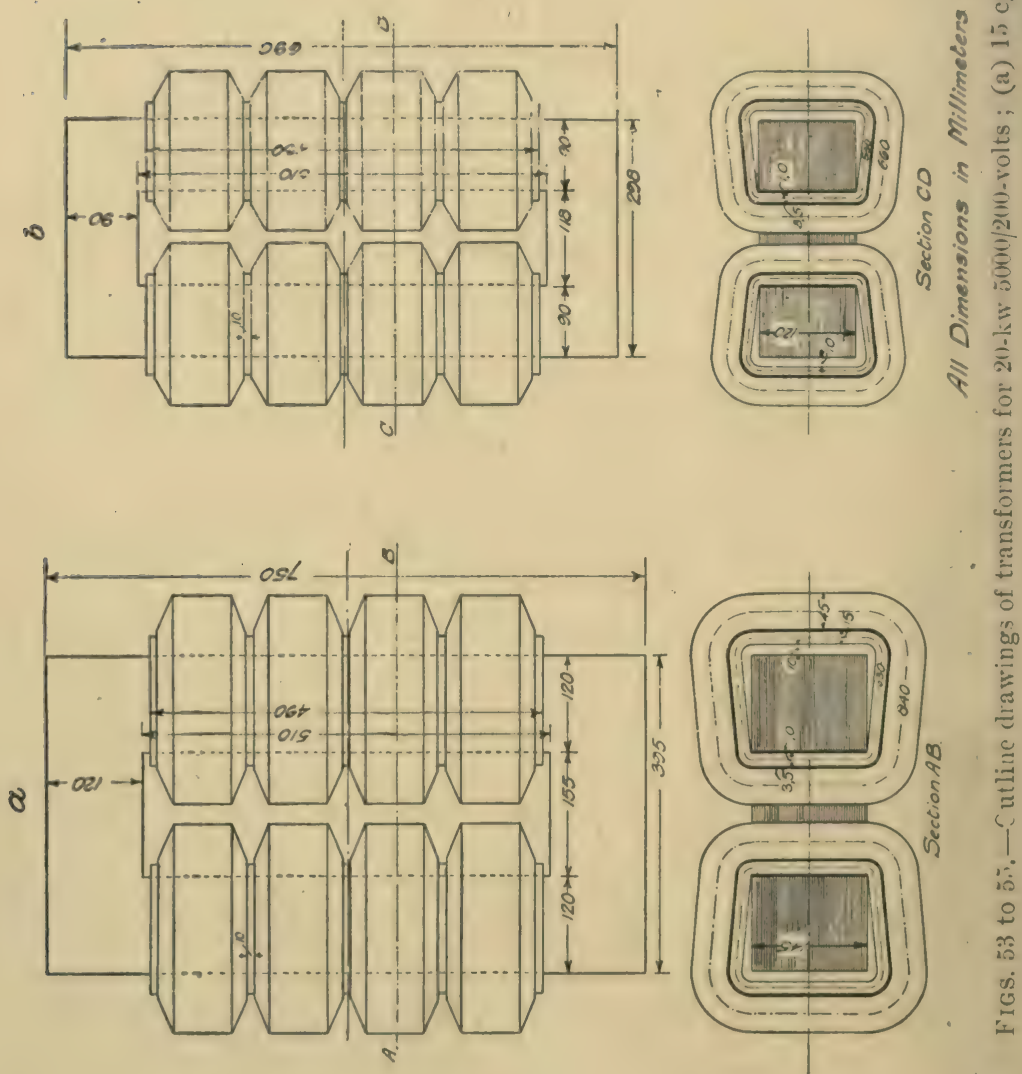


\section{CHAP'TER VII}

THE REGTLATION OF TRANSFORMEIS

Oru 20-kva transformer has 3100 primary turns and 124 secondary turns. Its " ratio of transformation" is $\left(\frac{3100}{124}=\right) 25$. If a pressure of 5000 volts be applied at the terminals of the primary winding, and if the secondary winding is on open circuit, i.e., if the transformer is in cirenit but unloaded, then the pressure at the terminals of the secondary winding will be $\left(\begin{array}{c}5000 \\ 25\end{array}=200\right.$ voits. If the secondary circuit be closed through an impeiance, then current will flow from the secondary winding into this external secondary cireuit and the pressure at the sccondary terminals will decrease below 200 volts (except in the unusual case that the current flowing into the external secondary circuit is leading).' The percentage by which the secondary terminal pressure falls below the value corresponding to no load (in this case 200 volts) is termed the "regulation" corresponding to the load in question. If the pressure has fallen to 196 volts, then, for the corresponding load, the regulation is said to be $\left(\frac{200-196}{200} \times 100=\right) 2,0$ per cent. The fall in pressure is greater the grenter the current flowing and the liswer the value of $G$ (the power factor of the external circuit). If, without any accompunying siatement as to load and power factor, it is stated that the regulation of a transformer is, say, 1,5 per cent., this is usually intended to men that when the transformer is delivering its rated load to a non-inductive

I For a kirm tran-formm there will, for any given ralue of the secoulary entent, in sume farficulat angle of lead alove whels the terminal pressure will Le greater when this eurrent flows than on open cireut. 
circuit $(G=1,00)$ the pressure at the secondary terminals will be 1,5 per cent. lower than at no load.

The drop in pressure is due to two causes, (1) the resistance of the windings, and (2) the inductance of the windings. The more the primary and the secondary windings are intermixed with one another, the less will be the second component (i.e., the inductance of the windings). It is, however, for obvious practical reasons, chief amongst which is the importance of having excellent insulation, not feasible to go very far in the direction of intermixing the primary and secondary windings. 'The inductance is, greater the lower the magnetic

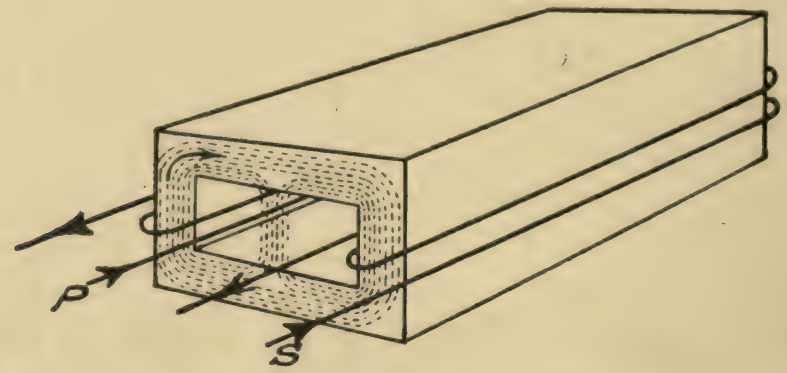

FiG. 56.-Diagram showing magnetic leakage in core-type transformer.

reluctance of the path offered to the passage of magnetic flux between the primary and secondary. This flux is termed the leakage flux. To keep down the inductance it is important that as much as possible of the magnetic flux shall be linked both with the primary and secondary windings, i.e., it is important that the magnetic flux shall be restricted to the main magnetic circuit, so far as practicable.

In Fig. 56 the coil marked $P$ represents the primary and the coil marked $S$ represents the secondary. When the secondary is delivering electricity to an external circuit, the current in its windings flows in the opposite direction to that of the current in the primary windings. Consequently if we consider the conductors lying within the winding window, we 
shall find the primary current flowing, say, from front to back, as in the diagram in Fig. 56, while the secondary current flows from back to front. It is thus clear that the conductors will co-operate to set up) a leakage flux (as shown in the diagram) arross the winding window from the top portion of the core represented in Fig. 56 to the bottom portion. The core and winlings in Fig. 56 are arranged in a very unfavourable way so far as relates to minimising the magnetic leakage. By such a

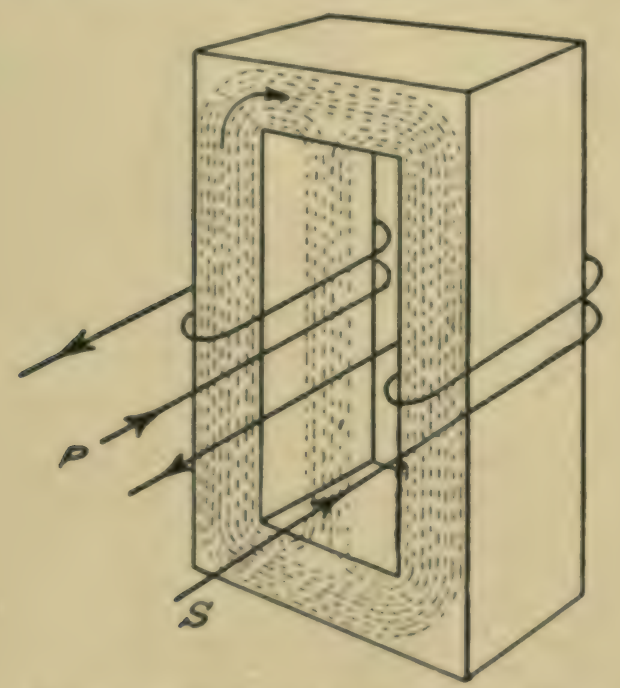

F10. 57.-Diagram showing magnetic lenknge in core-type transformer.

re-arrangement as that shown in Fig. 57 , where the coils are wound on the long sides of the core, the leakagre path is much linger and is consequently of much higher magnetie reluctance, and the leakinge flux will consequently be less. But as regards magnetic leakage, the arrangement shown in Fig. 57 is still very bad. The reader will now be better able to appreciate one of the chief advantages of employing magnetic circuits of the general proportions of that alrealy shown in Fig. 36 on p. 58. The longer and narrower the winding window, the grenter will be the reluctance of the magnetic path for the 
leakage flux. But even in such a case as that of Fig. 36, it would not suffice to have the primary windings occupy one of the vertical legs and the secondary windings the other. Such an arrangement would still afford far too great a cross-section for the leakage flux between the primary and secondary windings. But by winding the secondary the full length of each vertical leg and by arranging the primary coils immediately over the secondary coils, as shown in Figs. 49 and 50, on pp. 82 and 83 , only leaving enough room between them to ensure effective insulation, the opportunity for leakage flux to pass between primary and secondary is much reduced. Moreover by having the windings shallow we keep down the magnetomotive force per centimeter of length of winding window, and since the leakage flux is proportional to this specific mmf, the use of these shallow windings is in the interests of low inductance. For such a case as our 20-kva transformer, the simple concentric arrangement shown in Fig. 30, on p. 51, and in Figs. 53, 54 and 55 , on p. 92 , with the secondary wound inside and the primary outside on each vertical leg, leads to a sufficiently low inductance, but cases often arise where a triple-concentric arrangement, such as that indicated in Fig. 31 , on p. 51, must be employed in order to obtain the required low inductance and close regulation. The sandwich winding of Fig. 32, p. 52, may also lead to low inductance and close regulation if the subdivision is carried far enough, but when this arrangement is employed with a long and narrow winding space, it must be kept in mind that the length of the leakage path from one side of the narrow winding space to the other, is very low, and this in itself tends to low magnetic reluctance of the leakage path between the primary and secondary windings.

Other things being equal, the inductance will obviously be less the higher the magnetic density employed in the core, for this will tend toward minimising the mean length of both primary and secondary turns and consequently will reduce the cross-section of the leakage path. 
The higher the incluctance of a transformer, the greater will be the pressure which will be required at the primary terminals to send a given current through the secondary winding when the latter is short-circuited. Consider a $100-\mathrm{kw}$ transformer wound for 3000 primary volts and 200 secondary volts. The ratio of transformation is $\left(\frac{3000}{200}=\right) 15$. Its secondary current, at its rated load of $100 \mathrm{kw}$, is (for unity power-factor) equal to $\left(\frac{100000}{200}=\right) 500$ amperes. If the secondary is shortcircuited through an ammeter, and if the pressure at the primary terminals is gradually raised, then, for a reasonably good design, it may be found that it will require a pressure of, say, 100 volts at the primary terminals to send the full-load current of 500 amperes through the short-circuited secondary. The corresponding primary current is $\left(\frac{500}{15}=\right) 33,3$ amperes. The "impedance" of the transformer under these conditions may be said to be $\left(\frac{100}{33,3}=\right) 3,3$ ohms. The imperlance is made up of two components, the resistance and the reactance. As reasonable valnes for the resistances of the primary and secondary windings of this $100-\mathrm{kw}$ transformer, we may take 0,60 ohm and 0,0020 ohm respectively. It is convenient at certain steps in transformer calculations to reduce the data to an "equiralent" transformer, but with a $1: 1$ ratio of transformation. Thus our 100-kw transformer, for 3000 primary and 200 secondary volts and a ratio of transformation of 15 , can be replaced by an "equivalent" transformer for $100 \mathrm{kw}$, but with both primary and secondary coils wound for 3000 volts. For this "equivalent" transformer we should still have the resistance of the primary winding equal to $0,60 \mathrm{ohm}$ as

I Imprelance and reautance are dealt with in n non-mathematical mnuner in a litcle treation by the anthor, entutlesl " Electricity, " and published in 1910 ly Mesurs, Constable, London.

8.. 
before, but the resistance of the secondary winding would now be

$$
15^{2} \times 0,0020=0,45 \text { ohm. }
$$

Instead of dealing separately with the resistance of the primary and the resistance of the secondary, we may, for such a $1: 1$ transformer, speak of the "resistance of the transformer," and say that it is equal to

$$
0,60+0,45=1,05 \text { ohm } .
$$

The "resistance drop" in this transformer, when the input is 33,3 amperes, is

$$
1,05 \cdot \times 33,3=35 \text { volts. }
$$

The 100 volts which we have stated to be necessary to send fuli-load current into the transformer when the secondary is short-circuited, is made up of two components. One component is the "resistance drop" of 35 volts, which we have just calculated. The other component is the "reactance drop," and is equal to

$$
\sqrt{100^{2}-35^{2}}=94 \text { volts. }
$$

In the example we have taken, we should say that for a primary current of 33,3 amperes, the "resistance drop" is

$$
\frac{35}{3000} \times 100=1,17 \text { per cent. }
$$

and the "reactance drop" is

$$
\frac{94}{3000} \times 100=3,1 \text { per cent. }
$$

The resistance drop is simply calculated from the number of turns, the cross-section and the mean length of turn in the primary and secondary windings. Such calculations have already been carried through step by step in Chapter II.

The reactance drop can only be very roughly estimated. It varies greatly with different types of magnetic circuit, with different proportions of the winding-space and with different arrangements of the winding. 
In $1896 \mathrm{I}$ devised a method of estimating the reactance drop of a core-type transformer with concentric windings and an elongated winding-space, and I have used it with good results during the last fourteen years. The method is based on the following formula :-

$$
\text { percentage reactance drop }=f \frac{a}{b \times c}
$$

$f=$ a factor depending upon the width of the wiuding window, the depth of the windings, the number of concentric windings employed and the thickness of the insulation or of the air or oil space between the primary and secondary windings.

$a=$ virtual (i.e., rms) value of the primary ampere-turns at rated load.

$b=$ height of winding space in $\mathrm{cm}$.

$c=$ core density in kilolines per $\mathrm{sq} \mathrm{cm}$.

For a single concentric winding, i.e., for a winding of the type employed in our 20-kva transformer (see also Fig. 30), the values for $f$ range from 0,05 to 0,12 , being higher the greater the depth of the coils. For triple-concentric windings (see Fig. 31) the range of values for $f$ is from 0,03 to 0,07 . For still greater subdivision of the winding, lower values must be used for $f$. For more definite values, each designer will acquire his own experience, recording the results observed on test and working back to the factor $f$. For single-concentric windings the curve in Fig. 58 may be found useful in obtaining values for $f$. Our 20-kva design has decidedly shallow coils and a narrow winding window. It is for only moderate pressure (5000 volts), and the primary and secondary coils come quite close up to one another (as shown in Fig. 50, on p. 83). It will be appropriate in this case to take

$$
f=0,080 .
$$

The primary winding has 3100 turns, and the input at rated load is 4,12 amperes. Consequently for " $a$," the virtual value of the primary ampere-turns, we have

$$
a=4,12 \times 3100=12800 .
$$




\section{THE DESIGN OF STATIC TRANSFORMERS}

The height of the winding space (" $b$ " in the formula) is 51 . The core density (" $c$ " in the formula) is 11,5 kilolines per sq cm. Substituting these values in the formula, we obtain

Percentage reactance drop $=0,080 \times \frac{12800}{51 \times 11,5}=1,75$.

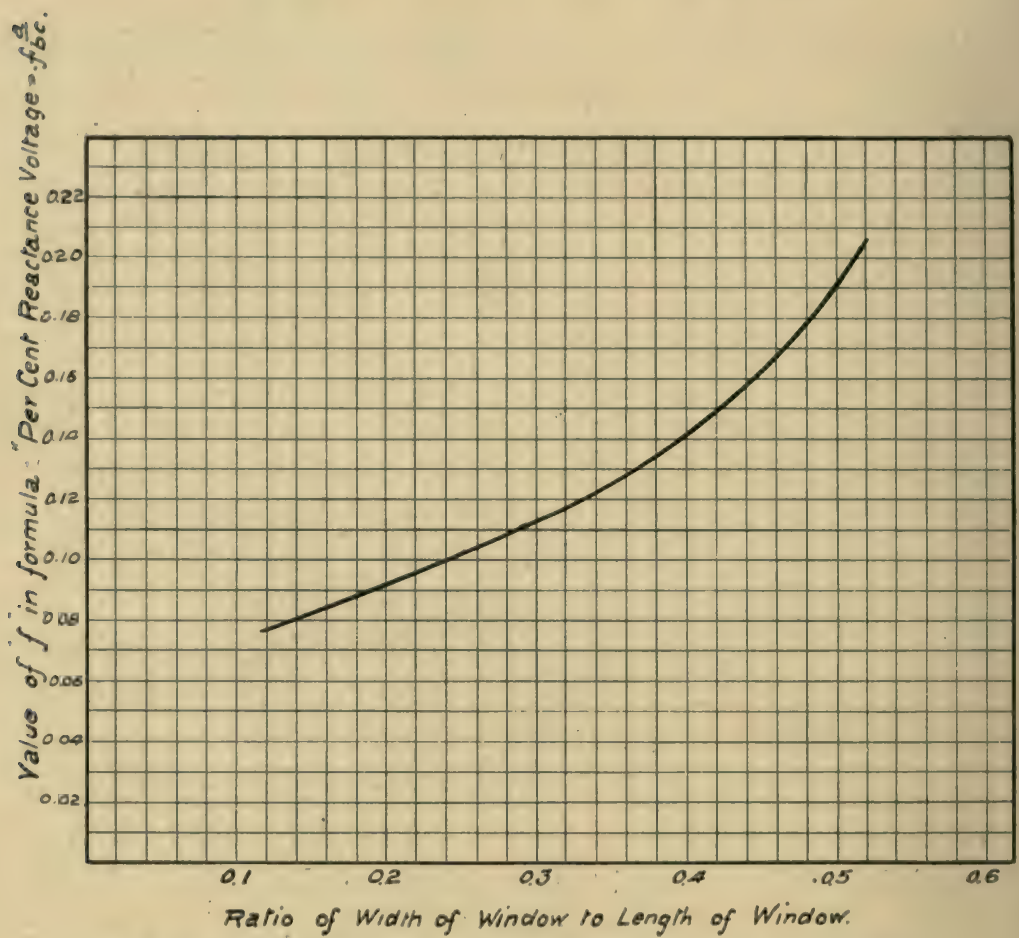

Fig. 58.-Curve of values for $f$ in formula "percentage reactance drop $=f \frac{a}{b c}, "$

We have already seen that the resistance drop is equal to 1,80 per cent. Thus we have

Reactance drop $=0,0175 \times 5000=87,6$ volts Resistance drop $=0,0180 \times 5000=90,0$ volts Impedance voltage $=\sqrt{87,6^{2}+90,0^{2}}=125$ volts. 
The result indicates that in order to send full-load current of 100 amperes through the short-circuited secondary of our 20-kva transformer, a primary pressure of 125 volts will be required.

Let us study the influence of the two component drops on the regulation of a transformer. In actual practice these components constitute but a very small percentage of the terminal pressure, but for our examination of the subject, it will be preferable to take a case in which the component drops are quite considerable. Let the transformer have a $1: 1$ ratio of transformation and let the secondary pressure be 100 volts at no load. Then at no load the primary pressure will also be

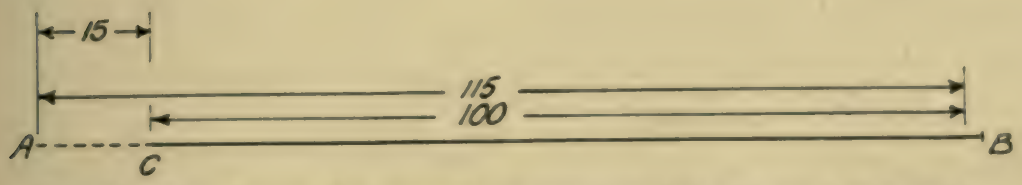

Frg. 59,-Transformer diagram with no reactance, but with an $I R$ drop of 15 per cent.

100 volts. Let the resistance drop at full load be 15 per cent. of the secondary pressure.

If the transformer had no reactance drop, then in order to have, at full load and unity power factor, a pressure of 100 volts at the terminals of the secondary winding, it would be necessary to apply a pressure of 115 volts at the terminals of the primary winding. Or if at all loads we maintain a constant pressure of 115 volts at the terminals of the primary winding, then as the load is increased the pressure at the terminals of the secondary winding (which is 115 volts at no load) will gradually decrease until at full load the secọndary pressure will only be 100 volts. 'This is shown diagrammatically in Fig. 59. If, instead of having a negligible reactance drop at full load, there is, in addition to the resistance drop of 15 volts, also a reactance drop of 30 volts, then (for unity power factor of the external circuit supplied from the 


\section{THE DESIGN OF STATIC TRANSFORMERS}

secondary) the diagram will be modified, as shown in Fig. 60 , and we see that a primary pressure of 119 volts is necessary

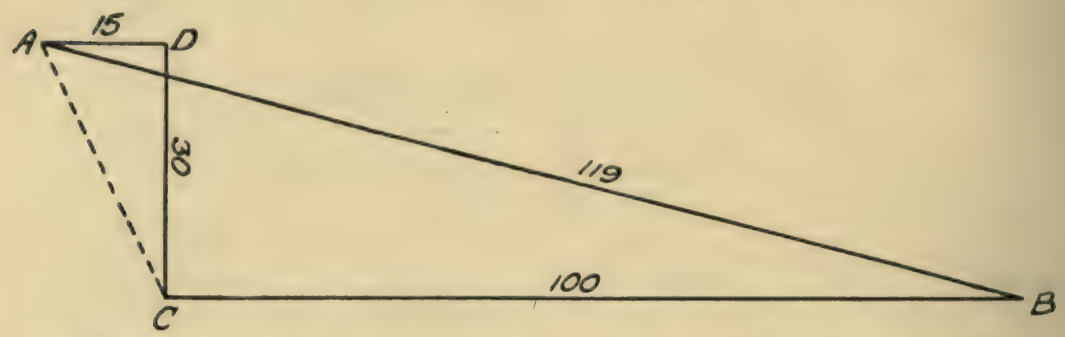

FIG. 60.-Transformer diagram with 30 per cent. reactance drop and 15 per cent. $I R$ drop. Power factor $=$ unity.

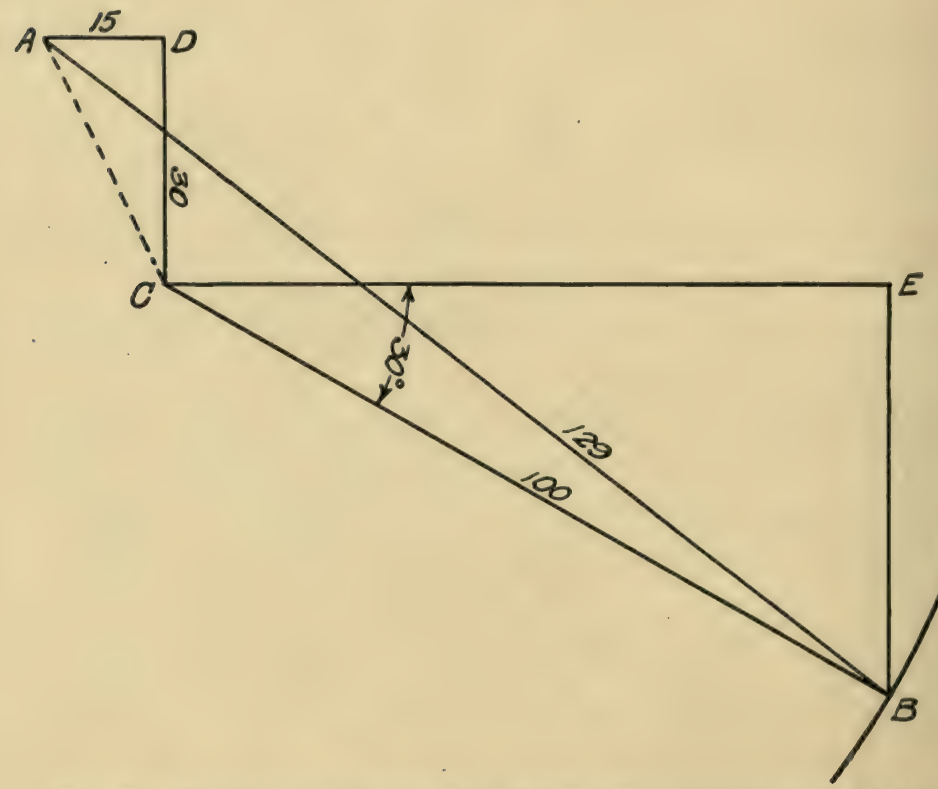

FIG. 61.--Transformer diagram with 30 per cent. reactance drop and 15 per cent. $I R$ drop. Angle of lag $\phi=30^{\circ} . \operatorname{Cos} \phi=0,886$.

in order that we may, at full load, obtain 100 volts at the secondary terminals; in other words, the pressure at the secondary terminals will gradually fall from 119 volts at no load to 100 volts at full load. 
The diagram in Fig. 61 shows the construction which should be employed when the power factor of the circuit supplied by the secondary is less than unity, and the current lags behind the terminal pressure. In the case illustrated, $C B$ represents the secondary terminal pressure of 100 volts. The current lags behind the pressure by $30^{\circ}$. Since $\cos 30^{\circ}=0,886$, the power factor of the circuit supplied from the secondary is 0,886 $(G=0,886)$. The vector $C E$ indicates the direction of the secondary current, and is $30^{\circ}$ behind $C B$, the vector representing the secondary terminal pressure. In Figs. 59 and 60 the single vector $C B$ represented the phase of the secondary terminal pressure and also the phase of the secondary current which was in phase with the pressure. $C D$ of Fing 61 represents the

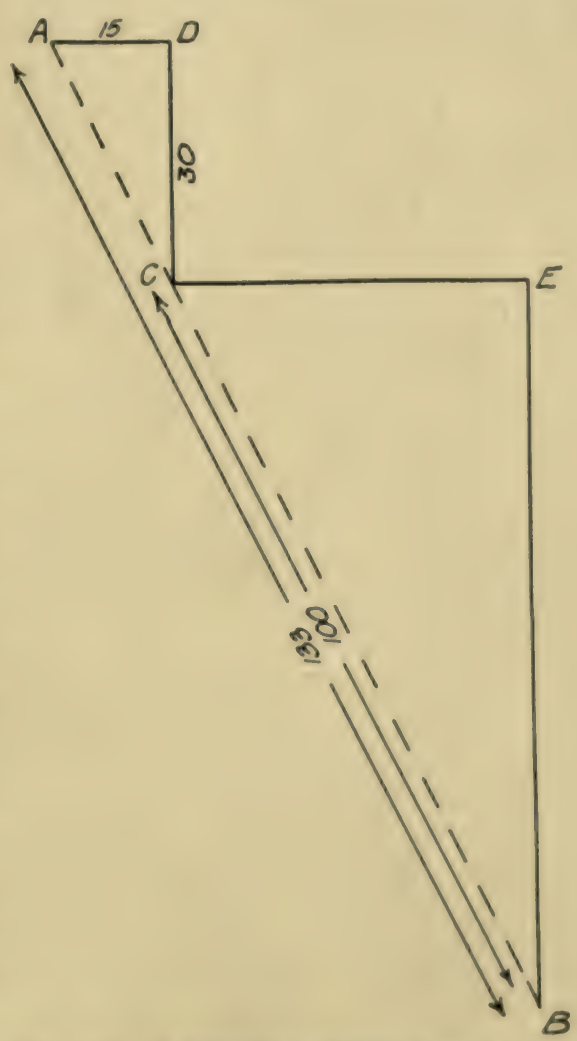

F16. 62.-... Transformer diagram with 30 per cent. reactance drop and 15 per vent. $I R$ drop. Angle of lag $\phi=63^{\circ}$. $\operatorname{Cos} \phi=0,440$.

reactance drop of 30 volts at rated load, and is $90^{\circ}$ in phase behind the vector $C E$ representing the current. The resistance drop is represented, as in Fig. 60 , by a vector $A D$, which has the same direction as (i.e, is parallel to) the vector $C E$ representing the current. The primary pressure is represented in 


\section{THE DESIGN OF STATIC TRANSFORMERS}

phase and magnitude by the vector $A B$, and is seen to be equal to 129 volts when, as in Fig. $61, G$ is equal to 0,886 .

In Fig. 62 we arrive at the value of $G$ corresponding to the

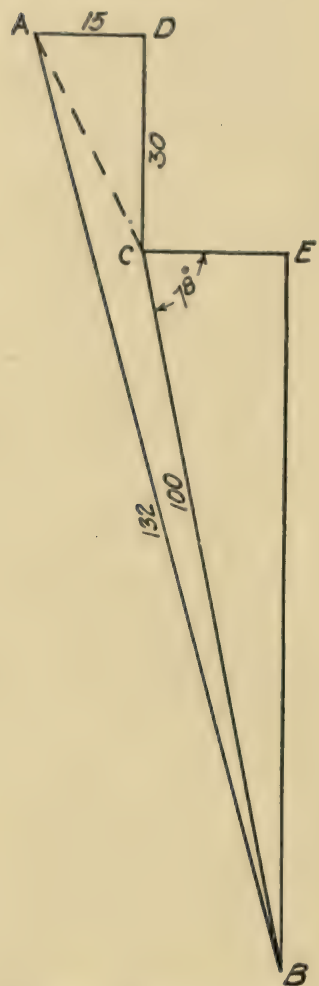

FIG. 63.-Transformer diagram with 30 per cent. reactance drop and 15 per cent. $I \boldsymbol{R}$ drop. Angle of lag $\phi=78^{\circ}$. $\operatorname{Cos} \phi=0,21$.

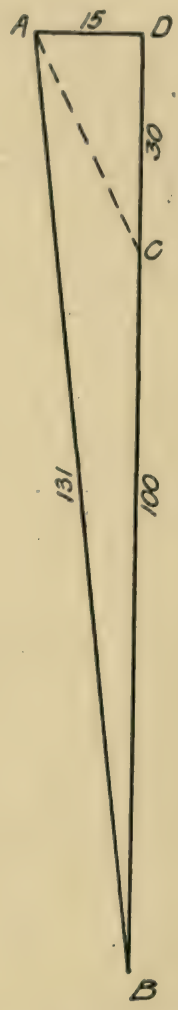

FIG. 64.-Transformer diagram with 30 per cent. react. ance drop and 15 per cent. $I \boldsymbol{R}$ drop. Angle of lag $\phi=90^{\circ}$. $\operatorname{Cos} \phi=0$.

maximum drop. This always occurs when the tangent of the angle of lag of the secondary current behind the secondary pressure is equal to the ratio of the reactance drop to the resistance drop, i.e., for the condition

$$
B E: C E=C D: A D \text {. }
$$


For the example we are employing, this oceurs for $G=0,44$. For still lower power factors of the external secondary circuit, the pressure drop again decreases, as will be seen by a study of Figs. 63 and 64 , the latter representing the limiting case of $90^{\circ}$ lag. In Fig. 65 the values of the drop are plotted in two curves-in the one the drop is plotted as a function of the power
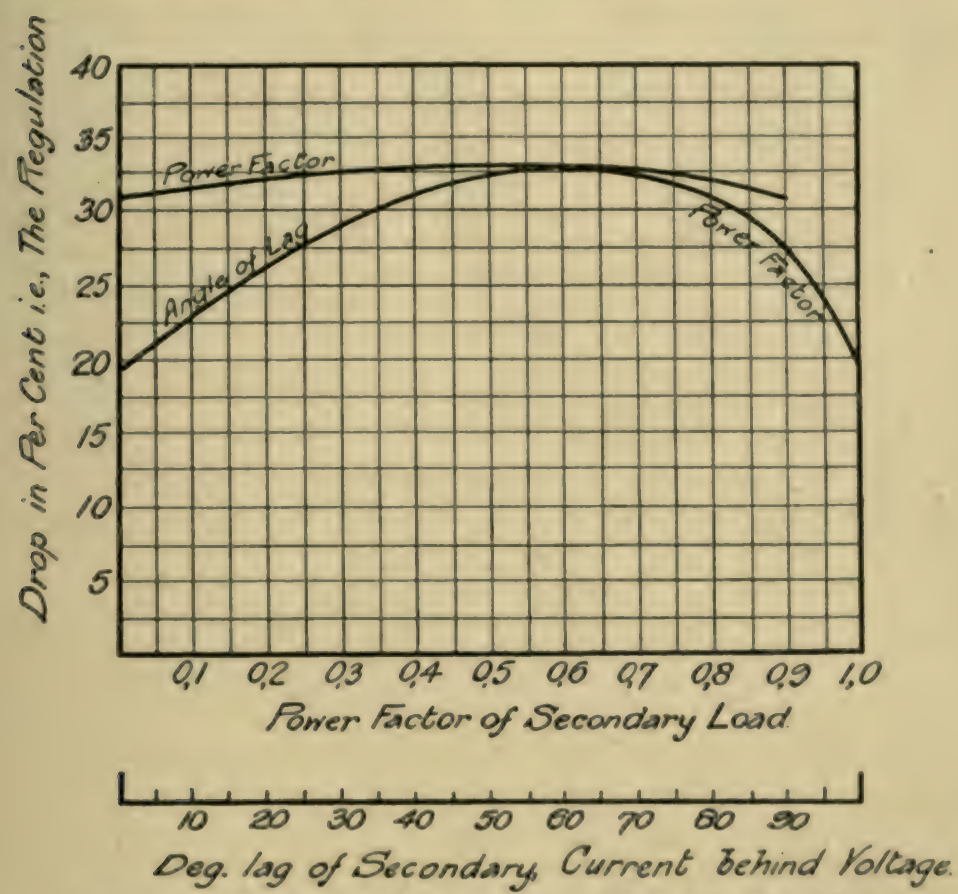

Fin. 65.- Variation of irop with power factor and angle of lag.

factor of the external secondary circuit, and in the other the drop is plotted as a function of the angle of lag of the secondary current behind the secondary terminal pressure. It is seen that the drop at first increases with decreasing power factor, reaches a maximum and then decreases. The method and diagrams in Figs. 59 to 65 were worked out by the author in 1895. It is not usual (as shown in these diagrams and in Fig. 65) to designate as the regulation the percentage which 
the drop in volts from no load to full load constitutes of the secondary pressure at fuli load, but rather the percentage which it bears to the secondary pressure at no load, the primary pressure being assumed to be maintained constant as the load increases. Nevertheless, since the author originally worked

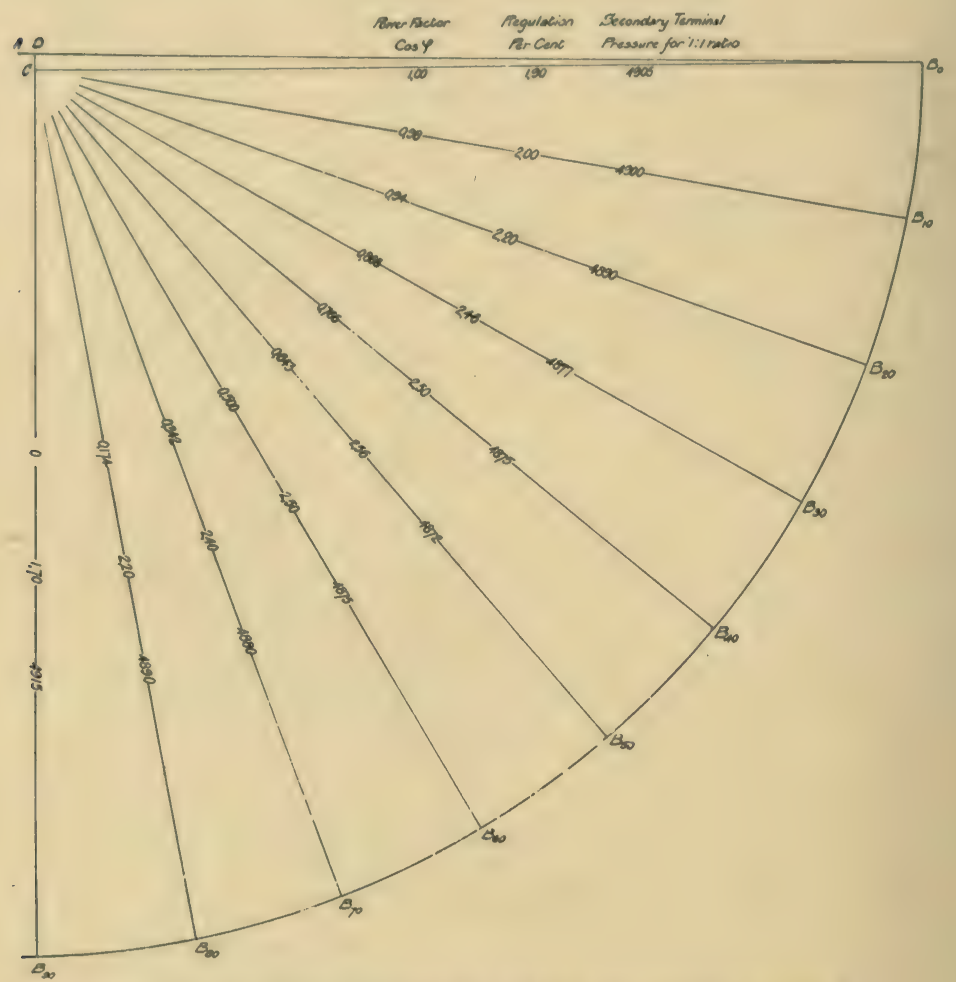

FiG. 66.-Regulation diagram of 20-kva 5000/200-volt 50-cycle single-phase transformer.

out the diagrams in the former way, it has been to him a matter of interest to preserve them unchanged, and it is not apparent that the principles involved are thereby rendered any less clear.

Returning to the case of our 20-kva transformer, we have seen on p. 100 that the reactance drop is 87,6 volts and the 
resistance drop 90,0 volts. In Fig. 66 (which is based on a diagram devised by Kapp $\left.{ }^{1}\right) A D$ and $D C$ are drawn to scale, and are respectively proportional to 87,6 and 90,0 . With $A$ as a centre, and a radius proportional to 5000 (the constant primary pressure), the arc $B_{0} B_{90}$ is drawn. Radiating from $C$ are drawn lines representing the phase of the secondary terminal pressure for various power factors. These lines intersect the are $B_{0} B_{90}$ at various points, $B_{0}, B_{10}, B_{20}$, etc., the subscripts denoting the angle by which the vector $C B_{0}$, representing the secondary current, lags behind the secondary terminal pressure. The lengths of the lines $C B_{0}, C B_{10}, C B_{20}$, etc., are proportional to the secondary terminal pressure for the case of an equivalent transformer with a $1: 1$ ratio of transformation. The actual secondary terminal pressures for these conditions of load, and for the constant primary pressure of 5000 volts, may be found by dividing these results by 25 , the ratio of transformation of the actual transformer. It is seen from the diagram that the regulation lies between 1,70 per cent. and 2,56 per cent. according to the power factor of the external circuit supplied by the secondary.

Kapp's Modified Diagram of Drop.-The graphical method of estimating the regulation at various power factors, as shown in Fig. 66, suffers from the disadrantage that in practice the distance representing the drop is generally very small in comparison with the radii of the circle, so that an accurate determination of the drop by a purely graphical method becomes impracticable. If, however, $A D$ and $D C$ (Fig. 66) are very sma!l compared with $C B_{10}, C B_{20}$, etce, then Kapp ${ }^{2}$ has shown that it becomes practicable to simplify the dingram, without introducing appreciable error.

He thus avoids the diffienlty above-mentioned. The method will be explained by reference to Figs. 66 and 67 . If in Fig. 66 a line is drawn joining $A$ and $B_{10}$, then this will be 
nearly parallel to $C B_{10}$, and if (as in Fig. 67) a perpendicular is dropped from $C$ intersecting $A B_{10}$ at $E_{10}$, then $A E_{10}$ will be equal very nearly to the actual drop at the power factor represented by the radius $C B_{10}$, i.e., at a power factor of 0,98 .

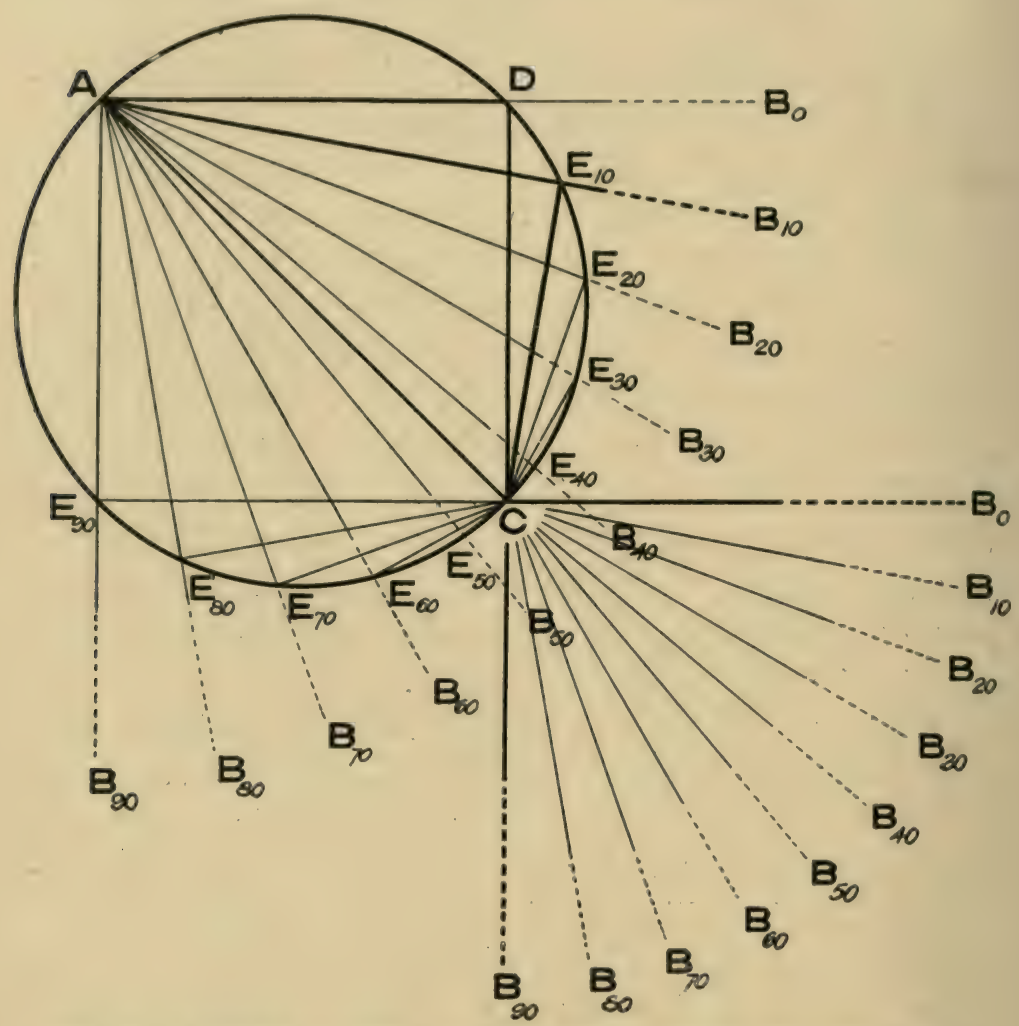

FIt. 67.-Modified regulation diagram of 20-kva 5000/200-volt single-phase transformer.

The diagram may thus be conveniently drawn to a large scale, as shown in Fig. 67, thereby eliminating to a large extent inaccuracy in drawing and scaling off the diagram. In Fig. 67 $A D$ represents the resistance drop and $D C$ the inductive drop. $A B_{10}$ is drawn parallel to $C B_{10}$, which makes an angle of lag of $10^{\circ}$ with $C B_{0}$. A line $C E_{10}$ is drawn perpendicular to $A B_{10}$. 
We thus obtain $A E_{10}$, which represents the drop. It will at once be obvious that the points $E_{10}, E_{20}$, etc., will lie upon the circumference of a circle whose diameter is equal to $A C$ (i.e., to the impedance drop), and whose centre lies midway between $A$ and $C$. The drop at various angles of lag will be represented by the chords $A E_{10}, A E_{20}$, etc., of this circle. Com-

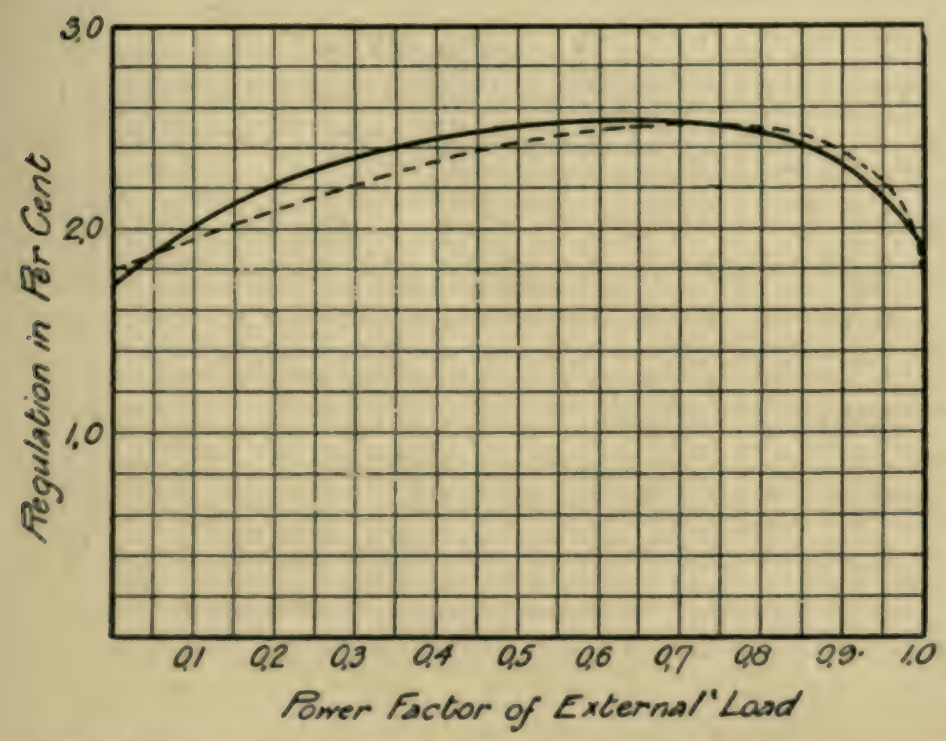

Fui. 6.8.--Regulation eurves of 20-kva sorx)/2(1)-vo't single-phase transformer.

paring this diagram with that in Fig. 66 it will be observed that the modified diagram is more inaccurate at high and low power factors of the external circuit, and that between power factors of 0,5 and 0,95 (for the particular example taken), the inaccuracy is very small. The results obtained respectively from Figs. 66 and 67 are compared in the curves in Fig. 68, the broken line curve representing the results obtained from Fig. 67 , and the full line curve the original results obtained by means of Fig. 66. The inaccuracy introduced by Fig. 67 will be smaller the smaller the resistance drop and the reactance drop are as compared with the terminal pressure. 


\section{Regulation of Transformers for Three-Wire Secondary Circuits}

The majority of core-type transformers used for lighting purposes have windings of the concentric type, i.e., the primary is wound over the secondary, or vice versâ, and primary and secondary each consist of long cylindrical coils. The simple concentric type (see Fig. 30 on p. 51) consists of two coils per leg, the primary usually being wound over the secondary; the triple-concentric type (see Fig. 31 on p. 51) consists of three coils per. leg. 'T'wo of these three coils may constitute the secondary, the primary coil being wound in between these two secondary coils. When using a transformer on a three-wire secondary circuit, it is necessary to provide two separate groups of secondary coils, each group of coils giving the same pressure. At first sight, the most obvious way of connecting a transformer of the core type to supply a three-wire secondary circuit would appear to be to utilise the secondary coils on one leg of the transformer for one side of the three-wire circuit, and the secondary coils on the other leg for the other side of the three-wire circuit. With these connections, equal pressures would be obtained from both secondaries provided they were equally loaded; but if the two secondaries are not equally loaded it is evident that the transformer will regulate badly, the pressure of the side on which the greater load exists being below normal, while the pressure of the lightly loaded side will rise above normal, the sum of the pressures on the two sides remaining constant, whatever the distribution of the load. That this must be the case may be explained as follows:-

Consider one side of the three-wire system to be unloaded and the other side to be fully loaded. If both the primary windings are connected in series, the same primary current must flow in all parts. One-half of the primary ampere turns will be on that leg of the transformer whose secondary is loaded, and the other half will be on the leg with the unloaded 
secondary. The first part of this chapter dealt with magnetic leakage, and it was shown that for close regulation the primary and secondary coils must be close together and intermixed. If, therefore, the pressure on one side of the three-wire system is provided by a secondary coil on one leg, and the pressure on the other side by a secondary coil on the other leg, and if only one of these coils be loaded, there will be a large leakage flux caused by the ampere turns of that part of the primary winding which is wound on that leg whose

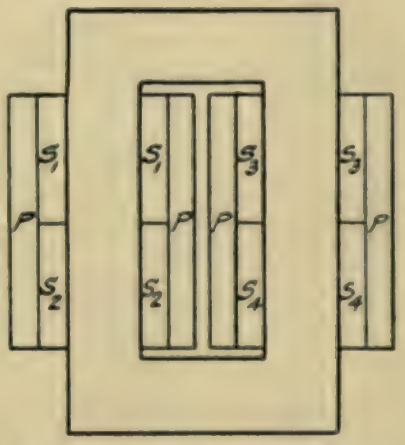

F16. 69,-Arrangement of coils in core-type transformer for three-wire secondary. secondary is unloaded. For full load 'on one side and no load on the other side of the three-wire system, this may easily result in $\mathrm{n}$ rise of as much as 25 per cent. in the pressure on the unloaded side, and a drop of 25 per cent. in the pressure on the loaded side, making the pressure across the nnloaded side greatly exceed that on the loaded side. This was first pointed out and investigated by $\mathrm{Mr}$. W. \$: Moody. The inequality in the mag-

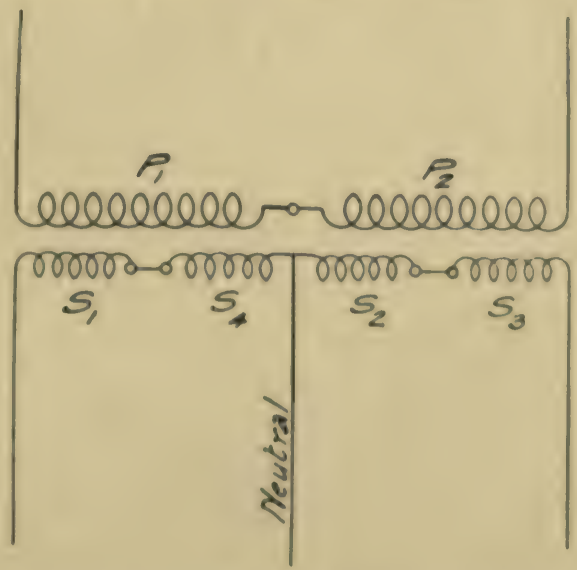

Fro. 70.-Arrangement of coils in core-type transfurmer for three-wire sccondary.

netic lenkage may be prevented by adopting connections (originally suggested by Mr. Moody) which distribute both halves of the secondary winding equally over the two legs. 


\section{THE DESIGN OF STATIC TRANSFORMERS}

This may be done by splitting the coil up as shown in Fig. 69 and connecting the primaries in series, the secondary coils $S_{1}$ and $S_{3}$ being connected in

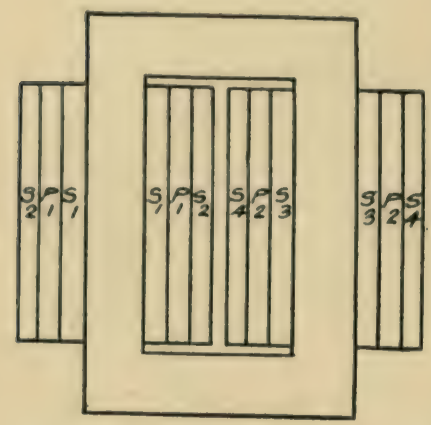

FiG. 71.-Arrangement of coils in core-type transformer for tbree-wire secondary. series for one side of the threewire system and $S_{2}$ and $S_{4}$ for the other side; or else $S_{1}$ and $S_{4}$ may (as indicated in Fig. 70) be connected in series for one side, and $S_{2}$ and $S_{9}$ for the other side.

Where the primary winding is interposed between two secondaries as shown in Fig. 71, it becomes practicable to remedy the unbalancing by connecting $S_{1}$ and $S_{4}$ in series on one side and $S_{2}$ and $S_{3}$ in series on the other side of the three-wire system, i.e., to connect the outside secondary coil on one leg, in series with the inside secondary on the other leg, as this tends to ensure the exact equality of resistance and reactance in the two halves. 


\section{CHAPTER VIII}

\section{THE HEATING OF TRANSEORMERS}

Althovgu the efficiencies of static transformers are generally high and the losses consequently small, nevertheless, owing to the absence of any ventilating effects from moving parts, the problem of limiting the temperature rise is one of considerable difficulty. The difficulties encountered are greater the greater the rated capacity of the transformer. In the early days when the demand for transformers was confined to small sizes, the problem of limiting the temperature rise would hardly have arisen except for the fact that the material employed for the magnetic circuit was at that time very poor and the losses in it were high. If the active material in a transformer only amounts to some two or three KILograms, the surface per kilogram of material will, with ordinary forms, be far greater than in a transformer containing two or three ToNs of active material; and consequently while in the former size it suftices that the transformer need simply be surrounded by air, and will be maintained cool by natural processes of heat emission, it becomes necessary in the latter case to resort to additional means, such as immersing the transformer in a tank of oil and abstracting the heat from the oil and its contents by the circulation of water through pipes immersed in the oil.

In Fig. 72 is shown a design for an air-cooled transformer in which the emission of heat from the active material is very sppreciably increased by the various ways in which additional surface is provided. The windings are sub-divided into a number of small coils, and cooling ribs of sheet copper about $0,5 \mathrm{~mm}$. thick are arranged between adjacent coils. It will be seen that the core is also of such a shape as to have a large s.T. 


\section{THE DESIGN OF STATIC TRANSFORMERS}
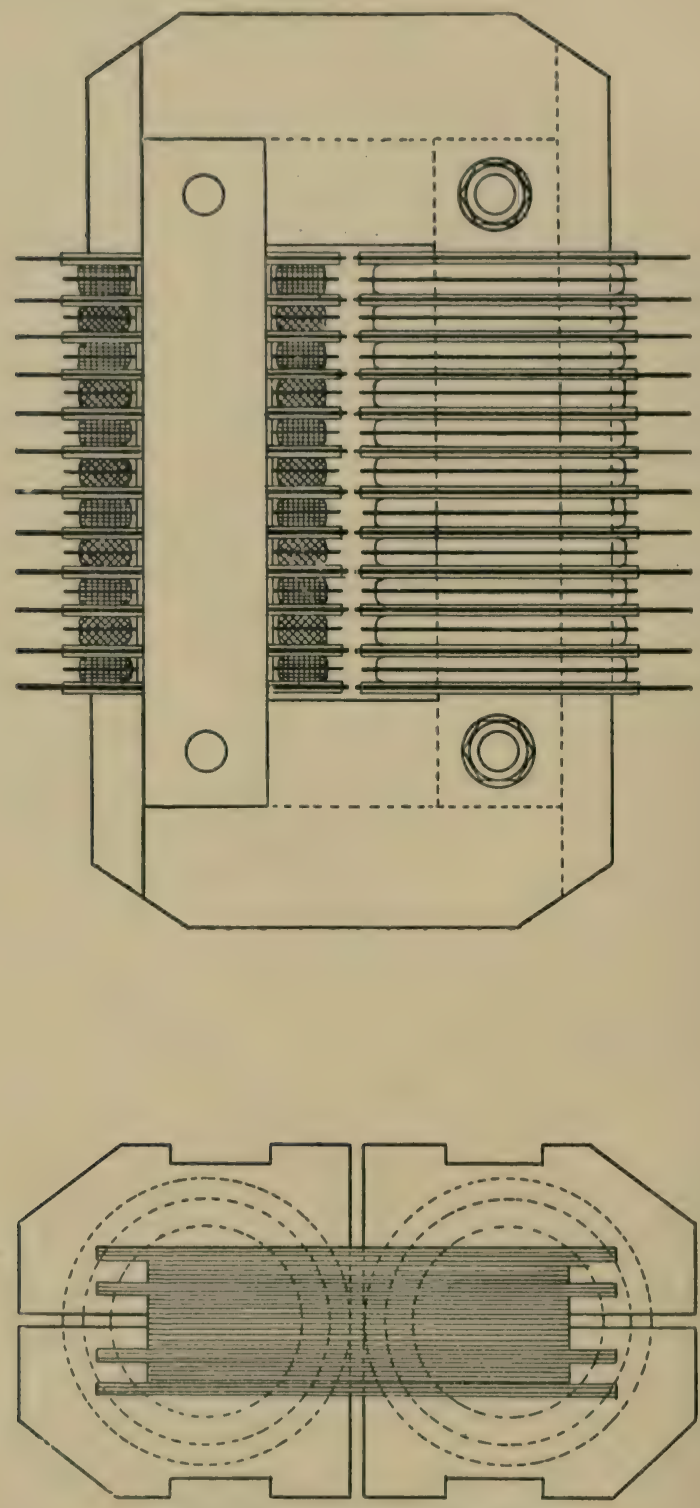

FIG. 72.-Air-cooled transformer. 
cooling surface. Some tests are reported to have been made on a 5,5-kw transformer of this type in comparison with an ordinary transformer of the same size. The transformers were operated for a sufficient length of time to obtain the ultimate temperature rise. In the transformer without the ribs this occurred after eight or nine hours, and in a somewhat shorter time in the ribbed transformer. It is stated that it was found that the construction permitted of rating the transformer at twice as great a load as could, for the same temperature rise, be obtained by the ordinary construction, and that for a given total loss the temperature rise of both copper and iron is halved by the use of the ribbed construction. It is further claimed that a more uniform temperature was secured throughout all parts of the transformer. It is stated that no appreciable eddy loss occurred in the ribs, and that the efficiency of the $5,5 \cdot \mathrm{kw}$ transformer was about 94,4 per cent.

\section{Oth-Immersed Transformers}

The natural circulation of air affords insufficient means of dissipating the heat from other than very small transformers, and the simplest alternative consists in immersing the transformer in a tank of oil. If the case is filled with oil and if suitable attention is given to providing for a free natural circulation of oil through all portions of the transformer, then the ultimate temperature rise of an oil-immersed transformer will be proportional to the watts total loss in the active material of the transformer per square decimeter of external radiating surface of the case. Oil-immersed transformers were employed in England at an early date, but soon came into disrepute owing, in my opinion, to a failure to understand the requirements of a design of this kind and to the use of poor grades of oil. Suitable transformer oil is expensive, but the use of the best qualities should be rigorously insisted upon, and, furthermore, the greatest of care should be exercised in 


\section{THE DESIGN OF STATIC TRANSFORMERS}

keeping the oil clean, and free from impurities or moisture. Many insulating materials which ean be employed with great advantage in air-immersed transformers must not be used in oil-immersed transformers, as not only will the oil destroy their good properties, but the presence of these insulating materials will destroy the good properties of the oil. 'That

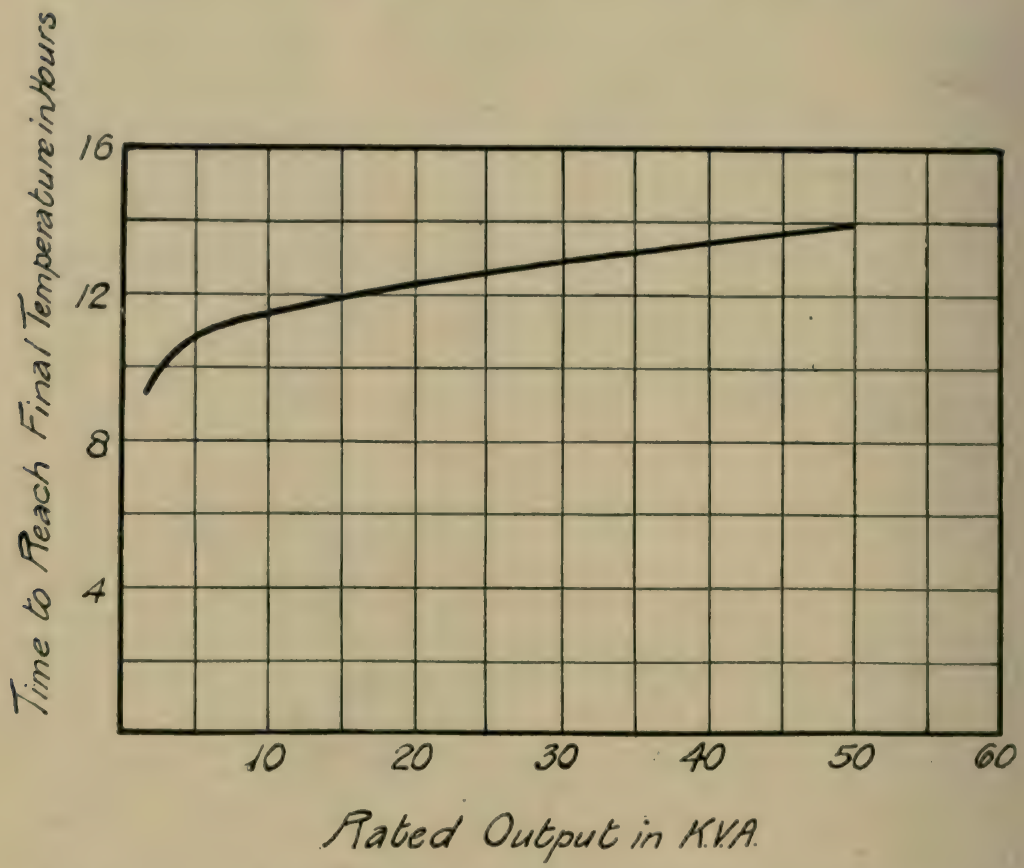

FIG. 73.-Curve showing the time taken for transformers of various outputs to reach final temperature at full load.

there can still exist prejudices against the oil-immersed type of transformer is very remarkable, and such a state of affairs is not likely to long continue. Some ten years ago these same strong prejudices existed in certain large electrical manufacturing firms in Germany, but they have long since been overcome, and the appropriateness of the oil-immersed type for a wide range of work is now almost universally admitted. 
In some investigations of transformer troubles in Germany I once found an instance where the oil was kept in wooden barrels in the open air, and in rainy weather pools of water collected on the heads of the barrels and gradually worked through into the oil. Under any such conditions, of course, the use of oil is fatal, but with reasonable intelligence, great advantages, chiefly as regards cooling, attend the use of oil in transformers

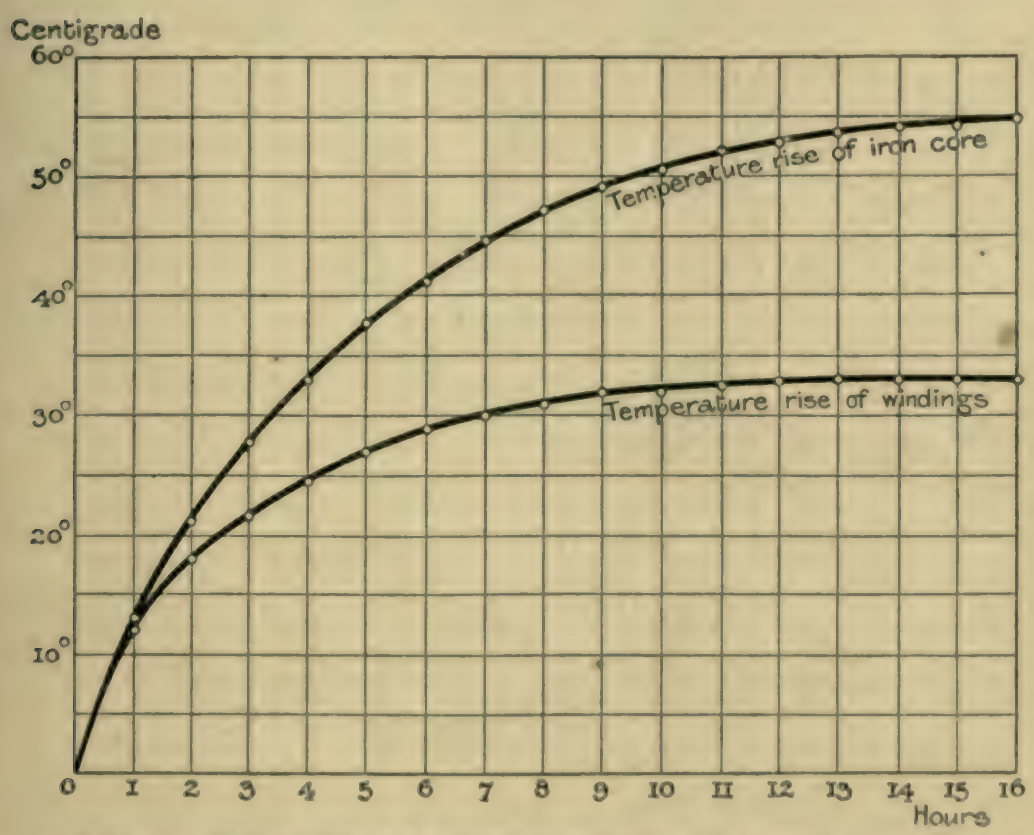

Fir: 74.-Heating curves of $7,5-\mathrm{kw}$ Felton-Guillaume-Lahmeyer trunsformer.

The curve in Fig. 73 gives a rough idea of the time which will elapse for a 50-cycle oil-immersed trunsformer of representative design to reach its ultimate temperature when operated at its rated load. Great variations exist, however, with variations in the proportions and construction of the transformer. Very large transformers require many hours to attain their ultimate temperature. Thus the temperature of an oil-immersed transformer of $200-\mathrm{kw}$. capacity ma continue 


\section{THE DESIGN OF STATIC TRANSFORMERS}

to rise for well on toward twenty-four hours. In Vol. 38 of the Journal of the Institution of Electrical Engineers, Prof. Epstein publishes the curves of temperature rise reproduced in Figs. 74 and 76 , and relating to transformers manufactured by the Felton-Guillaume-Lahmeyer Company. The curves

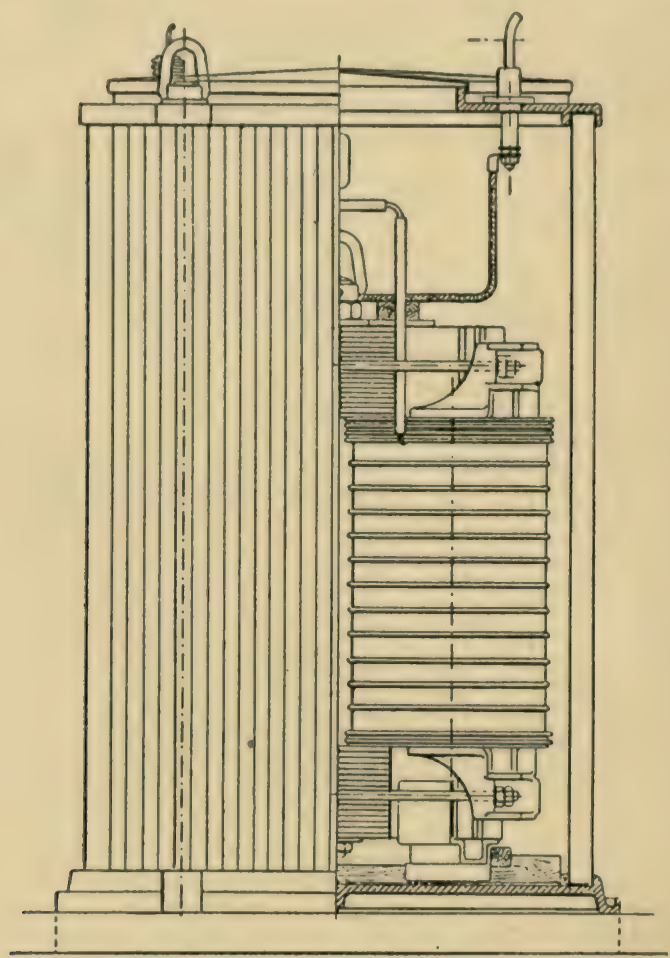

FIG. 75.-40 000-volt oil-immersed transformer.

in Fig. 74 relate to a $7,5-\mathrm{kw}$ transformer, and it will be seen that even at the end of sixteen hours the curves of temperature rise of the core and the windings have only just become flat. 'The curves of Fig. 76 relate to the temperature rise of the 40 000-volt oil-immersed transformer illustrated in Fig. 75. Prof. Epstein stated that he had found that " in all his firm's transformers of the same design, from 3 up to $100 \mathrm{kw}$, the 
temperature became stationary after a run of about sixteen hours, and the temperature rise after a six-hour run was, for all of them, some 80 per cent. of its final value for the copper and 66 per cent. for the iron." As regards the oil transformer illustrated in Fig. 75, and to which the curves of Fig. 76 apply, Prof. Epstein stated: "'The lower parts do not heat at all at the beginning of the test. The lower the thermometer is placed the greater the difference between the temperature

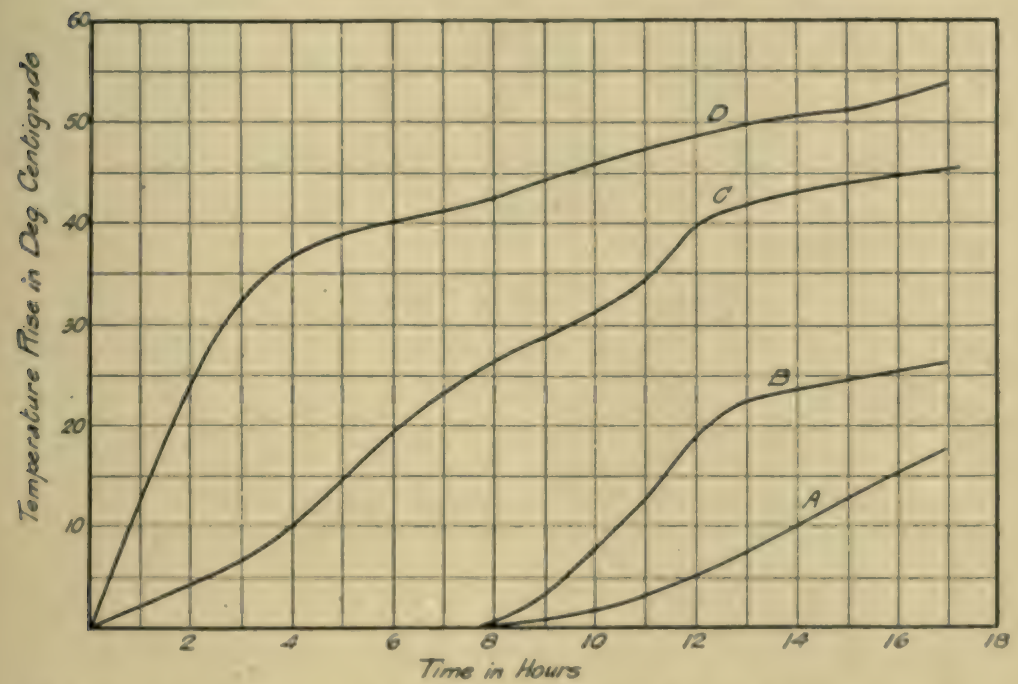

Fr: 76. - Heating curves of oil transformer. (Sie Fig. 77 , for key to positions of thermometers for curves $\mathbf{A}, \mathrm{B}, \mathrm{C}$, and D.)

rise obtained after a few hours' run and the stationary value." The diagram in Fig. 77 indicates the positions of the thermometers corresponding to the four curves in Fig. 76. Prof. Epstein explained the singular shape of the curves of Fig. 76 as follows :-

"As the transformer becomes heated, the warmed oil rises to the surface and consequently the upper thermometer $I$ ) will indicate the rise in temperature first, while the lower ones will not be affected at the beginning of the test, as there is no 
convection of heat in a horizontal direction. It takes practically about five hours before the volume of oil at $G$ is heated up. Immediately after this stage is reached, heated oil begins to fill up the space $H$, which process takes another three hours, and during this time the rate of rise of temperature proceeds more rapidly, owing to the narrower space. As I have already pointed out, the question of the rate of temperature rise has nothing to do with the size of the apparatus-it is

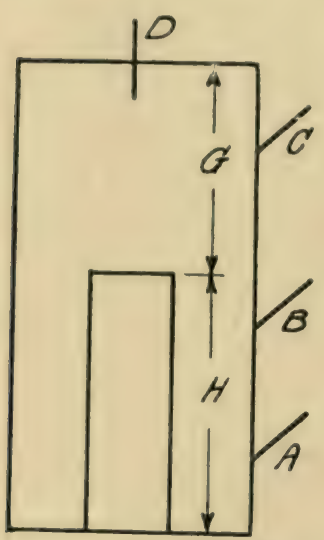

FIG. 77.-Diagram show. ing positions of thermometers for the heating curves shown in Fig. 76. merely a question of the ratio of two effects, viz., the ratio of the coolingsurface to the heat capacity of the whole volume. The case of the oiltransformer experiment is somewhat complicated by the motion of the oil."

Prior to Prof. Epstein's explanation of the curves of Fig. 76 (which occurred in his reply to the discussion on his paper), Mr. J. S. Peck had offered the following comments :-

"I have made a large number of tests of oil transformers, but I have never before seen an accurate curve which had a hump in it at the end of four hours. The temperature curve should be a perfectly smooth one. It is well known that wide differences in temperature are obtained at different oil levels, as shown in the curve, but it seems remarkable to me that the oil at the bottom of the case should remain cold for so long a time."

The temperature rise of a transformer when arranged in a case containing air will be very much greater than the temperature rise of the same transformer when contained in the same case filled with oil. Instances of this for two transformers of $5 \mathrm{kva}$ and $50 \mathrm{kva}$ rated capacity respectively are given in the curves in Figs. 78 and 79. 


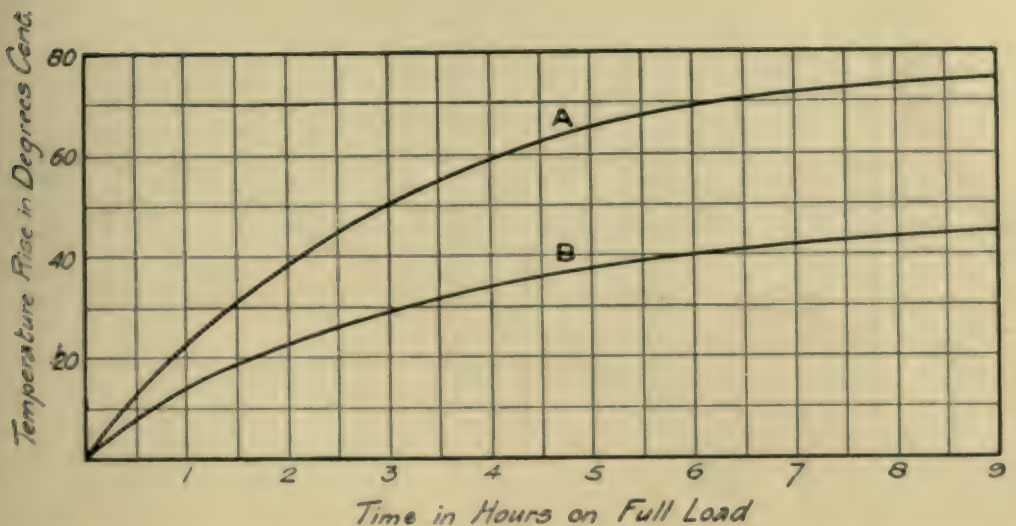

FiG. 78.--Heating curves for 5-kva transformer in air and vil. Curve $A$ in case without oil ; Curve B in case with oil.

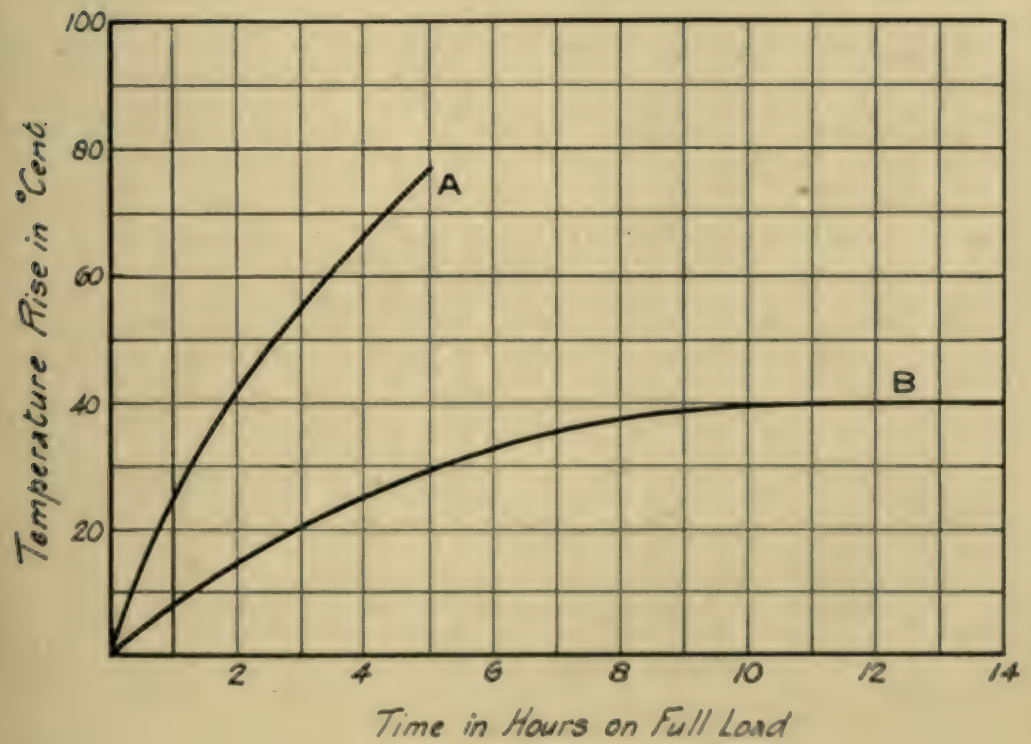

Curve A = In Air

$\mathrm{B}=\operatorname{In} \mathrm{O}_{11}$

Fus. 79. - Heating curves for iol-kra transfurmer in air and in wil. 


\section{THE DESIGN OF STATIC TRANSFORMERS}

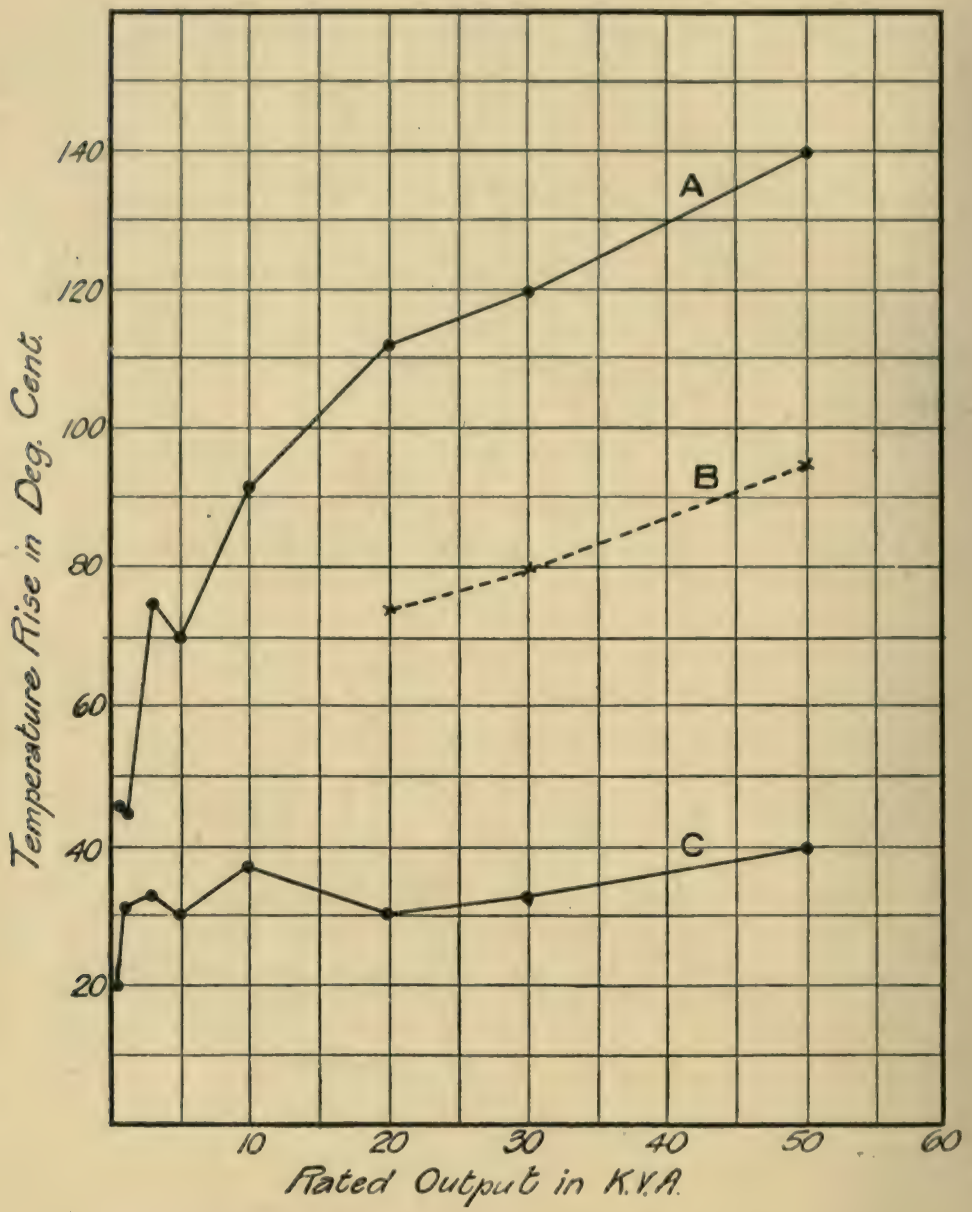

Curve $\mathbf{A}=$ Final Temperature Rise in Air

$\mathbf{B}=$ Temperature Aise afüer 8 Hours in hir $\mathbf{C}=$ Final Temperabure Tise in Oil

FIG. 80.-Curves showing temperature rise of transformers in air and in oil.

In Fig. 80 are given curves showing the final temperature rise in air, the rise after eight hours in air and the rise in oil, for a line of oil-immersed transformers comprising 
ratings of from 1 to $50 \mathrm{kva}$. The temperatures plotted in the curves are those of the windings as determined by measuring the resistances before and after the tests. In the instances of the 20-, 30-, and 50-kva transformers, when run in air, the figures for the ultimate temperature rise (curve $A$ ) are not based on actual observations, but are inferred from the results of the eight-hour tests (curve $B$ ), since the ultimate temperatures would have been so high as to injure the insulation. The curves show that the difference in temperature for air and oil operation is greater for the large than for

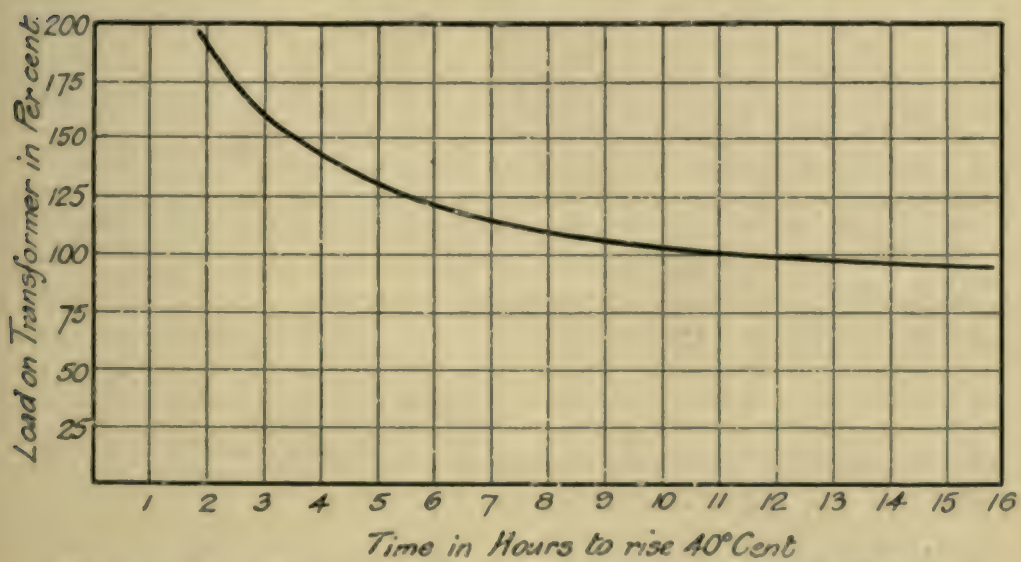

Fia. 81.--Curve showing time fur a0-kva transformer to reach $40^{\circ} \mathrm{C}$. at various loads.

the small transformers. The curve in Fig. 81 , which relates to a 50-kva oil-immersed transformer, shows the number of hours during which the transformer can carry various loads without sustaining a temperature rise of more than $40^{\circ}$ above the temperature of the room. The curve shows that the transformer can carry double its rated load for nearly two hours without sustaining a temperature rise of more than $40^{5}$ if, at the commencement of that time, its temperature is that of the room in which it is installed. The standard practice of most transformer manufacturers is to guarantee that at rated load the temperature rise at the end of 


\section{THE DESIGN OF STATIC TRANSFORMERS}

eight hours, as determined in the hottest part of the oil, shall not be more than some $40^{\circ}$ to $45^{\circ}$ above the temperature of the room. It would be much better to stipulate that the ultimate temperature rise as thus determined should not be more than $50^{\circ}$ (or preferably $45^{\circ}$ ) above room temperature.

The Engineering Standards Committee's Report No. 36 of August, 1907, contains (on pp. 13 and 14) the following clauses dealing with the temperature rise of transformers:-

"(VII.) For alternating-current transformers, whether oil-cooled or otherwise, in which cotton, paper and its preparations, linen, micanite, or similar insulating materials are employed, $80^{\circ} \mathrm{C}$. shall be the highest mean temperature permissible.

"(virr.) They shall be run on load for a period sufficiently long to enable the transformer to attain such a temperature that the increase of temperature does not exceed $1^{\circ} \mathrm{C}$. per hour. Under these conditions the observed temperature rise at the hottest part, as determined in Clause (x.), shall not exceed $50^{\circ} \mathrm{C}$., based on the assumption that the air temperature of the room in which the transformer is to be used in actual service will not exceed $25^{\circ} \mathrm{O}$.

"(Ix.) If the air temperature of the room in which the transformer is to be used in actual service may exceed $25^{\circ} \mathrm{C}$., then the temperature rise specified above is to be decreased by one degree for each degree of difference between the room-temperature possible and $25^{\circ} \mathrm{C}$.

"(x.) In the case of air-cooled transformers the temperature shall be ascertained by rise in electrical resistance.

"(xI.) In the case of oil-cooled transformers the temperature shall be ascertained by rise in electrical resistance, in addition to which the temperature at the surface of the oil shall be ascertained by means of a thermometer, and should the temperature obtained by the two methods differ, the lower figure shall be discarded."

The following clause in the Standardisation Rules of the American Institute of Electrical Engineers relates to the permissible temperature rise of transformers for intermittent service, and consequently to most transformers supplying lighting loads:-

"In the case of transformers intended for intermittent service, or not operating continuously at full load, but continuously in circuit, as in the ordinary case of lighting transformers, the temperature elevation above the surrounding air temperature should not exceed $50^{\circ} \mathrm{C}$. by resistance in electric circuits, and $40^{\circ} \mathrm{C}$. by thermometer in other parts 
after the periorl corresponding to the term of full load. In this instance the test load should not be applied until the transformer has been in circuit for a sufficient time to attain the temperature-elevation due to core loss. With transformers for commercial lighting, the duration of the full-load test may be taken as three hours, unless otherwise specified."

If it is definitely known that a transformer, while in circuit continuously, will only be loaded for short periods and that these periods will be followed by considerable interrals of no load or of only small loads, then obviously it is not appropriate to provide a transformer capable of dealing with the maximum load for the entire twenty-four hours. On the contrary, the best results will be obtained by employing a transformer which will perform the required sertice without ever exceeding a reasonable temperature-rise, say $40^{\circ}$. But commendable efforts to provide the most suitable transformer should not be confused with the inclination of some manufacturers of basing their designs on the assumption that their transformers will, in a very large percentage of instances, never be called upon to earry the rated load for periods of more than a very few hours each. 'These firms may designate as of $20 \mathrm{kw}$ rated capacity a transformer which will be decidedly smaller than another firm's standard-rated transformer and consequently having a very much smaller core-loss, and in the few instances in which there are complaints, these firms are well able to afford to replace their misleadingly-rated transformer by a very liberal transformer. It is not for the manufacturer, but for the purchaser or his adviser to decide whether a certain transformer will suffice for some particular conditions of service. When the manufacturer represents his transformer as being of $20 \mathrm{kw}$ capacity he is undertaking (unless it is otherwise expressly specified) that the transformer will carry $20 \mathrm{kw}$ contimuously without exceeding a temperature rise of $40^{\circ}$ or $45^{\circ}$ (according to the stipulation) above the room temperature. The purchaser may analyse the conditions and satisfy himself that according to the amount and duration of the peak load, a 
$15-\mathrm{kw}$ or even a $12-\mathrm{kw}$ transformer will suffice for his particular purpose, but this is not within the province of the manufacturer.

Thus I strongly condemn such advice as that proferred by the engineer of a well-known transformer-manufacturing company in the following paragraph :-

"Perhaps the better course for an engineer to adopt is that of leaving the matter of temperature limits to be filled in by the individual manufacturers, who are specialists, and have their reputation at stake when tendering. To arbitrarily fix some apparently low figure, when in reality nothing standard for comparison exists, is to cause those manufacturers who declare their maximum temperature to put up prices in order to go under what to them must appear a ridiculous limit.

"For transformers working without cases under climatic conditions such as those existing, for instance, in many a London sub-station, the writer is of opinion that better and safer running may result by permitting transformer coils to assume a degree of warmth such as to obviate any risk of break-down that might result from the depositing of moisture on the surface of the coils.

"The rise in temperature of the iron core of a transformer should, however, be kept well under $80^{\circ} \mathrm{C}$. if any appreciable mechanical restraint is imposed upon it, as ageing may occur if the temperature of highly annealed iron remains at $80^{\circ} \mathrm{C}$. for long periods, and at the same time is subject to mechanical stresses.

"There appears to be a very considerable difference of opinion as to what temperature may be permitted in a transformer. To begin with, this limit of temperature should depend upon the class of insulation employed. With oil-varnishes, and insulations that oxidise, the limit is necessarily a low one, and wherever oil is employed, the temperature should be kept down to the lowest possible limits. The writer has run transformers of his own design at temperatures as high as $150^{\circ} \mathrm{C}$. for con- 
siderable periods together without any apparent deterioration, and yet transformer experts in America and Germany have found that even so low a temperature as $70^{\circ} \mathrm{C}$. rise is detrimental to certain oil-varnish insulations. Mica and compound irsulations with mica as a basis are very often capable of resisting far higher temperatures than those specified."

As opposed to the above leaning toward permitting high temperatures I would recommend to the reader's attention the following leading article from the Electrical Reriew of August 18th, 1905 (Vol. 57, p. 246). I am of opinion that, nowithstanding the five years which have elapsed since it was written, the article is exceedingly appropriate to the present transformer situation.

"The Effect of Temperature on Insulating Materials: The Fngineering Standards Committee recently issued Report No. 22 entitled, 'Report on the Effect of Temperature on Insulating Materials.' The report consists of three sections. The first section comprises the investigations carried out by Mr. E. H. Rayner, which, as an institution paper (Proceedings, Institution of Electrical Engineers, Vol. 34, p. 613, March 9th, 1905), has already received consideration in the columns of the Electrical Review. In the second and the third sections are given the results of tests of insulating materials employed in the manufacture of dynamo-electric machinery at the works of Messis. Crompton \& Co., Ltd., and of Messis. Siemens Bros. \& Co., respectively. These last two sections contain a mass of useful results set forth in a series of carefully-prepared tables. In spite of the fact that statements as to the conditions of test are exceedingly meagre, the results are very interesting.

" Pending the publication of results of really exhaustive practical tests, made with a full appreciation of the nature and scope which should obtain in such investigations, it is believed that the data published in this report will be widely consulted, and with advantage to the industry. It is, however remarkable that at so adranced a stage in the development 


\section{THE DESIGN OF STATIC TRANSFORMERS}

of dynamo-electric machinery, there is still so little appreciation of the necessity for taking many details into account, if tests on insulating materials are to be of thorough value.

"The samples of insulating materials were exposed to various temperatures for from nine to twelve months, and both reports are in agreement in recording that none of the materials were suitable for withstanding a temperature of $125 \mathrm{C}$. for this length of time. Even abestos and micanite suffered at this temperature, the latter in consequence of the charring of the material with which the component scales of the mica were cemented together.

"This experience with high temperatures further demonstrates the wisdom of not at present exceeding the customary temperature standards. If a thermometrically-determined temperature increase of $40^{\circ} \mathrm{C}$. is permitted, this will frequently mean an ultimate temperature of $70^{\circ} \mathrm{C}$. as thermometrically determined, and of fully $100^{\circ} \mathrm{C}$. as determined from resistance measurements. Still higher actual temperatures will occur at inaccessible parts of the machine, notably in those portions of the field coils most remote from any duct or surface. Hence, permitting a thermometric rise of even $40^{\circ} \mathrm{C}$. above the surrounding temperature, brings us nearly to the ultimate temperature where the tests of Messrs. Crompton \& Co, and of Messrs. Siemens Bros. indicate that there are few, if any, otherwise-suitable materials which do not deteriorate considerably in a year or so. It is to be hoped that progress in the production of suitable insulating materials will be stimulated by the report of the Engineering Standards Committee, as materials which will permit of higher temperatures will be of great value to designers and manufacturers. The present, however, is no time for increasing the standard temperature rise. Even when apparently-suitable materials are on the market, a few years must elapse before their suitability can be demonstrated in actual practice.

"It required several years of actual service to demonstrate that the insulating materials formerly employed in railway 
motors ultimately pulverised as the result of exposure to the combined effect of vibration and high temperature. Even at present there are plenty of manufacturers who are choosing their insulating materials more with reference to price per yard, per pound, or per gallon, as the case may be, than to whether the apparatus in which it will be employed will be subject to heat, moisture, or vibration, or to other deteriorating influences. Most electrical manufacturers are, however, desirous of employing sound materials and of keeping within as conservative temperature limits as the competitive struggle will permit.

"Raising the standard temperature-limit would simply result in a general lowering of the price per horse-power or per kilowatt. Competition would keep the manufacturer's profits as low as ever, and even the customer would not benefit, since his motors and dynamos would be subject to a greater rate of depreciation. Such a result would tend to bring discredit upon the electrical industry.

"The temperature limit should be raised by small amounts from year to year, keeping pace with the gradual progress made in the development of improved insulating materials. It will not suffice to produce one or two insulating materials capable of also withstanding a high temperature, for the requirements of the manufucturer of dynamo-electric machinery are only met by the employment of many different insulating materials." I

1 As further bearing upon this important subject of combating the tenclency to permit higher temperatures, I propose to quote Mr. E. (i. Reed. who, in an important paper on Transformers. read at the 32mi Annual convention of the National Electric Light Association, in June, 1909, puts the ease as follows :-

"Transformers operating at a temperature of 100 ilegrees centigrade will probably soxon fail, and assuming an average tompurature of the air of 25. ilegrees Centigrale, this limits the maximum permissible temperature rise of the transformer to less than 75 degrees Centigrade. Allowing a margin of, say, 10 to 15 clegrees Centigrale, gives a safe uperating temperature-rise of from 6.) to 6is degrees Centigrale. This refers to the temperature rise of the wintings and not to that of the surroumling oil, which whiously must to cosler. In gowal commereial transformers, depremeling on the size and on the croling efliciency of the oil-tucts through the wimlings, the temprerature of the windings is from is to 15 degrees above that of the last wil in the upper part of

8.T. 


\section{Relation between Temperature Rise and Output}

Although it is practicable to increase the rating of a transformer, provided a higher temperature rise is allowable, and although this is often done in practice, it is not to be recommended. Not only is the regulation rendered worse, but the insulation is liable to deteriorate if subjected to high temperature. The rating of a transformer designed for a temperature rise of $40^{\circ} \mathrm{C}$. may usually be increased some 15 per cent. for a temperature rise of $50^{\circ} \mathrm{C}$., and some 40 per cent. for a $60^{\circ} \mathrm{C}$. rise. The price of a transformer designed for a higher rating and temperature rise, but with the same amount of material, would be substantially the same as for the lower rating and temperature rise. A transformer of a given rating and with high temperature rise may, however, be built cheaper than one of equal rating, but with normal temperature rise. A comparison of two transformers built by a certain large manufacturing firm is given in Table 13, and bears on this point.

Table 13.-Comparisons of Cost of High and Low TemperatureRISE Transformers.

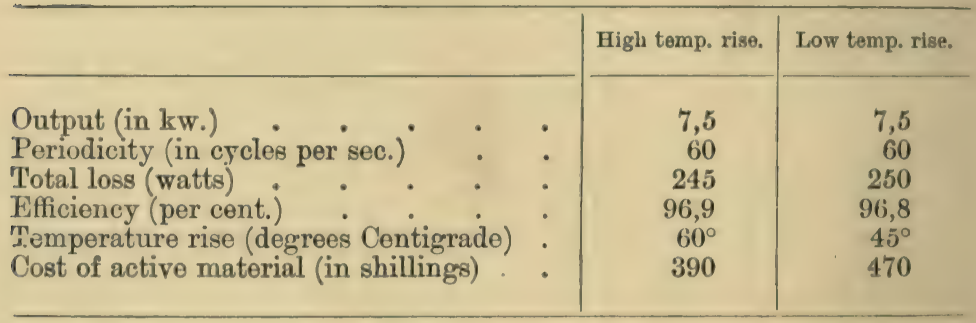

the case. The temperature guarantee of standard distributing transformers is 50 degrees Centigrade rise of the windings after continuous operation at normal load. If this guarantee were based on oil temperatures, rather than on that of the windings, a guarantee of approximately 40 degrees Centigrarle could be made instead of 50 degrees Centigrade. In determining the permissible load at which commercial transformers can be operated for a given time, and the permissible time for a given loal, this maximum operating temperature must not be exceeded." 


\section{Estmation of the Temperature Rise.}

In estimating the temperature rise in oil transformers, a leading factor relates to the capacity of the case for emitting heat from its outer surface. The temperature rise may be estimated from the basis of the loss per unit of external radiating surface of the transformer case. Thus we require to know the rate of generation of heat in the transformer per square decimeter of external radiating surface of the case. This is equal to the total of the watts lost in the transformer divided by the total external radiating surface of the case. The quotient bears a well-defined relation to the temperature rise, the two quantities being proportional.

The specific temperature rise is defined as the temperature rise in degrees centigrade per watt per square decimeter of external surface of the case, and since this quantity has a fairly uniform value, the permissible value of the watts per square decimeter as defined above depends on the specified temperature. For example, if a certain transformer has a temperature rise of $40^{\circ} \mathrm{C}$, and if the losses amount to 4 watts per $\mathrm{sq} \mathrm{dm}$ of external surface of the case, the specific temperature rise is equal to $\left(\frac{40}{4}=\right) 10^{\circ}$ per watt per sq dm.

The following data afford a rough basis for estimating the temperature rise of oil-immersed transformers :-

A. With iron cases with a smooth external surface, the specific temperature rise may be taken as $10^{\circ}$ per watt per $\mathrm{sq} \mathrm{dm}$ of external surface of the case. Hence, for $40^{\circ} \mathrm{C}$. ultimate rise the internal losses may amount to 4 watts per $8 q \mathrm{dm}$ of external surface.

B. With ribbed iron eases, where the radiating surface obtained by the addition of the ribs amounts to at least twice the surface of the case without the ribs, the radiating eapacity may be taken as increased by 50 per cent., and the temperature rise will be some 6 to 7 per watt per sq dm of exterunl 


\section{THE DESIGN OF STATIC TRANSFORMERS}

surface of the case, not including in this expression the increased surface provided by the ribs.

The temperature rise is in all cases estimated from the total watts loss in the transformer divided by the total external smooth surface of the case, this surface of reference being the cylindrical surface at the root of the ribs. The temperature rise is taken as the rise above the temperature of the surrounding air when indicated by a thermometer placed in the oil at the hottest part, which is usually near the top of the core of the transformer.

These constants (i.e., for cases $\mathrm{A}$ and B) relate to the ultimate temperature rise for continuous running when the transformer has attained a steady temperature. The time taken for medium-sized oil-immersed transformers to attain a steady temperature is generally at least 10 hours. After six hours the temperature-rise in such transformers is often of the order of seven-tenths of the ultimate rise. Hence, if transformers are required to be designed for $40^{\circ}$ rise after six hours' run (and not $40^{\circ}$ ultimate temperature rise), the value of the watts per $\mathrm{sq} d \mathrm{~m}$ may be some 1,4 times the values given above. 'Thus, for guarantees of $40^{\circ}$ rise after six hours, smooth-case transformers may be proportioned for some 5 to 6 watts per sq dm. But it is best to keep the value down, since estimates of temperature rise are, at the best, only very rough. An air-cooled transformer has generally only some two-thirds of the heat-emitting capacity of the same transformer in the same case, but immersed in oil.

The extent to which the heat-emitting capacity is increased by the addition of ribs on the exterior of the case is fairly represented by the statement $B$ above. The total external cooling surface may be increased to far more than twice the smooth surface of the case by the addition of very deep and numerous ribs. The cooling capacity is not, however, increased nearly in proportion, for the ends of the ribs are so removed from the surface of the case as to be much less effective. Consequently 
little gain will be marle by employing ribs of such dimensions as increase the surface by much more than two or three times, and for such proportions the above data will hold fairly true. In the early days of oil-immersed transformers it was sometimes the practice to provide ribs both inside and outside of the case, but the ribs inside are of relatively little use for the reason that the heat is transferred from the oil to the case much more readily than it can be transferred from the case to the surrounding air.

The heating data set forth in the preceding paragraphs is presented in orderly form in Table 14.

Table 14.-Coxstaxts for the Estimation of the Heatixg of Transformers.

\begin{tabular}{|c|c|c|c|c|}
\hline & \multicolumn{2}{|c|}{ Air Immersed. } & \multicolumn{2}{|c|}{ Oil Immersed. } \\
\hline & Smooth. & Ribbed. & Smooth. & Ribbed. \\
\hline $\begin{array}{l}\text { Ultimate temperature rise in } \\
\text { degrees per watt per sq dm. } \\
\text { Watts per sq dm per } 1^{\circ} \text { rise } \\
\text { Watts per sq dm for } 40^{\circ} \text { ulti- } \\
\text { mate rise } \\
\text { Watts per sq dm for } 40^{\circ} \text { rise } \\
\text { after } 6 \text { hours }\end{array}$ & $\begin{array}{l}15^{\circ} \mathrm{C} \\
0,067 \\
2,7 \\
3,8\end{array}$ & $\begin{array}{l}12{ }^{\circ} \mathrm{C} \\
0,084 \\
3,3\end{array}$ & $\begin{array}{c}10^{\circ} \mathrm{C} \\
0,10 \\
4 \\
5,7\end{array}$ & $\begin{array}{l}6,7^{\circ} \mathrm{C} . \\
0,15 \\
6 \\
8,5\end{array}$ \\
\hline
\end{tabular}

\section{Methods of Measuming 'Temperatures}

The guarantees given by manufacturers for the temperature rise of their transformers must be taken with caution unless the method of determining the temperature rise is clearly stated. That considerable precision of statement is necessary when framing temperature guarantees will appear from the following considerations :-

In the first case there may often be a difference of tem. pernture of some $6^{\circ}$ to $12^{\circ}$ or more, between mensurements of the resistances of the windings and measurements by thermometers placed in the hottest accessible part of the oil. This difference is, of course, readily accounted for. Also the ratio of the maximum temperature of the oil in an 


\section{THE DESIGN OF STATIC TRANSFORMERS}

oil-cooled transformer to the average external temperature of the case may be very high, especially in some designs employing large amounts of oil for cooling purposes. The ratio varies in commercial transformers from 1,4 when the circulation is good, up to 2,0 on transformers with bad circulation. The ideal figure for this ratio would obviously be unity. A difference of temperature will be observed between readings of thermometers placed on the outside of the case and of thermometers placed in a corresponding position inside the case.

'The temperature rise is generally specified as the average from the primary and secondary windings when taken by the resistance method, and as the maximum thermometricallydetermined temperature of the oil. This is generally found to be at a point just above the top of the core.

Contrary to the generally-accepted view that the results obtained by the resistance method of measurement of the temperature of the windings are higher than those obtained by thermometric measurements, the reverse may be the case in transformers employing large amounts of oil. There is usually a very considerable difference in temperature between the oil at the top and at the bottom of the tank in oil. immersed transformers of very large capacities, and this difference depends upon the size and shape of the actual transformer in relation to the size and shape of the case within which it is placed. When the temperature-rise of the coils is measured by thermometers, the measurements relate to the hottest part of the windings, since that part of the windings which is nearest the surface of the oil is usually the part in which the thermometers are placed. It may consequently be safely assumed that if the temperature of this part of the windings is within the guaranteed limits, the temperatures of all other parts will also be within these limits. In large oil-cooled transformers, more especially when they are placed in very deep cases, it is often found that the temperature-rise of the windings, when calculated by the observed 
increase of resistance, is less than that obtained by thermometric measurements. This is because the average temperature of the windings is less than that of their upper portion. 'Thus thermometric measurements may sometimes afford a more correct indication of the maximum temperature in any part of the winding than measurements based on the increase of resistance of the windings. However, the small depth of oil in small-sized oil-immersed transformers is rarely sufficient to occasion this result, and in small sizes the resistance method will usually give a more correct indication of the maximum temperature. An objection to the resistance method of determining the temperature arises in the case of transformers where the windings are divided into sections which are connected in series. In such a case the temperature calculated by resistance measurements is the mean temperature of all the coils, and therefore does not afford reliable indication as regards the temperatures of individual coils, some of which may be operating at temperatures much higher than the mean temperature.

Comparison of various types of transformer's as regards heating. -While either the shell or the core type of transformer may be so designed as to conform to any reasonable specification with respect to temperature rise, I nevertheless consider that the shell type is distinctly inferior to the core type as regards adaptability to oil immersion. In either type, ducts through which the oil shall circulate may be readily provided, but there would appear to be no such natural arrangement possible for the shell type as that of which our 20-kva transformers of Figs. 49, 50, 51, 53, 54 and 55, are typical examples. Both coils and core are well bathed with the circulating oil. In the shell type the coils are less readily cooled than the core unless valuable space be sacrificed in the winding window. The circular-shell type represented diagrammatically in Figs. 3 and 4 is still more greatly inferior as regards the difficulty of cooling the copper, and it is significant that it is the exploiters of the circular-shell type who have displayed the greatest 
concern and eagerness that the permissible temperature rise should be inciensed above that at present generally accepted.

But in very small transformers (i.e., transformers from, say, $2 \mathrm{kw}$ rated capacity downwards), the question of heating does not control the design, for if the transformer is designed for good regulation and low core loss, it will also be a correct design as regards heating. Consequently the course of events as regards oil-immersed transformers will, in virtue of inevitable evolutionary processes, in all probability be in the direction of the general use of the core type for large sizes and of various types for very small sizes. In very small sizes, particularly transformers for $1 \mathrm{kw}$ output and less, the labour cost and the establishment charges constitute a very large component, and it is less imperative to select a type requiring a minimum of material.

Quantity of oil used in transformers.-In the early days of oil-immersed transformers, the idea was to immerse the transformer in oil, in a case of just sufficient size to contain the transformer. A transformer designed on this plan to comply with customary heating specifications will run at needlessly-low current densities, and, except as regards pressure regulation, the rating may be considerably increased if by any means the temperature rise may be maintained within specified limits. By placing the transformer in a case with sufficient radiating surface, the temperature rise may be kept within the desired limits without increasing the size of the transformer itself, i.e., without increasing the amount of material in the windings and core.

It is still the practice of some manufacturing firms to provide cases of only just sufficient size to contain the transformers and to fill in the intervening space with oil. For small tranformers one may, by this plan, be able to obtain sufficient radiating surface, but for large ratings it is insufficient. Such practice leads either to a great weight of active material per $\mathrm{kw}$ of output, if the temperature rise is not to be excessive, or to an 
excessive temperature rise if the transformer is given the rating of which, in a larger case, it would be capable. There is a

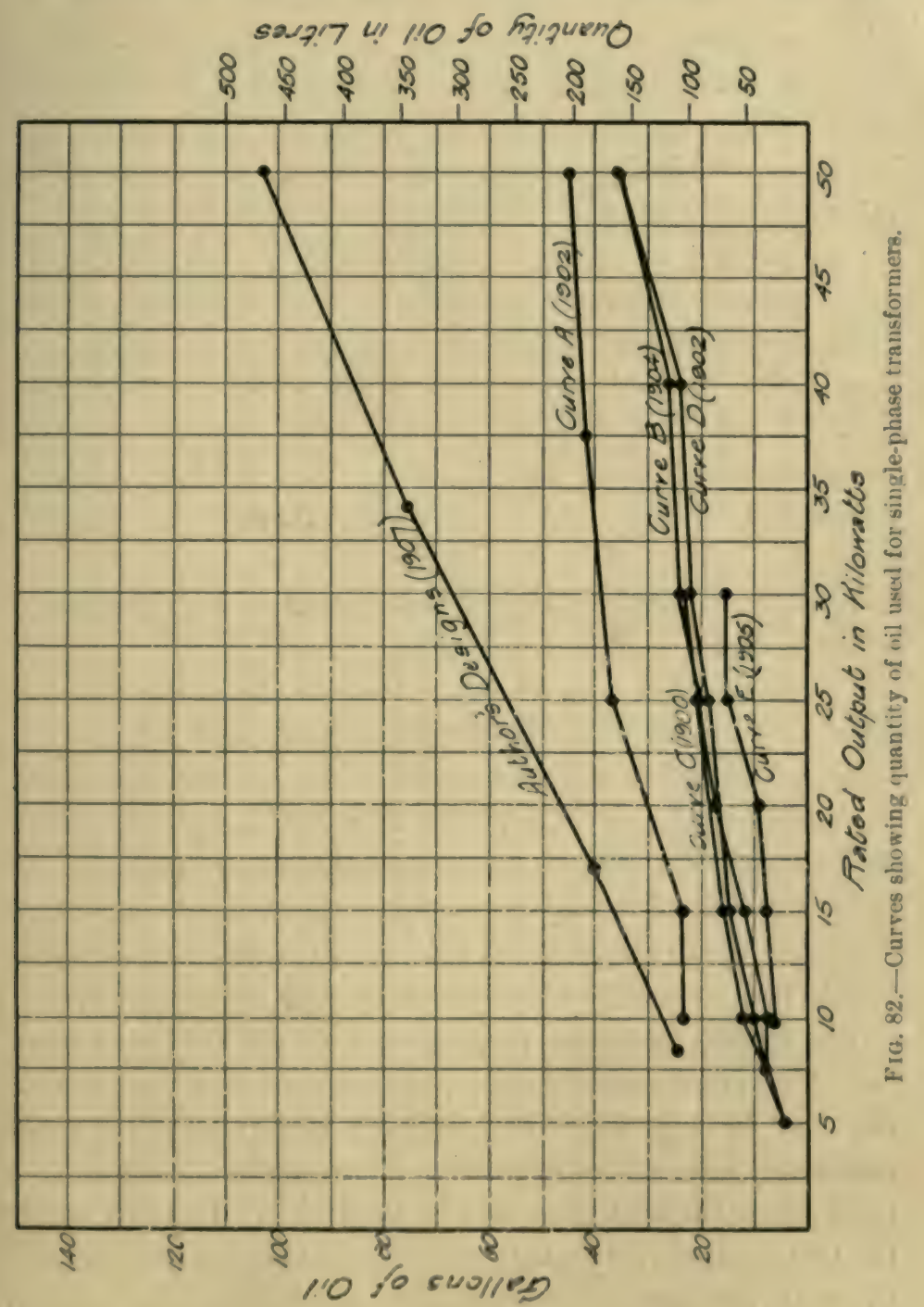

remarkable discrepancy between the quantity of oil used by rarious manufacturers. In Fig. 82 is given, for the product 


\section{THE DESIGN OF STATIC TRANSEORMERS}

of several makers, curves in which the quantity of oil employed is plotted as a function of the rated output. Since these curves relate to the product of different makers, they should not be taken as representing progress in transformer design during the past few years, but rather as representative of widelyemployed proportions. The values given by the curve applying to my own designs appear very high as compared with the values corresponding to the other curves. 'This is accounted for by severul reasons. 'The transformers corresponding to this curve are designed with' modern alloyed steel laminations which render the transformers comparatively small as compared with the older makes to which the other curves in Fig. 82 refer. The cases and quantities of oil for these transformers are so proportioned as to ensure an ultimate temperature rise of not more than $40^{\circ} \mathrm{C}$. above the surrounding air.

With transformers having as small quantities of oil as correspond to some of the curves in Fig. 82, it is doubtful whether the temperature rise would not be excessive if the transformers were run at full load for many hours or until the ultimate temperature corresponding to continuous running is attained. Under practical conditions, a transformer is, after shipment, rarely operated at full load for other than short periods, and thus there is rarely occasion to observe whether the temperature rise conforms to the specified limit, and there is thus a temptation to take unscrupulous advantage of this circumstance.

The transformer cases proportioned to conform to my curve in Fig. 82 are designed on the principle that the temperature rise may be kept down to practically any value which could reasonably be specified by providing a case of sufficient surface to dissipate the heat generated by the losses. In other words the temperature rise is, for a given type, fairly proportional to the watts per square decimeter of external surface of the case. Hence, a transformer may be designed to be of small dimensions, weight and cost (for copper and core), provided that it 
is put into a sufficiently large case with free circulation of the oil. Any sacrifice in efficiency will be but slight, since while

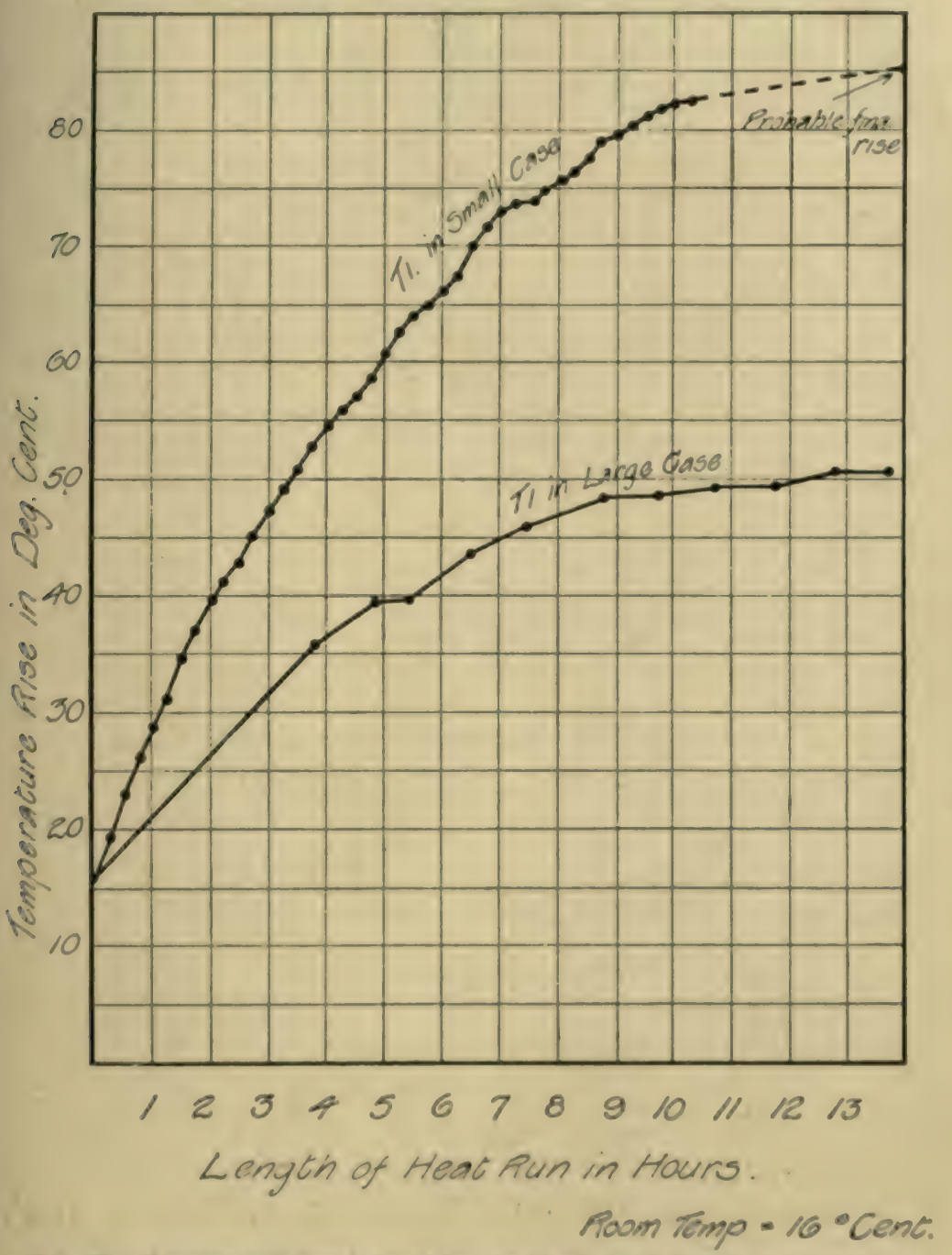

Fi6. 83.-Temperature curves for 10-kva single-phase oil-conlen transformer in small and large cases.

the heat-loss per kilogram of active materinl is high, the total weight of active material is low. 


\section{THE DESIGN OF STATIC 'TRANSFORMERS}

This principle should not, however, be carried to extremes, since there is a limit beyond which excessive local heating $\Gamma$ occurs in parts of the transformer. For the range of practical
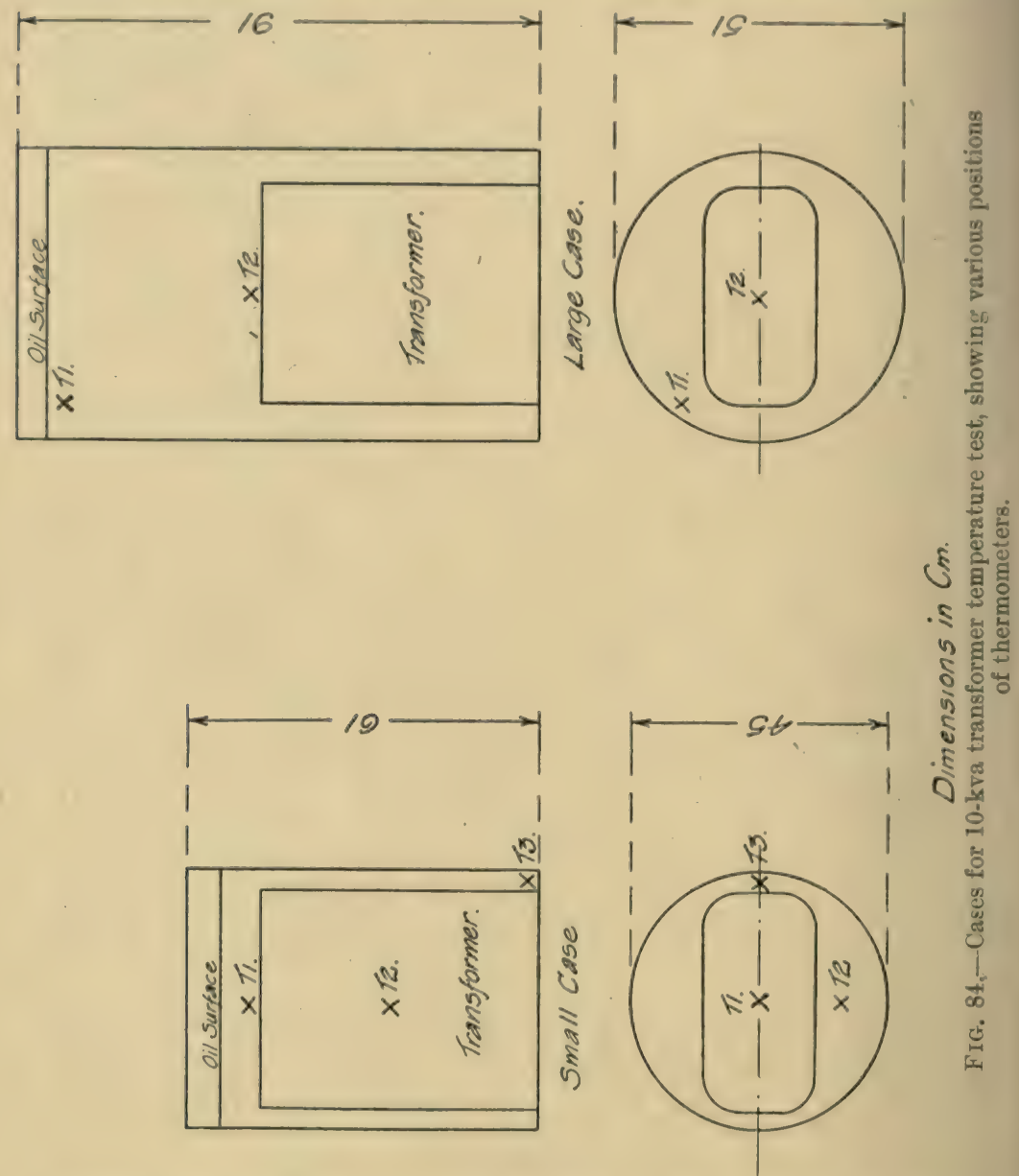

propositions, such dimensions as would give rise to this occurrence are, however, not likely to be approached, and the principle has not yet been applied to the full extent which will be attended with commercial advantage.

As illustrative of the above methor of designing, there are 
given in Fig. 83 temperature curves for a 10-kva 50-cycle 2000: 210-volt single-phase oil-immersed transformer which was tested at full load in two different sizes of case. The relative sizes of the two cases are shown in Fig. 84 . The heating data for these two tests are as follows:-

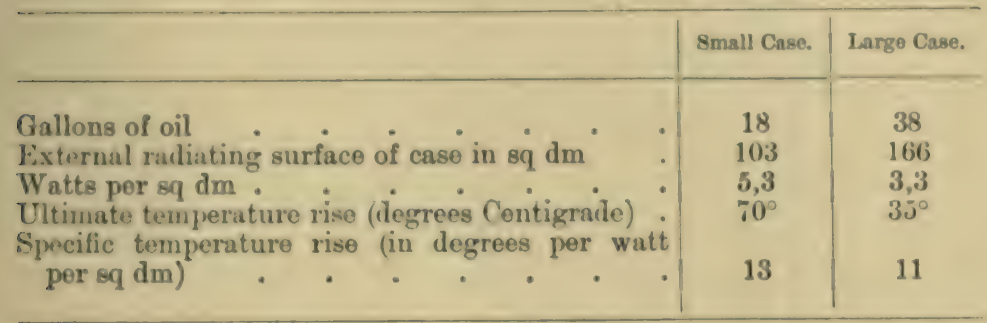

From these figures it is seen that for this particular transformer (or these particular tests) the temperature rise was halved by increasing the radiating surface by 60 per cent. The specific temperature rise is 13 and 11 respectively, the higher figure relating to the higher temperature. The results must be taken as liable to quantitative error, but as strongly confirming the correctness of the principle.

In the above tests the temperature was thermometrically determined at a point near the top just below the surface of the oil. 'The tempernture at such a point is usually the maximum which occurs in an oil-immersed transformer. Indeed the temperature at all points in the oil above the top of the core is usually quite uniform. The temperature at other parts of the transformer usually varies greatly and is a minimum at the bottom of the case.

Fig. 85 shows a set of temperature curves for the same 10-kva single-phase oil-immersed transformer, but loaded to only $8 \mathrm{kw}$. The positions of the three thermometers T1, T2 and 'T3, are shown in Fig. 84. These curves show clearly the temperature distribution and also the rate at which the temperature increases at different purts. T1, at the top of the case, rises rapidly at first, and then at a decreasing rate 


\section{THE DESIGN OF STATIC TRANSFORMERS}

until the ultimate temperature is reached. This is the case because the oil rises to the top after being heated by the transformer. T2, situated near the body of the transformer which is the seat of the losses, presents a similar characteristic although the value of the temperature is not so great. T3, at the bottom of the case, presents a different shape of heating

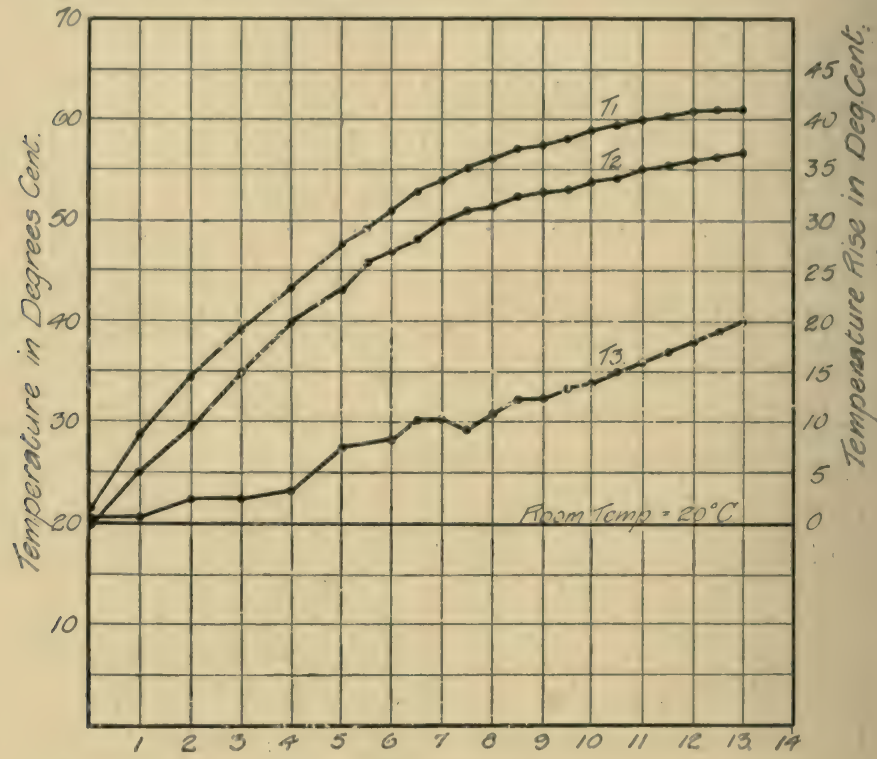

\section{Highest Totalpise $42^{\circ} \mathrm{C}$ \\ Time in Hours.}

FIG. 85.--Temperat ure test on a 10-kva single-phase transformer, with a load of $8 \mathrm{kw}$. (For positions of thermometers $T_{1}, T_{2}, T_{8}$, see Fig. 84.)

curve. The temperature rises very slowly at first for a considerable number of hours, and then more rapidly as the entire transformer becomes heated up.

This fact has been also pointed out by Epstein ${ }^{1}$ and some of his tests have already been shown in Fig. 76 (p. 119). It will be observed that the lower the thermometer is placed in the oil

1 "Testing of Electric Machinery and of Materials for its Construction," Jour. Inst. Elec. Engr8., Vol. XXXVIII., p. 49. 
the greater the difference between the temperature rise obtained after a few hours run and the stationary value. The curves $A, B, C$ and $D$ of Fig. 76 (p. 119) refer to the temperatures given by thermometers placed in the positions shown in Fig. 77 (p. 120).

The effect of varying the depth of oil in a transformer placed in a given case is illustrated by the data given in Table 15. These data refer to a 100 -kva 5000 to 2000-volt 60-cycle single-phase transformer. The first heating test was made with a depth of oil of only $7 \mathrm{~cm}$ above the transformer core. The figures show that not only is the temperature of the transformer considerably decreased by the extra depth of oil, but that the distribution of temperature is much more even throughout the whole volume of the oil, thus showing a better circulation.

Table 15.-Heatixg Tests ox a 100-kya Transformer.

\begin{tabular}{|c|c|c|}
\hline · & Teat 1. & Test. 2. \\
\hline $\begin{array}{l}\text { Depth of oil above core in } \mathrm{cm} \text {. } \\
\text { Oil radiating surface (exclusive of bottom of }\end{array}$ & 7 & 30 \\
\hline case), $\left[8 r_{1} \mathrm{dm}\right]$. & 441 & 532 \\
\hline Watts dissipated . . . . & 1430 & 1300 \\
\hline$. \quad . \quad . \quad$. & 3,24 & 2,44 \\
\hline Temperature at top of punchings after $24 \mathrm{hr}$. & $40^{\circ} \mathrm{C}$ & $366^{\circ} \mathrm{C}$. \\
\hline " of oil at surface (close to case) & $40^{\circ} \mathrm{C}$. & $36 \mathrm{C}$. \\
\hline " " case at surface of oil. . . . & $27^{\circ} \mathrm{O}$ & $32^{\circ} \mathrm{C}$ \\
\hline Height from louttom of case at which no further & $23^{\circ} \mathrm{O}$. & $20^{\circ} \mathrm{C}$. \\
\hline $\begin{array}{l}\text { temperature rise was recorded after } 24 \mathrm{hr} \\
\text { Temperature of primary by resistance measure- }\end{array}$ & $3: 3 \mathrm{~cm}$ & $18 \mathrm{~cm}$ \\
\hline Temperature of mecondiry loy resistance & $62^{\circ} \mathrm{O}$. & $58^{\circ} \mathrm{C}$. \\
\hline $\begin{array}{l}\text { mensurements } \\
\text { Specifie teujurature rise in degrees per watt }\end{array}$ & $50^{\circ} \mathrm{C}$. & $41^{\circ} \mathrm{O}$ \\
\hline per $s q \mathrm{dcm} . \quad . \quad . \quad . \quad . \quad$. & 12,3 & 14,7 \\
\hline
\end{tabular}

In considering the somewhat high specific temperature rises recorded in these tests, the length of time for which the tests were made, namely, twenț-four hours at full load, must be kept in mind. 


\section{THE DESIGN OF STATIC TRANSFORMERS}

Ventilation Ducts.--It is desirable that the temperature throughout the transformer should be as uniform as possible, and that there should be no excessive local heating at any part of the transformer. In the interests of achieving this result, the windings and core should be provided with ducts or channels through which the oil can circulate. In older designs of transformers this provision was not made, and the maximum temperature attained was considerably in excess of the temperature at any accessible part. In a modern transformer liberally provided with wide ventilating ducts, there is much less liability to local heating, and the ratio of the maximum temperature to the highest accessible temperature does not vary greatly from unity.

In large transformers it is absolutely essential in the interests of maintaining the insulation in good condition, to provide ventilating ducts both in the windings and the core. In the case of transformers of the core type I usually prefer the arrangement of the ventilating ducts illustrated in Figs. 49, $50,51,53,54$, and 55. In this construction the coil is separated from the core by means of specially-shaped distance strips of suitably-impregnated wood or other material. In this manner, parts of the inside of the coils, as well as of the outside, are subject to the cooling effects of the oil. It is most desirable to avoid undue local heating, as this conduces to ageing of the iron, and to deterioration of the insulation. 


\section{CHAPTER IX}

\section{TRANSFORMER CASES AND TANKS}

Axy one of a variety of materials may be employed in the construction of transformer cases. The rated output required of the transformer and the appropriate mehod of cooling will usually affect the choice. The principal materials used are cast iron, galvanised sheet iron, sheet steel, and boiler iron. For small sizes of transformers cast iron is generally used, both for air-cooled and oil-cooled designs. This is for several reasons. The pattern will, for small sizes, not entail large outlay, and this outlay will be spread over a very great number of transformers. Furthermore, the cost of iron castings is small. The labour item in building sheet-iron cases for housing transformers of small capacity renders their cost excessive when compared with cast-iron cases of similar size. Furthermore, the larger the case, the more difficult it is to cast, in view of the small thickness of metal. In fact, owing to this difficulty of obtaining a good, sound, thin casting when using cast iron, the walls of the case must be made thicker than would otherwise be desirable. For this reason, and because large cast-iron cases are much heavier than either galvanised sheet-iron or boiler-iron cases of the same capacity, the cost, when cast iron is used, is nearly or quite as great for large transformers as for the sheet-iron alternative, especially since the necessary patterns are more expensive the larger the case. Sheet-iron cases have also the advantage that a much greater height can be employed with a given thickness of metal. With cast iron it is not practicable to muke any considerable increase in surface for a giren thickness of cast iron and for the same floor space. In other words, the height of a cast-iron case 
146 THE DESIGN OF S'TATIC TRANSFORMERS

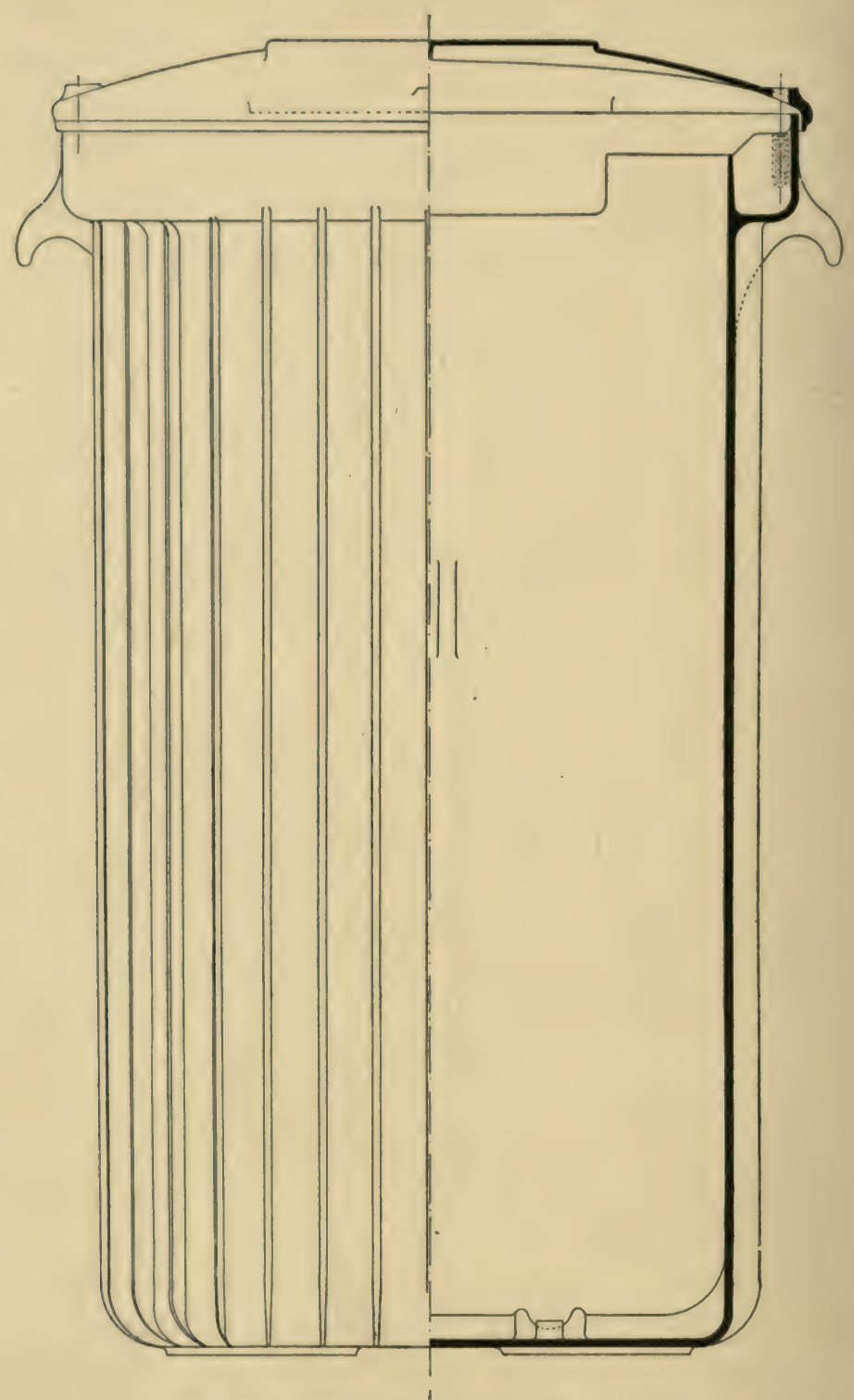

FIG. 854.-Elevation of ribbed cast-iron case.

cannot be greatly increased without also increasing the thickness of its walls, if due regard is given to the mechanical strength 
and rigidity of the case. A cast-iron case, with ribs to increase the radiating surface, is shown in Figs. $85 \mathrm{~A}$ and $85 \mathrm{~B}$.

Another objection to the employment of cast iron for the cases of oil transformer's is the liability that blow-holes, flaws and

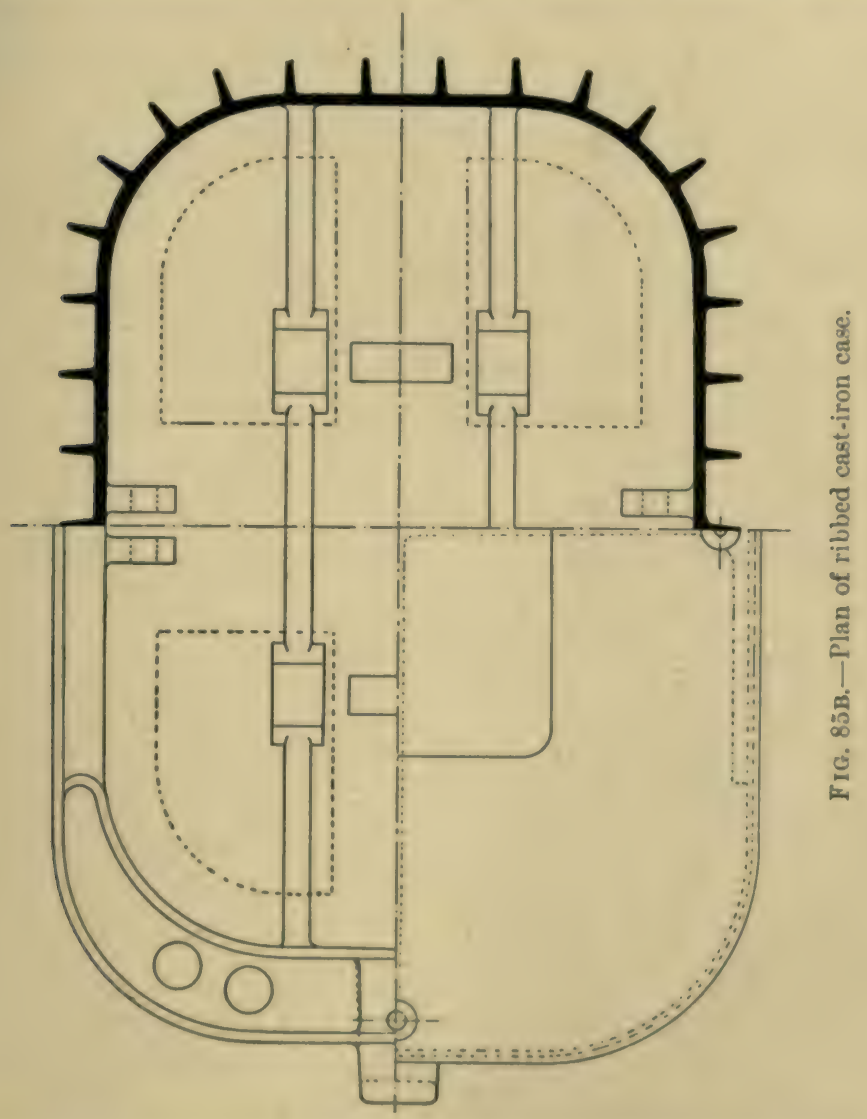

cracks may occur in the metal. Since a transformer case must be absolutely oil-tight, any flaw renders the case useless. Thus, in the event of requiring prompt delivery of some large transformer, the loss to the manufacturer in paying penalties incident to delay may be considerable if the cast-iron cases prove faulty and have to be rejected. Nevertheless, for moderately-large 


\section{THE DESIGN OF STATIC TRANSFORMERS}

transformers some firms employ deeply-corrugated cast-iron cases. In some instances the height of the required case leads to difficulties in the manufacture of these corrugated castings. To overcome these difficulties such cases have sometimes been made in sections, which are bolted together with a lead lining between adjacent sections. When this plan is adopted, the number of sections employed for a given transformer may be roughly obtained by dividing the losses of the transformer by the rate at which each section is known by experience to be capable of dissipating heat. 'This plan, when applied to large sizes, generally leads to a heavier and more expensive case than when corrugated wrought-iron plate is employed. Cast iron emits slightly more heat per unit of surface than either sheet iron or boiler iron, and this has been put forward as an argument in favour of cast-iron cases; but the difference in this respect is too slight to constitute a practical consideration. Any flaws in a cast-iron case can be autogenously welded, or they can be patched up with a blow-pipe or by other familiar workshop methods. Nevertheless, these eventualities may add considerably to the cost. The sides of cast-iron cases may be considerably strengthened when external ribs are employed; and consequently resort to ribs extends the usefulness of the castiron type of case. This is in addition to the circumstance that by means of the ribs a much larger radiating surface is available for heat emission. The minimum thickness practicable in cast-iron cases (due regard being given to the danger of fracture during transit and to the initial difficulties in casting) is some $8 \mathrm{~mm}$, the range of thicknesses used in practice varying between this figure and some $14 \mathrm{~mm}$, according to the size and the weight of the case. On the whole, the disadvantages associated with the use of cast iron for transformer cases, taken in conjunction with the liability of fracture during transit, are sufficient to make it generally preferable to employ sheet-iron or sheet-steel cases for all but small-sized transformers. 
Shect-iron Cases. - For the majority of transformer cases, galvanised sheet-iron or sheet steel is generally preferable, owing to the small thicknesses which suffice with such constructions. Another advantage of employing sheet-iron or sheet-steel for transformer cases, relates to the lightness of such designs as compared with cast-iron cases, and the ease with which they may be ribbed, thus not only providing a greater surface for heat emission, but increasing the mechanical strength of the case. The sheet-iron is, however, generally used only for the sides of the case. The bottoms and covers of the cases are usually formed either of cast-iron or wrought-iron, these being subsequently jointed to the sides by some one of several suitable methods, by means of which the joints may be made oil-tight. Where the sides are constructed of sections, these sections may be welded together, but this, although sound practice, is expensive. Vertical joints are necessary with cases of corrugated sheet iron, owing to the fact that the iron rollers cannot corrugate iron of more than a certain width. In Fig. 86 is illustrated a satisfactory method of jointing the sides to the bottom of the case. This method consists in providing two pieces of boileriron riveted together to form the bottom, in addition to the ordinary cast-iron base. These pieces of metal are so unequally dimensioned that when flanged to a certain height a channel is formed into which the sheet-steel sides are placed. Solder is then poured into the channel, in order to render the joint oil-tight. An alternative method of accomplishing the same object consists in forming the channel of two ribs cast into the base itself. 'These methods are both rather expensive, especially when the corrugations in the sides ure very deep, since this requires a large amount of solder to fill in the channel. 'The joint thus obtained is, however, quite oil-tight, nnd the method constitntes a reliable means of providing a joint that will continue to resist the hot oil after the transformer hns been placed in service. A cheap and frequently-employed method of jointing the base to the sides cousists in placing the 


\section{THE DESIGN OF STATIC TRANSFORMERS}

lower portion of the sides into a mould, into which molten iron is poured, and which forms the base. The method has the defect that blow-holes may occur around the joint, which, though not sufficiently pronounced to be detected at the time, may, under the continual influence of the hot oil, ultimately
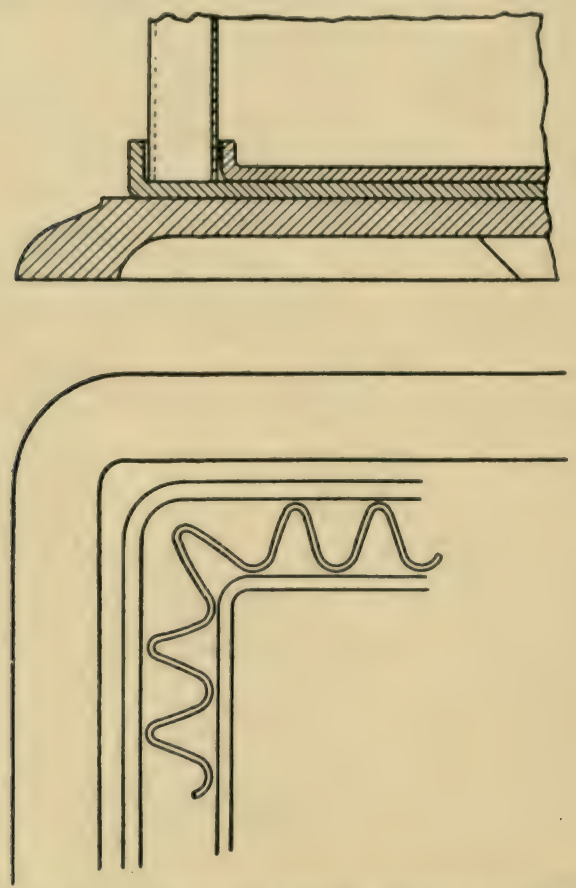

FIG. 86.-Method of jointing the sides and bottom of a transformer case.

develop into leaks. Ordinary materials, such as are used in everyday workshop practice to fill in flaws in cast-iron, are useless for the purpose of oil tanks, since the ingredients of which they are composed are often readily dissolved by hot oil.

The mechanical construction of a sheet-iron case requires careful attention, since the thickness of the walls is too slight to permit that the weight of the transformer shall be taken up by the sheet iron itself. On the contrary, the weight should 
be borne entirely by bolts or massive lifting-hooks. If the eyebolts or lifting-hooks are not suitably located, then considerable injury may result when lifting, due to buckling of the sides. The sides may be strengthened by providing a light angle-iron framework, placed either inside or outside, and it should be arranged that the weight of the transformer, when lifted, shall come directly on this framework. In some methods of handling the weight, the eyebolts are made an integral part of long bolts which extend from the base of the transformer. The entire weight is thus carried by the bottom of the case. Annular ditches may be provided in the base to catch any dripping or leakage of the oil. The sheet-iron walls vary in thickness from $1,5 \mathrm{~mm}$ to $4 \mathrm{~mm}$, according to the size and capacity of the transformer.

\section{Boller-iron Cases.}

Boiler-iron cases are used principally for lurge water-cooled and forced-oil-cooled transformers (see Chapter X.), and in special types where great strength is required, as in portable transformers. Their advantage lies principally in the fact that they are stronger and more durable and are cheaper than sheetiron cases. Ordinary boiler-plates ranging between $7 \mathrm{~mm}$ and $15 \mathrm{~mm}$ in thickness are used, with thoroughly caulked singleriveted lap-joints, and the construction provides a very satisfactory and permanent oil-tight joint.

The maximum size for which a transformer can be built to be self-cooling is limited by the amount of heat-emitting capacity for which the case can be designed. Cases with corrugated sides are often supplied with transformers up to some 750 kva capacity, but beyond this size, the weight and dimensions of the case become so great that some method, other than mere increase in size, must be resorted to in order to provide the necessary radiating surface.

A special type of case has recently been developed by the 


\subsection{THE DESIGN OF STATIC TRANSFORMERS}

Westinghouse Co. with a view to overcoming this difficulty, and it is claimed that it is capable of being designed for a

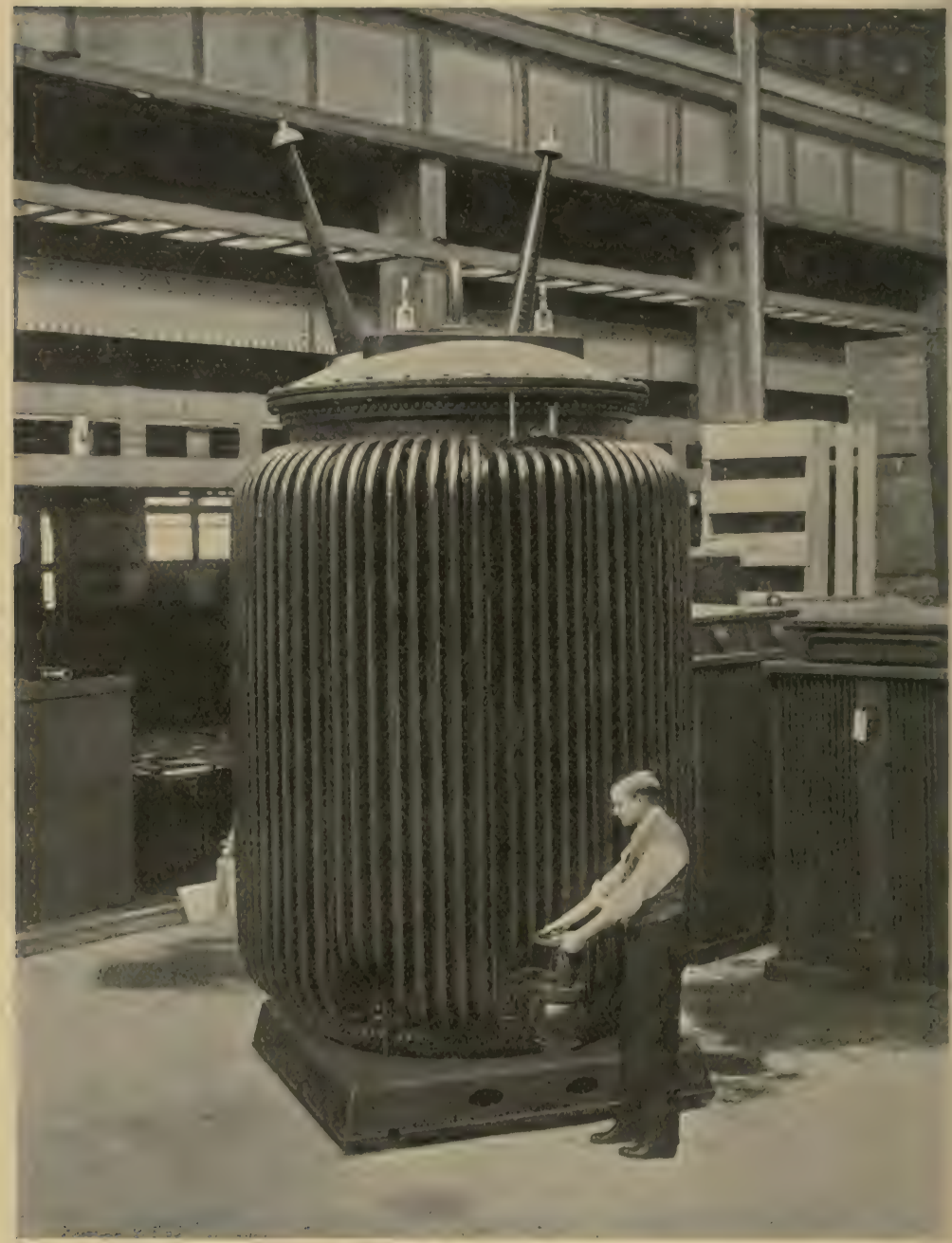

FIG. 87.-Westinghouse 1000-kva 100000 -volt 60 -cycle oil-immersed selfcooled transformer.

greater cooling capacity than has heretofore been attempter for a self-cooled transformer. It consists simply of a plain 
boiler-iron case to the outside of which are welded a number of couling tubes. 'These tubes are arranged vertically, and are

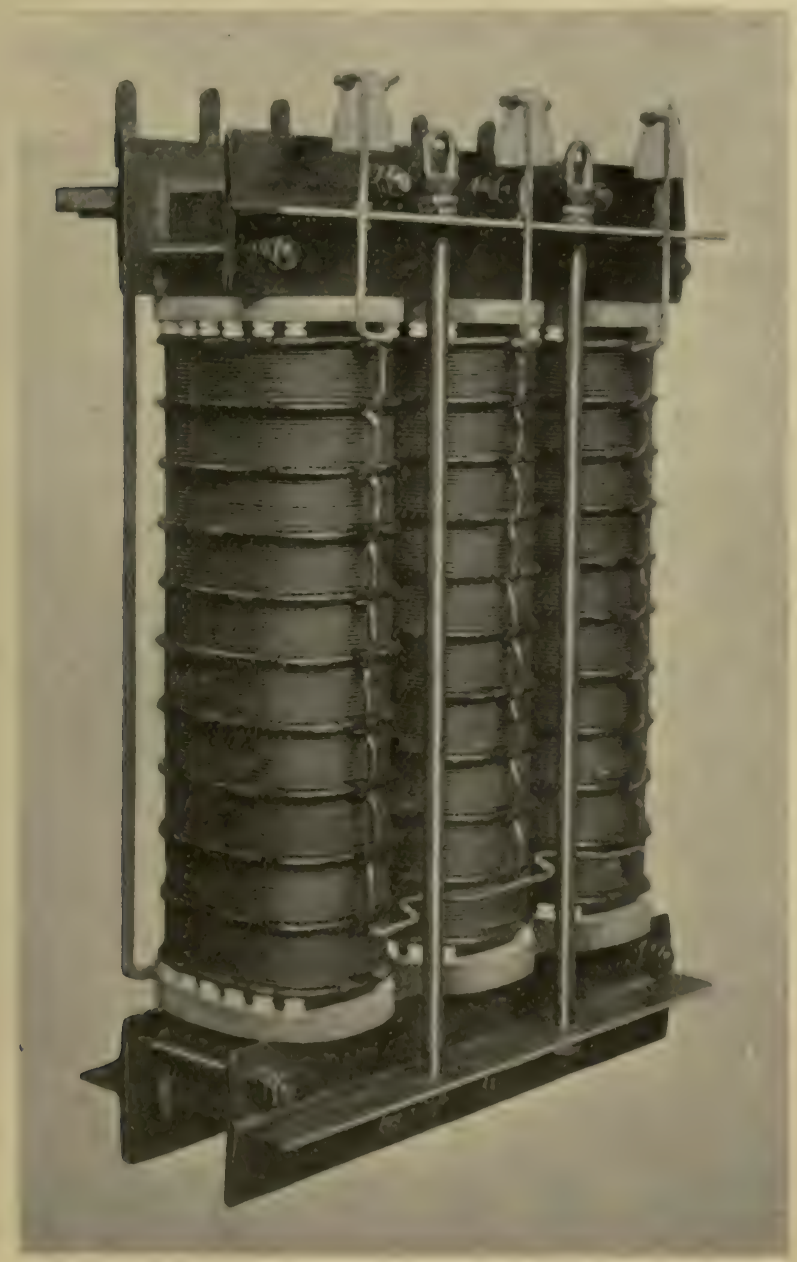

Fil: RS. Johusm \& Ihilligis' likl-kva transformer for oil immersion.

given a 90-rlegree bend at the top and bottom where they enter the case. The mechanienl construction is very strong, and it is claimed that there is practically no clance of ever springing 


\section{4 'IHE DESIGN OF STATIC TRANSFORMERS}

a leak. As the tubes are well separated from one another, and as the air consequently circulates very freely among them, the efficiency of the radiating surface is considerably higher than for the ordinary corrugated case. Self-cooled oilimmersed transformers are very appropriate for sub-stations wherever water for cooling purposes is either not available or else expensive, or where it is of special importance that the transformers shall require but little attendance.

The Westinghouse Electric and Manufacturing Co. has recently built twelve 1000-kva 100 000-volt 60-cycle transformers of the above-described type for the Southern Power Co. Fig. 87 is an illustration of the design. Of the twelve supplied, three are for outdoor service, and nine are installed indoors.

In Fig. 88 is shown, out of its case, a three-phase, selfcooled, oil-immersed, 50-cycle transformer recently designed by the author for Messrs. Johnson \& Phillips, and of which two are now in service at the generating station of the Aston Manor Corporation. The transformer is for $600 \mathrm{kva}$ at a primary pressure of 6300 volts and a secondary pressure of 356 volts. The periodicity is 50 cycles per second. 700 gallons of oil are used in this transformer. 


\section{CHAPTER X}

\section{FORCED-COOLED TRANSFORMERS}

Wrrn the progress of the introduction of electricul methods, the eapacities required of individual transformers rapidly
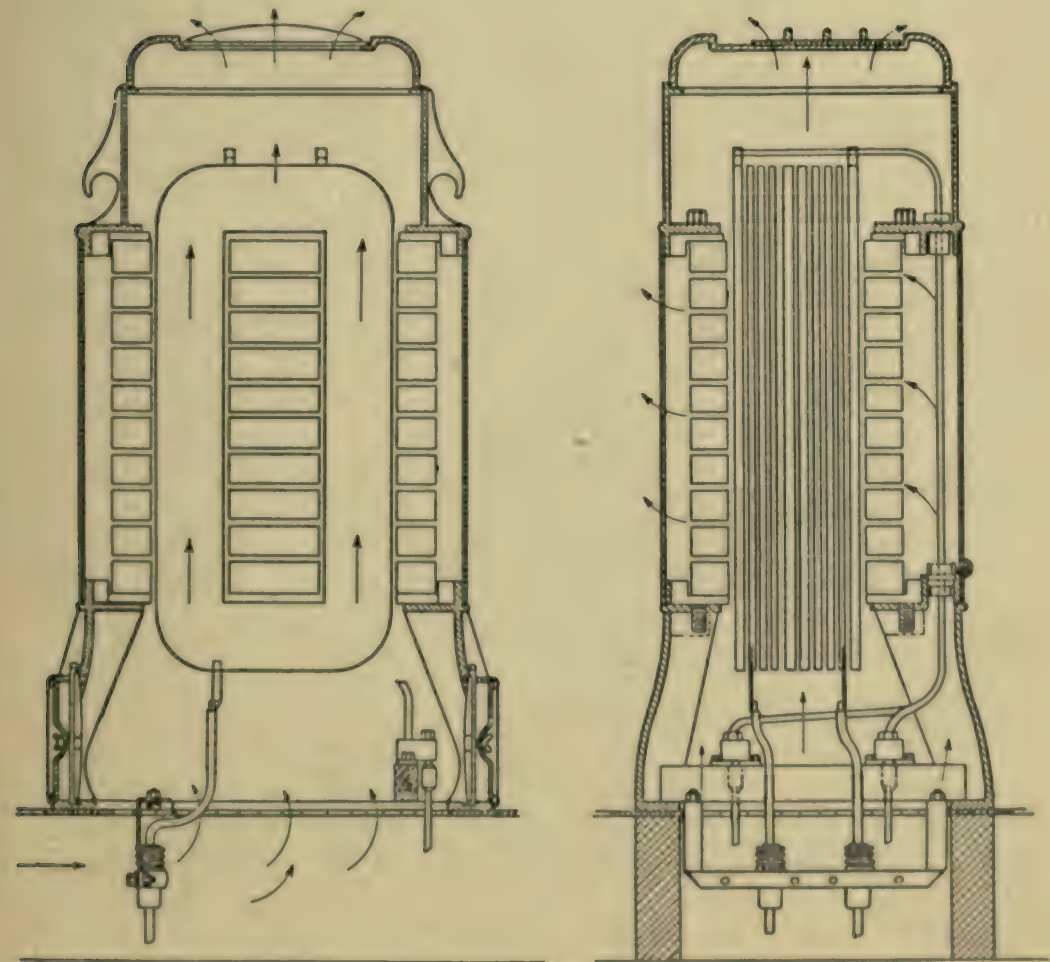

F1:. 89. - Diagram showing construction of an air-blast transformer.

increased, and manufacturers experienced difficulties in the matter of restricting the temperature rise. Ultimately they turned their attention to methods of forced cooling, and three 


\section{6 'THE DESIGN OF' STATIC TRANSFORMERS}

types of forced-cooled trunsformers came into extensive use. These may be designated Air-Blast 'Transformers, Forced-

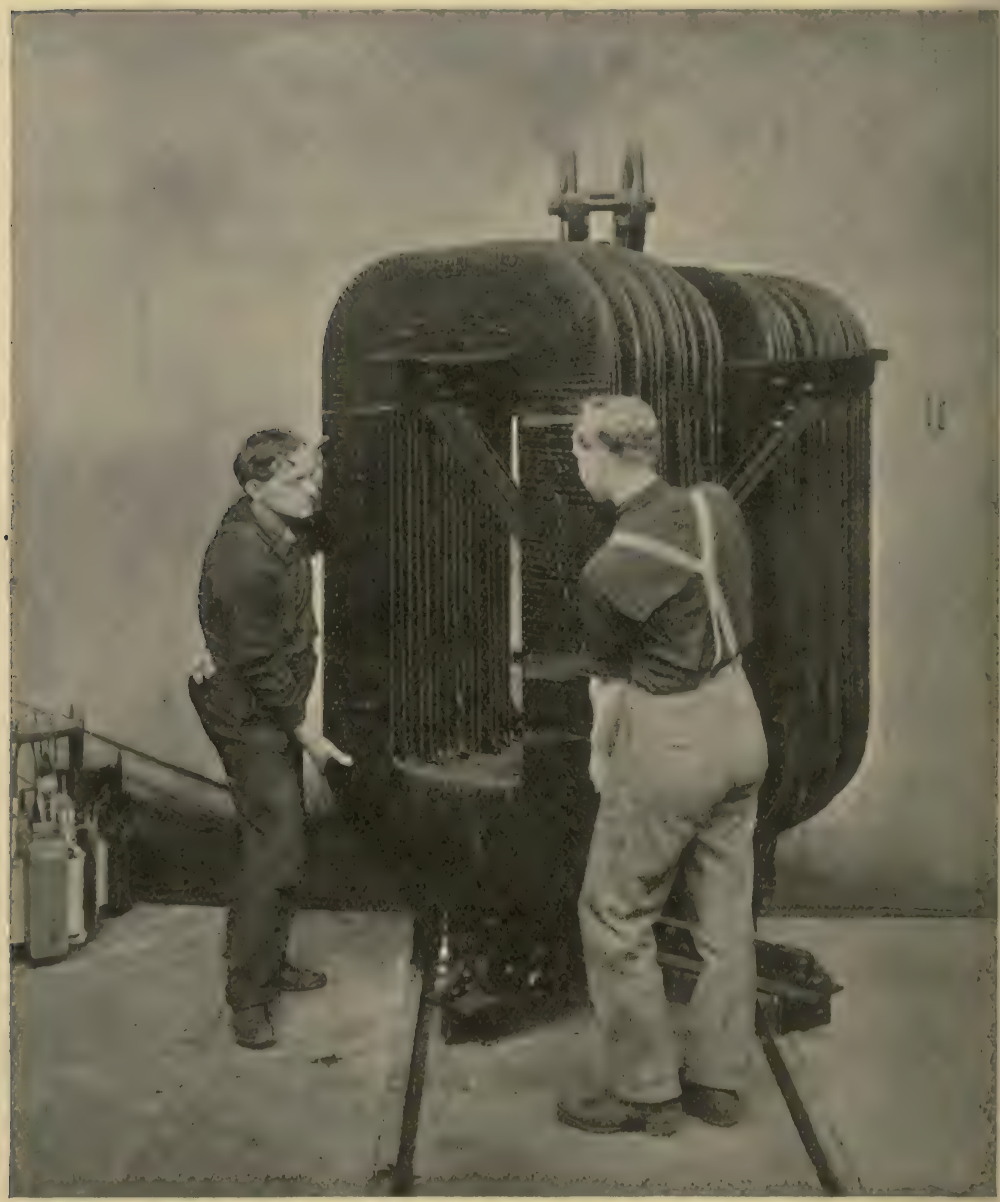

FIú. 90.-Coils of a shell-type air-blast transformer after completion of impregnating process.

Water-Cooled Oil Transformer's and Forced-Oil-Cooled Transformers.

Air-Blast Transformers. - A typical design for a shell-type air-blast transformer is indicated in Fig. 89. A view of the 
coils of an air-blast transformer taken at a certain stage of their manufacture, is given in Fig. 90. By regulation of the amount of openings in the case by means of dampers provided for the purpose, the relative amounts of air passing respectively through the core-ducts and through the passages between the coils, may be adjusted. Air-blast transformers are nowadays
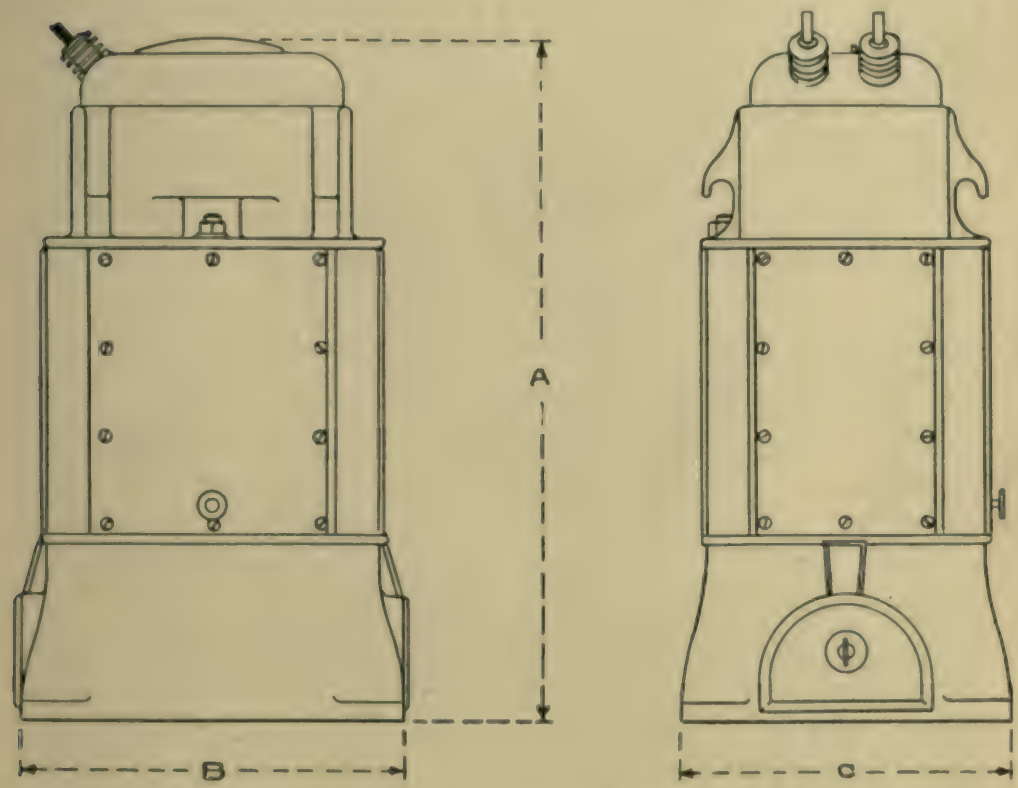

Fir: 91. Diagrammatic sketch of American (ieneral Electric Co,'s air-blast transformers.

rarely employed for units of less than $300 \mathrm{kw}$ capacity. 'The general external appearance of the type to which Figs. 89 and 90 apply is shown in Fig. 91 relating to designs by the General Electric Co. of America. In Fig. 91, the overall dimensions $A, B$ and $C$ are, for transformers for primary pressures of some 12000 volts and secondary pressures of some 1000 to 2000 volts, and for rated outputs of 500 kva and 1000 kva, roughly as set forth in 'Table 16. 
158 THE DESIGN OF STATIC TRANSFORMERS

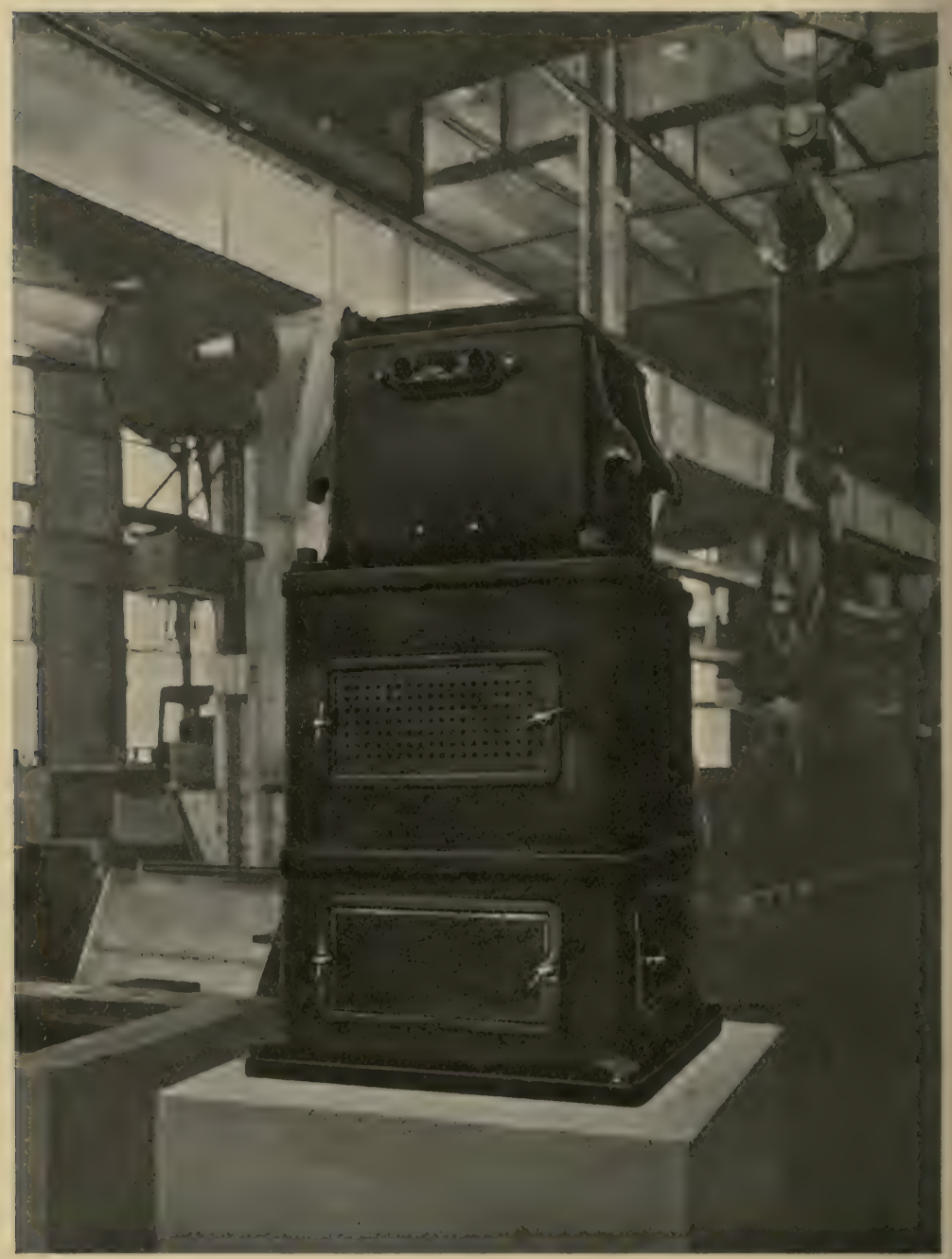

FIG. 92.-550-kva 50-cycle air-blast transformer by the Westinghouse Co. 
Table 16.-Oyemall Dimersions of Air-Blast Thasgrormem.

\begin{tabular}{|c|c|c|c|c|c|}
\hline \multirow{2}{*}{ Rated Output. } & \multirow{2}{*}{$\begin{array}{l}\text { Perienlicity } \\
\text { in Cycless } \\
\text { in sec. }\end{array}$} & \multicolumn{3}{|c|}{ Leading Dimensions in mm. } & \multirow{2}{*}{$\begin{array}{l}\text { W.iphtit. } \\
\text { in thess. }\end{array}$} \\
\hline & & A. & B. & c. & \\
\hline \multirow[t]{2}{*}{$500 \mathrm{kva}$} & 25 & 2200 & 1400 & 1200 & 5 \\
\hline & 50 & 2150 & 1300 & 1100 & 4 \\
\hline \multirow[t]{2}{*}{$1000 \mathrm{kva}$} & 25 & 2600 & 1600 & 1400 & 7 \\
\hline & 30 & 2300 & 1500 & 1300 & 6 \\
\hline \multirow{2}{*}{$1500 \mathrm{kva}$} & 23 & - & - & - & 10 \\
\hline & 50 & - & - & - & 9 \\
\hline
\end{tabular}

In Fig. 92 is shown a view of a 50 -cycle Westinghouse air-blast transformer for 550 kva supplied to the Brighton Corporation.

For pressures above some 20000 volts it is not desirable to

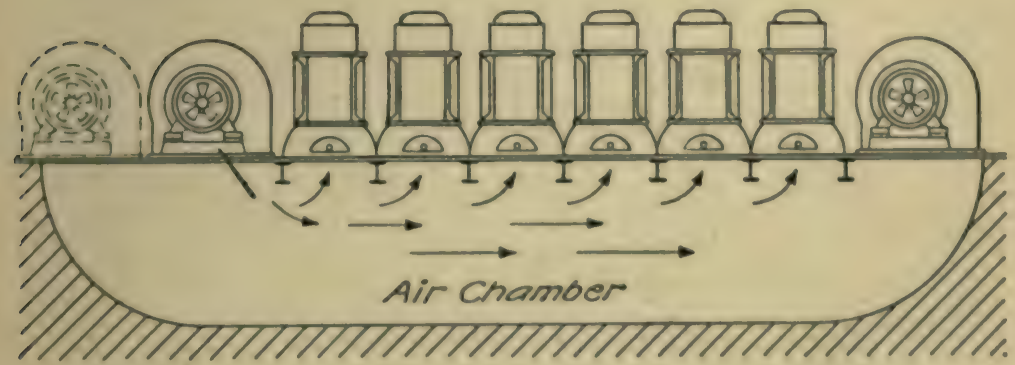

FI6. 93.- Liagram showing arrangement of transformers and bluwers.

employ air-blast transformers, as the design of the insulation for pressures above 20000 volts may be made much more effective when the transformer is arranged for oil immersion. Air-blast transformers are, as shown in Fig. 93, usually installed in rows, over a longitudinal duct through which air flows to the transformers. In Fig. 94 are shown nine air-blast transformers as installed at a sub-station of the 
160 THE DESIGN OF STATIC TRANSFORMERS

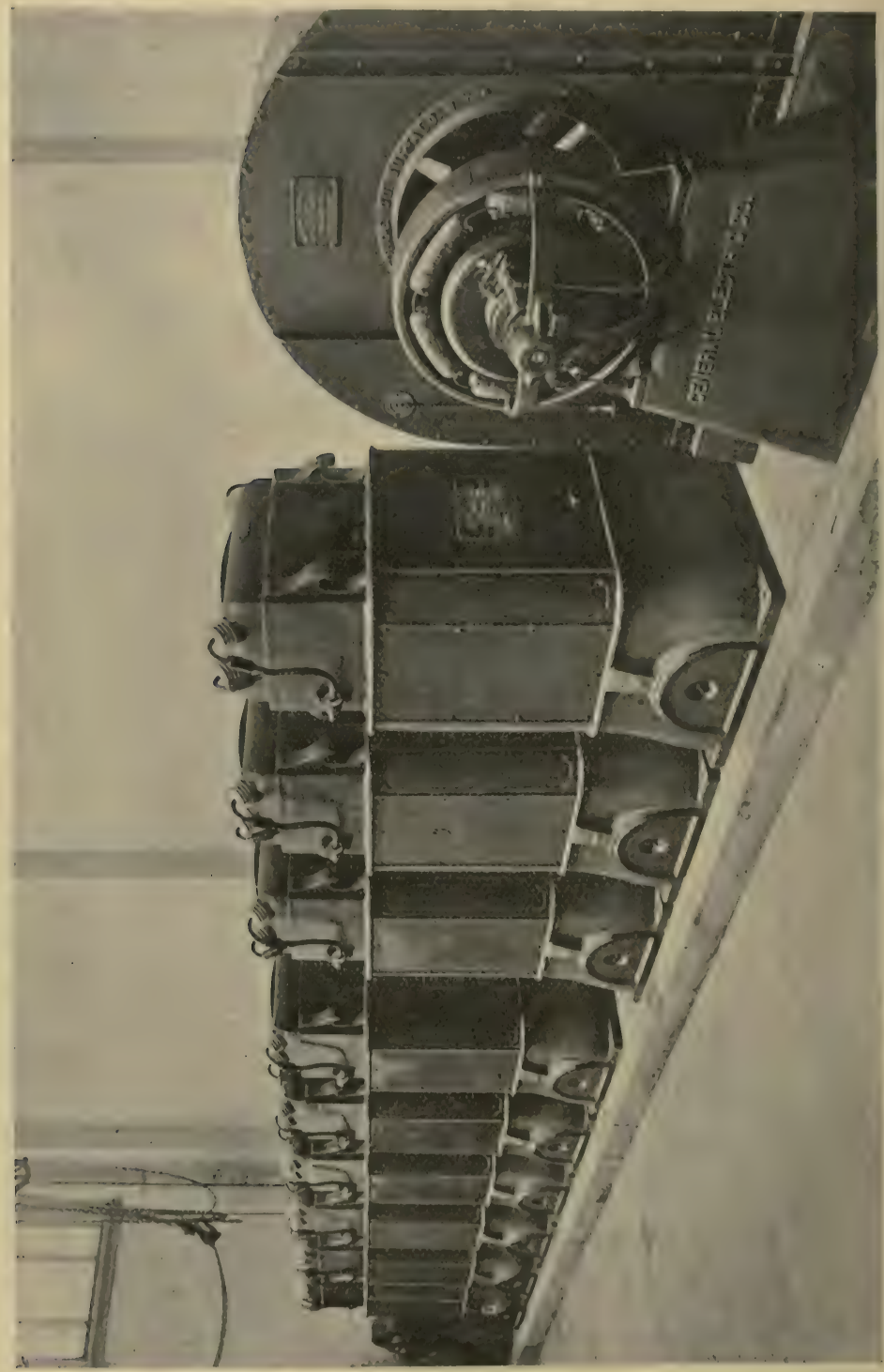

मू.

Buffalo Railway Co. The nine transformers are divided into three groups of three each. Each group is connected to con- 
stitute a three-phase transforming set, and one, two or all three groups are used according to the amount of the load being supplied. The power necessary for circulating the required amount of air varies considerably in different installa. tions, according to the length and size of the supply duct and the general arrangements adopted. The blower rarely requires (even in small installations) to have a capacity of more than 1 per cent. of the aggregate rated capacity of transformers installed, and it is more usually, especially for groups of very large transformers, well down toward one-tenth of 1 per cent. It is usually safe to estimate on a motor whose capacity is onehalf of 1 per cent. of the aggregate capacity of the transformers to be cooled. It is important that the duct or passage supplying the transformers shall be of large size, and that plenty of air shall reach even the must distant transformers of the group. The velocity at which the air flows along the duct should be of the order of 1 meter per second, and the air pressure at the transformers will need to be some 3 to 4 grams per sq $\mathrm{cm}$ (some three-quarters of an ounce per sq in) or some 5 to 6 grams per sq $\mathrm{cm}$ as delivered from the blower. The quantity of air and the power required for 500-kva and 1000 -kva sizes will be roughly as shown in Table 17.

TABLE 17.

\begin{tabular}{|c|c|c|}
\hline Size of Traumformes. & $\begin{array}{l}\text { Quantity of Air per Transformer } \\
\text { in eis. meters jur sees. }\end{array}$ & Ditto in ca. $\pi$. per min. \\
\hline $500 \mathbf{k v a}$ & 1,0 & 1700 \\
\hline $1000 \mathrm{kva}$ & 1,4 & 2400 \\
\hline
\end{tabular}

Owing to the disastrous consequences of a prolonged interruption of the supply of air, it is very desirable to duplicate the air-circulating apparatus, and in general every care must be exercised in providing for contingeneies. I recall a case

B.T. 


\section{THE DESIGN OF STATIC TRANSFORMERS}

where a bank of air-blast transformers was located in a basement right below the switchboard. In installing the switchboard, various undesirable materials fell through into the transformers, which had been carelessly left with their top dampers open. Whether due to this initial cause or not, considerable trouble was subsequently experienced with burn-outs of these transformers. One of them actually overheated to the extent of igniting its insulating materials, and the combustion was intensified by the air-blast. Yet to shut down the air blast under such circumstances would also intensify the henting. My own opinion is that when the air-blast type is used, it is necessary to take the very greatest care. Thus even the contingency of rats destroying the insulation or causing other damage is by no means remote, and has constituted a serious danger in certain important installations. The manufacturers of air-blast transformers direct that all accessible parts of such transformers shall be given a systematic cleaning at intervals of once a month or thereabouts. This cleaning should include getting at the inside of the transformer and wiping away dirt and dust from the coils and from the spaces between them, Even if the transformer is protected from the entrance of any foreign matter through carelessness, nevertheless an undesirable amount of dirt and fine dust will always gain access to the interior as it will accompany the circulating air. Compressedair plant, enabling a considerable pressure to be directed against remote parts, will be of much assistance in cleaning air-blast transformers.

Forced-Water-Cooled Oil-Transformers. - In transformers for outputs of 500 to $5000 \mathrm{kva}$ or more, the most-widely-employed design is that in which the active material is deeply immersed in oil and has, arranged above it, a coil of cooling pipes through which water is circulated. Such transformers are usually enclosed in a heavy boiler-plate casing. The general external appearance is well illustrated by Fig. 95 which relates to a Westinghouse 10000 -kva three-phase 66000 -volt transformer 
of the Pennsylvania Power and Water Co. The boilerplate shell is riveted to a cast-iron base to which the trans-

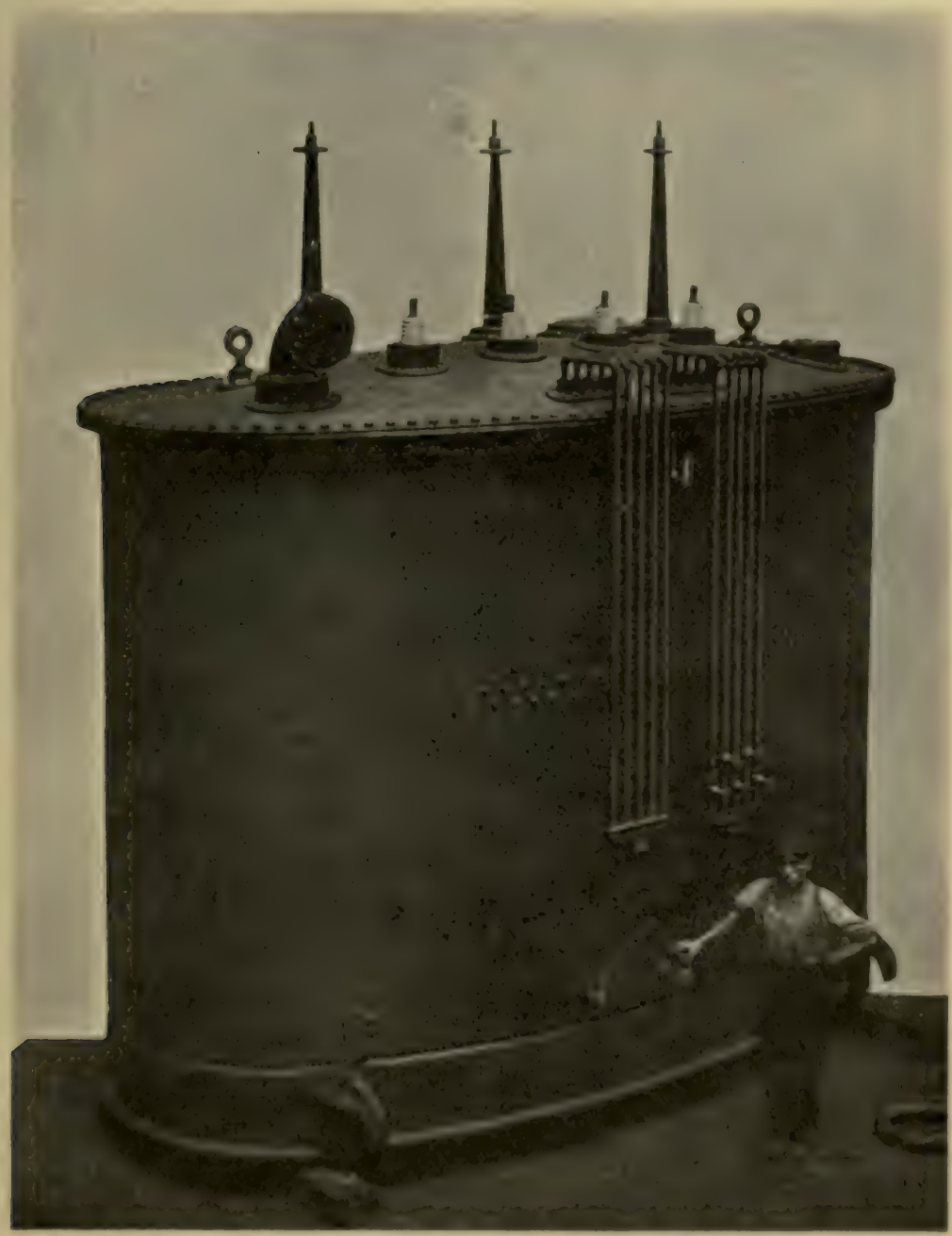

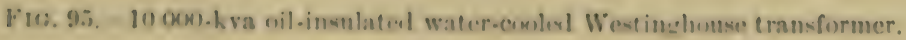

former core is securecl. Fig. 96 is an interior view of a trunsformer of the same type, built by the American General 


\section{THE DESIGN OF STATIC TRANSFORMERS}

Electric Co., and also for 10000 kva output. In this view the cooling coils have not yet been placed in position. In Fig. 97

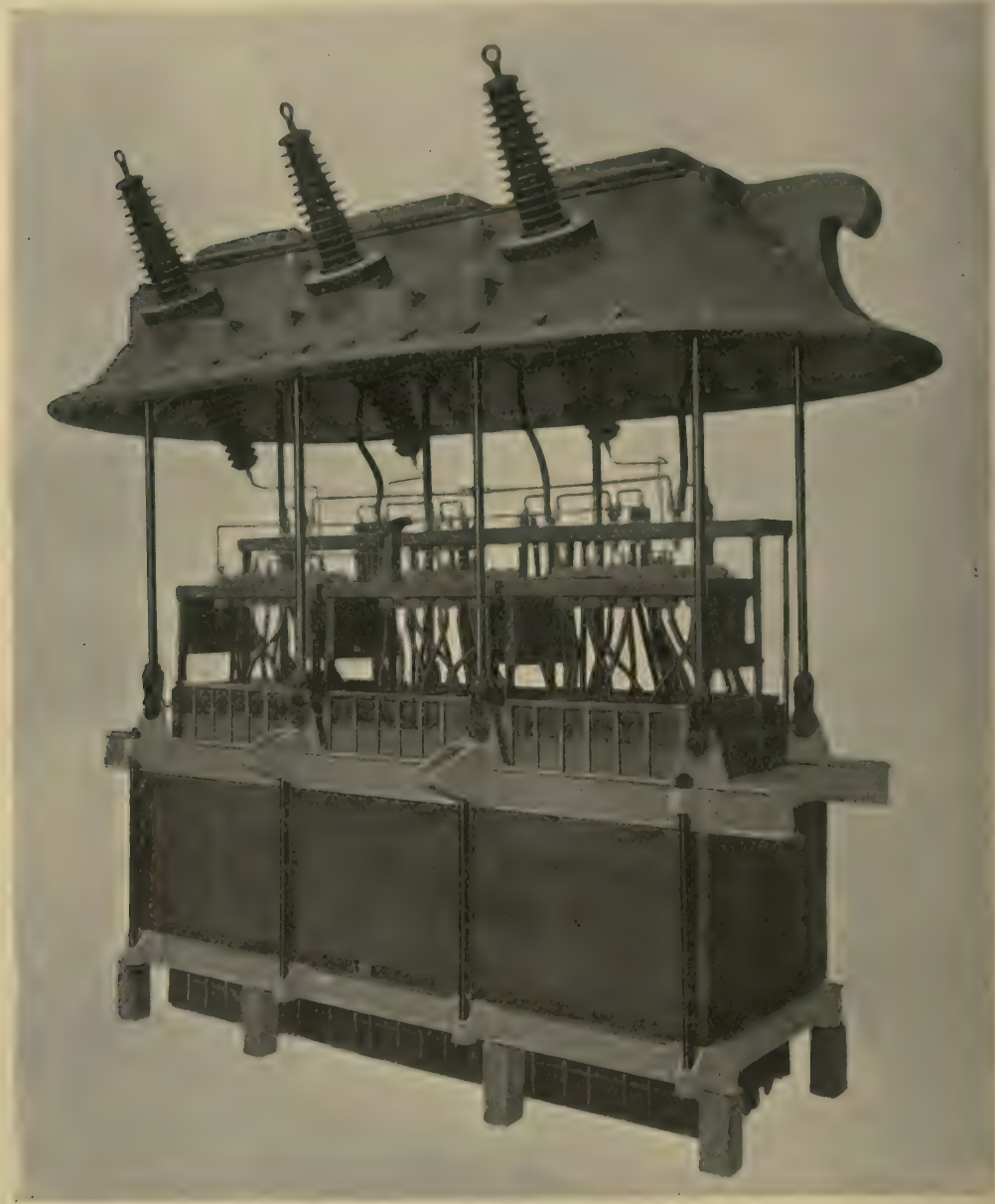

Fig. 96.-View of the interior of the American General Electric Co.'s $100(00)$-kva 1(x) 600 )-volt 60 -cycle design for a water-conled oil-immersed transformer before the cooling coils have been mounted.

the cooling coils are also seen. This transformer is for 100000 volts. 
In Figs. 98 and 99 are shown views of two large oil-immersed, water-cooled transformer's by the Westinghouse Co. 'The first

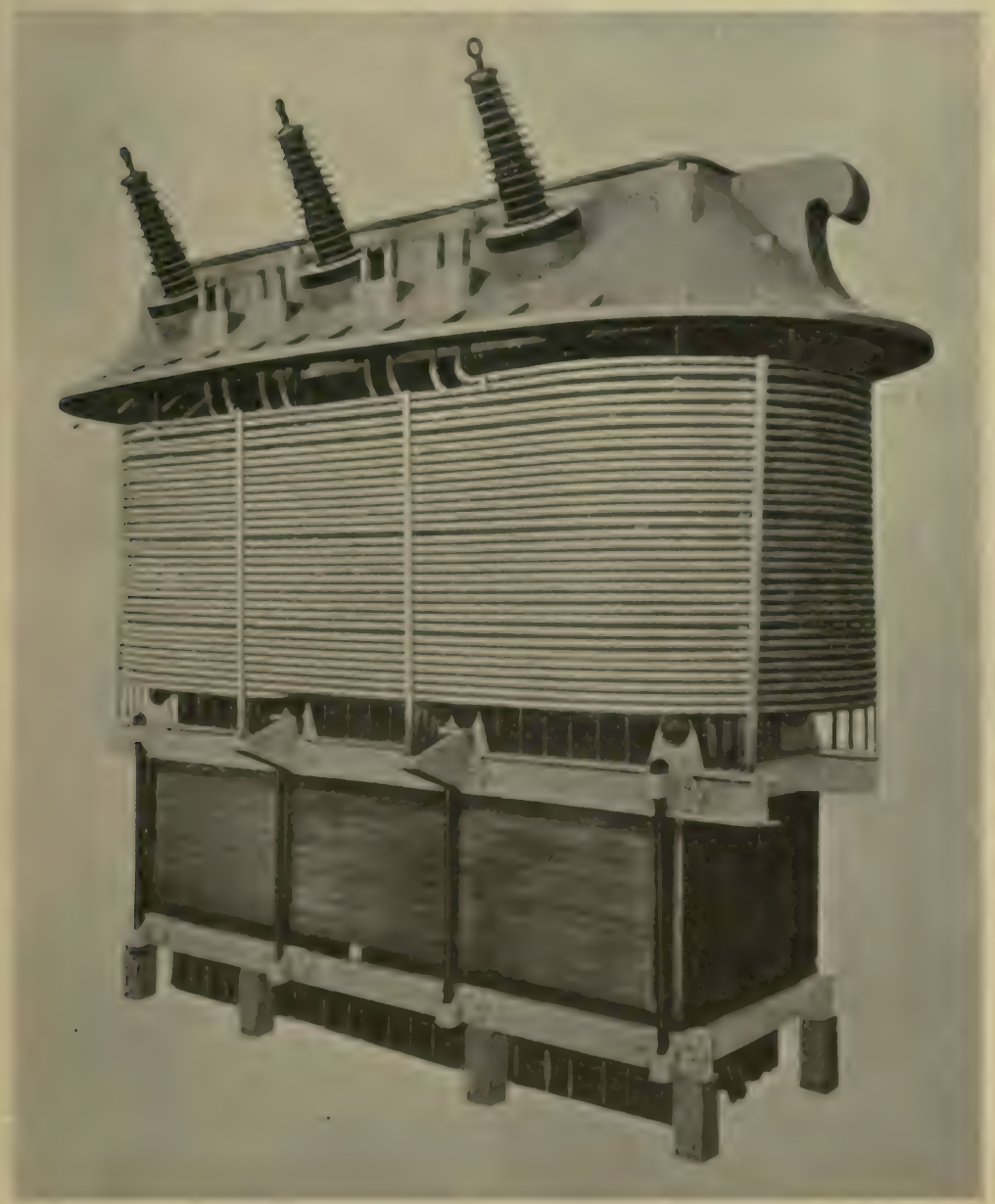

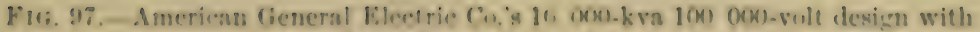
the cooling coils in place.

is (as may be seen from the terminals) for very high pressure and small eurent, while the second is for low pressure and 


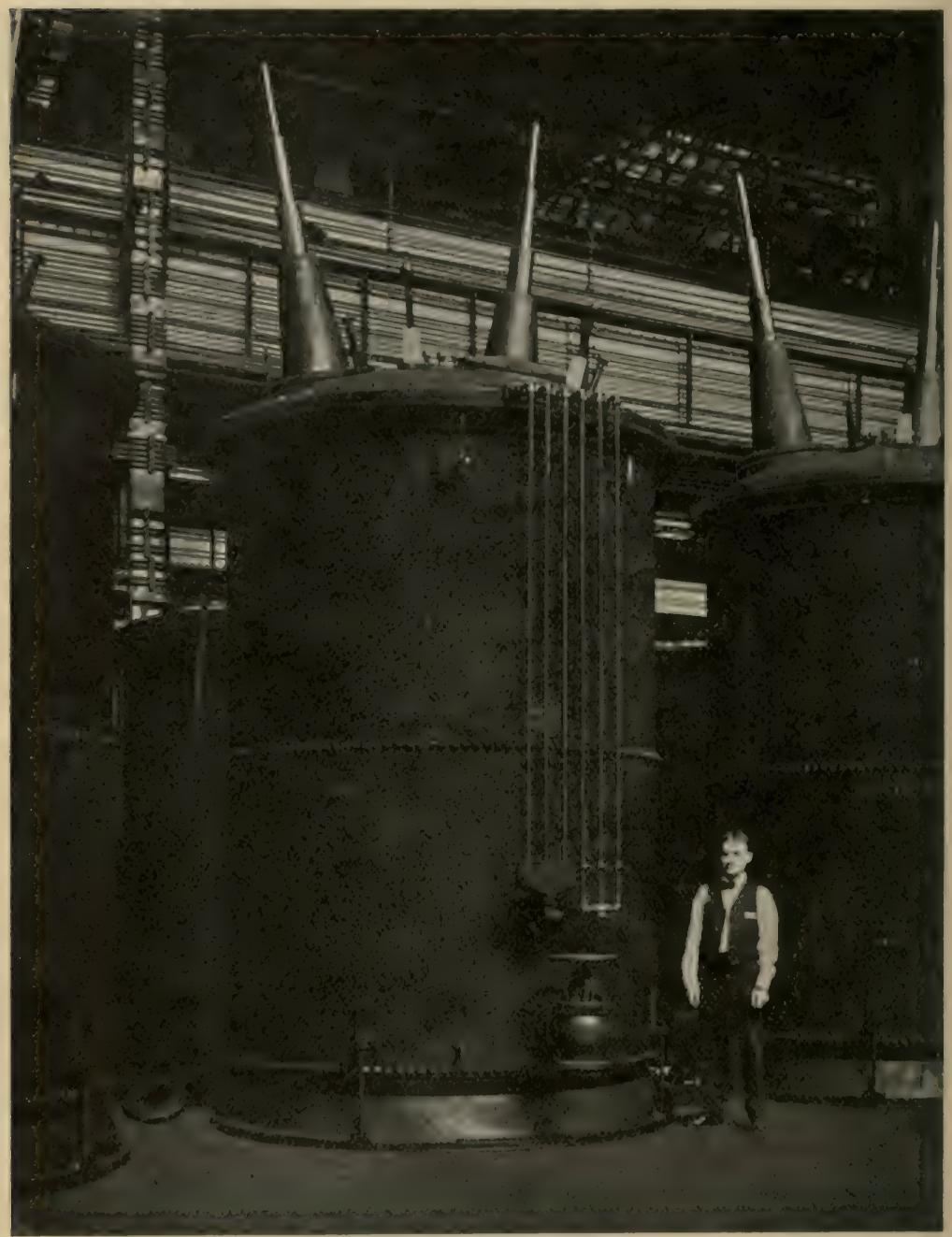

FiG. 98.-Westinghouse oil-insulated water-cooled transformer for high-pressure and small current.

large current. Fig. 99A shows the interior of a 50-cycle 1800kva water-cooled oil-immersed transformer with the cover in place. 'The transformer is for a primary pressure of 55000 volts. 
It is preferable that the mechanical support of a transformer shall be supplied entirely by the cast-iron base, and that there

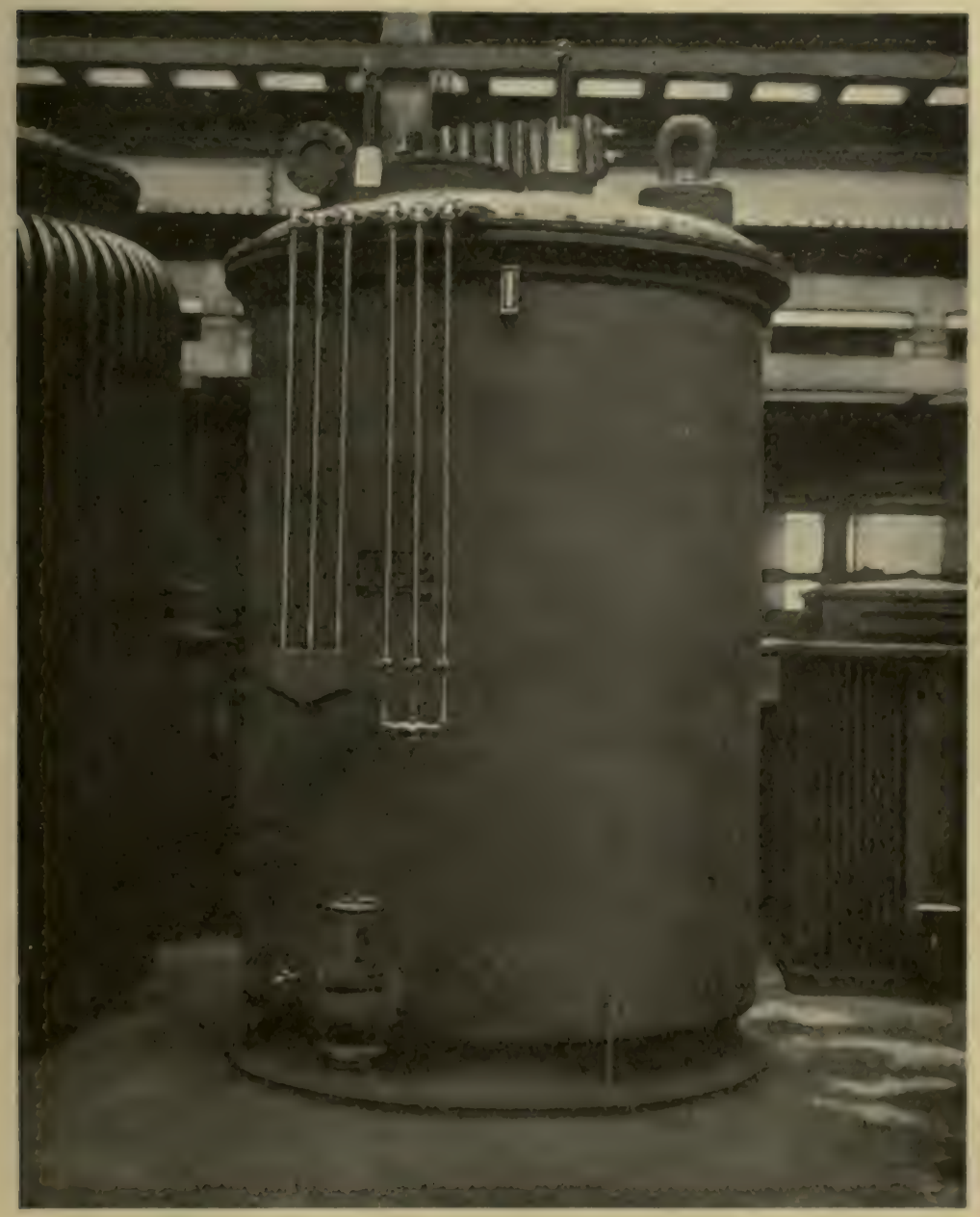

Fi6. 99. - Westinghuse oil-insulnted water-couled transformer for luw pressure and large current.

shall be no dependence upon the boiler-plate shell. Alternative suitable constructions for supporting the active material from 


\section{THE DESIGN OF STATIC TRANSFORMERS}

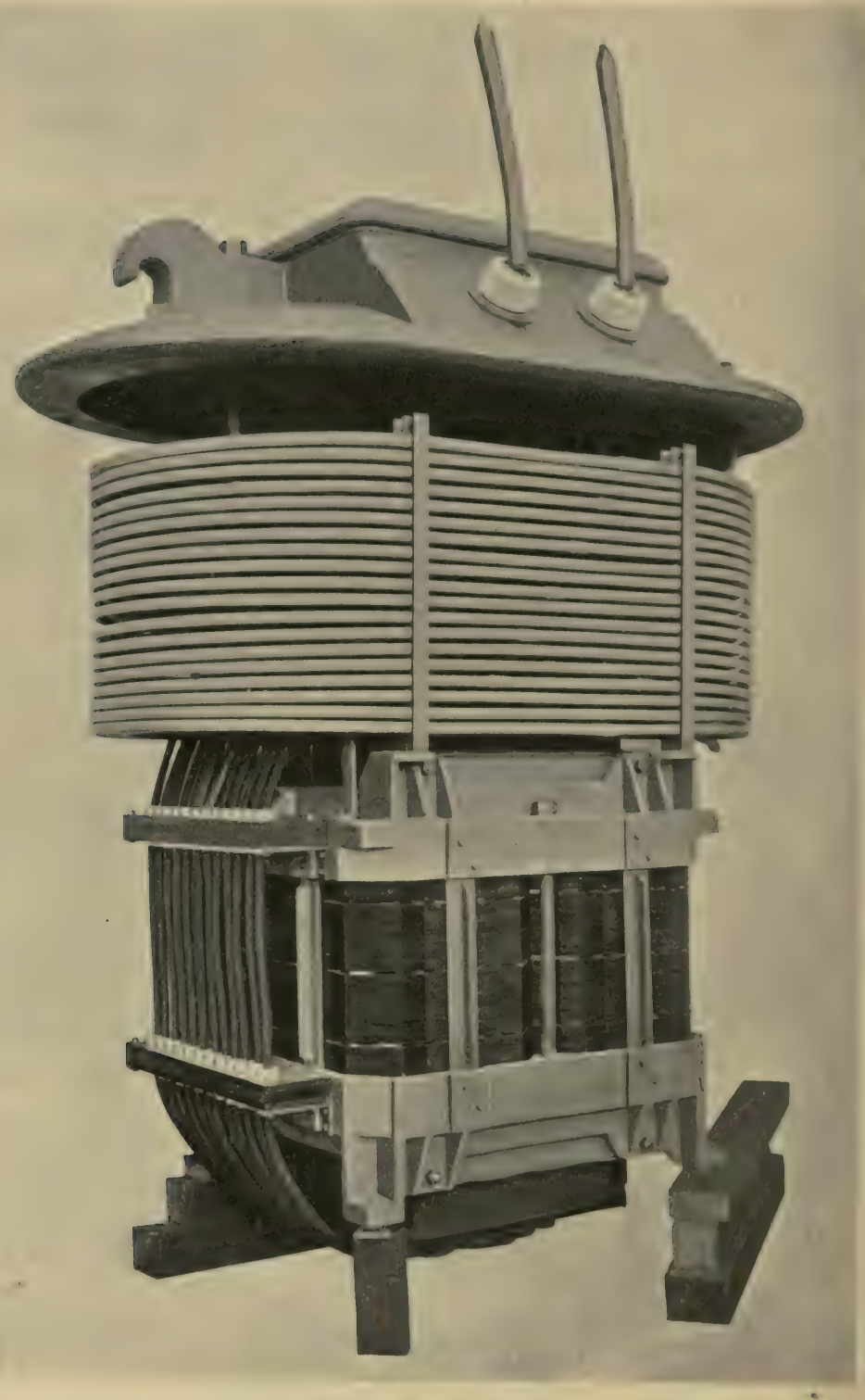

FIG. 99A.-1806-kva water-cooled cil-immersed transformer built by the American General Electric Co. 
the cast-iron base are indicated in various of the designs illustrated in this chapter.

The spiral cooling-coil for the circulating water should be of brass with a view to ensuring a minimum of corrosion. Brass pipes for the purpose may be thinner than iron pipes, and also, since the heat conductivity of brass is greater than that of iron, the heat is more effectively abstracted from the transformer by way of the oil, the brass pipes, and, finally, the circulating water.

In the bulletins of a transformer-manufacturing firm of wide experience, the amount of circulating water required at full load (entering at a temperature of 15 ) is given as approximately

0,8 gallon per minute for $500-\mathrm{kw}$ transformers

$\begin{array}{lllll}1,1 & , & , & , & , 1000-\mathrm{kw}\end{array}$

A thermometer is often provided, which extends through the case, and by means of which the attendant can intelligently control the amount of water supplied. It would be absolutely disadvantageous to reduce the oil temperature below the temperature of the room, as this would cause the transformer to "sweat."

It will be of interest to indicate the method of making cooling calculations for a forced-water-cooled oil-transformer. ${ }^{1}$ Let us take as an instance a 1000 -kw 50-cycle transformer. The core loss is $7 \mathrm{kw}$ and the $I^{2} R$ loss at rated loud is also $7 \mathrm{kw}$. Consequently the full-load efficiency is $\left(\frac{1000 \times 100}{1014}=\right)$ 98,5 per cent. To mantain a constant temperature, energy must be transferred from the oil in the case to the water inside the cooling pipes at the rate of $14 \mathrm{kw}$. 'Thus in each hour the water must carry away 14 kelvins of energy. 1,16 kelvin increases the temperature of 1 ton of water by $1^{\circ}$. If it is

1 These calculations are quite similar to the calculations involveal in connece. tiun with surface combensors for steam-engiues. Such eondenser enleulations are explainal in Clapter $\Gamma$. of the author' - Heary Eleetrienl Enginerring," (C'onstable \& Co., London). 


\section{THE DESIGN OF S'TATIC 'RANSFORMERS}

desired that the temperature rise of the transformer shall be not more than, for instunce, 30 , then if the temperature of the room is $20^{\circ}$ we may take $(20+30=) 50^{\circ}$ as the temperature of the oil in the immediate neighbourhood of the cooling pipes. As in the case of steam condensers, it will not be practicable to raise the temperature of the water quite up to the temperature of the medium external to the pipes. Consequently if the water enters the transformer at, say, $18^{\circ}$, it will, with a sufficient length of piping, leave the transformer at, say, $45^{\circ}$. It will thus have sustained a temperature rise of $(45-18=) 27^{\circ}$, and each ton will carry away $(27 \times 1,16=)$ 31,3 kelvins of energy. The amount of water passing through the cooling coil must consequently be $\left(\frac{14,0}{31,3}=\right) 0,447$ ton per hour. (Since there are 220 gallons in one ton of water, this is equal to $0,447 \times 220=99$ gallons per hour, or 1,65 gallons per minute.)

If in another instance, a temperature rise of $40^{\circ}$ is permitted, if the room temperature is $20^{\circ}$, if the water enters at $15^{\circ}$, and if its final temperature attains to within $7^{\circ}$ of the temperature of the oil, then the quantity of water would be calculated as follows:-

T'emperature of room . . . . . . . $20^{\circ}$

Temperature rise of oil . . . . . . . $40^{\circ}$

Ultimate temperature of oil . . $\quad(20+40=) 60^{\circ}$

Entrance temperature of water . . . . . $15^{\circ}$

Exit temperature of water . . . $\quad(60-7=) 53^{\circ}$

'Temperature rise of water . . . $\quad(53-15=) 38^{\circ}$

Energy absorbed by each ton of water $\quad(1,16 \times 38=) 44$

kelvins

Weight of water per hour . . . $\quad\left(\frac{14,0}{44,0}=\right) 0,319$ ton

Volume of water per hour $\quad . \quad(0,319 \times 220=) 70$ gallons

Volume of water per minute . $\quad \cdot \quad\left(\frac{70}{60}=\right) 1,17$ gallons 
It is thus evident that each case must be separately considered. One gallon is equal to $4530 \mathrm{cucm}$, and the volume of water per second may in the last case be expressed as

$$
\frac{1.17 \times 4530}{60}=88 \mathrm{cu} \mathrm{cm} .
$$

If we adopt 0,5 meter per second for the speed of flow of the water, then the area of the pipe must be $\frac{88}{50}=1,76 \mathrm{sq} \mathrm{cm}$ and the internal diameter must be $15 \mathrm{~mm}$. The thickness of the brass tubing will usually be about $1,25 \mathrm{~mm}$. Consequently the external diameter is $17,5 \mathrm{~mm}$ and the external surface per meter length of tubing is $(10 \times 0,175 \times \pi=) 5,5 \mathrm{sq} \mathrm{dm}$. The rate of transference of heat from one medium to another is a matter which has not yet been reduced to a reliable basis and is still usually determined by experiments. It depends upon the speed of How of the water and on other variables. Let us take it at 1,5 watt per degree per sq $\mathrm{dm}$ of heating surface. In our case we are dealing with 14000 watts. The mean difference of temperature between the oil and the water is

$$
60-\frac{53+15}{2}=26^{\circ}
$$

Consequently the water will take up the heat at the rate of $(26 \times 1,5=) 39$ watts per sq $\mathrm{dm}$, and we shall require to provide $\left(\frac{14000}{39}=\right) 360 \mathrm{sq}$ dm or a total length of $\left(\frac{360}{5,5}=\right)$ 66 meter's of tubing.

In a paper read before the Schenectaly section of the American Institute of Electrieal Engineers, Tobey describes the arrangement illustrated in Fig. 100, in which a transformer is provided with a cylindrical barrier interposed between the transformer and the external cylindrical sides of the case. 'This barrier does not extend quite down to the bottom of the case. The oil adjacent to the core and windings becomes 


\section{2}

heated and rises to the upper part of the transformer. By means of a small motor the oil is pumped over to the part exterior to the barrier where it cools and fall to the bottom, ready to start on another journey through the transformer and to abstract further heat from the active material.

Forced-Oil-Cooled Transformers.-As an alternative to employing a coil of tubes in the oil and circulating cooling

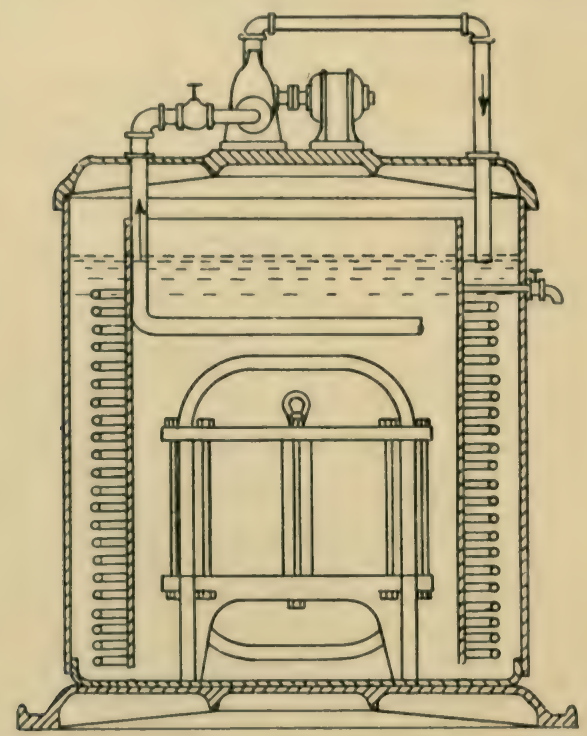

Fig. 100.-Oil-immersed transformer provided with cylindrical barrier to promote circulation.

water through the coil, there are occasions where it is more advantageous to pump the oil out of the transformer, cool it, and pump it back again. In the arrangement shown in Fig. 101 the hot oil leaving the transformer at B, is, by means of the pump A, forced through the spiral pipe $\mathrm{C}$, and is then forced into the transformer again at $D$. In its passage through $\mathrm{C}$ the heat is transferred from the oil to the cooling water which is forced into and from the tank $\mathrm{E}$ by the pump $\mathrm{F}$ driven by the motor $\mathrm{G}$. 'The difference in temperature bet ween 
the oil when entering and when leaving the transformer is usually only allowed to be some $10^{\circ}$. The specific gravity of transformer oil is about 0,9 and its specific heat is about $0,75 .^{1}$ Consequently $(1,16 \times 0,75 \times 0,9=0,78$ kelvin is absorbed by $1 \mathrm{cu} \mathrm{m}$ of oil when its temperature is raised $1^{\circ}$. In our transformer the temperature of the oil is raised $10^{\circ}$, absorbing 7,8 kelvins per $\mathrm{cu} \mathrm{m}$. Thus the quantity requiring to be circulated is $\left(\frac{14,0}{7,8}=\right) 1,80 \mathrm{cu} \mathrm{m}$, or $(1,80 \times 220 \Rightarrow 400$ gallons per hour, or 6,7 gallons per minute.

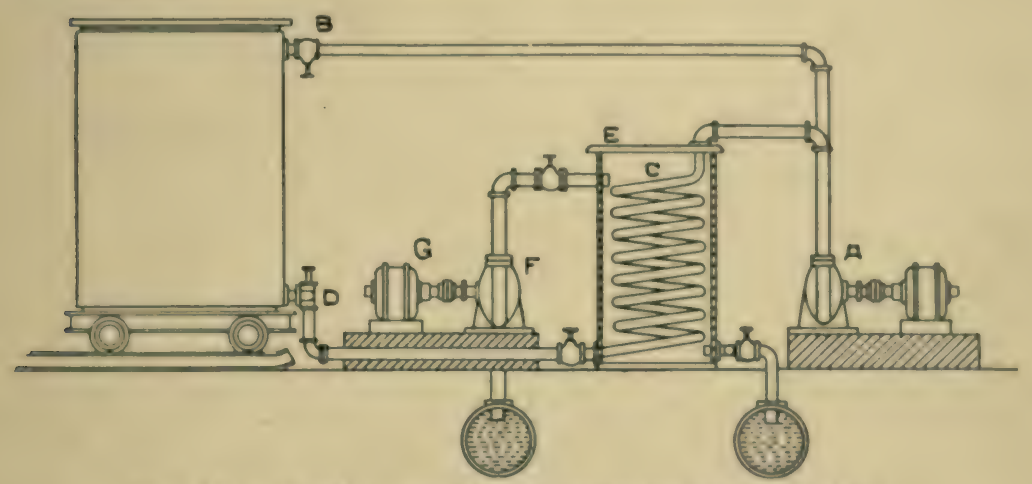

FiG. 101.-Furcel-oil-cioled transformer and accessory plant.

In forced-oil-cooled transformers there arises the important question whether each transformer shall be provided with its own complete oil-circulating and cooling plant, or whether all the transformers in the installation shall be supplied from a common oil main. Although the latter plan leads to the lowest first cost, the former is to be preferred, since, in the event of a breakdown anywhere, it is important that the entire plant shall not be incapacitated. Oil is greatly affected by the admixture of impurity or moisture, and if any single transformer of a bank of transformers goes wrong, with the consequence of impairing the quality of any oil entering it, then it

1 See Table VI. un p. 11 and Example VII. on p. 13 of the author's "Heary Eleetrieal Engineering " (Cinusable \& Cu, Lomben). 
174 THE DESIGN OF STATIC TRANSFORMERS is important that the damaged oil shall not gain access to any of the other transformers.

While for a time, considerable attention was given to forcedoil-cooled transformers, and the plan was adopted on several installations, it has often been found that the extra cost of the auxiliary plant required, largely offsets any advantages, and the present tendency in large transformers is toward the employment of oil-immersed transformers with water cooling by means of coils of piping within the transformer through which the water circulates. Nevertheless the oil-circulating proposition affords a sound and appropriate solution in many instances.

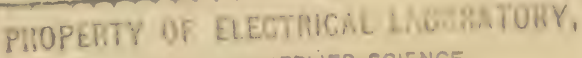
FACULTY OF APPLIED SCIENCE.

Dato.

BRADBURY, AGNEW, \& CO, LD., PRINTERS, LONDON AND TONBRIDGE. 
FROM CONSTABLE'S LIST.

WORKS BY THE AUTHOR OF

"THE DESIGN OF STATIC TRANSFORMERS."

\section{HEAVY ELECTRICAL ENGINEERING.}

By If. M. HOB.ART, M.Inst.C.E. Fully illustrated with I)ingrams,

\&o. Demy 8vo. 16/-net.

The author luere supplies a text-leosk, the neesl of which has lower long and

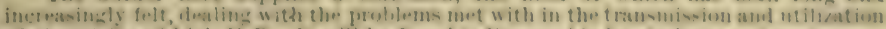

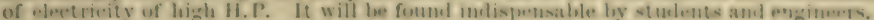

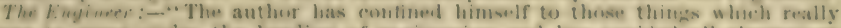
deserve to come nuder the headiong of enginewring, and has avoident all elementary

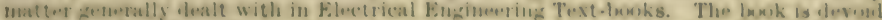
of advasced mathematies, and ean be understood and apprectated by the stnient as well as the practical man."

\section{ELECTRICITY.}

$$
\text { Also by the same Author. }
$$

By H. M. HOBART. A Text-Book designed in particular for Eingineoring Students. 228 pages. 43 Tables and 115 Illustrations.

\section{Demy 8vo. 6/-net.}

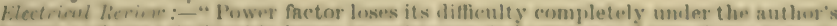

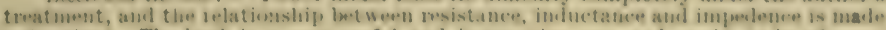
inite elear. The bork is a very useful and instructive one, and ought to be of great service."

Eilentrival Enginerimg:- "The final chapter on insulating materials is in itseif a masterly little treatise on the subject."

Blectrioal Times:- "Mr. Holsart's book should prove extremely useful. The student, already primed with a little techuical knowledge. will be liftud forthwith into a fut more nseful and practieal siew of things . . . and that he is unaking his way into the fleld of action."

The bintimes :- - A rapid glanee at the illustrations contained in this lonok is sufficient to sloww that it differs very materially from mest others lasing the some title. Ineleed, it may be said that the colnme possesses that desinable hut unustual frature-orisuality. A chapter on the maznetie theld contains information whieh the sturent will timi well worth actuiring and the satme applies to that secting of then lrook whieh d als with enductors moring in a naghet ie fleld The brok, as we have already intimated, is wruten on practural lines, and it is a decideel improvement on most books we have seen having for their title the word 'Blectricity."

Engineering Kerien :- "A sound work, which the morlern sindent of olectrical prgiawesng will fiml of very wreat assistaner in prejaring him for his entranee ujom the practical gide of his businesg."

Timea :- "The suthor's book contains some sound information for those who have worked thimogh an elementary course and who desire to give theor sturlius sume

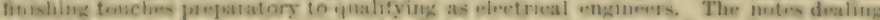

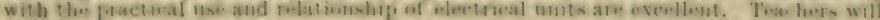

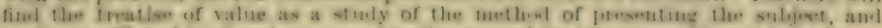

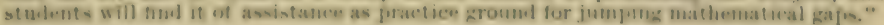

\section{SOLENOIDS, ELECTROMAGNETS, AND ELECTROMAGNETIC WINDINGS.}

By UHARI.ES UNDERHII.I, Assoc.Mem.A.I.E.E. With 218

Illustrations. Cloth. 8 - net.

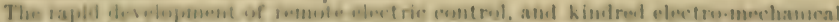

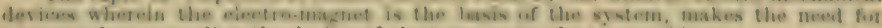
accurate data regneding the design of electronagnets the niore evident.

\section{INDUSTRIAL ELECTRICAL MEASURING INSTRUMENTS.}

By KF.NF.M EDGCUMBE, A.M.Inst.C.F., M.I.E.E. 120

Illustrations. Demy 8vo。 8 - net.

l'ART Contustm:-Inemoluctury. Aceuracy of Mesanuretment. Conutructional

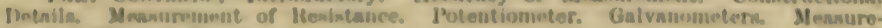
ment of Curmul, dte., de.

\section{ELECTRIC POWER AND TRACTION.}

By F. II DAVILS, A.M.I.E.E. With Go Illuntrations. Kx. Crown 8vo. B - net. 


\section{ELECTRIC POWER TRANSMISSION.}

Fifth Edition, Revised and Enlarged. A Practical Treatise for Practical Men. By LOUIS BELL, Ph.D., M.Am.I.E.E. With

350 Diagrams and Illustrations. Demy 8vo. 16 net.

Part Conients:-General Conditions of Power Trnnsmission. Power Trans. mission by Continuous Currents. Some Properties of Alternating Circuits. Power. Trausmission by Alternating Currents. Alternating Current Motors. Current. Reorganizers. IIylraulic Development. The Organization of a Power station. The Messurement of Electrical Enorgy. High Voltage Transmission.

\section{THE THEORY OF ELECTRIC CABLES AND NETWORKS.}

By ALEXANDER RUSSELL, M.A., D.Sc. Illustrated. Demy 8vo. 8 - net.

A thoronghly trustworthy work concerning the network of cables counecting the dynamos with the lamps and motors of the consumer.

\section{ELECTRIC FURNACES.}

By J. WRIGHT. New Edition, Revised and Enlarged. With 67

Illustrations. Demy 8vo, $8 / 6$ net.

Contents :-Efficiency of the Electric Furnace. Are Furnaces. Resistance Furnaces. Carbide Furnaces. Smelting and Ore Reduction in the Electric Furnaces. I istillation of Metals. Electrolytic Furnaces. Laboratory Furnaces and Dental Muftes. Tube Furnaces. Glass Manufacture in the Electric Furnace. Electrodes and Terminal Connections. Furnace Thermometry.

\section{SEARCHLIGHTS : THEIR THEORY, CON- STRUCTION AND APPLICATION.}

By F. NERZ. Translated from the German by CHARLES RODGERS. Very Fully Illustrated. Royal 8vo. 7/6 net.

\section{ELECTRO-METALLURGY.}

By J. B. C. KERSHAW, F.I.C. With 61 Illustrations. Extra Crown 8vo. B/-net.

Part Cuntwens :-Introduction and Historical Survey. Aluminium. Production. Details of Processes and Works. Costs. Utilization. Future of the Metal. Various Metal Extraction and Refining Processes, \&c., \&c.

\section{CONTINUOUS CURRENT ENGINEERING.}

By ALFRED HAY, D.Sc., M.I.E.E. About 330 pages. Fully Illustrated. Demy 8 vo. $\mathbf{5}$ - net.

A simple account of the component parts of a continuous eurrent lighting and power plant, dynamos, motors, secondary cells, measuring instruments, \&c. An excellent text-book.

\section{DIRECT AND ALTERNATING CURRENT TESTING.}

By FREDERICK BEDELL, Ph.D., Professor of Applied Electricity, Cornell University. Assisted by CLARENCE A. PIERCE,

Ph.D. Demy 8vo. Illustrated. 8 - net.

This manual consist; of a series of tests on direct and alternating current apparatus, selected with reference to their practical usefulness and instructive value.

"Contains a vast amount of carefully reasoned natter-a useful text-book."Electricity.

\section{FOSTER'S ELECTRICAL ENGINEER'S POCKET BOOK.}

By HORATIO A. FOSTER, Mem.A.I.E.E., Mem.A.S.M.E., with the Collaboration of Eminent Specialists. A Handbook of Useful Data for Electricians and Electrical Engineers. Fifth Edition, completely Revised and Enlarged. Pocket Size. Leather bound.

Over $1,600 \mathrm{pp}$. Illustrated, $\mathbf{2 1}$ - net.

This new edlition embraces the vast changes and advances that have occurred in every branch of electrical engineering.

\section{LONDON : 10 ORANGE STREET W.C.}





$$
4 n^{-13^{-13}}
$$




\section{PLEASE DO NOT REMOVE \\ CARDS OR SLIPS FROM THIS POCKET}

\section{UNIVERSITY OF TORONTO LIBRARY}

S\&M

A

138 
